Aus der Klinik für Mund-, Kiefer- und Gesichtschirurgie

(Prof. Dr. med. Dr. med. dent. H. Schliephake)

im Zentrum Zahn-, Mund- und Kieferheilkunde

der Medizinischen Fakultät der Universität Göttingen

\title{
Histomorphometrische und molekularbiologische \\ Untersuchungen zur Osseointegration von dentalen \\ Implantaten am mit Zoledronat behandelten Tiermodell \\ des Göttinger Minipigs
}

Eine Pilotstudie

\author{
INAUGURAL - DISSERTATION \\ zur Erlangung des Doktorgrades \\ für Zahnheilkunde \\ der Medizinischen Fakultät der \\ Georg-August-Universität zu Göttingen
}

vorgelegt von

Wiebke Katrin Behrens

aus

Kerkrade/Niederlande

Göttingen 2019 
Dekan:

Referent:

Ko-Referent/in:

Drittreferent/in:

Datum der mündlichen Prüfung:
Prof. Dr. Heyo K. Kroemer

Prof. Dr. Dr. Franz-Josef Kramer

Prof. Dr. Stephan Sehmisch

Prof. Dr. Thomas Meyer

20.06.2019 


\section{Inhaltsverzeichnis}

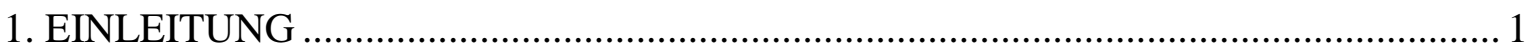

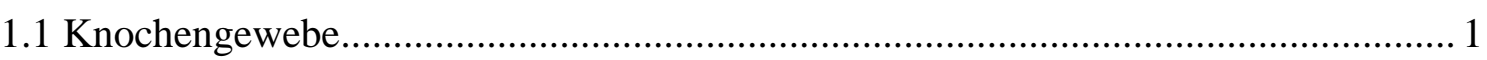

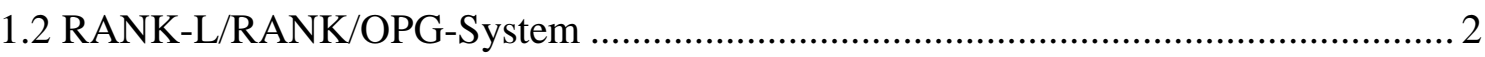

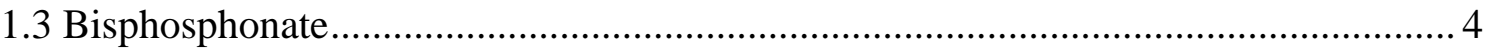

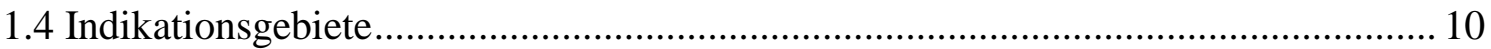

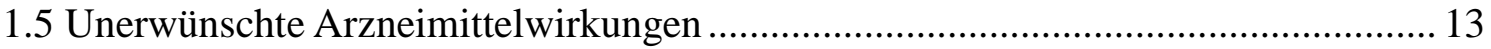

1.6 Bisphosphonat-assoziierte Osteonekrosen der Kiefer (ONJ) ................................. 13

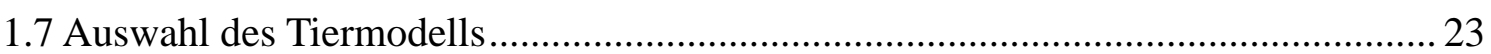

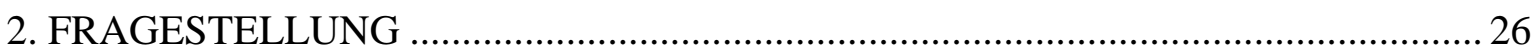

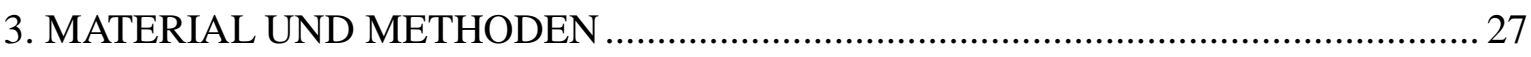

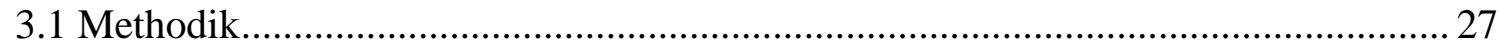

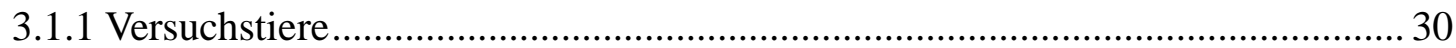

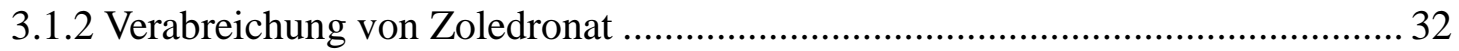

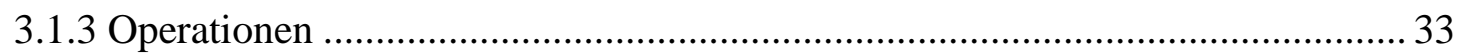

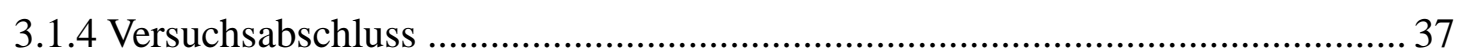

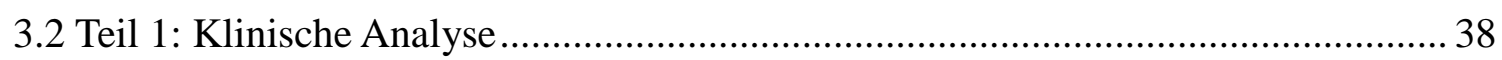

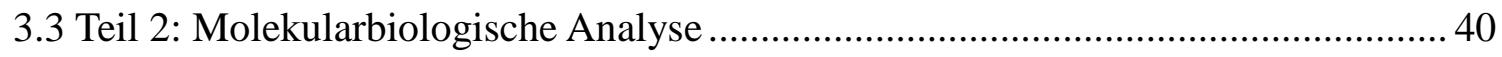

3.3.1 Material für die molekularbiologische Analyse ................................................ 40

3.3.2 Methode der molekularbiologischen Analyse ............................................... 43

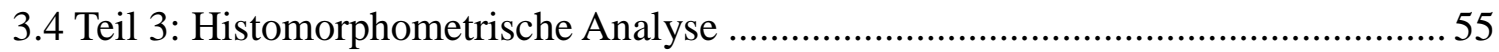

3.4.1 Material für die histomorphometrische Analyse ........................................... 55

3.4.2 Methode der histomorphometrischen Analyse .................................................. 56

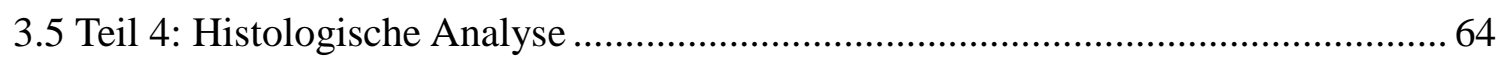

3.5.1 Material für die histologische Analyse …........................................................ 64

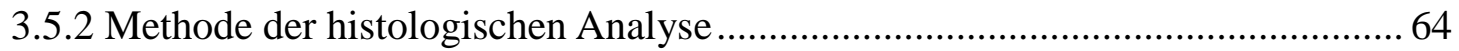

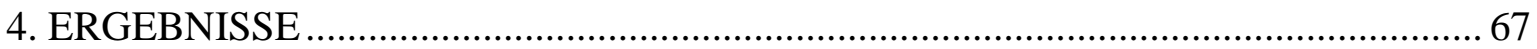

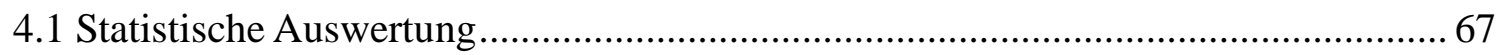

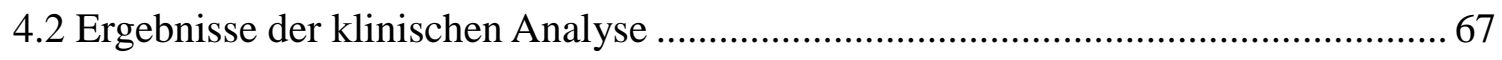

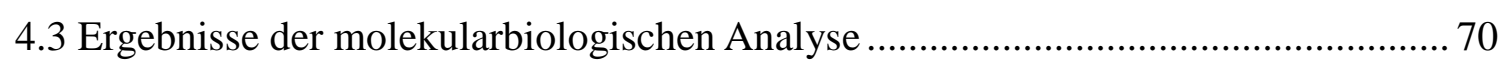

4.3.1 Ergebnisse der OPG-Expression in Beckenkamm und Unterkiefer ................... 70

4.3.2 Ergebnisse der OPG-Expression im Beckenkamm ......................................... 72

4.3.3 Ergebnisse der OPG-Expression im Unterkiefer ............................................. 74 
4.3.4 Ergebnisse der OPG-Expression im Alveolarkamm des OK/UK ...................... 75

4.3.5 Ergebnisse der OPG-Expression im Alveolarkamm des Oberkiefers ................ 77

4.3.6 Ergebnisse der OPG-Expression im Alveolarkamm des Unterkiefers ............... 78

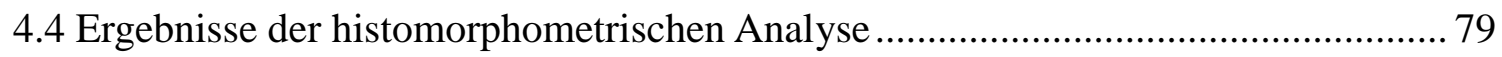

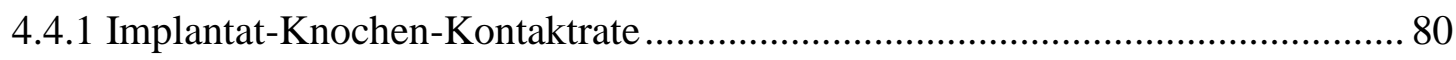

4.4.2 Knochendichte in den Gewindegängen ......................................................... 81

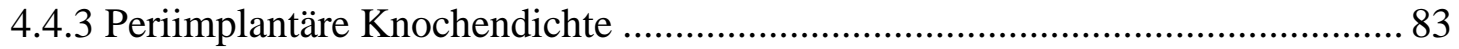

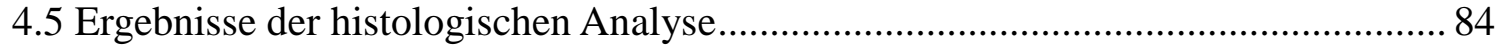

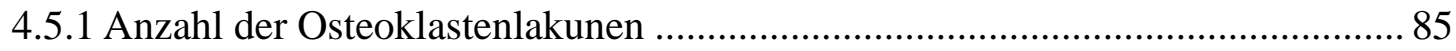

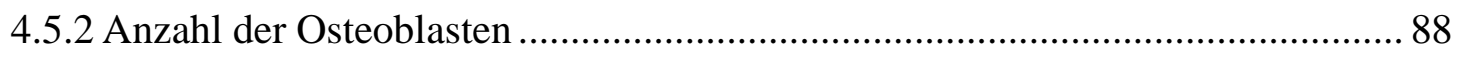

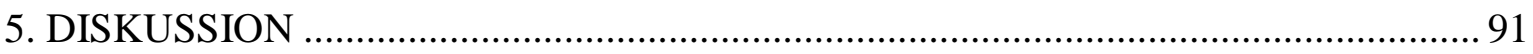

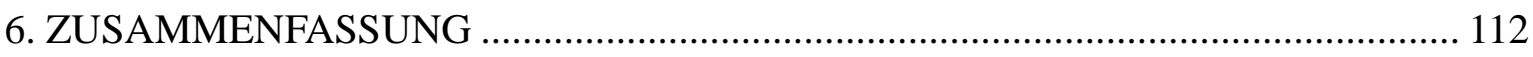

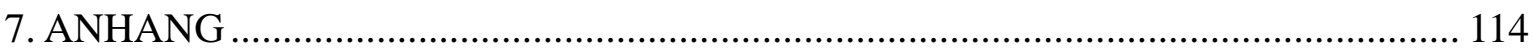

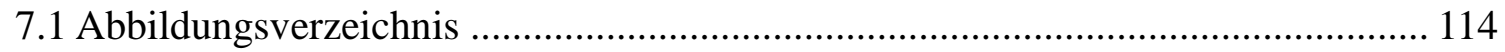

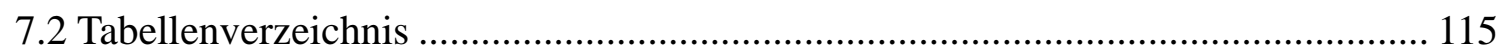

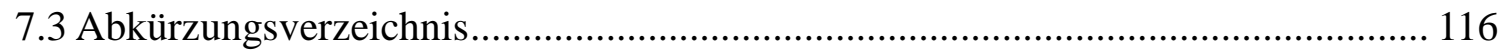

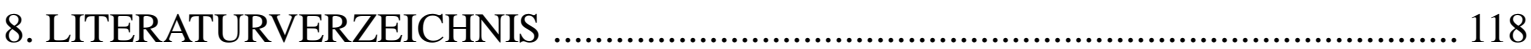




\section{EINLEITUNG}

\subsection{Knochengewebe}

Knochengewebe gehört zu den Bindegeweben und erfüllt aufgrund seines speziellen Aufbaus neben der Stütz- und Skelettfunktion auch metabolische Funktionen. Physiologisches Knochengewebe befindet sich ständig im Umbau und hat durch diese Dynamik einen hohen Stoffumsatz und ein hohes Heilungsvermögen. Im Wesentlichen ist es zusammengesetzt aus zwei verschiedenen Phasen. Etwa $35 \%$ bilden die organische Phase, bestehend aus Matrixproteinen, z. B. Kollagen Typ I (ca. 90 \%), Osteocalcin, Osteopontin oder Osteonektin (synthetisiert von Osteoblasten, s. u.) und Proteoglykanen. Die übrigen ca. $65 \%$ bilden die mineralische Phase, bestehend aus Hydroxylapatit $\left(\mathrm{Ca}_{10}\left[\mathrm{PO}_{4}\right]_{6}[\mathrm{OH}]_{2}\right)$, einer kristallinen Ablagerungsform des Calciumphosphats.

Für den Strukturerhalt des Knochengerüstes werden im Wesentlichen vier relevante Knochenzelltypen unterschieden: Osteoprogenitorzellen (Vorläuferzellen), Osteoblasten, Osteozyten und Osteoklasten.

Die ersten drei genannten Zellen beschreiben verschiedene Funktionsphasen eines Zelltyps und entstammen den mesenchymalen Stammzellen (mesenchymal stem cells, MSCs), welche sich zu Osteoprogenitorzellen differenzieren. Sie entwickeln sich zu Osteoblasten, sobald sie die Knochenmatrix durch die Sekretion von Osteoid, einer vorerst unmineralisierten organischen Knochenmatrix, aufbauen. Histologisch liegen sie epithelähnlich der Matrixoberfläche des Knochens an (Welsch 2005). Sind Osteoblasten von mineralisierter Matrix umgeben, nennt man sie Osteozyten. Diese sind in Lakunen zwischen den Knochenlamellen eingelagert und durch zahlreiche Nexus untereinander und mit den Osteoblasten an der Oberfläche des Knochens verbunden.

Osteoklasten sind mehrkernige Riesenzellen, die sich aus der Fusion von monozytären Vorläuferzellen der hämatopoetischen Stammzelllinie des Knochenmarks (hematopoietic stem cells, HSCs) im Knochenmark entwickeln. Sie resorbieren mineralisierte Knochenmatrix und sind für die lebenslangen Umbau- und Neuaufbauprozesse des Knochengewebes bedeutsam. Man findet sie isoliert in flachen Höhlungen, den sogenannten HowshipLakunen, wo sie der Knochenoberfläche anhaften. Aktive Osteoklasten bilden apikal mit ihrem Faltensaum (ruffled border) ein subosteoklastisches Kompartiment aus, über wel- 
ches die Knochenresorption durch die Sekretion von Protonen und proteolytischen Enzymen zur Schaffung eines sauren, demineralisierenden Mikromilieus stattfindet (Welsch 2005).

Sowohl Osteoblasten als auch Osteoklasten besitzen auf ihren Zelloberflächen zahlreiche Rezeptoren für eine Vielzahl von Hormonen, Zytokinen, Vitaminen und anderen Faktoren, welche Proliferation, Differenzierung oder Aktivitätszustand der Zellen beeinflussen können. Eine bedeutende Rolle spielen hierbei u. a. Parathormon, Dexamethason, Triiodthyronin (T3) oder 1,25-(OH) $)_{2} \mathrm{VitD}_{3}$ als aktivierende, also knochenresorptiv wirkende Hormone. Bisphosphonate, Calcitonin oder Estrogene hingegen wirken antiresorptiv auf das Knochengewebe.

\subsection{RANK-L/RANK/OPG-System}

Eine bedeutsame Rolle im Knochenstoffwechsel spielt das RANK-L/RANK/OPG-System. Hierbei handelt es sich um einen Regelkreislauf verschiedener Proteine, die von Osteoklasten oder Osteoblasten exprimiert werden und für eine ausgeglichene Bilanz zwischen kontinuierlicher Osteolyse und Knochenneubildung (remodelling) relevant sind (Walsh und Choi 2014).

RANKL (receptor activator of $N F-\kappa B$ ligand, Gen-Name: TNFSF11) ist ein Signalmolekül, das von Osteoblasten exprimiert wird und welches zur Superfamilie der Tumornekrosefaktoren (TNFs) gehört. Es ist ein transmembranes Glykoprotein mit 317 Aminosäuren, das neben einer membrangebundenen auch als lösliche Form mit 178 Aminosäuren von Osteoblasten sezerniert wird (Ikeda et al. 2001).

RANKL kann von seinem zugehörigen Rezeptor RANK oder von dem Glykoprotein OPG gebunden werden (s. u.). Hohe Expressionsraten von RANKL konnten in Lymphknoten, Thymus und Lunge festgestellt werden, eine niedrigere Expression hingegen in einer Vielzahl anderer Gewebe, so auch Milz und Knochenmark (Wada et al. 2006).

Bei RANK (receptor activator of $N F-\kappa B$, Gen-Name: TNFRSF11A) handelt es sich um ein transmembranes Glykoprotein mit 616 Aminosäuren. Es wird auf der Zelloberfläche von Osteoklasten sowie deren monozytären Vorläuferzellen, jedoch auch in anderen Geweben exprimiert. Eine Stimulation von RANK durch RANK-Ligand der Osteoblasten 
bewirkt über verschiedene zytoplasmatische Signalwege eine Differenzierung der Osteoklasten-Vorläuferzellen sowie eine Aktivierung von Osteoklasten (Boyce und Xing 2007).

OPG (Osteoprotegerin, Gen-Name: TNFRSF11B), auch osteoclastogenesis inhibitory factor $(O C I F)$ genannt, ist ein von Osteoblasten sezerniertes lösliches Glykoprotein mit 401 Aminosäuren und gehört wie RANKL der Superfamilie der Tumornekrosefaktoren an. Auch OPG wird neben Osteoblasten in vielen anderen Geweben exprimiert, so z. B. in Herz, Leber, Nieren oder Milz (Wada et al. 2006). Als antagonisierender Rezeptor zu RANK bindet OPG an RANKL, wodurch dieser der Stimulation von RANK nicht mehr zugängig ist. Durch diese Inhibition der RANK/RANKL-Interaktion über die Expression von OPG können Osteoblasten einer Osteoklastendifferenzierung und -aktivierung und damit einer Knochenresorption entgegenwirken. Das Verhältnis von OPG und RANKL ist folglich ein wichtiger Bestimmungsfaktor für die Menge und Qualität des Knochens (Boyce und Xing 2007) (Abb. 1).

Die Expression der mRNA von OPG in Osteoblasten wird durch verschiedene Stimulatoren der Osteoklastogenese, so z. B. proinflammatorische Zytokine (Interleukin IL-1), Prostaglandin ( $\mathrm{PGE}_{2}$ ), Parathormon (PTH), 1,25(OH) 2 Vitamin $\mathrm{D}_{3}$ (Murakami et al. 1998) oder Glukokortikoide (Graefe et al. 2011) gehemmt. Umgekehrt führen z. B. Estrogene (Hofbauer et al. 1999), transforming growth factor (TGF- $\beta 1$ ) (Murakami et al. 1998) oder bone morphogenic protein (BMP-2) (Hofbauer et al. 1998) zu einer Steigerung der OPGExpression.

Das RANK-L/RANK/OPG-System ist für die skelettale Gesundheit bedeutsam. Jegliche Störung in diesem System bedingt zahlreiche Knochenerkrankungen. So führt z. B. eine Überproduktion von OPG transgener Mäuse zum Krankheitsbild der Osteopetrose durch eine deutliche Reduktion der Anzahl an Osteoklasten (Boyce und Xing 2007).

Denosumab ist ein humaner monoklonaler Antikörper $\left(\operatorname{IgG}_{2}\right)$, der wie OPG an RANKL bindet und damit die RANK/RANKL-Interaktion auf den Osteoklasten unterbindet. Damit senkt Denosumab in gleicher Weise wie OPG die Knochenresorption und steigert die Knochendichte über die Inhibition der Funktion und Überlebensrate der Osteoklasten (Elsaid et al. 2016). Der Effekt des zirkulierenden Denosumab ist dabei im Gegensatz zu der langen HWZ der Bisphosphonate limitiert auf die Dauer der Einnahme des Medikaments (Meier et al. 2017). 


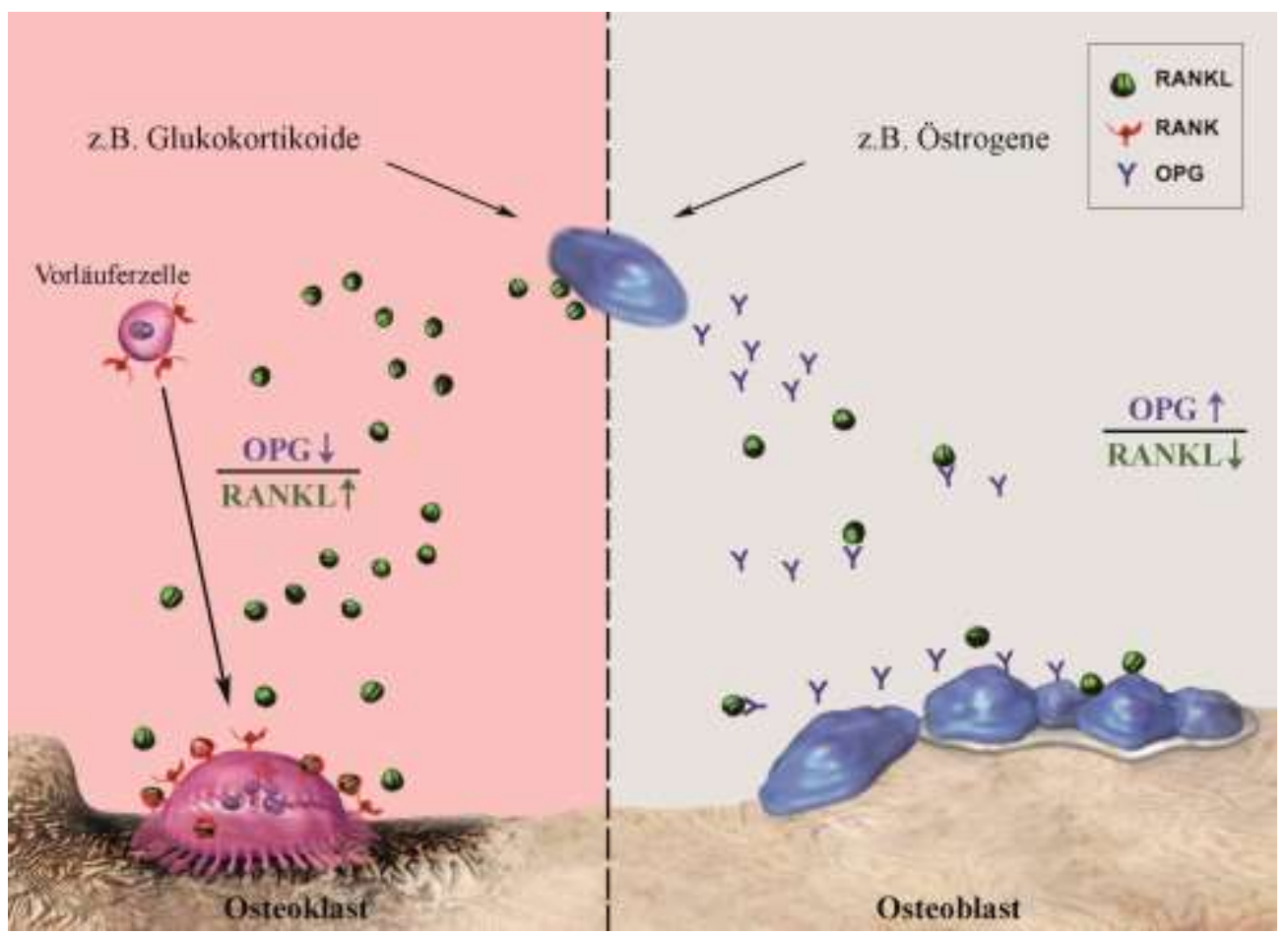

Abb. 1: RANK-L/RANK/OPG-System (modifiziert nach Consolaro 2015)

\subsection{Bisphosphonate}

\section{Chemische Struktur}

Bisphosphonate sind stabile Analoga des physiologisch vorkommenden Pyrophosphats oder Diphosphonats, bei denen der Sauerstoff der zentralen P-O-P-Bindung durch Kohlenstoff zu einer P-C-P-Bindung ersetzt wird. Die verschiedenen Bisphosphonate unterscheiden sich jeweils durch unterschiedliche Substituenten am Kohlenstoffatom, die eine wichtige Rolle bei der Knochenbindung und der Osteoklasten-Inhibition des Bisphosphonats spielen (Fleisch 2000). Durch die unterschiedlichen Seitenketten wird die Molekülstruktur hinsichtlich ihrer biologischen Eigenschaften, Aktivität, Pharmakokinetik und Toxizität modifiziert (Diel 2007).

Die zweite Generation der Bisphosphonate unterscheidet sich durch die Einführung von Aminogruppen $\left(\mathrm{NH}_{2}\right)$ in einer der beiden Seitenketten des zentralen Kohlenstoffatoms mit deutlich gesteigerter antiresorptiver Potenz von der ersten Generation (Russell et al. 1999). Die dritte Generation beinhaltet weitere chemische Modifikationen wie die Einführung von stickstoffhaltigen Heterozyklen und besitzt die höchste pharmakologische Potenz ihrer Medikamentenklasse (Tab. 1). Bisphosphonate lassen sich auf diese Weise in Aminobisphosphonate und Nicht-Aminobisphosphonate klassifizieren, wobei erstgenannte um das 10-20.000-Fache potenter sein können als Nicht-Aminobisphosphonate (erste Generation). 
Tab. 1: Verschiedene Bisphosphonate und ihre relative Potenz

\begin{tabular}{|c|c|c|c|c|c|}
\hline Substanz & $\begin{array}{l}\text { Handels- } \\
\text { name }\end{array}$ & $\begin{array}{l}\text { Relative } \\
\text { Potenz }\end{array}$ & Generation & Darreichung & Indikationsgebiete (Auswahl) \\
\hline Etidronat & Didronel® & $1 \mathrm{x}$ & 1. & p.o. & $\begin{array}{l}\text { Postmenopausale/Glukokortikoid- } \\
\text { induzierte Osteoporose; Morbus Paget }\end{array}$ \\
\hline Clodronat & Ostac $\AA$ & $10 x$ & & p. o./i. v. & $\begin{array}{l}\text { Osteolytische Knochenmetastasen } \\
\text { solider Tumoren/hämatologischer } \\
\text { Neoplasien; tumorinduzierte Hyperkalz- } \\
\text { ämie }\end{array}$ \\
\hline Pamidronat & Aredia ${ }^{\circledR}$ & $100 x$ & 2. & i. $v$. & $\begin{array}{l}\text { Osteolytische Knochenmetastasen } \\
\text { solider Tumoren oder multiples } \\
\text { Myelom; tumorinduzierte Hyperkalzäm- } \\
\text { ie; Morbus Paget d. Skeletts }\end{array}$ \\
\hline Alendronat & Fosamax® & $1.000 \mathrm{x}$ & & p. o. & $\begin{array}{l}\text { Postmenopausale/Glukokortikoid- } \\
\text { induzierte Osteoporose }\end{array}$ \\
\hline Risedronat & Actonel® & $5.000 x$ & 3. & p. o. & $\begin{array}{l}\text { Postmenopausale/Glukokortikoid- } \\
\text { induzierte Osteoporose; Morbus Paget } \\
\text { d. Skeletts }\end{array}$ \\
\hline Ibandronat & $\begin{array}{l}\text { Bondronat® } \\
\text { Bonviva } \AA\end{array}$ & $10.000 \mathrm{x}$ & & p. o./i. v. & $\begin{array}{l}\text { Tumorinduzierte Hyperkalzämie mit } \\
\text { und ohne Metastasen; postmenopausale } \\
\text { Osteoporose }\end{array}$ \\
\hline Zoledronat & $\begin{array}{l}\text { Zometa }{ }^{\circledR} \\
\text { Aclasta }{ }^{\circledR}\end{array}$ & $20.000 x$ & & i. v. & $\begin{array}{l}\text { Zometa: Osteolytische Knochenmetasta- } \\
\text { sen solider Tumoren/hämatologischer } \\
\text { Neoplasien; tumorinduzierte Hyperkalz- } \\
\text { ämie. } \\
\text { Aclasta: Postmenopausale/ Glukokor- } \\
\text { tikoid-induzierte Osteoporose; Morbus } \\
\text { Paget }\end{array}$ \\
\hline
\end{tabular}

[modifiziert nach Schindler und Kirch 2008 sowie Leitlinie Osteoporose 2014 und Produktinformationen der einzelnen Hersteller]

\section{Zoledronat}

Zoledronat ([1-Hydroxy-2-(imidazol-1-yl) ethyliden] diphosphonsäure) gehört aufgrund seiner chemischen Struktur, die einen Imidazolring in der Seitenkette R2 beinhaltet, zur dritten Generation der Bisphosphonate. Der seit 2003 zur Anwendung am Patienten zugelassene, von der Firma Novartis Pharma GmbH entwickelte Wirkstoff Zoledronat wird „zur Verhinderung von Komplikationen am Knochen, z. B. Knochenbrüche (Frakturen), bei Erwachsenen mit Knochenmetastasen“ sowie zur Behandlung einer tumorinduzierten Hyperkalzämie verwendet (Gebrauchsinformation Zometa 2017). Seither findet Zoledronat bei metabolischen Knochenerkrankungen mit gesteigerter Osteoklastenaktivität sowie in der Osteoporose-Therapie hinsichtlich gesteigerter Knochendichte und Verminderung skelettaler Komplikationen erfolgreich klinische Anwendung (Lambrinoudaki et al. 2008).

Viereck et al. konnten Zoledronaten eine dosisabhängig gesteigerte OPG-Expression durch humane Osteoblasten nachweisen (Viereck et al. 2002). Diese war entsprechend der Potenz 
des Bisphosphonats noch deutlich höher als die OPG-Expression durch Pamidronate. Neue Studien gehen zusätzlich von einer im Detail noch unklaren tumorsuppressiven Aktivität bezüglich Progression, Wachstum und Metastasierung durch Zoledronate aus (Gnant 2011).

Zometa ${ }^{\circledR} 4 \mathrm{mg} / 5 \mathrm{ml}$, zur Herstellung einer Infusionslösung, ist ein Konzentrat von $5 \mathrm{ml}$, welches $4 \mathrm{mg}$ Zoledronsäure enthält, entsprechend 4,264 mg Zoledronsäuremonohydrat (1 ml Konzentrat enthält $0,8 \mathrm{mg}$ Zoledronsäuremonohydrat). Die empfohlene Dosierung bei erwachsenen Patienten mit Knochenmetastasen (ohne Nierenfunktionsstörung) zur Prävention skelettbezogener Komplikationen ist mit $4 \mathrm{mg}$, verdünnt in $100 \mathrm{ml}$ steriler isotonischer Natriumchloridlösung oder 5\%iger Glukoselösung, alle 3-4 Wochen angegeben. Zusätzlich wird bei diesen Patienten die orale Einnahme von $500 \mathrm{mg}$ Calcium und 400 I.E. Vitamin D pro Tag empfohlen. Zur Behandlung einer tumorbedingten Hyperkalzämie werden 4 $\mathrm{mg} / 100 \mathrm{ml}$ als Einzelgabe empfohlen. Jede Dosis sollte als intravenöse Infusionslösung über mindestens 15 min verabreicht werden (Gebrauchsinformation Zometa 2017).

\section{Pharmakokinetik}

Oral verabreichte Bisphosphonate haben durch eine Resorption von nur 1-2 \% der eingenommenen Dosis im Gastrointestinaltrakt eine schlechte Bioverfügbarkeit. Deutlich höher ist diese bei Bisphosphonaten, die zur intravenösen Applikation zur Verfügung stehen (Aminobisphosphonate der 3. Generation). Ca. $39 \%$ der verabreichten Dosis Zoledronat werden innerhalb von 24 Stunden fast vollständig renal und unmetabolisiert ausgeschieden. Der übrige Anteil wird selektiv und kumulativ fast vollständig von Knochengewebe gebunden und infolge der Remodellierungsprozesse im Laufe von Jahren langsam wieder systemisch freigesetzt (Wellington und Goa 2003). Das Ausmaß der skelettalen Aufnahme, Retention und auch späteren Freisetzung des Bisphosphonats hängt eng von individuellen Parametern wie der Umsatzrate des Knochens, der Verfügbarkeit freier Knochenbindungsstellen, der Nierenfunktion und der Affinität des jeweiligen Bisphosphonats zum Knochen ab (Cremers et al. 2005). Derzeit lassen sich noch schwer genaue Angaben zur langfristigen HWZ derzeit verwendeter, skelettal gebundener Amino-Bisphosphonate machen (Weiss et al. 2008). Schon nach einer Einzeldosis Zoledronat 4-5 mg lassen sich bei postmenopausalen Frauen bis zu 1 Jahr reduzierte biochemische Marker einer Knochenresorption feststellen (Black et al. 2007). Die biologische HWZ für das potente Bisphosphonat Alendronat wird auf mehr als 10 Jahre nach einer intravenösen Einzeldosis geschätzt 
(Khan et al. 1997). Black et al. geben für den Menschen nach der initialen Clearance sogar eine kontinuierliche Nachweisbarkeit des Wirkstoffs im Urin in geringer Menge über einen Zeitraum von bis zu 12 Jahren an (Black et al. 2006).

\section{Wirkungsmechanismus}

Bisphosphonate haben eine hochselektive Affinität zu Knochengewebe, insbesondere an Knochen mit einer hohen Umsatzrate, was auf die starke Bindung an Hydroxylapatit zurückzuführen ist. Diese Tatsache führt zu einer aktiven und hochkonzentrierten Anlagerung der Moleküle an freie, mineralisierte Knochenoberflächen hauptsächlich von osteoklastären Resorptionslakunen. Die Effekte auf das Knochengewebe lassen sich hierbei über einen direkten und einen indirekten Weg beschreiben, wobei der Hauptangriffsort auf zellulärer Ebene überwiegend die Osteoklasten und ihre Vorläuferzellen sind (Bartl et al. 2006).

\section{Direkte Effekte}

Die direkte Wirkungsweise der Bisphosphonate findet über eine Hemmung der Bildung von Osteoklasten aus ihren Vorläuferzellen im Knochenmark, ihrer Adhäsion an die Knochenoberflächen, der Inaktivierung aktiver Osteoklasten und einer Reduzierung ihrer Lebensdauer über den programmierten Zelltod (Apoptose) statt. Dadurch nimmt die Anzahl der Osteoklasten und damit auch der osteoklastären Knochenresorption insgesamt ab (Badros et al. 2006; Licata 2005). Dies stellt den primären Mechanismus moderner (Amino-) Bisphosphonate dar, die Knochenresorption zu inhibieren. Während der Knochenresorption nehmen Osteoklasten den Wirkstoff von der Knochenoberfläche aktiv in ihr Zytoplasma auf. Hier greift er in den Mevalonat-Stoffwechsel ein, indem er Schlüsselenzyme in der Cholesterinbiosynthese hemmt. Dies hat zur Folge, dass für die posttranslationalen Modifikationen bestimmter Proteinfamilien notwendige Metabolite wie FarnesylPyrophosphat und Geranyl-Pyrophosphat nicht mehr katalysiert werden. Dies führt zum Funktionsverlust und zur Apoptose der Zelle, da die Ausbildung des Zytoskeletts, des basalen Faltensaums (ruffled border) und damit die Polarisation der Osteoklasten nicht mehr organisiert werden kann (Rogers 2004). Nicht-Aminobisphosphonate und eine kleine Anzahl an Amino-Bisphosphonaten wirken der Knochenresorption entgegen, indem sie als nicht hydrolysierbare, toxische ATP-Analoga von aktiven Osteoklasten ins Zellinnere aufgenommen werden und hier mit ATP-abhängigen Prozessen interferieren. Dies induziert den Zelltod durch Apoptose der Osteoklasten (Li et al. 2011). 


\section{Indirekte Effekte}

Neben dieser direkten Hauptwirkung der Bisphosphonate auf die Inhibition der osteoklastären Knochenresorption sind auch Osteoblasten als weitere Zielzellen anzusehen. Durch eine Reduzierung der Genexpression von RANKL und eine Steigerung der Expression von OPG sollen Bisphosphonate die Osteoklastogenese ebenso indirekt-regulatorisch über ein erhöhtes Verhältnis von OPG zu RANKL maßgeblich einschränken (Li et al. 2011). $\mathrm{Zu}$ diesem Ergebnis einer zum Teil signifikanten Steigerung von OPG kommen viele Studien bei der Untersuchung der Effekte unterschiedlicher potenter Bisphosphonate auf humane oder tierische Osteoblastenkulturen (Ribeiro et al. 2014; Sievers 2012; Koch et al. 2012; Pan et al. 2004; Viereck et al. 2002), der Untersuchung von humanem Serum mit verschiedenen Bisphosphonaten behandelter Patienten (Mercatali et al. 2013; Martini et al. 2007; Perifanis et al. 2007; Martini et al. 2006) oder auch über einen Proteinnachweis mittels ELISA (Çankaya et al. 2013).

Die direkten Wirkungen von Bisphosphonaten über Osteoklasten und die indirekten Wirkungen auf Osteoklasten über OPG und RANKL müssten folglich mit einer Reduktion der Osteoklastenanzahl auf der Knochenoberfläche einhergehen (Plotkin et al. 2006). Die Literatur spiegelt allerdings andere Ergebnisse wider: Hier wird vielfach von einer zum Teil signifikanten Steigerung der Osteoklastenzahlen infolge der Verabreichung von verschiedenen Bisphosphonaten berichtet (Otto et al. 2017; Nagata et al. 2017; Bi et al. 2010; Weinstein et al. 2009) oder von keiner Veränderung der Zellzahlen (Jobke et al. 2014). Mehrheitlich werden in den Publikationen auch ähnliche morphologische Veränderungen der Osteoklasten genannt.

Aktuell wird ebenso ein direkter Effekt potenter Bisphosphonate auf Osteoblasten und damit eine Modulation der osteoblastären Knochenneubildung durch die Bisphosphonate angenommen. Die vorliegenden Daten dieser Beeinflussung sind jedoch widersprüchlich. Welche Rolle Osteoblasten bei der Wirkung der Inhibition der Knochenresorption durch Bisphosphonate direkt spielen, ist somit noch unklar. Einige Autoren berichten von einer Reduktion der osteoblastären Aktivität und einer geringeren Überlebensrate durch den Einfluss von Bisphosphonaten in vitro und vivo (Ubellacker et al. 2017; Haider et al. 2014; Orriss et al. 2009; Idris et al. 2008), während andere Studienergebnisse einen positiven Effekt von Amino-Bisphosphonaten auf Proliferation, Überlebensrate und Wachstum zeigen (Maruotti et al. 2012; Bellido und Plotkin 2011; Corrado et al. 2010; Xiong et al. 2009). 
Über diesen direkten und indirekten Weg inhibieren Bisphosphonate die Knochenresorption und steigern dadurch die Knochendichte bzw. halten diese aufrecht (Elad et al. 2010).

Die Auswirkung der Bisphosphonate auf das Knochengewebe wird zusammenfassend auch als freezing bone- Effekt bezeichnet: Der Knochenumsatz wird reduziert und die Knochenmasse dadurch gesteigert. Dies ist über laborchemisch bestimmbare Knochenumsatzparameter nachzuweisen (Tab. 2).

Ging man also bislang davon aus, dass der antiresorptive Effekt über eine Reduzierung der Differenzierung und Proliferation sowie der Aktivität der Osteoklasten einhergeht, konnte in neueren Untersuchungen ebenso eine indirekte Wirkung auf Osteoklasten über die OPG und RANKL-Expression der Osteoblasten und ebenso eine direkte Wirkung auf die Osteoblastogenese sowie Apoptose und Funktion der Osteoblasten gezeigt werden. 
Tab. 2: Typische laborchemisch bestimmbare Knochenumsatzparameter

\begin{tabular}{|c|c|c|}
\hline \multicolumn{3}{|c|}{ Basisdiagnostik Knochenstoffwechsel } \\
\hline Parameter & Fragestellung & Material \\
\hline Ca und $\mathrm{P}$ & $\begin{array}{l}\text { Basisuntersuchung zur Erkennung von Störungen des } \\
\text { Calcium- und Phosphatstoffwechsels }\end{array}$ & Serum \\
\hline ALP und Gamma-GT & $\begin{array}{l}\text { Erhöhter Knochenumsatz, Metastasen; Gamma-GT zum } \\
\text { Ausschluss einer hepatischen ALP-Erhöhung }\end{array}$ & Serum \\
\hline Kreatinin & Renale Osteopathie (Kreatinin > 2-3 mg/dl) & Serum \\
\hline TSH & Ausschluss Hyperthyreose & Serum \\
\hline BSG/ CRP/ großes Blutbild & Ausschluss entzündlicher Ursachen & Serum \\
\hline $25(\mathrm{OH})$-Vit. D & Vitamin D-Mangel, Malabsorption & Serum \\
\hline \multicolumn{3}{|c|}{ Erweiterungsdiagnostik in Abhängigkeit von der Fragestellung } \\
\hline PTH intakt & Hyperparathyreoidismus & $\begin{array}{l}\text { EDTA- } \\
\text { Plasma }\end{array}$ \\
\hline Kortisol/ DXM- Hemmtest & Hyperkortisolismus/ M. Cushing & Serum \\
\hline \multicolumn{3}{|c|}{ Parameter des Knochenumsatzes } \\
\hline \multicolumn{3}{|l|}{ Knochenaufbau: Osteoblasten } \\
\hline Knochen-ALP, BAP & $\begin{array}{l}\text { M. Paget, Knochenmetastasen, Hyperparathyreoidismus, } \\
\text { Osteomalazie, Osteoporose (Verlaufskontrolle), funktio- } \\
\text { nelle Osteoblastendefekte (Hypophosphatasämie) }\end{array}$ & Serum \\
\hline $\mathrm{OC}$ & $\begin{array}{l}\text { Glukokortikoid-bedingte Osteopenie (Osteoblastenakti- } \\
\text { vität vermindert), Knochenmetastasen, Osteoporose (Ver- } \\
\text { laufskontrolle) }\end{array}$ & Serum \\
\hline \multicolumn{3}{|l|}{ Knochenabbau: Osteoklasten } \\
\hline $\begin{array}{l}\text { Pyridinolin (PYD)/ Desoxypyri- } \\
\text { dinolin (DPD) "Crosslinks" }\end{array}$ & $\begin{array}{l}\text { Osteoporose (Verlaufskontrolle), Erkrankungen mit } \\
\text { erhöhter Knochenresorption }\end{array}$ & Morgenurin \\
\hline (TRAP 5b) & $\begin{array}{l}\text { Osteoporose (Verlaufskontrolle), Erkrankungen mit erhöh- } \\
\text { ter Knochenresorption: wenig etablierter Parameter }\end{array}$ & Serum \\
\hline
\end{tabular}

[modifiziert nach Labor Schottdorf GmbH 2014]

\subsection{Indikationsgebiete}

Bisphosphonate werden heute bei metabolischen Knochenerkrankungen, die mit einer gesteigerten osteoklastären Knochenresorption einhergehen (Reinholz et al. 2000), präventiv oder therapeutisch eingesetzt. Hierdurch kann das Risiko skelettaler Komplikationen (SRE: skeletal-related event") wie beispielsweise Frakturen, Rückenmarkskompressionen durch Wirbelkörperfrakturen, Knochenschmerzen und Hyperkalzämien (Clemons et al. 2012) signifikant gesenkt werden (Talreja 2012; So et al. 2012; Van Poznak et al. 2011).

Hierzu zählt insbesondere die postmenopausale/primäre Osteoporose, die als häufigste systemische Knochenerkrankung des höheren Lebensalters ca. 30 \% aller Frauen nach der Menopause infolge des Östrogenabfalls betrifft (Bischoff et al. 2009). Reduziert sich der anabole Effekt von Östrogen auf das Knochengewebe, kommt es zu einer Imbalance im Knochenremodelling zugunsten eines gesteigerten Knochenabbaus (Abb. 1) mit 
der Folge einer gesteigerten Frakturanfälligkeit (insbesondere Schenkelhals, Wirbelkörper, Radius). 2003 wurden $10 \%$ aller Erkrankten wegen ihrer antiresorptiven Wirkung Bisphosphonate zur Frakturprophylaxe verordnet (Häussler et al. 2007).

Die sekundäre Osteoporose kann infolge einer anderen Grunderkrankung oder beispielsweise durch eine hochdosierte Langzeit-Therapie mit Kortikosteroiden („Glukokortikoid-induzierte Osteoporose“) entstehen. Hier lässt sich primär ein hemmender Effekt der Glukokortikoide auf die Bildung, Differenzierung und Aktivität der Osteoblasten mit gesteigerter Apoptose nachweisen (Abb. 1), aus dem ein erhöhter Knochenabbau resultiert (Anić und Mayer 2014).

Morbus Paget des Knochens (Osteodystrophia deformans) ist eine chronischprogrediente Erkrankung des Skelettsystems, die 1-2 \% der Bevölkerung westlicher Länder ab einem Alter von 55 Jahren betrifft (Ralston 2008; Whyte 2006). Damit stellt er die zweithäufigste Knochenerkrankung nach der Osteoporose dar (Roodman und Windle 2005). Bei M. Paget kommt zu einer exzessiv gesteigerten Knochenresorption, der reaktiv eine unorganisierte Knochenneubildung folgt. Die Ätiologie der Erkrankung wird auf genetischer Ebene vermutet. Genmutationen von Proteinen, die im Zusammenhang mit dem RANK-L/RANK/OPG-System stehen, konnten als Auslöser des typischen Krankheitsbildes identifiziert werden (Daroszewska und Ralston 2005; Roodman und Windle 2005). Die Therapie mit Bisphosphonaten gehört heute zur Standardtherapie, um die unkontrollierte Knochenresorption zu unterbinden.

Tumoren, die in fortgeschrittenem Stadium primär ins Knochengewebe metastasieren $(M B D=$ metastatic bone disease $)$, umfassen Mamma-, Prostata-, Bronchial-, Schilddrüsen- und Nieren-Karzinome sowie Lymphome. Durch die Metastasen kommt es zu einer vermehrten Sekretion osteotroper Zytokine, die über die Stimulierung der Osteoklasten zu einer verstärkten Knochenresorption führen. Für die Patienten können chronische Schmerzen und ein deutlich erhöhtes Risiko für pathologische Frakturen die Folge sein. 5$10 \%$ der betroffenen Patienten entwickeln ebenso einen erhöhten Serumcalciumspiegel (tumorassoziierte Hyperkalzämie) als typische Komplikation der verstärkten Osteolyse (Lambrinoudaki et al. 2008).

Auch beim multiplen Myelom (syn.: Plasmozytom, Kahler-Krankheit, monoklonale Gammopathie), bei dem die $\gamma$-Immunglobulin produzierenden Plasmazellen maligne entarten, kommt es bei 70-95 \% der Erkrankten zu osteolytischen Läsionen durch Osteoklastenstimulierende Faktoren (Coleman 2006). Das Plasmozytom zählt zu den aggressiven (hochmalignen) B-Zell-Non-Hodgkin-Lymphomen und stellt eine Erkrankung des höheren 
Lebensalters dar. Ca. 0,8 \% aller Krebserkrankungen sind Plasmozytome (Becker 2011).

Laut aktueller Leitlinie zu Osteoporose (Leitlinie Osteoporose 2014) gelten Bisphosphonate neben anderen Wirkstoffgruppen als sicher belegte Therapeutika zur Senkung des Frakturrisikos der postmenopausalen Osteoporose. Eine generelle Indikation zur medikamentösen Therapie gilt in Abhängigkeit von bestimmten Parametern wie vorausgegangenen Frakturen, einem bestimmten Wert des DXA T-Scores sowie in Abhängigkeit vom individuellen Risikoprofil des Patienten (Alter, Geschlecht, hochdosierte GlukokortikoidTherapie etc.). Beispiele sind Alendronat (Fosamax®, p. o. wöchentlich), Ibandronat (Bonviva ${ }^{\circledR}$, i. v. vierteljährlich), Risedronat (p. o. wöchentlich), Zoledronat (Aclasta®, i. v. jährlich).

Laut der Leitlinie zum Mammakarzinom sollte eine Bisphosphonat-Medikation bei Fernmetastasierung mit ossärer Manifestation als osteoprotektive Therapie erfolgen (Leitlinie Mammakarzinom 2017). Zoledronsäure (Zometa®) ist dabei zur Verhinderung von Skelettkomplikationen wie z. B. Frakturen (Dosierung: alle 3-4 Wochen eine Infusion) sowie zur Behandlung tumorinduzierter Hyperkalzämien am Menschen zugelassen (Dosierung: einmalige Infusion) (Gebrauchsinformation Zometa 2017).

Im Vergleich zur medikamentösen Therapie bei Osteoporosepatienten sind in der Onkologie vielfach potentere, ausschließlich intravenös verabreichte Bisphosphonate in höheren Dosierungen zugelassen. In einer Multicenter Kohortenstudie, die von 2007-2014 durchgeführt wurde (Schröder et al. 2017), sind von insgesamt 1094 Patienten $89 \%$ mit einem antiresorptiv wirkenden Medikament therapiert worden. Die meisten Patienten erhielten dabei Zoledronat (37 \%) oder (2014-2015) 36,2 \% Denosumab, was den aktuellen Empfehlungen der Leitlinien entspricht.

Interessanterweise zeigen aktuelle Laborstudien ebenso direkte und indirekte tumorsuppressive Effekte von Amino-Bisphosphonaten auf unterschiedliche Tumorzelltypen (Nakazawa et al. 2016). So beschreiben Nienhuis in ihrer In-vitro-Studie beispielsweise die Induktion des Zelltodes humaner Mamma-Karzinomzellen durch Zoledronat in Co-Kultur mit Stromazellen (Nienhuis et al. 2015). 


\subsection{Unerwünschte Arzneimittelwirkungen}

Als häufige schwerwiegende Nebenwirkungen hochpotenter Bisphosphonate wie Zoledronat werden schwere Nierenfunktionsstörungen und Hypokalzämien genannt (10\% der Behandelten), die selten auch schwerwiegende Folgen wie z. B. Herzrhythmusstörungen haben können $(0,1 \%)$. Gelegentlich können Symptome einer Osteonekrose im Kiefer, Vorhofflimmern oder schwere allergische Reaktionen auftreten. Daneben existieren eine Reihe weiterer, nicht schwerwiegender unerwünschter Arzneimittelwirkungen (Gebrauchsinformation Zometa 2017).

\subsection{Bisphosphonat-assoziierte Osteonekrosen der Kiefer (ONJ)}

Die Entwicklung einer auf die Kiefer limitierten Osteonekrose (ONJ/ osteonecrosis of the jaw oder BRONJ/ bisphosphonate-related osteonecrosis of the jaw) wird neben anderen unerwünschten Arzneimittelwirkungen als eine gelegentlich auftretende, schwerwiegende Nebenwirkung hochpotenter Bisphosphonate angegeben (s. 1.5). Die „gelegentliche“ Nebenwirkung wird hier mit: „kann bis zu 1 von 100 Behandelten betreffen“, also $1 \%$ der Behandelten, näher beschrieben.

\section{Definition und Staging}

Aufgrund der aktuellen Zunahme der Fälle von Kiefernekrosen nicht nur durch Bisphosphonate, sondern auch durch andere antiresorptiv (z. B. Denosumab) und tumorsuppressiv (z. B. antiangiogenetisch) wirkende Medikamente, sah sich die American Association of Oral and Maxillofacial Surgeons (AAOMS) (Ruggiero et al. 2014) gemäß ihrer jüngsten Stellungnahme dazu veranlasst, die Bezeichnung BRONJ (s. o.) in MRONJ (medicationrelated osteonecrosis of the jaw/medikamentenassoziierte Osteonekrose der Kiefer) zu ändern. Da sich die vorliegende Arbeit auf die Effekte von Zoledronat bezieht, wird im Folgenden der Begriff ONJ verwendet.

Nach aktueller Stellungnahme der AAOMS wird die Diagnose einer ONJ durch das Vorliegen von drei Kriterien definiert. Dadurch soll sie von anderen Zuständen verzögerter Wundheilung der Kiefer differenziert werden. 
1. aktuelle oder frühere Behandlung mit einem Bisphosphonat

2. exponierter Knochen oder Knochen, der über eine intra- oder extraorale Fistel im Mund-Kiefer-Gesichtsbereich sondiert werden kann mit einer Persistenz $>8$ Wochen und

3. fehlende Strahlentherapie-Anamnese oder offensichtliche Metastasierung im Kieferbereich

Anhand dieser klinischen Kriterien kann die Diagnose einer ONJ gestellt werden. Mehrere alternative Erkrankungen des Mund-Kiefer-Gesichtsbereiches, die häufiger auftreten als eine ONJ, sollten bei der Diagnosestellung einer ONJ im frühen Stadium berücksichtigt werden. Dazu gehören beispielsweise parodontale oder apikale Abszesse, Pulpitiden, Karies, Sinusitiden, Ulzerationen anderer Ursache sowie maligne Geschehen, womit der klinischen Untersuchung eine besondere Bedeutung zukommt. Die gängigen zahnärztlichen radiologischen Verfahren wie Zahnfilm und Panoramaschichtaufnahme sind wie auch CT, DVT oder MRT-Untersuchungen wenig spezifisch für die Früherkennung der ONJ, helfen aber beim Staging der ONJ, um die richtige Therapie auszuwählen (Fassio et al. 2017; Grötz et al. 2012). Radiologisch typisch sind anfangs persistierende Alveolen ohne knöcherne Durchbauung oder eine progrediente Osteolyse nach Zahnextraktion. Als typisches Zeichen einer manifesten ONJ wird auch eine gesteigerte Knochendichte (Osteosklerose) um Nekrosezonen beschrieben (Otto et al. 2017).

In der Fachliteratur sind zahlreiche Stadieneinteilungen der ONJ zu finden, meist basierend auf drei klinischen Stadien, wobei die AAOMS seit 2009 noch ein sehr frühes Stadium (,Stage 0“) hinzugefügt hat (Ruggiero et al. 2014; Fassio et al. 2017). Vom Stadium 0 abzugrenzen sind Patienten, die keine Anzeichen oder Symptome einer ONJ zeigen, sich jedoch unter oder nach einer antiresorptiven Therapie befinden, also potentiell gefährdet sind, eine ONJ zu entwickeln (Grötz et al. 2016). 
- Stage 0: Knochenschmerz, radiologische Anzeichen von Osteosklerose, keine Anzeichen freiliegenden Knochens

- Stage 1: Exponierter, nekrotischer Knochen (inspektorisch oder sondierbar über Fisteln), keine Zeichen von Inflammation/Infektion, asymptomatisch

- Stage 2: Exponierter, nekrotischer Knochen (inspektorisch oder sondierbar über Fisteln) mit Zeichen von Inflammation/Infektion, dadurch Schmerz, Erythem und ggf. Pusabgang

- Stage 3: Exponierter, nekrotischer Knochen (über den Alveolarkamm hinaus fortgeschritten), Inflammation/Infektion, dadurch Schmerz, und einer der folgenden Befunde: pathologische Frakturen, extraorale Fistelung, Osteolyse bis in den Sinus maxillaris/zur UK-Basis.

\section{Epidemiologie, Ätiologie und Risikofaktoren der ONJ}

Die ersten Fälle einer ONJ wurden im Jahr 2003/2004 erstmalig publiziert (Marx 2003; Ruggiero et al. 2004). Betroffen waren insbesondere Patienten mit malignen Tumoren, die eine hohe Dosis intravenöser Bisphosphonate (Pamidronat, Zoledronat) erhielten. Die Häufigkeit der ONJ bei Patienten mit Osteoporose hingegen scheint erheblich geringer zu sein (Khan et al. 2011).

Je nach Studiendesign unterscheiden sich Angaben hinsichtlich der Prävalenz und Inzidenz der ONJ in der Literatur deutlich voneinander.

In der aktuellen Leitlinie über „Bisphosphonat-assoziierte Kiefernekrosen (BP-ONJ) und andere Medikamenten-assoziierte Kiefernekrosen“ (Grötz et al. 2012) werden drei verschiedene Risikoprofile unterschieden, die eine unterschiedliche Prävalenz hervorbringen (niedrig, mittel, hoch):

Niedriges Risikoprofil: Medikamentöse Therapie der primären Osteoporose - Einnahme von oralen (meist Alendronat) oder intravenösen Bisphosphonaten (z. B. Zoledronat $5 \mathrm{mg}$ alle 12 Monate)

Prävalenz der ONJ: 0,1 \% (Lo et al. 2010)

Lo et al. unterscheiden hierbei eine Bisphosphonat-Medikation von $<4$ Jahren mit einer Prävalenz von 0,04 \% und eine Medikation von > 4 Jahren mit einer Prävalenz von 0,21 \%. Die literarischen Angaben für das Auftreten einer ONJ bei oralen Bisphosphonaten sind ambivalent und hängen stark von der Gesamtdauer der Einnahme des Medikaments ab. So 
geben Marx et al. an, dass der ONJ bei durchschnittlicher Dosis und Therapiedauer keine signifikante Prävalenz zukommt (Marx et al. 2005). Sedghizadeh et al. beschreiben bei kleineren Kollektiven für die orale Aminobisphosphonat- Medikation (Alendronat) deutlich höhere ONJ-Ereignisraten von 4 \% (Sedghizadeh et al. 2009).

Für die jährliche i. v.- Applikation über einen kurzen Zeitraum mit Zoledronat wurden niedrige ONJ-Ereignisraten beschrieben (Grbic et al. 2008; Lyles et al. 2007).

Mittleres Risikoprofil: Medikamentöse Therapie der Glukokortikoid-induzierten Osteoporose - Einnahme von intravenösen Bisphosphonaten (z. B. Zoledronat 4 mg alle 4-6 Monate)

Prävalenz der ONJ: $1 \%$ (Hines et al. 2009)

Hohes Risikoprofil: Medikamentöse Therapie von onkologischen Erkrankungen - Einnahme von intravenösen Bisphosphonaten (Zoledronat 4 mg alle 4 Wochen)

Prävalenz der ONJ: 1-19 \% (Himelstein et al. 2017; Khan et al. 2015; Walter et al. 2010)

Die Ergebnisse zur Prävalenz einer $\mathrm{ONJ}$ bei Patienten mit multiplem Myelom unter Zoledronat-Therapie von Walter et al. (2010) machen ebenso deutlich, dass das Vorliegen einer ONJ stark vom Studiendesign abhängig ist: Bei 20,5\% seines prospektiv und intraoral untersuchten Patientenkollektivs lag eine ONJ vor, im Vergleich zu einer Prävalenz von nur $4,9 \%$ bei retrospektiv gefragten Patienten, die nicht intraoral untersucht wurden.

Mit steigender Potenz des Bisphosphonats und mit zunehmender Dauer des Verabreichungszeitraumes steigt das Risiko einer ONJ (Grötz et al. 2012).

\section{Ätiopathogenese der ONJ}

Zahlreiche Theorien versuchen Unterschiede zwischen dem Knochengewebe des Gesichtsschädels und dem des übrigen Skelettsystems aufzuzeigen, um eine Begründung für die Entstehung der Bisphosphonat-assoziierten Kiefernekrose zu finden, wohingegen alle anderen Knochen offensichtlich nicht betroffen sind. Diese ortsspezifische Wirkungsdifferenz von Bisphosphonaten ist bis heute ungeklärt und Gegenstand aktueller Forschung.

Ein Schwerpunkt liegt hierbei auf der unterschiedlichen embryologischen Herkunft der menschlichen Stützgewebe: Die Stützgewebe des Viszerokraniums, also der kraniofazialen und pharyngealen Region, entstammen überwiegend den Neuralleistenzellen (Ektoderm, 
auch „Ektomesenchym“ oder „Mesektoderm“), die anderer Körperabschnitte gehen ganz überwiegend aus Progenitorzellen des Mesoderms hervor. Auch entstehen Maxilla und Mandibula infolge der Differenzierung migrierter Neuralleistenzellen durch desmale Ossifikation, alle anderen Skelettabschnitte, so auch der Beckenknochen, werden hingegen, ausgehend von Mesenchymzellen (Mesoderm), durch chondrale Ossifikation gebildet (Rohen und Lütjen-Drecoll 2016; Noden und Trainor 2005). Die Osteoblastenvorläuferzellen der Kiefer und des Beckenknochens sind also unterschiedlicher Herkunft, was als Begründung für die unterschiedlichen Reaktionen dieser Knochengewebe auf eine Behandlung mit Bisphosphonaten diskutiert wird.

Auch Akintoye et al. fokussieren in ihrer Studie diese unterschiedliche embryologische Herkunft der Knochenmarkszellen des Viszerokraniums (Maxilla und Mandibula samt Alveolarknochen, Dentin, Pulpa und Desmodont) im Vergleich zu jenen der anderen Knochen des Skeletts (Akintoye et al. 2006). Sie beschreiben eine durch Pamidronat ausgelöste, unterschiedliche Beeinflussung des Differenzierungsverhaltens mesenchymaler Stammzellen in Prä-Osteoblasten und Osteoblasten in den Kieferknochen im Vergleich zum Beckenknochen desselben Individuums. Dies könnte zur Entstehung der kieferspezifischen ONJ beitragen. Pamidronat hatte in ihrem Experiment einen dosisabhängig steigernden Einfluss auf die Differenzierung der MSCs des Beckenkamms, ohne eine Veränderung der Zellzahl hervorzurufen. Im Unterkiefer konnte hierbei hingegen nur ein wenig steigernder Effekt verzeichnet werden, jedoch eine Reduktion der Zellzahl.

Ein weiterer Unterschied zwischen dem Unterkiefer und anderen Knochen des Skeletts besteht in der überdurchschnittlich hohen funktionellen Belastung des Unterkiefers durch seine Bewegungen während der Mastikation oder des Sprechens und die tägliche Okklusion der Zähne. Durch die ständige Belastung des parodontalen Ligaments über die Zähne oder auch eine Kompression durch herausnehmbaren Zahnersatz unterliegen die Kiefer einer höheren Umsatzrate (remodelling) als andere Knochen mit einhergehender starker Blutperfusion. Die hohe Affinität der Bisphosphonate zu umsatzaktivem Knochengewebe führt hier infolgedessen zu einer höheren Konzentration der Bisphosphonate als in anderen Skelettabschnitten. Stefanik et al. diskutieren, dass durch die Einwirkung von Bisphosphonaten wie Pamidronat das Unterkiefer-Remodelling über eine Unterbindung der physiologischen Differenzierung der MSCs zu Osteoblasten bei einer gleichzeitigen Erhöhung der Osteoklastendifferenzierung aus HSCs gestört werde. Da die Kiefer trotz der hieraus resultierenden Imbalance zwischen Osteoblasten und Osteoklasten täglich einer hohen funktio- 
nellen Belastung ausgesetzt seien, könne es zu Mikrofrakturen im Alveolarknochen kommen. Bakterien der physiologischen oder pathogen veränderten Mundflora (z. B. bei Parodontitis) können nun leicht über den Desmodontalspalt zum Kieferknochen vordringen und hier zu subklinischen Entzündungen und Gewebsnekrosen führen, welche wiederum auslösend für die Entwicklung einer ONJ sein könnten (Stefanik et al. 2008).

Auch Erkrankungen oder Traumata (auch durch regelmäßige zahnärztliche Eingriffe) der nur dünnen, den Kieferknochen bedeckenden Mukosa können besondere prädisponierende Faktoren für die Entstehung einer Osteonekrose in dieser Region sein (Marx et al. 2005; Grötz et al. 2016).

Fournier et al. konnten in vitro und vivo am Modell einer Ratte zeigen, dass potente Bisphosphonate wie Pamidronat oder Zoledronat auch die Angiogenese und die Synthese von VEGF (vascular endothelial growth factor) unterdrücken und die Neubildung von Kapillaren reduzieren. Diese antiangiogenetischen Effekte könnten besonders bei der hohen Vaskularität der Kiefer zu einer Reduktion von Blutgefäßen und damit einhergehender avaskulärer Nekrose, wie sie bei der ONJ aufritt, führen (Fournier et al. 2002). Diese Theorie unterstützt, dass die intraoralen Defekte bei der ONJ vermehrt im Molarenbereich, dem Kauzentrum, mit einhergehender hoher Blutversorgung (Marx et al. 2005) und wenig bis keine Nekrosen in proximalen Anschnitten des Unterkiefers auftreten. Auch ist die Weichgewebsabdeckung in proximalen Kieferabschnitten deutlich höher.

Otto et al. postulieren die Freisetzung des vom Alveolarknochen gebundenen Bisphosphonats durch einen lokal niedrigeren Gewebe-pH-Wert aufgrund dentaler Entzündungen, wie z. B. bei einer Parodontitis. Der lokale Anstieg dieses freigewordenen, aktiven Bisphosphonats könnte zu einer Inhibition der Osteoklasten-Funktion im Bereich des Alveolarknochens führen (Otto et al. 2010).

\section{Prävention und Therapie der ONJ}

Für die Behandlung einer manifesten Kiefernekrose existiert bisher keine effektive kausale Therapie. So kommt der Prävention der ONJ eine besondere Bedeutung zu (Kalra und Jain 2013).

Gründliche zahnärztliche Untersuchungen und -Behandlungen stehen hierbei im Fokus. Orale Infektionsherde, pathologische Prozesse und Risikofaktoren, welche die orale Mundgesundheit auch in Zukunft gefährden können und zu dental-invasiven Eingriffen 
führen könnten, sollten beseitigt werden, insbesondere vor dem Beginn einer i. v.- Therapie mit Bisphosphonaten und anderen antiresorptiv oder antiangiogenetisch wirkenden Medikamenten bei onkologisch behandelten Patienten (Rosella et al. 2016). Tegumental getragener Zahnersatz sollte adäquat korrigiert oder ersetzt werden, um das Risiko von Druckstellen auf das Weichgewebe zu minimieren. Durch Mundhygieneinstruktionen und Motivation sowie regelmäßige professionelle Zahnreinigungen sollte die Mundhygiene der betroffenen Patienten optimiert und dieser Zustand aufrechterhalten werden. Wenn die allgemeinen gesundheitlichen Umstände des Patienten es erlauben, sollte der Beginn der antiresorptiven Therapie solange aufgeschoben werden, bis die orale Mundgesundheit stabil ist bzw. zumindest Schleimhautdefekte wie z. B. nach Extraktionen geschlossen sind (2-3 Wochen) (Ruggiero et al. 2014). Es sollten regelmäßig detaillierte klinische und radiologische Kontrollen der Patienten in individuell ermittelter Frequenz stattfinden. Die Patienten sollten des Weiteren instruiert werden, sich bei jeglichem oralen Schmerz, jeglicher Entzündung oder bei freiliegendem Knochen umgehend beim Zahnarzt zu melden (Rosella et al. 2016). Gerade bei bereits bestehender Therapie mit intravenöser antiresorptiver Medikation ist dies wichtig, um eine ONJ möglichst frühzeitig zu diagnostizieren.

Während der Therapie mit Bisphosphonaten sollten dann insbesondere invasive Behandlungen, die den Knochen implizieren wie z. B. Zahnextraktionen, vermieden werden. Falls doch eine Extraktion notwendig ist, sollte diese atraumatisch und unter antibiotischer Abschirmung erfolgen.

Patienten, die aufgrund einer Osteoporose mit oralen Aminobisphosphonaten $(<4$ Jahre $)$ behandelt werden, sollten über das, wenn auch (ohne begleitende Komorbiditäten) geringe, Risiko einer ONJ und eine gute orale Hygiene sowie regelmäßige zahnärztliche Kontrollen instruiert werden (Ruggiero et al. 2014).

Der Behandlungsumfang einer manifesten ONJ hängt von dem Ausmaß der Defektgröße und der onkologischen Behandlungssituation ab. Die grundsätzlichen Ziele der ONJTherapie beinhalten eine Schmerzreduktion, Infektionsprophylaxe und Verhinderung eines ONJ-Rezidivs sowie den Erhalt bzw. die Wiederherstellung einer mundbezogenen Lebensqualität. Eine konservative Therapie mit engmaschiger Verlaufskontrolle oder eine begrenzte operative Therapie im Sinne einer umschriebenen Dekortikation/Sequesterotomie mit primär plastischer Defektdeckung unter systemischer antibiotischer Abschirmung im ambulanten Setting kommen nur bei geringer Defektgröße der ONJ in Frage. Bei fortgeschrittenen oder multiplen ONJ-Befunden ist ein operativer Eingriff in stationärer Betreu- 
ung und unter i. v.-Antibiose notwendig. Hierbei wird je nach Defektausdehnung in Intubationsnarkose eine Spangen-/Kastenresektion oder eine Kontinuitätsresektion mit anschließender Kieferrekonstruktion erforderlich.

Es existieren nur wenige Daten darüber, ob das Aussetzen der intravenösen Bisphosphonatmedikation bei onkologisch behandelten Patienten vor oralchirurgischen Eingriffen sinnvoll ist oder nicht (Rosella et al. 2016). Durch die langen Halbwertszeiten von Bisphosphonaten gibt es bislang keine Hinweise für den kurativen Erfolg einer ONJ durch eine Unterbrechung der Bisphosphonat-Medikation. In der aktuellen Leitlinie wird eine temporäre Unterbrechung der Bisphosphonatgabe aufgrund pathophysiologischer Überlegungen und präklinischer Daten während der ONJ-Sanierung dennoch nahegelegt (Grötz et al. 2012), zumindest bis eine Weichgewebeheilung stattgefunden hat (Rosella et al. 2016). Die Rehabilitation nach ausgeheilter ONJ wird hier als anspruchsvoll beschrieben und ist mit einer hohen Rezidivrate verknüpft.

\section{Lebensqualität der Patienten mit manifester Kiefernekrose}

Die Lebensqualität der betroffenen Patienten kann durch eine ONJ relevant und dauerhaft kompromittiert sein. Je nach Ausmaß kann neben Schmerzen eine Verminderung der Kaufunktion durch den Verlust von zahntragenden Kieferkammanteilen bzw. dem Alveolarkamm als Prothesen- bzw. Implantatlager eintreten. Die Schluck- und Sprechfunktion kann durch Fistelgänge oder Hyp-/Anästhesien im Ausbreitungsgebiet des Nervus alveolaris inferior gestört sein. Auch das äußere Erscheinungsbild ist beispielsweise durch einen Verlust der Vertikaldimension, eingefallene Gesichtskonturen infolge eines Zahn/Kieferverlustes oder durch orokutane Fistelgänge beeinträchtigt. Ein Rückzug aus dem sozialen Umfeld kann die Folge sein. Eine weitere Konsequenz der ONJ stellt das erhöhte Risiko dar, durch Prothesendruckstellen oder ein insuffizientes Heilungsvermögen des betroffenen Kieferkammareals nach zahnärztlich-chirurgischen Eingriffen ein ONJ-Rezidiv zu erleiden. Die Therapie einer fortgeschrittenen ONJ ist für die betroffenen Patienten belastend. Sie zieht die Notwendigkeit eines umfangreichen, operativen Eingriffs in Vollnarkose, einer langen postoperativen stationären Verweildauer, eine intravenöse antiinfektiöse Therapie und oft auch eine nasogastrale Sondenernährung der Patienten mit sich. Die postoperative Wundbehandlung ist oft langwierig und mit einer hohen Rezidivrate der ONJ verknüpft, woraus häufig weitere Operationen resultieren. Dies hat nicht nur eine gesundheitsökonomische Bedeutung (Grötz et al. 2012); die betroffenen Patienten weisen zudem eine signifikant gesteigerte Morbidität auf (Walter et al. 2016; Ruggiero et al. 2014). 


\section{Dentale Implantationen bei antiresorptiv-behandelten Patienten}

Antiresorptive Medikamente wie z. B. Bisphosphonate oder Denosumab sind Bestandteil der medikamentösen Behandlung einer primären/sekundären Osteoporose sowie von malignen Grunderkrankungen, um einen progressiven (pathologischen) Knochenabbau einzudämmen. Gerade bei hochdosierten intravenös verabreichten Bisphosphonaten, wie sie bei der Behandlung bestimmter Tumoren eingesetzt werden, sollten dentoalveolär-chirurgische Eingriffe jedoch vermieden werden, weil sie mit dem Risiko der Etablierung einer ONJ einhergehen.

Dentale Implantationen können folglich auch einen lokalen Risikofaktor für die Entstehung einer ONJ darstellen. Anderseits können durch Implantat-gelagerten Zahnersatz Probleme eines tegumental gelagerten Zahnersatzes vermieden werden und damit der Entstehung einer ONJ vorgebeugt werden (Grötz et al. 2016). Gerade vor dem Hintergrund einer massiven Einschränkung der Lebensqualität der Patienten, die eine manifeste Osteonekrose aufgrund von Bisphosphonaten erleiden (Ruggiero et al. 2014), sollte ein breiter Fokus auf der Prävention dieser Komplikation liegen. Die Lebensqualität von Frauen, die aufgrund einer Osteoporose antiresorptiv mit Bisphosphonaten oder Denosumab behandelt wurden und zum Teil zahnlos waren, konnte durch Implantat-getragene Prothesen signifikant gesteigert werden im Vergleich zu nicht implantär unterstützten dentalen Situationen (DeBaz et al. 2015).

Insgesamt existieren nur wenige Studien, die den Zusammenhang zwischen der Entstehung einer Bisphosphonat-assoziierten ONJ und dentalen Implantaten analysieren.

In den meisten Studien einer systematischen Literaturrecherche von Walter et al. ohne zeitliche Limitation der Publikationsdaten (Walter et al. 2016) konnte kein Fall einer ONJ nach dentaler Implantation bei Bisphosphonat-Therapie aufgrund benigner Grunderkrankung (Osteoporose) gefunden werden (z.B. Al-Sabbagh et al. 2015; Mozzati et al. 2015; Famili et al. 2011).

Bezüglich erfolgreicher Implantationen bei Patienten mit einer malignen Grunderkrankung unter antiresorptiver Therapie hingegen wird mehrheitlich von der Entwicklung von ONJ unter Bisphosphonatgabe berichtet (Giovannacci et al. 2016; Tam et al. 2014; Jacobsen et al. 2013) und es werden nur wenige erfolgreiche Implantationen genannt. Viele Fallberich- 
te setzen sich vielmehr mit den Triggerfaktoren der ONJ, wie z. B. Prothesendruckstellen, auseinander oder gehen der Frage einer perioperativen antibiotischen Abschirmung nach (Walter et al. 2016).

Die Leitlinie zu Zahnimplantaten bei Knochenantiresorptiva (Grötz et al. 2016) gibt Handlungsempfehlungen zur Indikation dentaler Implantate bei Patienten unter antiresorptiver Medikation, um für diese Patienten eine verbesserte Kaufunktion und Lebensqualität zu erreichen, ohne dass damit ein unangemessenes Osteonekroserisiko einhergeht.

Demnach sollte bei jedem Patienten unter oder nach antiresorptiver Therapie bei geplanter Implantation das individuelle Osteonekroserisiko evaluiert werden.

Grund- und Allgemeinerkrankungen sowie systemische Faktoren, die sich negativ auf die Wundheilung auswirken können, z. B. Nikotinabusus, Begleiterkrankungen wie Diabetes und auch die Compliance des Patienten bezüglich einer optimalen Mundhygiene, sollten vor einer möglichen Implantation erfasst werden (Walter et al. 2016). Bei onkologischer Grunderkrankung sollte bezüglich der krankheitsbedingten Lebenserwartung des Patienten ebenso Rücksprache mit dem behandelnden Onkologen gehalten werden und dies in die Indikationsfindung miteinbezogen werden.

Auf die generelle Möglichkeit der erfolgreichen Implantation bei antiresorptiv behandelten Patienten wird unter Einhaltung bestimmter Kautelen hingewiesen (Grötz et al. 2016; Walter et al. 2016). Ziel der Implantatversorgung soll stets die Reduktion der Belastung der Mundschleimhaut sein. Jegliche augmentative Verfahren am Kiefer sollten nach Möglichkeit vermieden werden, da hierbei hohe Anforderungen an die Vaskularität und das Knochenremodelling gestellt werden, die unter der antiresorptiven Therapie kompromittiert sind, was zu einer ONJ oder/und dem Misserfolg des Implantates führen kann. Der antiresorptiv behandelte Patient muss über das Risiko der ONJ oralchirurgischer Eingriffe aufgeklärt sein, eine systemische, perioperative Antibiotikaprophylaxe sollte durchgeführt werden und die OP-Technik sollte atraumatisch sowie mit plastischer Deckung der Wunde erfolgen (Grötz et al. 2012; Grötz et al. 2016). Zu einem zeitweiligen, perioperativen Absetzen der antiresorptiven Medikation wird in der Leitlinie zu Zahnimplantaten aufgrund mangelnder belastender Daten keine Empfehlung ausgesprochen, Ruggiero et al. hingegen raten dazu (Ruggiero et al. 2014). Eine strukturierte Nachsorge aller mit Antiresorptiva behandelten Patienten (s. o.), ob mit oder ohne Implantation, ist obligat, um das Risiko einer Inflammation/Infektion als Trigger einer ONJ zu reduzieren.

Auch ein erfolgreich osseointegriertes Implantat kann ein Risiko als potentieller Trigger- 
faktor für die Entstehung einer ONJ darstellen (Giovannacci et al. 2016; Jacobsen et al. 2013), was stets in Relation zu einem möglichen Gewinn an Lebensqualität jedes einzelnen Patienten gewertet werden muss (Giovannacci et al. 2016; Walter et al. 2016; DeBaz et al. 2015).

\subsection{Auswahl des Tiermodells}

Der genaue Pathomechanismus der $\mathrm{ONJ}$ ist noch nicht vollständig geklärt. Präklinische Studien sind diesbezüglich von besonderem Wert für gezieltere Untersuchungen, um ein besseres Verständnis der ONJ zu erlangen und ihr damit zukünftig erfolgreicher vorbeugen zu können (Otto et al. 2017).

Großtiermodelle bieten den Vorteil, dass die Morphologie ihrer Kiefer und Zähne dem Menschen ähnlich sind (Voss et al. 2016). Die Größe der Kiefer erlaubt, im Gegensatz zu Tiermodellen wie z. B. Ratte oder Kaninchen, dentale Implantationen mit klinisch relevanten Implantatgrößen (3,75 mm x 11,5 mm). Derartige Implantationen in ossifizierte Extraktionsalveolen der Großtiere kommen der realen Situation am Patienten folglich recht nahe. Auch die orale Mikroflora ähnelt sich bei Großtier und Mensch sowie der Grundumsatz, sodass durch ähnliche pharmakologische Dosierungen beim Großtier auch Rückschlüsse auf die Wirkungen beim Menschen gezogen werden können (Allen 2015).

Beim adulten Schweinemodell besteht eine hohe biologische Ähnlichkeit des Knochens zum humanen Knochen, weshalb sich das Schwein als geeignetes Studienmodell für die Evaluation von Knochenheilung und -remodelling erwiesen hat. Im Gegensatz zu Hunden zeigen Schweine eine dem Menschen ähnliche Knochenregeneration (Thorwarth et al. 2005), Physiologie und Knochenumsatzrate (Glowacki et al. 2004). Von Mosekilde et al. wird die Mikrostruktur des Knochens vom Schwein als lamellär und dem humanen Knochen ähnlich beschrieben, genauso wie eine ähnliche Mineralisationsdichte und konzentration geschildert wird (Mosekilde et al. 1987). Durch das aus zwergwüchsigen Rassen gezüchtete ideale Verhältnis zwischen Körpergröße und -gewicht von Miniaturschweinen (Beglinger et al. 1975) ergeben sich ökonomische und logistische Vorteile für ihre Haltung. Eine unkomplizierte Haltung, eine gute Anzahl und Qualität der Ohrvenen und eine Indolenz nach chirurgischen Eingriffen zeichnen die Tiere aus (Beglinger et al. 1975). 
Es liegen diverse präklinische Studien über die Auswirkungen unterschiedlicher Bisphosphonate auf Implantate an Kleintieren wie Ratten oder Kaninchen vor, aber nur wenige Arbeiten wurden am Großtiermodell durchgeführt.

Huja et al. konnten nach einer monatlichen Verabreichung von Zoledronat bei Hunden $(0.1$ $\mathrm{mg} / \mathrm{kg}$, insg. über 4 Monate vor chirurgischem Eingriff, i. v.) keinerlei Anzeichen von intraoralen Nekrosen 8 Wochen nach Zahnentfernung und Mini-Implantat-Insertion feststellen. Über Fluoreszenzmarkierungen konnte im Bereich der Implantate und der Extraktionsalveolen auch bei der Zoledronatgruppe Knochenneubildung/-remodelling festgestellt werden, wenn auch dieses sehr viel geringer war als das der Kontrolltiere ohne Zoledronat (Huja et al. 2011).

Kim et al untersuchten Kaninchen, welche dieselbe Dosierung Zoledronat wie bei Huja erhielten $(0.1 \mathrm{mg} / \mathrm{kg}$, insg. über 4 und 8 Wochen vor chirurgischem Eingriff, i. v.), diese allerdings zweimal wöchentlich. Zahnentfernungen und die Insertion von MiniImplantaten in die Maxilla wurden durchgeführt, die 4 und 8 Wochen später ausgewertet wurden. Hier entwickelten alle Tiere unter Zoledronat-Medikation Kiefernekrosen in den OP-Gebieten im Gegensatz zu den Tieren der Kontrollgruppe ohne Medikation. Die Analyse der Implantat-Knochen-Kontaktrate zeigte eine gute initiale Stabilität der Implantate aller Tiere nach 4 Wochen mit ähnlichen Werten für die Knochenkontaktrate in beiden Gruppen, in der 8. Woche dann aber diesbezüglich nur noch eine Steigerung in der Kontrollgruppe im Gegensatz zu einer Verminderung der Implantat-Knochen-Kontaktrate bei den mit Zoledronat behandelten Tieren (Kim et al. 2013).

Bei 5 Studien von insgesamt 22 zum Thema gefundenen präklinischen Studien wurden niedrigpotente Bisphosphonate (Alendronat) im Zusammenhang mit dentalen Implantationen am Tiermodell analysiert (Oh et al. 2017; Oh et al. 2015; Abtahi et al. 2013; Kim et al. 2011; Viera-Negrón et al. 2008). Die Osseointegration der Implantate war hier ganz überwiegend erfolgreich und es wird von keinem Auftreten einer ONJ-ähnlichen Läsionen berichtet. Nur Abtahi et al. konnten bei allen Tieren, die Alendronat erhielten, klinisch kiefernekrotische Areale feststellen und geben bei den Versuchsgruppentieren einen erhöhten periimplantären Knochenverlust an (Abtahi et al. 2013).

Pautke et al. publizierten eine Großtierstudie, welche die Auswirkungen von Extraktionen unter systemisch verabreichter Zoledronatgabe in hoher Dosierung am Minipig untersuchte. Die Exposition von Knochen im Bereich der Extraktionsareale im Sinne einer ONJ konnte bei jedem Tier aus der Versuchsgruppe identifiziert werden (Pautke et al. 2012). 
Auch Otto et al. stellen das Minipig als ein gut geeignetes Tiermodell für die Entwicklung von ONJ bei systemischer Bisphosphonat-Medikation (Zoledronat) in onkologischer Dosierung vor. Sie konnten sowohl bei den Tieren, die unter Zoledronat-Medikation Zahnextraktionen erfuhren, als auch bei Tieren, die nur Zoledronat ohne chirurgische Interventionen erhielten, zu 100 \% ONJ-Läsionen etablieren (Otto et al. 2017). Voss et al. verabreichten (z. T. ovarektomierten und mit Dexamethason vorbehandelten osteoporotischen) Schafen Zoledronat und extrahierten währenddessen 2 Prämolaren. Die Tiere der Versuchsgruppen entwickelten ONJ-ähnliche Läsionen in den Extraktions- und auch in anderen Kieferabschnitten, die Kontrolltiere nicht (Voss et al. 2016; Voss et al. 2015). Allen et al. hingegen konnten in ihrer Untersuchung an Hunden, welche mit Zoledronat (und z. T. mit Dexamethason) behandelt wurden und die Extraktion von Molaren erfuhren, bei $>80 \%$ der Versuchstiere klinisch und histologisch keinerlei Hinweise auf eine ONJ finden, wenngleich hierbei im Gegensatz zur Kontrollgruppe radiologisch eine periostale Knochenneubildung als ein mögliches Zeichen kompromittierter Knochenheilung festgestellt werden konnte (Allen et al. 2013). 


\section{FRAGESTELLUNG}

Ziel der vorliegenden Arbeit war es, die Auswirkungen des Bisphosphonats Zoledronat (Zometa®) auf ausgewählte Aspekte des Knochenstoffwechsels und der Implantateinheilung am Großtiermodell des Göttinger Minischweins zu untersuchen. Der Fokus lag hierbei auf einer quantitativen Analyse der Expression des Proteins OPG mittels quantitativer Echtzeit-Polymerasekettenreaktion einerseits und einer histomorphometrischen Untersuchung der Osseointegration dentaler Implantate in die Ober- und Unterkiefer der Tiere andererseits. Zusätzlich wurden klinische Analysen in Bezug auf die Defektgrößen intraoral entstandener Kiefernekrosen sowie histologische Analysen bezüglich der Quantität von Osteoklasten und Osteoblasten durchgeführt.

Folgende Fragestellungen sollen durch dieses Projekt beantwortet werden:

- Ist beim Göttinger Minischwein durch die intravenöse Verabreichung von Zoledronat eine Kiefernekrose induzierbar?

- Welche Auswirkungen hat Zoledronat auf die Expression von OPG beim Minischwein?

- Welche Auswirkung hat die Verabreichung von Zoledronat auf die Osseointegration dentaler Implantate beim Göttinger Minischwein in Bezug auf die ImplantatKnochen-Kontaktrate, die Knochendichte in den Gewindegängen und die periimplantäre Knochendichte?

- Sind quantitativen Veränderungen bezüglich der Anzahl von Osteoklasten und Osteoblasten in der Region um die Implantate unter Zoledronat-Einfluss erkennbar? 


\section{MATERIAL UND METHODEN}

\subsection{Methodik}

Zur Versuchsdurchführung wurden 15 weibliche Göttinger Minischweine randomisiert in 3 experimentelle Gruppen $(n=5)$ eingeteilt. Zwei der Gruppen wurden als Versuchsgruppen (VG1 und VG2), die dritte Gruppe als Kontrollgruppe (KG) determiniert.

Den Versuchsgruppen wurde im Verlauf der Studie über einen gruppenspezifischen Zeitraum monatlich intravenös eine hochdosierte Gabe Zoledronat (Zometa ${ }^{\circledR}$ ) verabreicht.

Bei den Tieren der Kontrollgruppe wurde keine Behandlung mit Zoledronat durchgeführt, sie erfuhren ansonsten jedoch die gleiche Behandlung wie die Versuchsgruppentiere.

Die Stoffwechsellage der mit Zoledronat behandelten Versuchsgruppen im Vergleich zur normalen Stoffwechsellage der Tiere der Kontrollgruppe wurde laborchemisch durch monatliche Blutanalysen aller Tiere hinsichtlich ALP, OC, PTH, 25(OH)-Vit.D, Ca, P und Kreatinin kontrolliert (Tab. 2).

Um die von einer Zoledronat-Behandlung unabhängigen Ausgangswerte der OPGExpressionsrate (Baseline) eines jeden Tieres zu bestimmen, wurden in einer ersten Operation (OP 1) zu Beginn des Experiments (Zeitpunkt 0) allen Tieren aus dem Beckenkamm (BK) und der Unterkiefer-Submentalregion (UK) Knochenbiopsien entnommen. Ebenso erfolgte im II. und III. Gebissquadranten der Tiere (Ober- und Unterkiefer links) die Extraktion von jeweils 3 Prämolaren und die Gewinnung von Knochenproben aus den Alveolarfortsatzregionen von Oberkiefer (AOK) und Unterkiefer (AUK). Die Alveolen wurden anschließend mit einem Mukoperiostlappen verschlossen.

Zur physiologischen Ossifikation der Extraktionsalveolen wurden die Tiere in den folgenden 3 Monaten keiner weiteren Therapie unterzogen. Ab dem 3. Monat schloss sich bei den Versuchsgruppen VG1 und VG2 die intravenöse Therapie mit Zoledronat an, welche in einem regelmäßigen Intervall von 4 Wochen wiederholt wurde.

7 Monate nach der Gewinnung des Ausgangsprobenmaterials wurden im Zuge einer zweiten Operation (OP 2, Zeitpunkt: 1) bei jedem Tier erneut Knochenbiopsien aus der Beckenkamm- und Unterkiefer-Submentalregion sowie den Alveolarfortsatzregionen beider Kiefer (hier: I. und IV. Gebissquadrant, nach hiesiger Zahnextraktion dreier Prämolaren) entnommen. Dieses Probenmaterial sollte der vergleichenden Analyse einer möglichen quantitativen Veränderung der OPG-Expressionsrate in den verschiedenen Körperregionen 
unter der erfolgten Zoledronat-Behandlung der Tiere dienen.

Im Zuge der OP 2 wurden bei jedem Tier weiterhin jeweils 2 dentale Implantate in die ossifizierten Extraktionsregionen des II. und III. Quadranten inseriert. Insgesamt erhielt jedes Tier damit 4 dentale Implantate. $\mathrm{Zu}$ diesem Zeitpunkt konnte davon ausgegangen werden, dass die Extraktionsalveolen vollständig verknöchert und die umliegenden Weichgewebe verheilt waren.

Eine dritte Operation (OP 3, Zeitpunkt: 2) umfasste die erneute Gewinnung von Knochenbiopsaten aus dem Beckenkamm und der Submentalregion des Unterkiefers jeden Tieres für die molekulare Analytik. Anschließend wurden die Tiere euthanasiert.

Für die klinische Analyse der Defektgrößen in der Implantatregion hinsichtlich einer Osteonekrose erfolgte zu diesem Zeitpunkt ebenso eine fotografische Erfassung der behandelten intraoralen Situation eines jeden Tieres.

Unmittelbar nach der Euthanasie erfolgte die Gewinnung der Implantat-tragenden Kieferabschnitte, aus welchen histologische Dünnschliffpräparate zur histomorphometrischen und histologischen Analyse hinsichtlich der Osseointegration der dentalen Implantate hergestellt wurden.

Der Zeitpunkt der OP 3 der VG1 einerseits und der VG2/KG andererseits unterschied sich um einen Monat. So wurde bei der Gruppe VG1 4 Wochen nach der zweiten Operation (ca. 8 Monate nach Beginn des Experiments) die Euthanasie eingeleitet, um die frühe Osseointegration der Implantate zu analysieren. VG2 wurde 8 Wochen nach der 2. Operation (ca. 9 Monate nach Beginn des Experiments) zur Analyse der späten Osseointegration euthanasiert. Knochenproben aus den Alveolarregionen der Kiefer zur molekularen Analytik von OPG konnten durch die Entnahme der Implantat-tragenden Kieferabschnitte zu diesem Zeitpunkt nicht mehr entnommen werden. Für die vergleichende Analyse der OPGExpression stand für den Beckenkamm und die Unterkiefer-Submentalregion folglich Knochenmaterial von 3 verschiedenen Zeitpunkten (Zeitpunkt 0, 1 und 2) für die Alveolarregionen des Ober- und Unterkiefers von 2 verschiedenen Zeitpunkten (Zeitpunkt 0 und 1) zur Verfügung (Abb. 2/Abb. 3).

Die Tierstudie wurde vom Niedersächsischen Landesamt für Verbraucherschutz und Lebensmittelsicherheit (Tierversuchs-Nr. AZ 33.9-42502-04-10/0096, Oldenburg) genehmigt. 
Versuchsgruppe 1 (VG1): $n=5$ Minipigs;

Zoledronattherapie, Euthanasie 4 Wochen nach Implantation

Versuchsgruppe 2 (VG2): $n=5$ Minipig5;

Zoledronattherapie, Euthanasie 8 Wochen nach Implantation

Kontrollgruppe (KG): $n=5$ Minipigs;

Keine Zoledronattherapie, Euthanasie 8 Wochen nach implantation

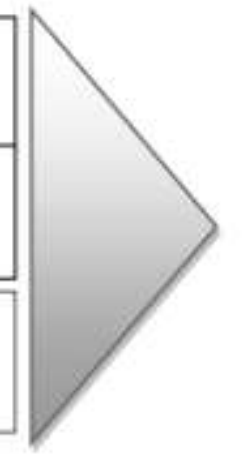

Klinische, molekulare,

histomorphometrische und histologische Analytik der

Wundheilung und

Osseointegration dentaler

Implantate

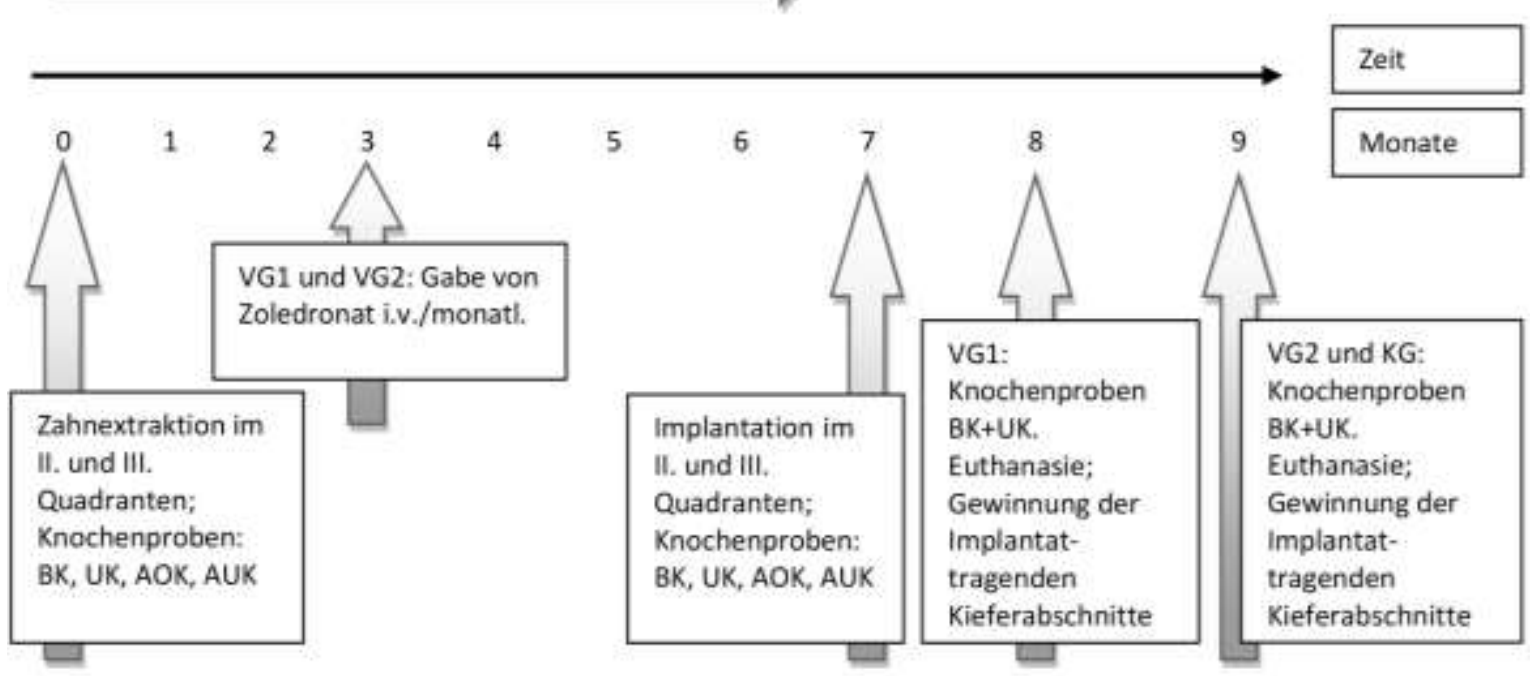

Abb. 2: Aufbau und zeitlicher Horizont des Experiments

$(\mathrm{BK}=$ Beckenkamm; UK = Unterkiefer; AOK = Alveolarkamm Oberkiefer; AUK = Alveolarkamm Unterkiefer) 

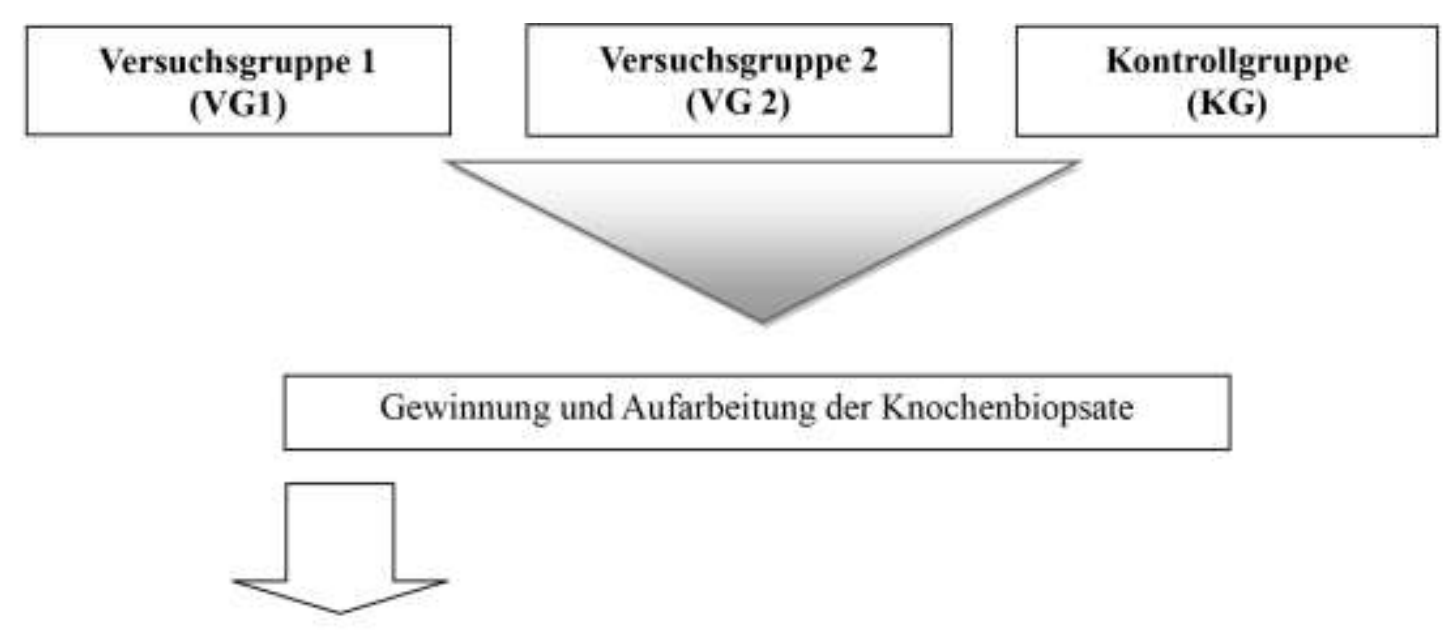
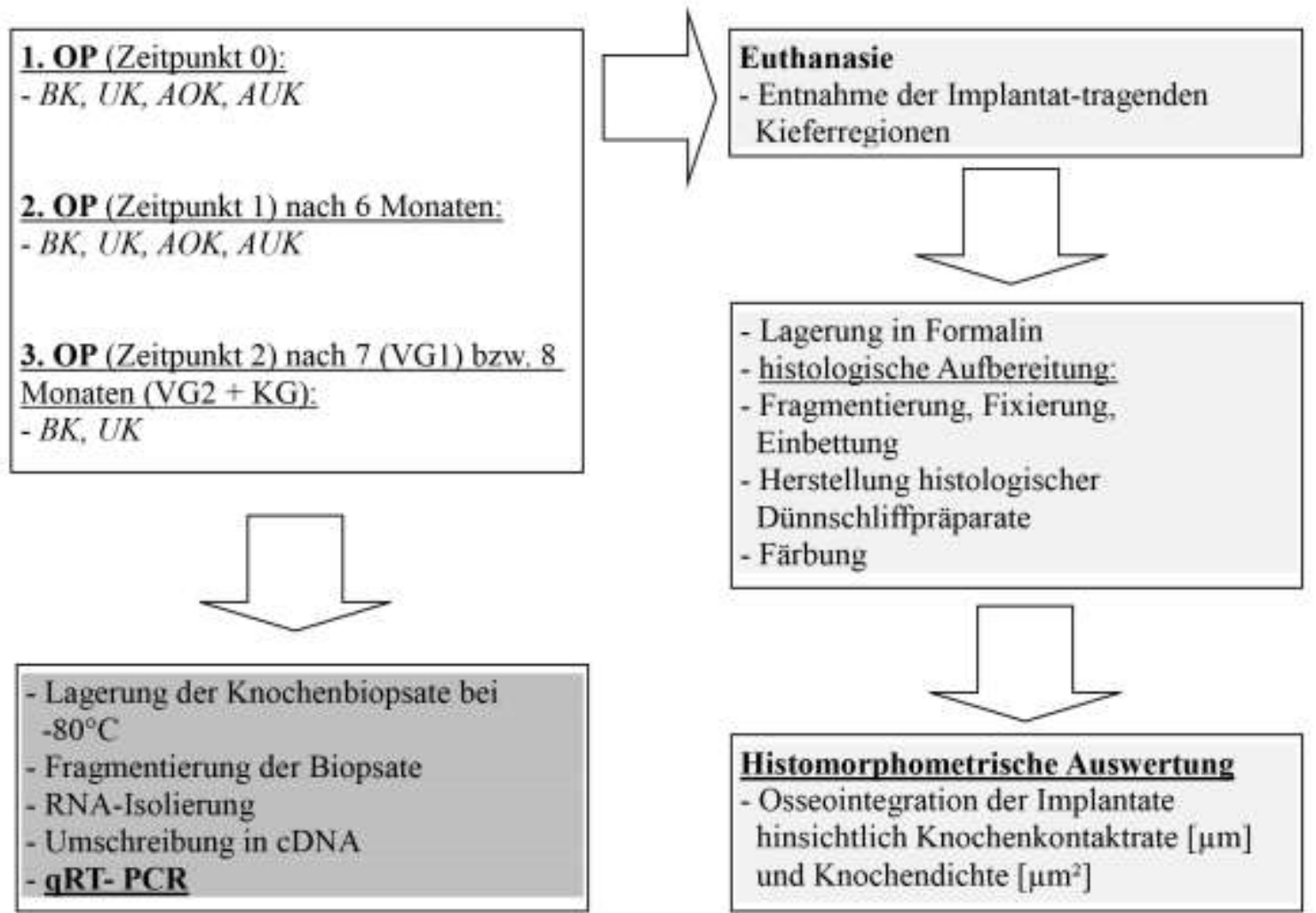

- Lagerung in Formalin - histologische Aufbereitung: - Fragmentierung, Fixierung, Einbettung - Herstellung histologischer Dünnschliffpräparate - Fărbung

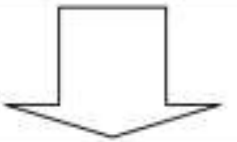

Histomorphometrische Auswertung - Osseointegration der Implantate hinsichtlich Knochenkontaktrate $[\mu \mathrm{m}]$ und Knochendichte $\left[\mu \mathrm{m}^{2}\right]$

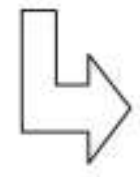

Statistische Auswertung

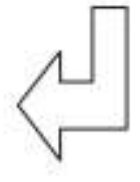

Abb. 3: Abfolge der Arbeitsschritte bezüglich der Knochenbiopsate

\subsubsection{Versuchstiere}

Die für dieses Experiment verwendeten 15 weiblichen adulten Göttinger Minipigs stammten aus dem Versuchsgut Relliehausen in Dassel bei Göttingen. Während der Studie waren die Tiere in dem zur Universität Göttingen gehörenden Versuchsgut in Holtensen in einem Großraumstall, der auf mehrere Laufställe aufgeteilt war, untergebracht. Die Laufställe 
hatten eine Größe von ca. 3 x 2,5 m und waren durch eine Holzwand von ca. 1,20 m Höhe voneinander separiert, sodass die Tiere akustisch nicht völlig isoliert voneinander standen. In jedem der mit Stroh ausgelegten Laufställe war eine Kleingruppe von maximal 3 Schweinen untergebracht. Zur Beschäftigung konnten die Tiere einen Ball in ihren Laufställen finden. Der Raum war Tageslicht- und Frischluft- zugängig. Zu Wasser hatten die Tiere stets freien Zugang; die Menge des Futters betrug pro Tier gewichtsabhängig anfangs 700 g, später 600 g und dann 500 g täglich. Das Futtermittel (Ssniff ${ }^{\circledR}$, Ssniff Spezialdiäten GmbH, Soest) war ein Futtermittel speziell für die Haltung von Minipigs und hatte folgende Zusammensetzung (Tab. 3).

Tab. 3: Zusammensetzung des Futtermittels

\begin{tabular}{|l|l|l|}
\hline Inhaltsstoff & Menge (\%) & Je Kilogramm \\
\hline Rohproteine & 14,50 & \\
\hline Rohfett & 3,00 & \\
\hline Rohfaser & 10,00 & \\
\hline Rohasche & 6,30 & \\
\hline Ca & 0,90 & \\
\hline Phosphor & 0,70 & \\
\hline Natrium & 0,20 & \\
\hline Lysin & 0,70 & \\
\hline Methionin+Cystein & 0,55 & \\
\hline Vit. A & & $15000 \mathrm{IE}$ \\
\hline Vit. D3 & & $1100 \mathrm{IE}$ \\
\hline Vit. E & & $100 \mathrm{mg}$ \\
\hline Kupfer & & $5 \mathrm{mg}$ \\
\hline Eisen & & $100 \mathrm{mg}$ \\
\hline Zink & & $50 \mathrm{mg}$ \\
\hline Mangan & & $30 \mathrm{mg}$ \\
\hline Selen & & $0,1 \mathrm{mg}$ \\
\hline
\end{tabular}

Zum Zeitpunkt der ersten OP lag das Durchschnittsalter der Tiere der VG1 bei 5,39 $\pm 0,17$ Jahren, das der VG2 bei 5,37 \pm 0,18 Jahren, während das durchschnittliche Alter der Kontrollgruppe bei 5,31 \pm 0,15 Jahren lag. Das Durchschnittsgewicht der Tiere lag zu diesem Zeitpunkt bei 68,4 $\pm 10,07 \mathrm{~kg}$ in Gruppe VG1, gegenüber 67,2 $\pm 12,48 \mathrm{~kg}$ in Gruppe VG2 und $70,9 \pm 10,68 \mathrm{~kg}$ in der Kontrollgruppe. 


\subsubsection{Verabreichung von Zoledronat}

Drei Monate nach den Zahnextraktionen im II. und III. Gebissquadranten der Tiere konnte von einer vollständigen Verknöcherung der Extraktionsalveolen ausgegangen werden. Es schloss sich die intravenöse Verabreichung von Zoledronat bei den Versuchsgruppen VG1 und VG2 an, welche in einem regelmäßigen Intervall von 4 Wochen bis zum Abschluss des Experiments wiederholt wurde.

$\mathrm{Zu}$ diesem Zweck wurden die Tiere mit einem Benzodiazepin (Diazepam, 0,5 mg/kg/KG p. o.) in ihrem Laufstall beruhigt. Es folgte die intramuskuläre Verabreichung von Ketamin (10\%ig) als Narkotikum/Analgetikum (10 mg/kg/KG Fa.Selectavet, Weyarn-Holzolling) und Azaperon als Neuroleptikum (Stresnil, $2 \mathrm{mg} / \mathrm{kg} / \mathrm{KG}$ ) sowie einer Gasnarkose, bestehend aus 1-2 \% Isofluran (Forene, Fa. Abbott GmbH \& Co. KG, Hannover), Druckluft und Sauerstoff.

Eine Sedierung der Tiere zum Zweck einer Infusion und Blutentnahme war notwendig, da ein Zugang aufgrund des Körperbaus eines Schweines am einfachsten über eine Punktion einer Ohrvene erreicht werden konnte. Nach Desinfektion der Einstichstelle (Kodan®, Schülke \& Mayr GmbH, Norderstedt) wurde eine geeignete Ohrvene punktiert und ein Zugang mit einer sterilen Braunüle (21 G, Fa. Braun, Melsungen) gelegt. Vor Verabreichung des Medikaments bei den Versuchstieren wurden über den Zugang ebenso regelmäBig monatlich bei allen Tieren ausreichende Mengen Blut zur laborchemischen Untersuchung bestimmter Blutparameter abgenommen (Abb. 4). Zur Verabreichung des Bisphosphonats wurden entsprechend den Empfehlungen des Herstellers (Fa. Novartis Pharma $\mathrm{GmbH}) 4 \mathrm{mg} / 5 \mathrm{ml}$ Zometa ${ }^{\circledR}$ als Konzentrat mit $100 \mathrm{ml}$ steriler, isotonischer Natriumchlorid-Lösung verdünnt und den Tieren über 15 min als Infusionslösung auf einmal zugeführt. Nach Entnahme des Ohrvenen-Katheters wurde die Verabreichung von Isofluran beendet, das Tier bis zum Aufwachen mit Sauerstoff weiter versorgt und im Anschluss wieder in den Laufstall gebracht. 


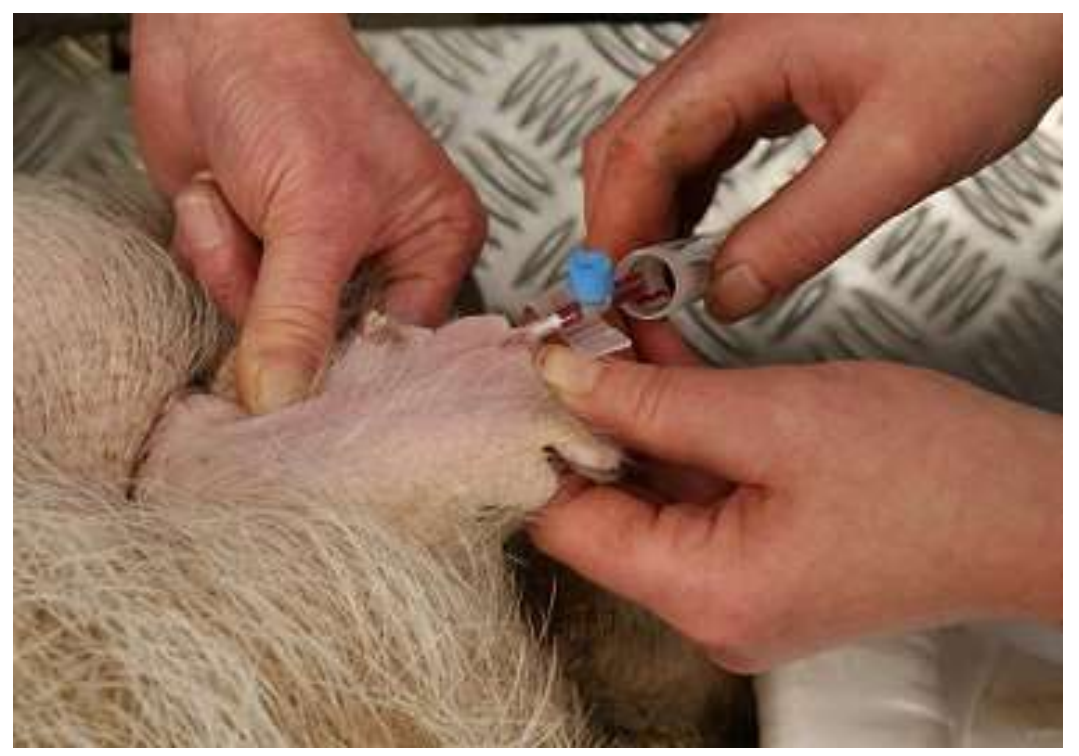

Abb. 4: Blutentnahme nach Ohrvenen-Punktion

\subsubsection{Operationen}

Die Operationen der Tiere fanden im Tier-OP des Universitätsklinikums Göttingen unter Aufsicht einer erfahrenen Veterinärmedizinerin mit Spezialisierung auf dem Gebiet der Großtiermedizin statt. Durchgeführt wurden die Operationen eines jeden Minipigs von einer erfahrenen Mund-Kiefer-Gesichtschirurgin des Klinikums Göttingen.

Präoperativ erhielten die Schweine in ihrer Unterbringung im Klinikum 4 mg/kg/KG p. o. Carprofen (Rimadyl, Fa. Zoetis, New Jersey, USA) zur Analgesie. Anschließend wurde den Tieren 2 mg/kg/KG Azaperon (Stresnil ${ }^{\circledR}$, Fa. Jansen; Neuss) zur Beruhigung und Sedierung intramuskulär verabreicht. Mit $10 \mathrm{mg} / \mathrm{kg} / \mathrm{KG}$ Ketamin (10\%ig, Fa.Selectavet, WeyarnHolzolling) in Form von intramuskulären Injektionen wurde schließlich die Narkoseeinleitung durchgeführt und ein Ohrvenen-Katheter gelegt. Über den Katheter erhielten die Tiere nach Bedarf das Barbiturat Thiopental-Natrium (Trapanal, Byk-Gulden; Konstanz), wurden intubiert und mit einem Gemisch aus Isofluran, Druckluft und Sauerstoff in dem Verhältnis $4: 1$ beatmet. Eine kontinuierliche intravenöse Ketamininfusion von 0,5 $\mathrm{ml} / 10 \mathrm{~kg} / \mathrm{KG} / \mathrm{h}$ (10\%ig, verdünnt mit physiologischer Natriumchlorislösung ad $50 \mathrm{ml}$ ) und die Verabreichung von 75-100 $\mu \mathrm{g} / \mathrm{kg} / \mathrm{KG} / \mathrm{h}$ Piritramid (1 Ampulle = 15 mg Piritramid, Dipidolor ${ }^{\circledR}$, Janssen-Cilag, Wien/Österreich, verdünnt mit Sterofundin B/G5, Fa. Braun, Melsungen, ad $50 \mathrm{ml}$ ) sorgten für eine Allgemeinanästhesie. Perioperativ erhielten die Tiere $0,04 \mathrm{ml} / \mathrm{kg}$ Pen-Strep-200/250 mg/ml-Injektionssuspension für Tiere (Fa. Univet, Tullyvin, Irland) als Antibiose. 
Die Operationen erfolgten bei Versuchs- und Kontrollgruppen in stets gleicher Weise.

In der ersten Operation zum Zeitpunkt 0 des Experiments wurde nach Rasur der Beckenkammregion diese mit Braunol (Fa. Braun, Melsungen) desinfiziert und das Tier bis auf das Operationsgebiet steril abgedeckt. Ein 10-12 cm langer Schnitt mit einem Skalpell durch die Dermis und die Subcutis legten darunterliegendes Muskelgewebe frei, welches mit einem Raspartorium von der Knochenoberfläche entfernt und so die Crista iliaca im Schaufelbereich des posterioren Os iliums freigelegt wurde (Abb. 5). Die Entnahme des Knochengewebes in dieser Region erfolgte mittels eines NaCl-gekühlten, genormten Trepanbohrers von $10 \mathrm{~mm}$ Durchmesser. Nach sorgfältiger Blutstillung wurde die Wunde durch einen mehrschichtigen Wundverschluss verschlossen, wobei Muskelgewebe und Subcutis nacheinander mir resorbierbarem Nahtmaterial (Fa. Ethicon, Vicryl, Stärke 1-0) und die Dermis mit einem Vicrylfaden der Stärke 0 vernäht wurden. Die Wunde wurde anschließend erneut desinfiziert und mit einem sterilen Verbandsstoff abgedeckt.
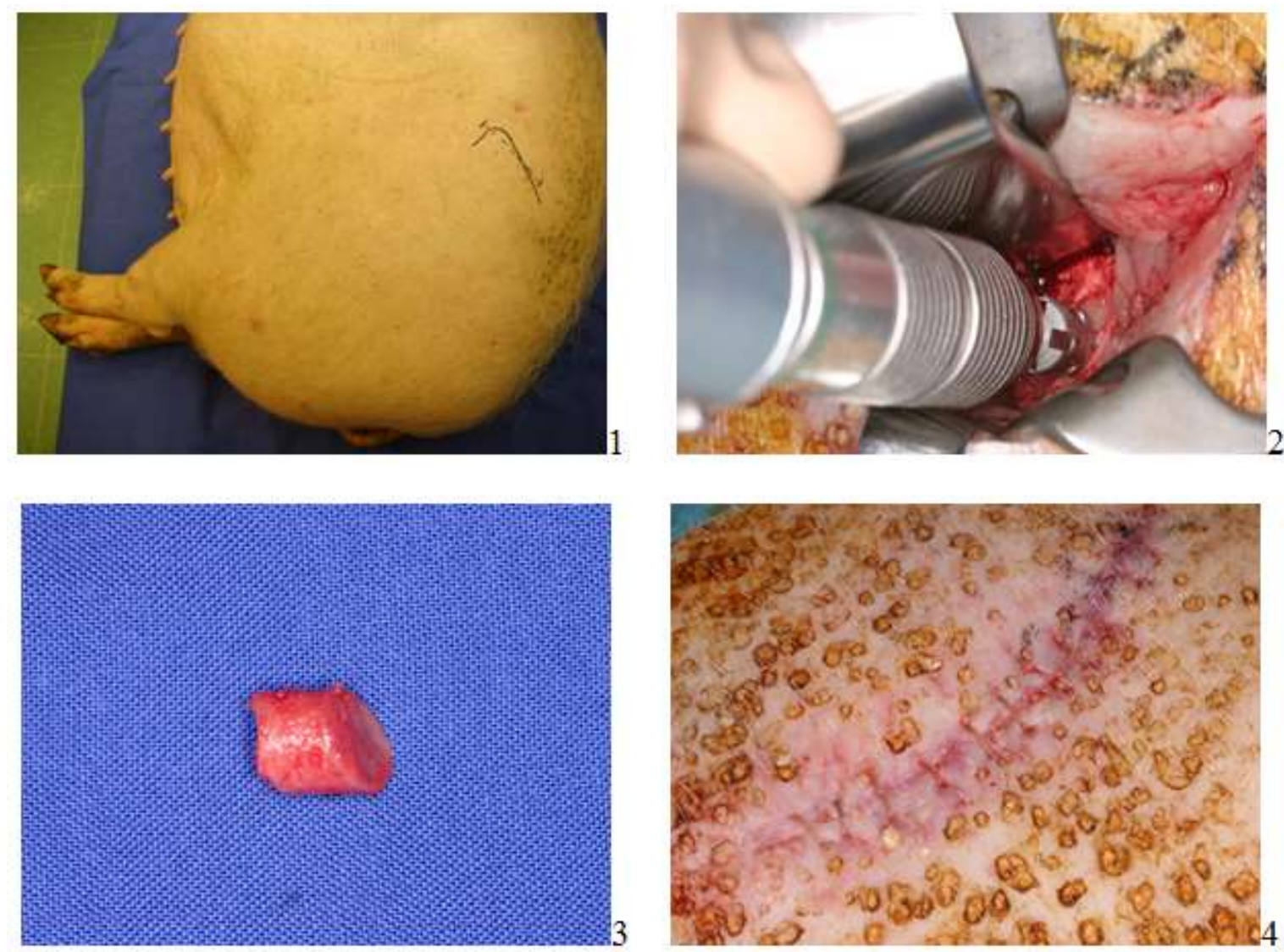

Abb. 5: Gewinnung Knochenbiopsat BK (Bildfolge 1-4)

1) Anzeichnung der Entnahmeregion des Beckenkamms 2) Entnahme eines Knochenfragments aus dem BK mittels Trepanbohrer 3) Knochenbiopsat BK 4) Hautnaht 
Im Anschluss daran wurde im anterioren UK in der Regio submentalis des Corpus mandibulae ein 3-4 cm langer Schnitt durch die Cutis bis auf den Knochen gesetzt und mit einem Raspatorium der Knochen freigelegt. Mit einem Trepanbohrer von 8 mm Durchmesser wurden Knochenfragmente der Region entnommen (Abb. 6) und die Wunde durch Naht (Vicryl, Stärke 2-0) verschlossen.
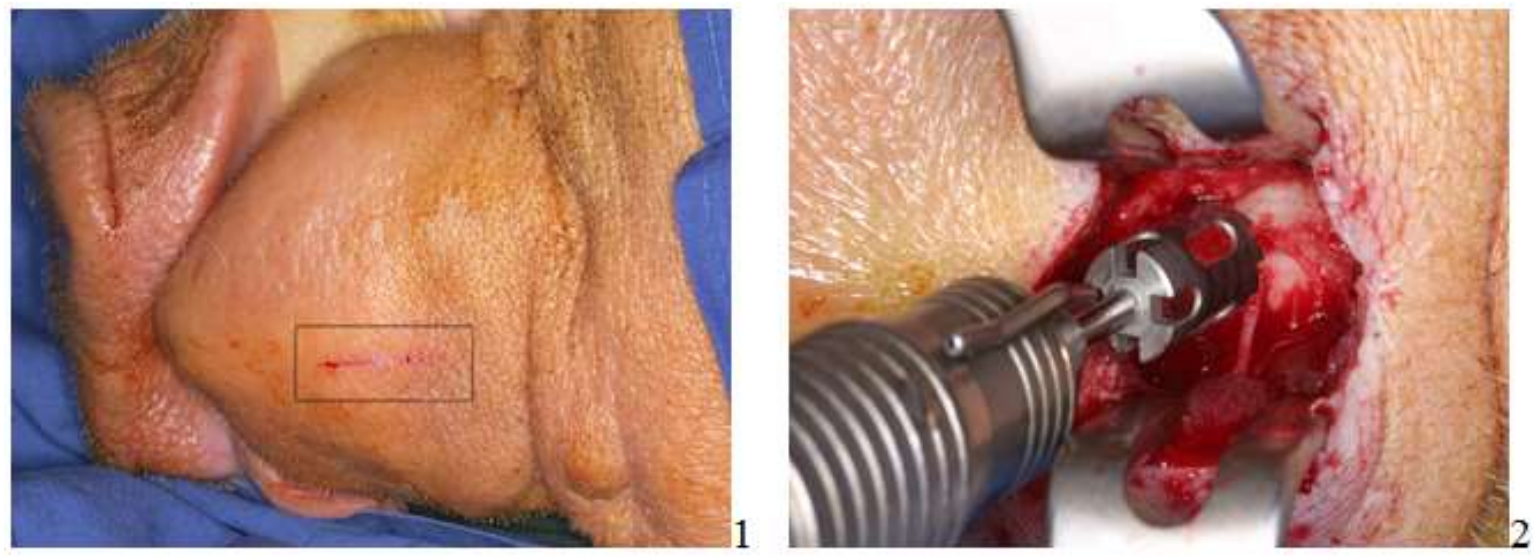

Abb. 6: Gewinnung Knochenbiopsat UK (Bildfolge 1-2)

1) Hautschnitt Regio Submentalis 2) Entnahme eines Knochenfragments der Region mittels Trepanbohrer

Schließlich erfolgten im II. und im III. Gebissquadranten eines jeden Tieres jeweils die Zahnextraktionen dreier Prämolaren und die Gewinnung von Knochenbiopsaten beider Kiefer aus den Extraktionsregionen. Hierzu wurde das OP-Gebiet vorerst sorgfältig mit Braunol desinfiziert. Mittels Hebeln nach Bein, Extraktionszangen und einer LindemannFräse zur Durchtrennung der Zahnkrone und damit Erleichterung der Extraktion wurden die Prämolaren sorgfältig und möglichst atraumatisch extrahiert. Im Anschluss daran wurden mit einem Trepanbohrer von 5 mm Durchmesser und einem Meißel einige Knochenfragmente des Alveolarkamms gewonnen (Abb. 7). Die Extraktionsalveolen wurden schließlich mit einem Mukoperiostlappen nach Rehrmann dicht und spannungsfrei verschlossen. 

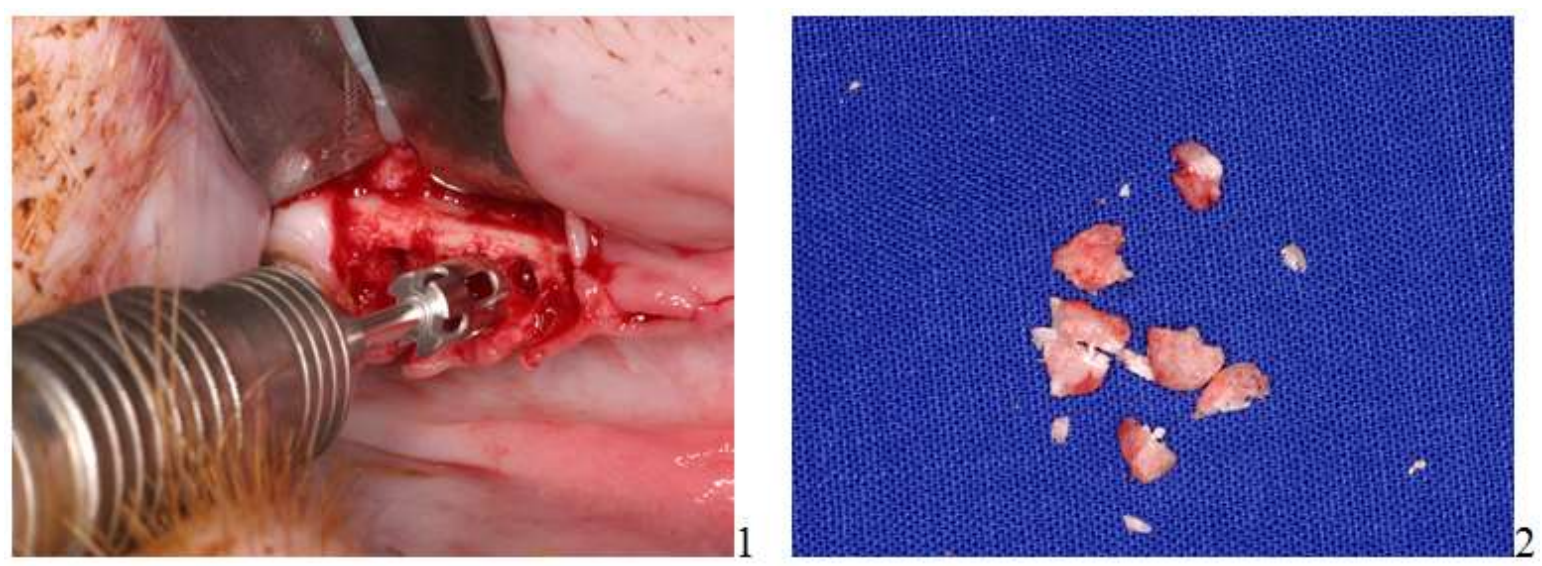

Abb. 7: Gewinnung Knochenbiopsat Alveolarkamm (Bildfolge 1-2)

1) Entnahme eines Knochenfragments aus dem Alveolarkamm mittels Trepanbohrer 2) gewonnenes Knochenbiopsat

Unmittelbar nach ihrer Entnahme wurden alle Knochenfragmente unter sterilen Bedingungen mit einem Seitenschneider und einer Zange nach Luer grob zerkleinert und in kleine Aluminiumbehältnisse überführt, welche zur Kryokonservierung sofort in flüssigen Stickstoff gegeben wurden. Auf Schnelligkeit beim Arbeiten und eine ausreichende $\mathrm{NaCl}-$ Kühlung sowie geringe Drehzahl bei rotierendem Instrumentarium wurde stets geachtet, um dem Gewebe bis zur endgültigen Lagerung bei $-80^{\circ} \mathrm{C}$ möglichst wenig Schaden zuzufügen. Ebenso wurde nach Möglichkeit auf die Entnahme von Spongiosa geachtet, obgleich sich ein gleichzeitiger Anteil von Kortikalis insbesondere im UK oft nicht vermeiden ließ. Am Operationstag wurden weiterhin Blutproben über den Ohrvenen-Katheter entnommen.

In gleicher Weise wie in der ersten Operation erfolgte auch in der zweiten Operation die Entnahme von Knochenproben des Beckenkamms und der Regio submentalis des Corpus mandibulae sowie Entnahmen von Knochenproben aus den Alveolarregionen beider Kiefer (hier: I. und IV. Gebissquadrant nach Prämolaren-Extraktion). Zusätzlich wurden jedem Tier in dieser Operation in die voll verknöcherten Extraktionsregionen des II. und III. Gebissquadranten unter strenger Beachtung von Sterilität und atraumatischer Arbeitsweise je Kieferkamm 2 dentale Implantate (Fa. Nobel Biocare; Typ: Brånemark Mk III TiUnite RP; $3,75 \mathrm{~mm} \times 11,5 \mathrm{~mm}$, LOT 729022) inseriert (Abb. 8). Die Implantatbett-Aufbereitung und Insertion der Implantate wurde nach Herstellerangaben durchgeführt. Die Einheilung der Implantate erfolgte geschlossen, wobei ein besonderes Augenmerk auf einen speicheldichten Wundverschluss im Anschluss an die erfolgten Implantationen geachtet wurde. 

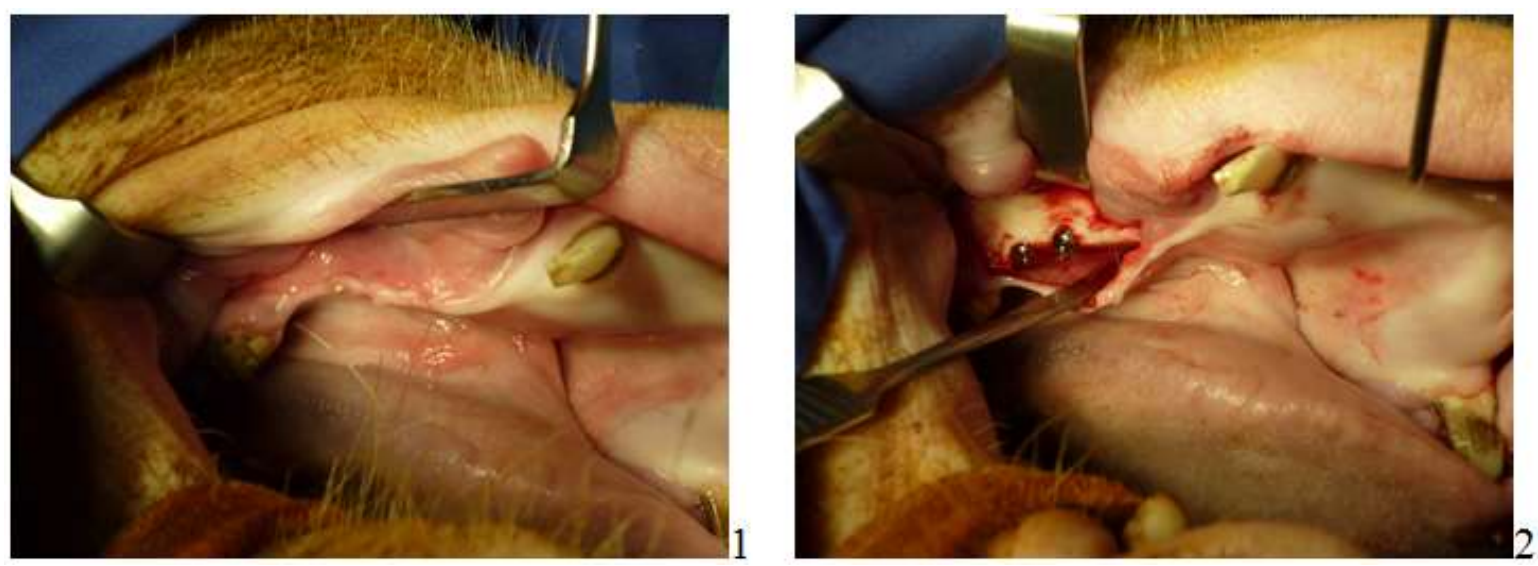

Abb. 8: Insertion zweier Implantate im UK (Bildfolge 1-2)

1) Intakte Schleimhaut eines Tieres der Versuchsgruppe VG2 - Zustand vor Implantation 2) Zustand nach erfolgter Implantation im III. Gebissquadranten

Auf ein zügiges und steriles Arbeiten wurde auch in dieser Operation streng geachtet und alle gewonnenen und zerkleinerten Knochenproben in sterilen Aluminiumgefäßen gesammelt und diese unverzüglich in flüssigem Stickstoff kryokonserviert und bis zur Aufarbeitung bei $-80{ }^{\circ} \mathrm{C}$ gelagert.

Postoperativ wurden die Tiere bei Feststellung einer sicheren Spontanatmung extubiert. Im Falle bradykarder Zustände wurde Atropin $(0,005-0,015 \mathrm{mg} / \mathrm{kg} / \mathrm{KG})$ intravenös verabreicht. Postoperativ erhielten die Tiere (bei Bedarf zusätzlich 1x täglich) 0,05 mg/kg/KG i. m. Buprenorphin (Temgesic $®$, Indivior Eu Limited, Slough, Großbritannien). AnschlieBend erfolgte ihre Verlegung in die Stallanlagen, wo die Tiere unter der Wärmelampe vollständig erwachten und regelmäßigen Kontrollen durch das Tierpflegepersonal unterzogen wurden.

\subsubsection{Versuchsabschluss}

Den Versuchsabschluss bildet eine dritte Operation (Zeitpunkt 2), bei welcher den Tieren in derselben Art und Weise, wie bereits in der ersten und zweiten Operation durchgeführt, jeweils eine Knochenprobe des Beckenkamms und der Submentalregion in Vollnarkose entnommen wurde. Im Anschluss daran wurde mit 6 ml/50 kg/KG Embutramid i. v. (T61, Fa. Hoechst Roussel Vet GmbH, Wiesbaden) die Euthanasie eingeleitet und die Tiere wurden im Anschluss daran durch eine intravenöse Injektion einer Überdosis Narkotikum (Stresnil, Janssen, Beerse/Belgien) euthanasiert.

Unmittelbar nach Eintritt des Todes der Schweine wurden zu diesem Zweck die Kiefer 
freigelegt. Mit einer oszillierenden Säge unter ständiger NaCl-Kühlung konnten nun die Implantat-tragenden Kieferkammabschnitte der Ober- und Unterkiefer gewonnen werden. Bis zur Einbettung der Kieferknochen für die Herstellung histologischer Schnitte wurden diese zur Fixierung der Gewebe für ca. 6 Wochen in neutraler, phosphatgepufferter Formalinlösung (4\%ig) gelagert.

\subsection{Teil 1: Klinische Analyse}

Die Unterschiede der klinischen Situation zwischen den einzelnen Gruppen (VG1, VG2, KG) wurden mittels vergleichender Analyse der fotografisch dargestellten periimplantären Situation der Mundschleimhaut jedes Tieres ermittelt.

Die Implantationsregionen der Ober- und Unterkiefer wurden hierzu im Verlauf der dritten Operation jeweils vor der Euthanasie der Tiere digital fotografiert und die Bilder anschließend auf einen PC übertragen. Jedes Foto beinhaltete dabei jeweils beide Implantationsregionen eines Kiefers. Basierend auf der Größe der Implantat-Verschlussschrauben (13.203 $\mathrm{mm}^{2}$ ), konnte nun über das Programm AxioVision Release 4.8.2 (Carl Zeiss Microscopy, Göttingen) die Größe der Fläche $\left(\mathrm{mm}^{2}\right)$ jedes fotografierten Schleimhautdefektes ermittelt werden (Abb. 9). Die auf den Fotos abgebildeten, freiliegenden Verschlussschrauben wurden dabei zur Kalibrierung herangezogen. Außerdem wurden die Schweregrade der Läsionen visuell festgestellt. Zeigte sich die Schleimhaut unauffällig, wurde ihr der Wert 0 zugeteilt. War kein Schleimhautdefekt, dennoch aber eine entzündliche Rötung der Region zu erkennen, so wurde ein Wert von 1 vergeben. Sichtbare Schleimhautdefekte wurden wie oben beschrieben vermessen und ihre Größen in $\mathrm{mm}^{2}$ angegeben. Auf diese Weise wurde jedes Implantatareal einzeln analysiert. Für die statistische Auswertung wurden die beiden ermittelten Werte jeden Implantates pro Kiefer jedoch zu einem gemeinsamen Wert addiert. Zeigten beide Implantate eines Kiefers denselben, also einen großen gemeinsamen Defekt, so wurde dieser für die statistische Auswertung verwendet (ohne Addition). 

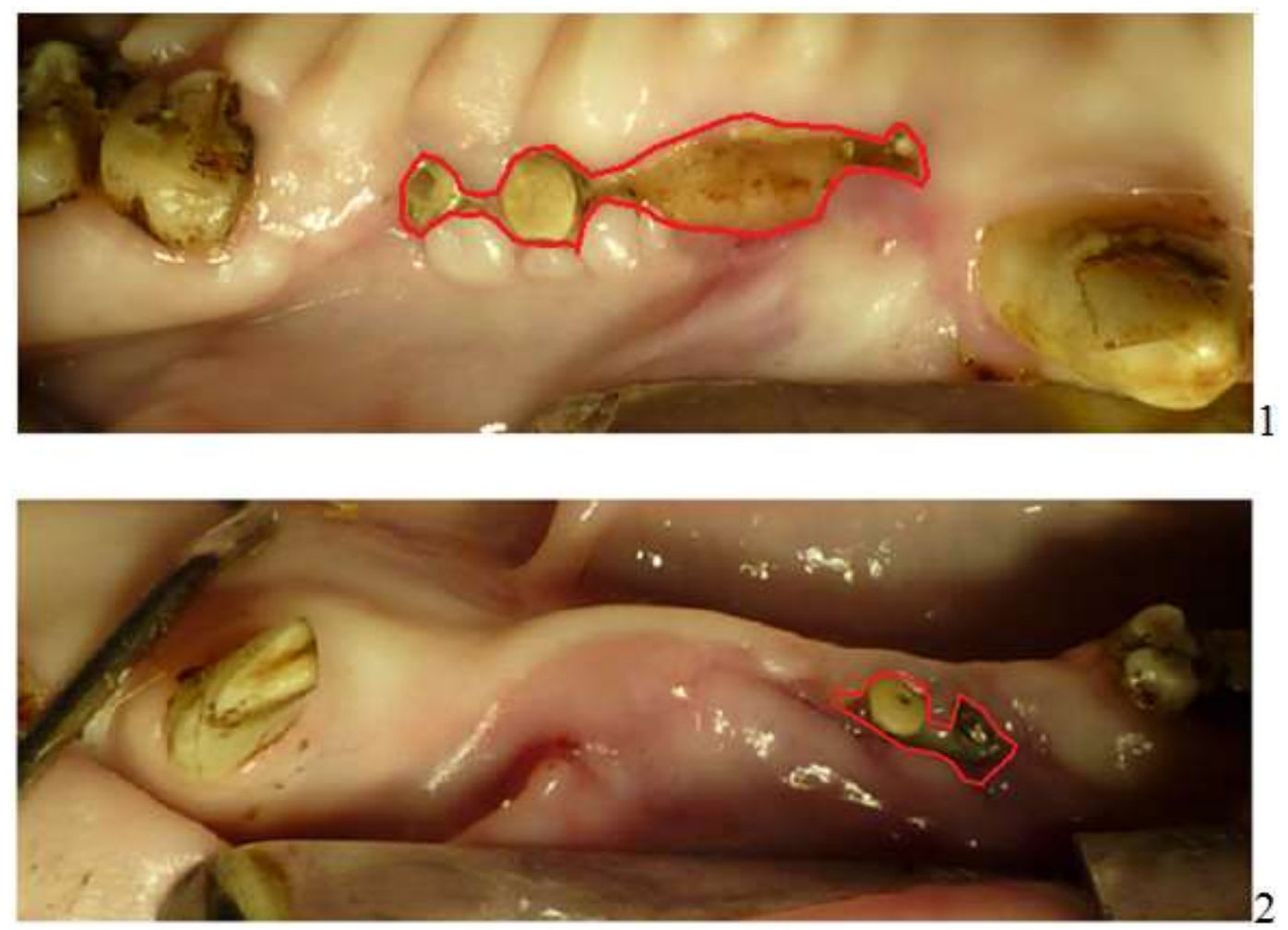

Abb. 9: Beispiele für die digitale Darstellung und Analyse intraoraler Defekte (Bildfolge 1-2)

Zur Bestimmung der Defektgrößen $\left(\mathrm{mm}^{2}\right)$ wurden die Wundflächen mit dem Programm AxioVision markiert (hier rot) 


\subsection{Teil 2: Molekularbiologische Analyse}

\subsubsection{Material für die molekularbiologische Analyse}

\section{Geräte}

Gerät

Hersteller

Bezeichnung

Homogenisator

Pipetten

Nano-Drop-

Spectrophotometer

Agilent 2100 Bioanalyzer

Mastercycler gradient

Thermocycler

Gel-Dokumentation

DNA-Abzugshaube

Elektrophoreseapparatur
Peqlab Biotechnologie GmbH, Erlangen Precellys ${ }^{\circledR}$

Eppendorf Vertrieb, Wesseling

Reference

Peqlab Biotechnologie GmbH, Erlangen ND 1000

Agilent Technologies GmbH, Böblingen

Eppendorf Vertrieb, Wesseling

Bio-Rad Laboratories GmbH, München $\quad$ MyiQ®iCycler

BioDocAnalyze, Biometra, Göttingen

AirClean 600, NC, USA

Model 300

Elite 300 Plus, Wealtec, NV, USA 
Zentrifugenröhrchen

Reaktionsgefäße

RNA-Präparation

KitDNAse-Verdau

Agilent RNA 6000 Pico Kit

Agilent RNA 6000 Nano

Kit

RNA Nano Chips

RNA Pico Chips

iScript cDNA Synthesis Kit
Sarstedt, Nümbrecht

Qiagen, Hilden

Qiagen, Hilden

Agilent Technologies $\mathrm{GmbH}$, Böblingen

Agilent Technologies $\mathrm{GmbH}$, Böblingen

Agilent Technologies GmbH, Böblingen

Agilent Technologies $\mathrm{GmbH}$, Böblingen

Bio-Rad Laboratories GmbH, München
$2.0 \mathrm{ml}, 1.5 \mathrm{ml}, 0.2 \mathrm{ml}$

RNeasy Mini

RNase-Free DNase Set

\section{Chemikalien}

Art

Hersteller

Bezeichnung

Qiazol-Lysis-Reagenz

Qiagen, Hilden

RNeasy Lipid Tissue Kit

Chloroform

Merck, Darmstadt

Ethanol, $70 \%$

Merck, Darmstadt

RNase-freies Wasser

Qiagen, Hilden

Agarose

Bio-Rad Laboratories GmbH, München

Blue Juice Gel Loading Invitrogen, Carlsbad, CA, USA

Buffer

Ethidiumbromid

Invitrogen, Carlsbad, CA, USA

iQ SYBR Green Supermix

Bio-Rad Laboratories GmbH, München

iScript Reaction Mix

Bio-Rad Laboratories GmbH,

München

$\beta$-Mercaptoethanol

Sigma-Aldrich, Steinheim

TRIS-Borat-EDTA-Puffer

(TBE) 
Software

Gerät

Nano Drop

Agilent 2100 Bioanalyzer

Thermocycler

BioDocAnalyze
Hersteller

Peqlab Biotechnologie GmbH,

V3.7

Erlangen

Agilent Technologies GmbH,

Expert

Böblingen

Bio-Rad Laboratories GmbH,

München

Biometra, Göttingen

V2.0

Molekulargewichtsmarker

Name

Hersteller

Bezeichnung

100 bp DNA Ladder

Invitrogen, Carlsbad, CA, USA

Perfekt Size 100 bp

XL Ladder

\section{Primer}

Die Primer wurden im Rahmen der Dissertation von Sievers entwickelt und etabliert (Sievers 2012) und von der Firma Metabion (Martinsried) bezogen.

\begin{tabular}{|c|c|}
\hline mRNA & Primersequenz $\left(5^{\prime} \rightarrow 3^{\prime}\right)$ \\
\hline
\end{tabular}

$\begin{array}{llcr}\text { OPG_9 [sus] fwd } & \text { AAGTCCCGACAGAAGACATCGAGGAA } & 150 & 68 \\ \text { OPG_9 [sus] rev } & \text { GGTACGTCTTGAGATGCTTCAGGGC } & 150 & 69 \\ \text { TBP_1 [sus] fwd } & \text { AACAGTTCAGTAGTTATGAGCCAGA } & 153 & 63 \\ \text { TBP_1 [sus] rev } & \text { AGATGTTCTCAAACGCTTCG } & 153 & 56\end{array}$




\subsubsection{Methode der molekularbiologischen Analyse}

\section{Fragmentierung der Knochenproben}

Zur RNA-Isolation erfolgte eine Zerkleinerung der bereits grob zerkleinerten Knochenproben aus Beckenkamm, Regio submentalis des Unterkiefers und dem Alveolarkamm des Ober- und Unterkiefers aller Operationen in noch kryokonserviertem Zustand mit einem Seitenschneider und einer Hohlmeißelzange nach Luer für die weitere Verarbeitung. Ein zügiges Arbeiten unter sterilen Bedingungen sowie eine konsequente Zwischenlagerung der Proben während des Zerkleinerns in flüssigem Sticksoff sollte die Kontamination mit Ribonucleasen (RNasen), Enzymen, die ubiquitär vorkommen und zur Hydrolyse von Ribonukleinsäuren führen, verhindern.

Angestrebt wurde eine Größe der zur RNA-Isolation genutzten Knochenfragmente von jeweils $3 \mathrm{~mm}^{2}\left(27 \mathrm{~mm}^{2}\right)$. Eine quadratische Probengröße von $4 \mathrm{~mm}$ Kantenlänge $\left(64 \mathrm{~mm}^{2}\right)$ der meisten tierischen Gewebeproben entspricht dabei einem Gewicht von 70-85 mg (Protokoll RNeasy® Lipid-Tissue-Mini-Kit/Firma Qiagen, Hilden). Ein 27 mm² großer Gewebequader entspricht demnach 30-35 mg Gewebe. Größere Gewebeproben wurden aufgrund der inkompletten Lysierung durch das Qiazol®-Lysis-Reagenz nicht verwendet. Hierdurch könnten umfangreiche zelluläre Fragmente zurückbleiben, welche die RNeasy Spin-Säule verstopfen und ihre RNA-Bindungskapazität dadurch reduzieren könnten mit der Folge einer geringeren RNA-Ausbeute und -Reinheit. Um eine schnelle Verarbeitung des Gewebes zu garantieren, wurde auf das Wiegen der zu verarbeitenden Proben verzichtet. Es wurde darauf geachtet, aus den Fragmenten nach Möglichkeit einen großen Anteil Spongiosa zur Weiterverarbeitung zu entnehmen, um eine maximale Menge RNA gewinnen zu können.

\section{Aufarbeitung der Knochenproben und RNA-Isolation}

Die weitere Aufarbeitung der gewonnenen Knochenstücke erfolgte nach dem Herstellerprotokoll zur Aufreinigung von Gesamt-RNA des RNeasy® Lipid Tissue Mini Kits (Qiagen, Hilden). Zu diesem Zweck wurde jedes Knochenfragment unmittelbar nach der Zerkleinerung in ein Zentrifugenröhrchen mit $1 \mathrm{ml}$ Qiazol®-Lysis-Reagenz (Qiagen, Hilden) überführt. Zur Effizienzsteigerung der RNA-Ausbeute erfolgte zusätzlich zur Lyse durch das Reagenz selbst eine mechanische Homogenisation des Gewebes mit dem Precellys ${ }^{\circledR}$ (Peqlab Biotechnologie GmbH, Erlangen) nach dem folgenden Protokoll (Tab. 4). Hierzu 
wurden die Zentrifugenröhrchen jeweils mit 6 sterilen Stahlkugeln (Durchmesser: 0,3 mm) beschickt.

Tab. 4: Homogenisations-Protokoll

\begin{tabular}{|l|l|l|l|l|}
\hline Zyklenanzahl & Zyklusdauer [sec.] & U/min & Temp. $\left[{ }^{\circ} \mathbf{C}\right.$ ] & Pause je Zyklus [sec.] \\
\hline 3 & 35 & 3500 & 5 & 30 \\
\hline
\end{tabular}

Die Durchschnittstemperatur von $5{ }^{\circ} \mathrm{C}$ während des Homogenisationsprozesses wurde durch die kontrollierte Zufuhr von Stickstoff in das Gerät aufrechterhalten.

Nach dem Homogenisationsprozess wurde jedem Zentrifugenröhrchen $200 \mu$ l Chloroform zugegeben, wodurch sich das Homogenisat in drei Phasen separierte:

- $\quad$ eine obere wässrige Phase, welche die RNA enthielt

- eine weiße Interphase, welche die DNA enthielt

- eine untere rote organische Phase mit den darin enthaltenen Proteinen.

Die wässrige Phase wurde vorsichtig abpipettiert und jeweils in ein steriles Reaktionsgefäß überführt, wo sie in gleichem Volumen mit 70\%igem Ethanol versetzt wurde. Diese Lösung wurde über eine Rneasy Mini Spin-Säule des Kits gefiltert und die RNA so im Filter der Säule gebunden. Für eine DNA-sensitive Weiterverarbeitung der Gewebeproben, z. B. in einer qRT-PCR, wird vom Hersteller des Kits die zusätzliche Anwendung eines DNaseVerdaus (RNase-Free DNase Set/Qiagen, Hilden) empfohlen. Dieser dient der Entfernung restlicher DNA aus dem Filter. Nach der Anwendung des DNase-Verdaus wurde die RNA schließlich infolge mehrerer Waschschritte mit einer Pufferlösung des verwendeten Kits in $30 \mu 1$ RNase-freiem Wasser aus dem Filter der Säule eluiert. Die RNA-Isolation erfolgte bei Raumtemperatur, die eluierte RNA wurde sofort auf Eis gekühlt.

\section{Quantitative Nukleinsäurenanalytik}

Die Konzentrationsbestimmung der isolierten RNA-Proben erfolgte mit dem NanoDrop®Spektrophotometer (Peqlab Biotechnologie GmbH, Erlangen). Zur Analyse wurden 1,5 $\mu 1$ des aus der Säule gefilterten Gesamt-RNA-Eluates benötigt.

Die RNA-Konzentration wurde durch die Messung der Lichtabsorption bei einer Wellen- 
länge von $260 \mathrm{~nm}$ bestimmt. Zur Abschätzung der Reinheit der Nukleinsäurelösung, insbesondere hinsichtlich einer Kontamination mit Proteinen oder Lösungsmitteln, wurde zusätzlich die Extinktion bei $280 \mathrm{~nm}$ gemessen und der Quotient $\mathrm{E}_{260 \mathrm{~nm}} / \mathrm{E}_{280 \mathrm{~nm}}$ bestimmt.

Dieser Absorptionsquotient sollte für eine reine RNA etwa 1,9-2,1 betragen. Verunreinigungen der RNA zeigen sich in Werten, die von diesem Absorptionsquotienten nach unten abweichen. Nach der Analyse wurden die Proben bis zur Weiterverarbeitung bei $-80{ }^{\circ} \mathrm{C}$ gelagert.

\section{Qualitative RNA-Analytik}

Die Analyse der Qualität der isolierten Gesamt-RNA erfolgte mittels Nano-Chip bzw. PicoChip (RNA 6000 Nano/Pico-Chip Kit, Agilent Technologies GmbH, Böblingen). Hierbei handelt es sich um eine standardisierte Lab-on-Chip-Technologie, basierend auf dem Prinzip der Kapillarelektrophorese, bei der mehrere RNA-Gesamtproben gleichzeitig und automatisiert hinsichtlich der Größe der einzelnen Fraktionen der rRNA (5S, 18S, 28S), der mRNA sowie fragmentierter RNAs aufgetrennt und visualisiert werden.

Tab. 5: Art des Chips in Abhängigkeit der RNA-Konzentration

(Zur Verdünnung der Proben wurde RNase-freies H2O verwendet)

\begin{tabular}{|l|l|l|}
\hline RNA-Konzentration $[\mathbf{n g} / \boldsymbol{\mu l}]$ & Art des Chips & Verdünnung $(\mathbf{1 : 1 0})$ ab $[\mathbf{n g} / \boldsymbol{\mu l}]$ \\
\hline $50-500$ & Nano & $\geq 500$ \\
\hline$\leq 50$ & Pico & $\geq 25$ \\
\hline
\end{tabular}

Für die Analyse reicht ein Probenvolumen von $1 \mu 1$, welches nach Herstellerprotokoll in eine der 12 Vertiefungen des Nano-Chips, bzw. 11 Vertiefungen des Pico-Chips, pipettiert wird. Die Wahl des Chips (Nano/Pico) steht in Abhängigkeit zur in der Probe enthaltenen RNA-Konzentration und wird nach Protokoll verdünnt (Tab. 5). Die RNA-Moleküle der Proben und die des mitgeführten Standards bewegen sich in einem elektrischen Spannungsfeld durch die Mikrokapillaren des Chips fort und werden am Ende ihrer Molekülgröße entsprechend durch den Molekularsiebeffekt aufgetrennt und zusammen mit ihrer Laufzeit über einen Fluoreszenzdetektor registriert. Die Messung erfolgte automatisiert über den Agilent 2100 Bioanalyzer (Agilent Technologies GmbH, Böblingen), welcher die Auswertung in Form eines Elektropherogramms und eines „virtuellen Gel-Bildes“ graphisch darstellt (Abb. 10). Die Software des Gerätes lässt durch die Bestimmung der RIN 
(RNA integrity number) die Einstufung der RNA-Integrität auf einer Skala von 1-10 zu. Ein Wert von 10 repräsentiert eine intakte, nicht degradierte und nicht fragmentierte RNA von sehr hoher Qualität. Ein Wert von 1 steht für komplett degradierte und fragmentierte RNA mit geringster Qualität (Schroeder et al. 2006).

Um mit RNA von ausreichender Qualität weiterzuarbeiten, wurde eine minimale Qualität mit einer RIN von $\geq 5$ festgelegt. Die durchschnittliche RIN lag bei 5,0 $( \pm 0,8)$. Der maximale Wert lag bei einer RIN von 7,0 und der geringste bei einer RIN von 2,4. Um diese Werte maximal zu optimieren, wurden die Proben teilweise dreifach isoliert oder in der Analyse Nano- und Pico-Chip variiert. War es dadurch dennoch nicht möglich, eine RIN $\geq$ 5 zu erreichen, wurde die Probe mit der maximal erreichten RIN zur Weiterverarbeitung verwendet.
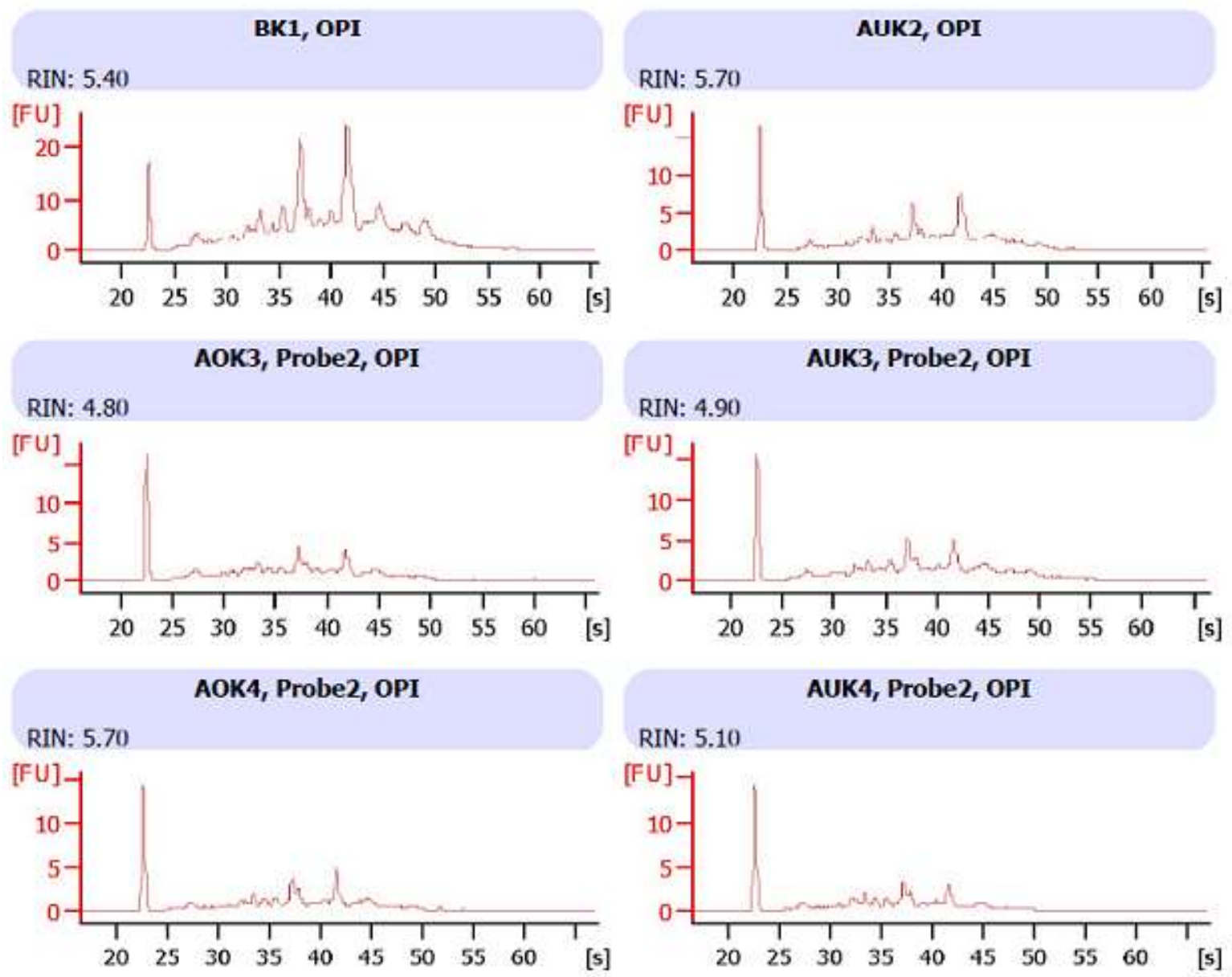

Abb. 10: Elektropherogramme einiger beispielhafter Proben und ihre RIN-Werte (erstellt mit dem Agilent 2100 Bioanalyzer, Agilent Technologies GmbH, Böblingen) 


\section{Reverse Transkription (cDNA-Synthese)}

Da RNA als Matrize für die Polymerase bei einer PCR nicht geeignet ist (Hill und Stewart 1992), mussten alle RNA-Proben mit geeigneter Qualität (RIN $\geq 5$, s. o.) in cDNA umgeschrieben werden. Verwendet wurde zu diesem Zweck das iScript cDNA Synthesis Kit (Bio-Rad Laboratories GmbH, München).

Diese Reverse Transkription wird durch Enzyme (RT/Reverse Transkriptasen) umgesetzt. Alle RT sind RNA-abhängige DNA-Polymerasen, einige RT sind jedoch auch DNAabhängig. Die RT des iScript cDNA Synthesis Kits ist eine modifizierte MMLV-RT (aus dem Moloney murine leukemia virus) und verwendet die mRNA-Einzelstränge der Proben als Matrize, um daran durch die Aneinanderreihung von Oligonukleotiden in vitro einen dem Ausgangsstrang komplementären DNA-Strang zu synthetisieren. In einem nächsten Schritt wird der RNA-DNA-Hybridstrang durch die RNase H-Aktivität des Enzyms hydrolysiert. Eine DNA-abhängige DNA-Polymerase synthetisiert nun einen zum bereits bestehenden cDNA-Einzelstrang komplementären DNA-Strang, sodass aus einzelstrangiger mRNA auf diese Weise doppelstrangige, komplementäre DNA gewonnen werden kann. Zur Durchführung wurde nach Herstellerangaben verfahren (Tab. 6).

Tab. 6: Reaktionsansatz cDNA-Synthese

\begin{tabular}{|l|l|l|l|}
\hline & Vol. $[\boldsymbol{\mu l}]$ & Komponente & Inhalt \\
\hline & 4 & iScript Reaction Mix & $\begin{array}{l}\text { Primer (Oligo-dT-Primer und Random } \\
\text { Hexamer Primer), Oligonukleoside, } \\
\text { RNase-Inhibitoren, Puffer, u. a. }\end{array}$ \\
\hline & 1 & $\begin{array}{l}\text { iScript Reverse Tran- } \\
\text { skriptase }\end{array}$ & \\
\hline & $\mathrm{X}(14)$ & RNase-freies $\mathrm{H}_{2} \mathrm{O}$ & Variabel: Erläuterung s. u. \\
\hline Total & $\mathbf{X}(1)$ & mRNA-Probe [bis 1 $\mu \mathrm{g}]$ & \\
\hline
\end{tabular}

Für die cDNA-Synthese wurde nach Herstellerangaben der Einsatz von jeweils $1 \mu \mathrm{g}$ Gesamt-RNA bei $20 \mu \mathrm{l}$ Reaktionsansatz angestrebt. Bei einer im Nano-Drop gemessenen RNA-Konzentration von $\leq 66 \mathrm{ng} / \mu \mathrm{l}$ wurde die Probe unverdünnt eingesetzt $(15 \mu \mathrm{l})$. War die RNA-Konzentration $\geq 66 \mathrm{ng} / \mu \mathrm{l}$, wurde das einzusetzende Probenvolumen nach folgender Formel berechnet und dieses auf $15 \mu \mathrm{l}$ Gesamtvolumen mit RNase-freiem Wasser verdünnt, um den Reaktionsansatz nicht zu überladen. 
Die Inkubation der Reaktionsansätze erfolgte durch einen programmierbaren Thermoblock (Mastercycler gradient, Eppendorf Vertrieb, Wesseling) und beinhaltete folgende Programmstufen (Tab. 7):

Tab. 7: Reaktionsprotokoll Mastercycler

\begin{tabular}{|l|l|l|}
\hline Zyklus & Zeit $[\mathrm{min}]$ & Temp. $\left[{ }^{\circ} \mathbf{C}\right]$ \\
\hline 1 & 5 & 25 \\
\hline 2 & 30 & 42 \\
\hline 3 & 5 & 85 \\
\hline 4 & 8 & 4 \\
\hline
\end{tabular}

Bis zur Weiterverarbeitung wurde die fertige cDNA bei $-20{ }^{\circ} \mathrm{C}$ gelagert.

\section{Quantitative Real-Time PCR (qRT-PCR)}

Die qRT-PCR (quantitative real time polymerase chain reaction) ist eine Technik zur gezielten Vervielfältigung (Amplifikation) eines spezifischen Genomfragments (mRNA) in vitro, die auf dem Prinzip der herkömmlichen Polymerase-Kettenreaktion basiert, jedoch zusätzlich eine Quantifizierung der gewonnen DNA ermöglicht. Das Prinzip gleicht dem der klassischen PCR, welche sich aus drei sich wiederholenden Schritten zusammensetzt:

1. Denaturierung: Die beiden Stränge der cDNA, die als Template dient, trennen sich durch Denaturierung bei ca. $95{ }^{\circ} \mathrm{C}$ für 5 min. auf und liegen schließlich als zwei Einzelstränge vor.

2. Annealing: Bei diesem Schritt kommt es zu einer Hybridisierung der spezifischen Oligonukleotide (Primer) jeweils an das 5`- und das 3`-Ende des zu amplifizierenden Bereiches. Hierzu ist ein Absenken der Temperatur auf die sogenannte annealing temperature notwendig, die ca. $5^{\circ} \mathrm{C}$ unterhalb der Primer-spezifischen Schmelztemperatur liegen sollte. Sie muss für jeden Primer folglich individuell ermittelt werden.

3. Elongation: In dieser Phase verlängert die thermostabile DNA-abhängige DNAPolymerase den Primer unter Verwendung der freien Desoxynukleosid-Triphosphate (dNTPs) des Reaktionsansatzes in einen dem cDNA-Template komplementären DNAStrang. Die Temperatur wird hierzu auf das Temperaturoptimum des verwendeten Enzyms erhöht. Es existieren eine Reihe verschiedener thermostabiler Polymerasen mit unterschiedlichen enzymatischen Eigenschaften und Temperaturoptima. Aufgrund ihrer hohen Syntheserate findet bis heute oftmals klassischerweise die Taq-DNA-Polymerase (isoliert 
aus Thermus aquaticus) Verwendung (Mülhardt 2006). Die nach diesem Schritt wieder vorliegende doppelstrangige DNA kann im Folgenden erneut denaturiert werden.

Die Abfolge dieser drei Reaktionsschritte wird als ein Zyklus bezeichnet, der sich während einer PCR 25-40-mal wiederholt (Mülhardt 2006). Auf diese Weise ist es möglich, kleine Mengen an Nukleinsäuren zu vervielfältigen. Diesem Prinzip folgend ist davon auszugehen, dass sich die DNA-Moleküle in jedem Zyklus der PCR verdoppeln, was einem Multiplikationsfaktor (MF) von 2 je Zyklus entspräche. Tatsächlich liegt dieser Faktor jedoch durchschnittlich zwischen 1,6 und 1,7 (Kainz 2000). Der Grund hierfür liegt darin, dass der Vermehrungsfaktor am Ende der PCR geringer ist als in der Mitte der Zykluszahl. Zu Beginn und in der Mitte der Reaktion ist der MF 2, die Vermehrungsrate ist exponentiell. Am Ende der Reaktion geht die Reaktion in eine lineare und schließlich in eine Plateau-Phase über (Kainz 2000).

Die Quantifizierung der DNA bei der qRT-PCR findet über eine Fluoreszenzdetektion statt. Der verwendete Fluoreszenz-Farbstoff SYBR Green interkaliert während der Elongationsphase in die DNA-Doppelhelix. Bei Anregung mit Licht bestimmter Wellenlängen kommt es zur Fluoreszenzemission, welche nach jedem Zyklus der PCR am Ende des Elongationsschrittes detektiert wird. Da sich die Amplifikate in der exponentiellen Phase der qRTPCR verdoppeln, nimmt auch die Fluoreszenz-Intensität linear proportional zu der Menge der entstehenden Amplifikate zu, was in „Echtzeit“" graphisch dargestellt wird.

Die Zykluszahl, bei der es zu einem exponentiellen Anstieg der Amplifikationskurve kommt, das Fluoreszenzsignal damit signifikant ansteigt und einen für die jeweilige Messung festgelegten Schwellenwert erreicht, nennt man threshold cycle (SchwellenwertZyklus; $\mathrm{C}_{\mathrm{T}}$-Wert). Der $\mathrm{C}_{\mathrm{T}}$-Wert ist für jede analysierte Probe aufgrund ihrer unterschiedlichen DNA-Konzentration zu Anfang der Reaktion charakteristisch und somit bedeutend für die Quantifizierung der Ausgangs-DNA bei der qRT-PCR.

Zur Durchführung der qRT-PCR wurde der in der Dissertation von Sievers etablierte Primer (s. o.) verwendet (Sievers 2012). Als housekeeping gene (Haushaltsgen), ein nicht reguliertes, konstitutiv und ubiquitär exprimiertes Referenzgen, wurde das TATA-boxbinding-protein $(T B P)$ verwendet. Die Expressionsrate eines Haushaltsgens wird bei einer PCR als interne Kontrolle stets mit analysiert. Da methodische Störfaktoren, wie z. B. Variationen in der Ausgangsmenge der eingesetzten RNA, Fehler bei der reversen Transkription oder Gewebe- und Matrixeffekte sowohl das Zielgen als auch das Haushaltsgen betref- 
fen, können Unterschiede der Expressionsergebnisse durch einen Abgleich der Daten auf das Haushaltsgen (sog. Normalisierung) reduziert werden (Pfaffl 2004).

Die qRT-PCRs wurden unter Verwendung des iQ SYBR Green Supermix (Bio-Rad Laboratories $\mathrm{GmbH}$, München) durchgeführt, welches eine iTaq-DNA-Polymerase, dNTPs, $\mathrm{MgCl} 2$, SYBR Green I Dye, Enhancer, Stabilisatoren und Fluorescein enthält.

Zur Versuchsdurchführung wurden 96-well-Probenplatten (Bio-Rad Laboratories GmbH, München) nach einem einheitlichen Pipettierschema mit den Reaktionsansätzen bestückt (

Tab. 8). Als Template für die PCRs kam von jedem Versuchstier jeweils die cDNA-Probe mit der maximal erreichten Qualität (RIN, s. o.) zu jedem Operationszeitpunkt und von jeder Entnahmeregion zum Einsatz.

Tab. 8: Ansatz für ein Gefäß einer 96-well-Platte

\begin{tabular}{ll}
\hline Komponente & Volumen $[\mu \mathrm{l}]$ \\
\hline iQ SYBR Green Supermix & 12,5 \\
Primer (fwd) & 0,4 \\
Primer (rew) & 0,4 \\
Nuklease-freies $\mathrm{H}_{2} \mathrm{O}$ & 6,7 \\
Template (cDNA) & 5,0 \\
\hline Totalvolumen & $\mathbf{2 5 , 0}$ \\
\hline
\end{tabular}

Alle Proben wurden als Triplikate eingesetzt. Jeder Versuch enthielt eine vierschrittige Verdünnungsreihe von 1:1 bis 1:1000, ausgehend von einer unverdünnten cDNAPoolprobe der gesamten Untersuchungsreihe (Standard S1-S4) zur Errechnung der Standardkurve für das eingesetzte Primerpaar. Aus der Standardkurve konnte die Effizienz der jeweiligen PCR-Reaktion als Grundlage für die spätere Quantifizierung ermittelt werden. Durch die zusätzliche Unterbringung einer Negativ-Kontrolle aus RNase-freiem $\mathrm{H}_{2} \mathrm{O}$ anstelle eines DNA-Templates (NTC/no-template-control) in jeder Versuchsanordnung sollte eine Kontamination mit Fremd-DNA ausgeschlossen werden (Tab. 9). 
Tab. 9: Plattendesign für qRT-PCR der einzelnen Versuche

(S1-S4: Verdünnungsreihe; S1 = 1:1, S2 = 1:1000. NTC = no-template-control; 1-15: alle 15 Versuchstiere, jeweils als Triplett)

\begin{tabular}{|l|l|l|l|l|l|l|l|l|l|l|l|l|}
\hline & $\mathbf{1}$ & $\mathbf{2}$ & $\mathbf{3}$ & $\mathbf{4}$ & $\mathbf{5}$ & $\mathbf{6}$ & $\mathbf{7}$ & $\mathbf{8}$ & $\mathbf{9}$ & $\mathbf{1 0}$ & $\mathbf{1 1}$ & $\mathbf{1 2}$ \\
\hline $\mathbf{A}$ & & S1 & S1 & 1 & 1 & 1 & 9 & 9 & 9 & & & \\
\hline $\mathbf{B}$ & & & S1 & 2 & 2 & 2 & 10 & 10 & 10 & & & \\
\hline C & & S2 & S2 & 3 & 3 & 3 & 11 & 11 & 11 & & & \\
\hline D & & & S2 & 4 & 4 & 4 & 12 & 12 & 12 & & & \\
\hline E & & S3 & S3 & 5 & 5 & 5 & 13 & 13 & 13 & & & \\
\hline F & & & S3 & 6 & 6 & 6 & 14 & 14 & 14 & & & \\
\hline G & & S4 & S4 & 7 & 7 & 7 & 15 & 15 & 15 & & & \\
\hline H & & & S 4 & 8 & 8 & 8 & NTC & NTC & NTC & & & \\
\hline
\end{tabular}

In jedem Versuch wurde parallel cDNA aus den Gewebeproben aller 15 Versuchstiere amplifiziert. Der Operationszeitpunkt und die Entnahmeregion waren je Versuch bei allen Tieren jedoch einheitlich.

Die qRT-PCRs wurden im Thermocycler MyiQ® icycler Real-Time PCR Detection System (Bio-Rad Laboratories GmbH, München) mit der Software Bio-Rad iQ5 (Bio-Rad Laboratories GmbH, München) durchgeführt (Tab. 10). 
Thermal Cycling Protokoll:

Tab. 10: PCR-Programm für sämtliche Versuche

\begin{tabular}{|c|c|c|c|}
\hline Temperatur $\left[{ }^{\circ} \mathbf{C}\right]$ & Dauer [min] & Zyklenzahl & Vorgang \\
\hline 98 & $0: 30$ & 1 & Initiale Denaturierung \\
\hline 94 & $0: 30$ & & Denaturierung \\
\hline 50 & $0: 15$ & 45 & Annealing \\
\hline 72 & $1: 00$ & & Elongation \\
\hline 94 & $1: 00$ & 1 & Denaturierung \\
\hline 60 & $0: 30$ & 1 & Annealing \\
\hline $55-92$ & $0: 10$ & 75 & $\begin{array}{l}\text { Schmelzkurvenanalyse } \\
\text { (Echtzeit): Je Zyklus 0,5 } \\
{ }^{\circ} \mathrm{C} \text { Temperaturanstieg }\end{array}$ \\
\hline
\end{tabular}

Durch die Steigungen der Standardkurven der mehrschrittigen Verdünnungsreihe (s. o. Standard S1-S4) kann für jeden $\mathrm{C}_{\mathrm{T}}$-Wert der experimentellen Proben, nach Bildung des Mittelwertes der Triplikate, auf die relative Anfangskonzentration an Template geschlossen werden (Wiedemann et al. 2004). Der $\mathrm{C}_{\mathrm{T}}$-Wert wird als Maß für die Quantifizierung der Startmenge jeder Probe herangezogen.

Zur Bestimmung der relativen Expression von OPG der experimentellen Proben wurde das Berechnungsmodell der Effizienz-korrigierten relativen Quantifizierung nach Pfaffl angewendet (Pfaffl 2004) (Abb. 11). Die relative Expression des Zielgens der Proben wird auf ein Kontrollprobenmaterial bezogen und daraus, basierend auf dem $\Delta \Delta \mathrm{C}_{\mathrm{T}}$-Modell, der Expressionsunterschied (Ratio/R) berechnet. Dieses beinhaltet die Normalisierung der Transkriptmengen des Zielgens (der zu untersuchenden Probe) auf die des Referenzgens (housekeeping gene, s. o.; hier: TBP) und berücksichtigt zur Optimierung der Ergebnisse ebenso die unterschiedlichen qRT-PCR-Effizienzen aller experimentellen Proben.

Die Effizienz E jeder PCR lässt sich aus der Steigung $\mathrm{m}$ der Standardkurve einer mehrschrittigen Verdünnungsreihe ( $\mathrm{s}$. o. Standard S1-S4) berechnen $\left(\mathrm{E}=10^{[-1 / \mathrm{m}]}\right)$ und wird von der icycler-Software mit angegeben. Als optimale Effizienz gilt hierbei ein Wert von $\mathrm{E}$ $=2(100 \%)$, da sich in diesem Fall die Anzahl der Amplifikate je Zyklus der PCR genau verdoppelt. 


\section{$\left(\mathbf{E}_{\text {Zielgen }}\right)^{\Delta \mathbf{C T}} \mathbf{Z i e l g e n}^{\text {(Kontrolle-Behandlung) }}$}

Ratio $=$

$\left(\mathrm{E}_{\text {Referenzgen }}\right)^{\Delta \mathrm{CT}}$ Referenzgen ${ }^{(\text {Kontrolle-Behandlung })}$

Abb. 11: Berechnungsmodell der Effizienz-korrigierten relativen Quantifizierung (nach: Pfaffl 2004)

\section{Gelelektrophorese}

Jede Probe wurde im Anschluss an die qRT-PCR hinsichtlich der Produktlänge des Amplifikats und des Ausschlusses von Nebenprodukten durch eine Gelelektrophorese analysiert. Das verwendete 1,5\%ige Agarosegel wurde aus TBE-Puffer (TRIS-BoratEDTA/Verdünnung 1:10 mit RNase-freiem $\mathrm{H}_{2} \mathrm{O}$ ) und Agarose-Pulver (Bio-Rad Laboratories $\mathrm{GmbH}$, München) selbst hergestellt. Zur Auswertung des Gels wurde als Fluoreszenzfarbstoff 0,25 $\mu$ l Ethidiumbromid (Invitrogen, Carlsbad, CA, USA) je Milliliter Gel verwendet. In jede Tasche des gegossenen Gels wurden jeweils $10 \mu 1$ des zu analysierenden PCR-Produkts mit 2,5 $\mu$ l blauem Ladungspuffer (Blue Juice Gel Loading Buffer, Invitrogen, Carlsbad, CA, USA) pipettiert. Als Molekulargewichtsmarker wurde jeweils in die zwei äußeren Taschen des Gels die Perfekt Size 100 bp XL Ladder (Invitrogen, Carlsbad, CA, USA) gegeben. Zur Auftrennung der Nukleinsäuren wurde eine Spannung von $180 \mathrm{~V}$ angelegt. Der Nachweis der Banden erfolgte durch Anregung des verwendeten Fluoreszenzfarbstoffes mit UV-Licht im BioDocAnalyzer (Biometra, Göttingen) (Abb. 12). 


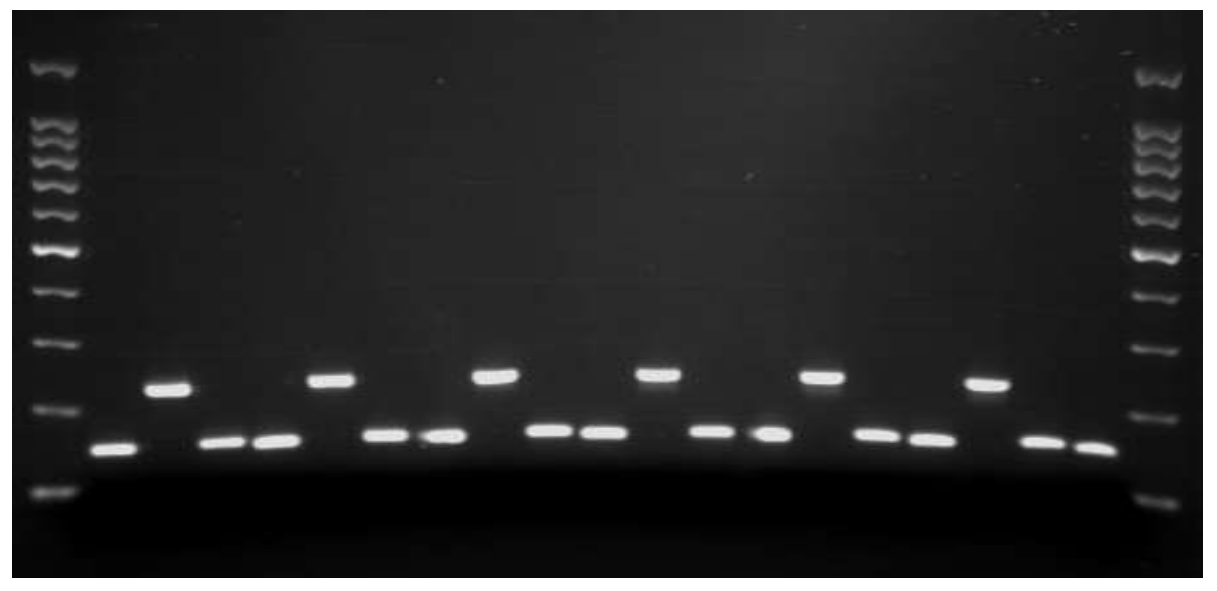

Abb. 12: Beispiel für die Auftrennung der PCR-Produkte durch eine Gelelektrophorese

Aufgrund der ohnehin schon geringen Fallzahl $\mathrm{n}$ in dieser Arbeit wurde für die Analyse der Expression von OPG beschlossen, die Versuchsgruppen VG1 und VG2 zu einer Versuchsgruppe (VG, $\mathrm{n}=10$ Tiere) zusammenzufassen und auf eine vergleichende Auswertung zwischen einer kürzeren (VG1) und einer längeren Lebenszeit (VG2) der Tiere wegen mangelnder Aussagekraft der Ergebnisse zu verzichten. Dies gilt für die Auswertungen aller Knochenproben: Beckenkamm, Unterkiefer-Submentalregion sowie die Proben der Alveolarkämme des OK und UK. 


\subsection{Teil 3: Histomorphometrische Analyse}

\subsubsection{Material für die histomorphometrische Analyse}

\section{Geräte}

Gerät

Hersteller

Bezeichnung

Schleifgerät

Struers GmbH, Willich

Rotopol-35

Trennsystem

Pathoservice GmbH, Oststeinbek

Trennband:

Pathoservice GmbH, Oststeinbek

$0.1 \mathrm{~mm}, \mathrm{D} 64$

Nassschleifscheiben

Hermes Schleifmittel, Hamburg

Körnung: 800, 1200

Polierscheibe

Dia-plus W. Messner, Oststeinbek

Körnung:

4000/Silikonkarbid

Objektträger

Pathoservice GmbH, Oststeinbek

$25 \times 75 \times 2 \mathrm{~mm} /$ Plexiglas

Tellerschleifgerät

Exakt, Norderstedt

Klebepresse

Eigenbau wissenschaftliche Werkstätten, Uni Göttingen

Deckglas

Menzel, Braunschweig

Digitalmikroskop

Olympus, Deutschland GmbH

Olympus BX51

Objektmikrometer

Zeiss, Deutschland

DL QS-500 5410 


\section{Chemikalien}

Formalinlösung (4\%ig, neutral, phosphatgepuffert) Merck, Darmstadt

Aqua dest.

Hausinterne Aufbereitung, Uni

Göttingen

Alkohol (-reihe)

Hausinterne Apotheke, Uni

Göttingen

Technovit 9100 (Einbettkunststoff

Heraeus Kulzer, Hanau

autopolymerisierend)

Sofortklebstoff Loctite 420

Henkel, Düsseldorf

Methylenblaulösung nach Löffler

Merck, Darmstadt

Alizarinrot S

Merck, Darmstadt

Eindeckmittel: Entellan

Merck, Darmstadt

\section{Digitale Medien und Software}

Gerät/Programm Hersteller

Bezeichnung

\begin{tabular}{|c|c|c|}
\hline Olympus dotSlide-System & $\begin{array}{l}\text { Olympus Soft Imaging Solutions, } \\
\text { Münster }\end{array}$ & V 2.1 \\
\hline Photoshop & Adobe & Version CS5 \\
\hline Mikroskop Software & $\begin{array}{l}\text { Carl Zeiss Microscopy, } \\
\text { Göttingen }\end{array}$ & AxioVision Release 4.8.2 \\
\hline Monitor 1 (Labor) & Dell, Round Rock, Texas & $\mathrm{U} 2410$ \\
\hline Monitor 2 (Privat) & Sony, Minato, TKY, Japan & Sony Vaio, VPCEB4L1E \\
\hline
\end{tabular}

\subsubsection{Methode der histomorphometrischen Analyse}

\section{Herstellung der Trenn-Dünnschliff-Präparate}

Die in Formalinlösung (Merck, Darmstadt) fixierten, Implantat-tragenden Kieferabschnitte wurden zur Herstellung der Trenn-Dünnschliff-Präparate nach der Technik von (Donath 1988) in Leitungswasser gewässert, um das überschüssige Formalin zu entfernen. Die für den Einbettvorgang in Kunststoff notwendige Dehydratation erfolgte nach der Wässerung durch das Einbringen der Knochenfragmente in eine aufsteigende Alkoholreihe. Es folgten die Inkubation im Intermedium Xylol und die Präinfiltration. Die Einbettung der Präparate 
wurde durch die Zugabe des autopolymerisierenden Kunststoffs Technovit 9100 (Heraeus Kulzer, Hanau) in Gießformen durchgeführt, welche zuvor mit den Knochenpräparaten bestückt wurden. Zur Polymerisation wurden die Präparate bei $-8,5^{\circ} \mathrm{C}$ in einen Gefrierschrank gestellt. Die Verarbeitung des Kunststoffs erfolgte den Herstellerangaben entsprechend.

Die vollständig polymerisierten und grob beschliffenen Blöcke mit den darin eingebetteten Kieferabschnitten wurden schließlich mit einer Säge mittig getrennt. Pro Kiefer resultierten daraus jeweils zwei Kunststoffblöcke mit je einem darin eingebetteten Implantat. Die Schnittflächen dieser Blöcke wurden stufenweise bis zu einer Körnung von 1200 allseitig plangeschliffen und dann mit Sofortklebstoff (Loctite 420, Henkel) auf einen Objektträger (Pathoservice $\mathrm{GmbH}$, Osteinbek) geklebt und gepresst. Von den aufgeklebten Blöcken wurde nun mit einer Bandsäge parallel zur Längsachse des Implantats ein Knochenfragment abgetrennt, sodass der mit dem Objektträger verklebte Teil noch eine Stärke von ca. $300 \mu \mathrm{m}$ aufwies. Der hierbei anfallende unverklebte Teil des Knochenblocks wurde nach dem Planschleifen der Sägefläche wiederum mit einem Objektträger verklebt, von welchem erneut parallel zur Implantat-Längsachse ein Knochenfragment abgesägt wurde. Auf diese Weise wurde solange verfahren, bis pro Kunststoffblock/Implantat 6-7 Sägeschnitte auf einem Objektträger von $300 \mu \mathrm{m}$ Dicke entstanden waren. Zur histomorphometrischen Analyse wurden pro Implantat zwei Sägeschnitte ausgewählt, die das Implantat nach Möglichkeit in seiner vollen Länge und Breite, also möglichst zentral, abbildeten (Abb. 13).

Die ausgewählten Sägeschnittpräparate wurden schließlich mit einem Tellerschleifgerät (Exakt, Norderstedt) unter Verwendung von Schleifscheiben verschiedener KörnungsgröBen (800er-1200er) von $300 \mu \mathrm{m}$ Dicke auf 50-60 $\mu \mathrm{m}$ dünngeschliffen und anschließend mit einer Polierscheibe der Körnung 4000 poliert.

Der abschließende Schritt bei der Herstellung histomorphometrisch auswertbarer Dünnschliffe bestand in einer Färbung der polierten Präparate nach der von Smith und Karagianes 1974 beschriebenen Färbemethode. Hierzu wurden die Schliffe für jeweils 30 Sekunden in ein Bad mit dem Farbstoff Methylenblau eingehängt. Diese Farbstofflösung wurde zuvor in einem Wärmeschrank auf eine Temperatur von $80{ }^{\circ} \mathrm{C}$ erhitzt. Anschließend wurde der Farbstoff mit aqua dest. gründlich aus den Präparaten heraus gespült und diese für 3-4 Stunden bei Raumtemperatur getrocknet. Der zweite Färbevorgang fand in einem Farbstoffbad mit Alizarinrot S bei Raumtemperatur statt, in welchem die Präparate für jeweils 60 Sekunden gefärbt wurden. Auch hier erfolgte nach dem Färben eine gründliche Reini- 
gung der Präparate mit aqua dest. und anschließende Trocknung für 24 Stunden bei Raumtemperatur. Durch die Färbung konnten verschiedene histologische Gewebe des Präparats farblich differenziert werden: Knochengewebe färbte sich orange, Kollagen dunkelblau, und andere Weichgewebe stellten sich hell blau dar. Abschließend wurden die Schliffpräparate zur Fixierung mit dem Eindeckmittel Entellan (Merck, Darmstadt) und einem Deckglas versehen.

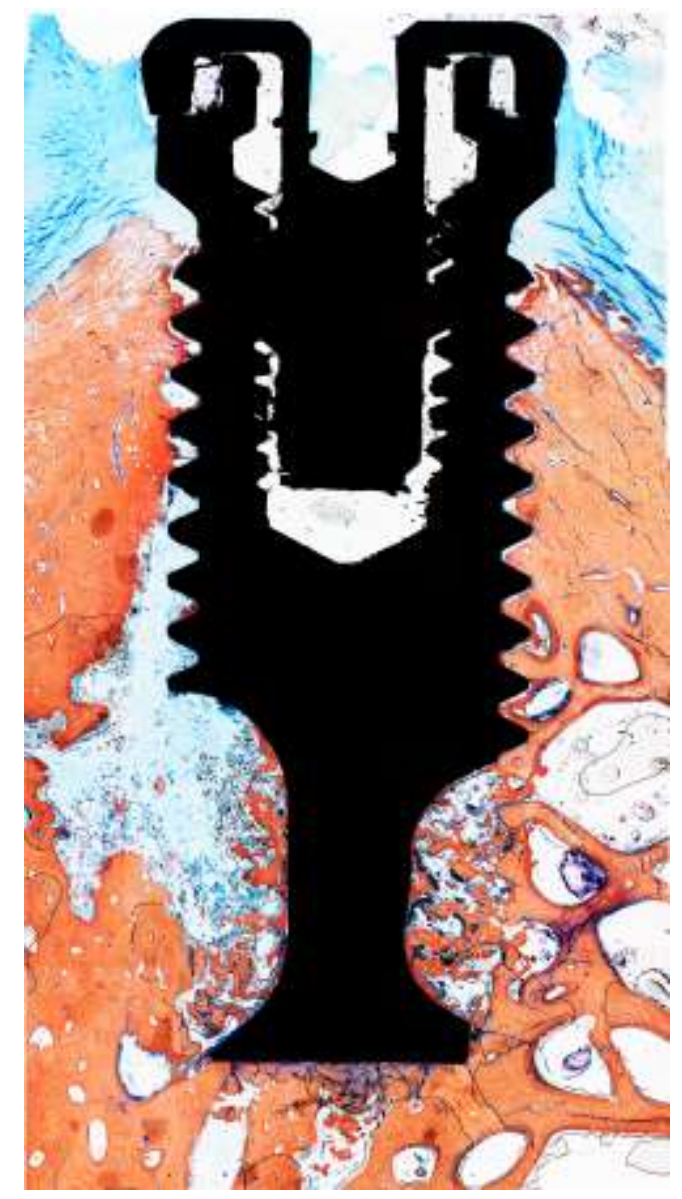

Abb. 13: Implantat-Längsschnitt

\section{Digitalisierung und Bearbeitung der Schliffpräparate}

Um die Einheilung der Implantate anhand der Schliffpräparate mit dem Programm AxioVision Release 4.8.2 (Fa. Carl Zeiss Microscopy GmbH, Göttingen) digital zu analysieren, wurden die Dünnschliffe mit dem Olympus dotSlide-System (Version 2.1, Olympus Deutschland $\mathrm{GmbH}$ ) digitalisiert. Hierbei wurde jedes einzelne Präparat von dem System mit der ausgewählten Vergrößerung automatisiert gescannt und anschließend als virtuelles Bild auf dem PC-Monitor in Form einer Web-basierten Datei wiedergegeben, die gespeichert und damit anderen Programmen zugeführt werden kann. Relevante Bildausschnitte aller Präparate wurden mit dem Digitalmikroskop Olympus BX51 bei einer 20-fachen Ver- 
größerung gescannt und als vsi-Dateien gespeichert, die wiederum zur Reduktion der Datenmenge in das kleinere tif-Dateiformat umgeschrieben wurden. Mit dem Bildbearbeitungsprogramm Adobe Photoshop CS5 wurde anschließend bei allen virtuellen histologischen Präparaten die Bildqualität erhöht, um die im Anschluss daran folgende Bildanalyse optisch zu erleichtern: Neben Helligkeit und Kontrast wurde ebenso die Tonwertspreizung über die Funktion der Tonwertkorrektur erhöht.

\section{Technik und Prinzip der histomorphometrischen Analyse}

Für die histomorphometrische Analyse der Osseointegration der inserierten Implantate wurden die virtuellen Schliffpräparate mit der Mikroskop-Software AxioVision Release 4.8.2 (Fa. Carl Zeiss Microscopy GmbH, Göttingen) untersucht. Die Skalierungseinheit der mit dem Programm AxioVision geöffneten tif-Dateien ist Pixel. Für die Umwandlung der Pixel in eine für die Auswertung der Daten anschaulichere Einheit wurde ein Objektmikrometer (Carl Zeiss Microscopy GmbH, Göttingen) verwendet. Auf diesem Objektträger ist eine Längenskala aufgebracht, welche 100 Linien mit 1/100 mm Intervallen in y- Richtung abbildet. Der Objektträger wurde ebenso wie die histologischen Präparate bei einer 20fachen Vergrößerung eingescannt und virtualisiert. Über den Skalierungsassistenten von AxioVision konnte auf diesem Wege allen Präparaten die Information zugeteilt werden, dass ein Bildpunkt (= 1 Pixel) dem reellen Abstand von 3,333 $\mu \mathrm{m}$ auf dem Präparat entsprechen sollte. Alle Messwerte der Bildanalyse sind folglich in Mikrometern $(\mu \mathrm{m}) \mathrm{bzw}$. $\operatorname{Mikrometern}^{2}\left(\mu \mathrm{m}^{2}\right)$ angegeben.

\section{Analyse der Implantat-Knochen-Kontaktrate}

Für eine Analyse des zum Zeitpunkt der Euthanasie der Tiere der Implantatoberfläche direkt anliegenden Knochens wurde mit der Software AxioVision und dem Werkzeug „Kurve“ der Toolbar bei jedem Implantat der Schnittpräparate zunächst die Gesamtstrecke der Implantatoberfläche gemessen. Hierzu wurde eine Linie entlang der Außenseite der Implantatkörper vom Unterrand der Implantatschulter der linken bis zum selben Punkt der rechten Seite gezogen und so die Gesamtstrecke ermittelt (Abb. 14). Im Anschluss daran wurden auf dieselbe Weise alle Strecken gemessen und danach addiert, auf denen Knochengewebe der Implantatoberfläche dicht anlag (Abb. 15). Die Knochenkontaktrate ergab sich aus der Subtraktion der addieren Knochenkontaktstrecken von der Gesamtstrecke und wurde in Prozent (\%) angegeben. 


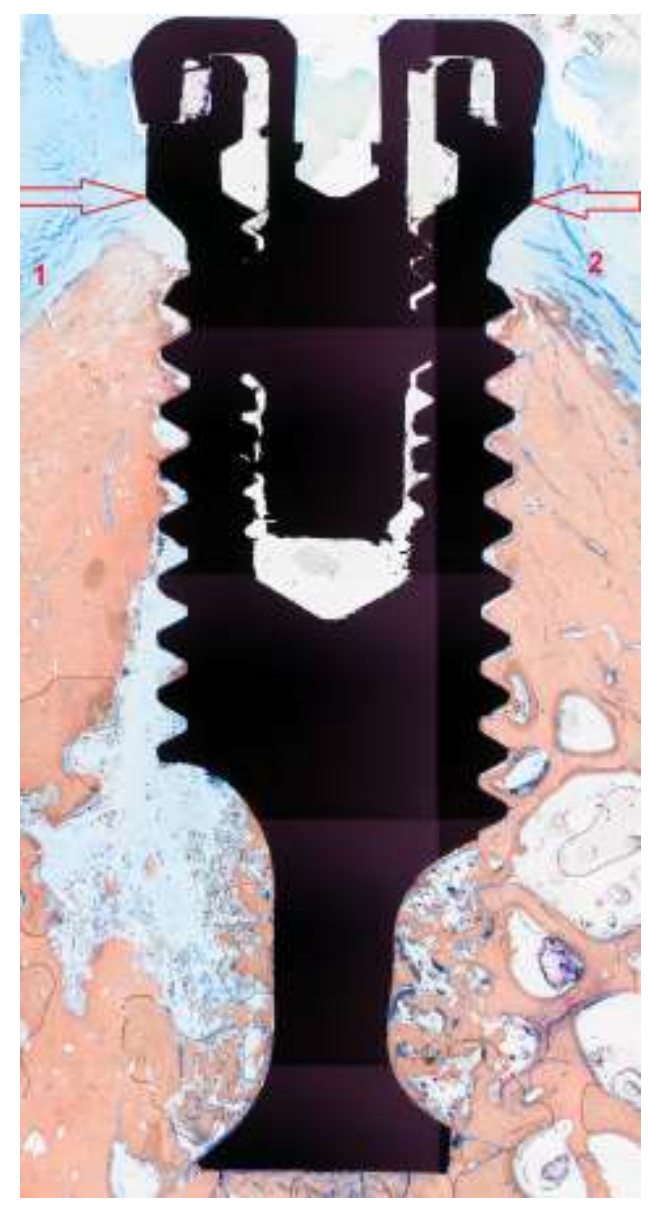

Abb. 14: Analyse der Implantat-Knochen-Kontaktrate

Hier: Ermittlung der Gesamtstrecke der Implantatoberfläche vom Unterrand Implantatschulter links (1) bis zum Unterrand der Implantatschulter rechts (2) 

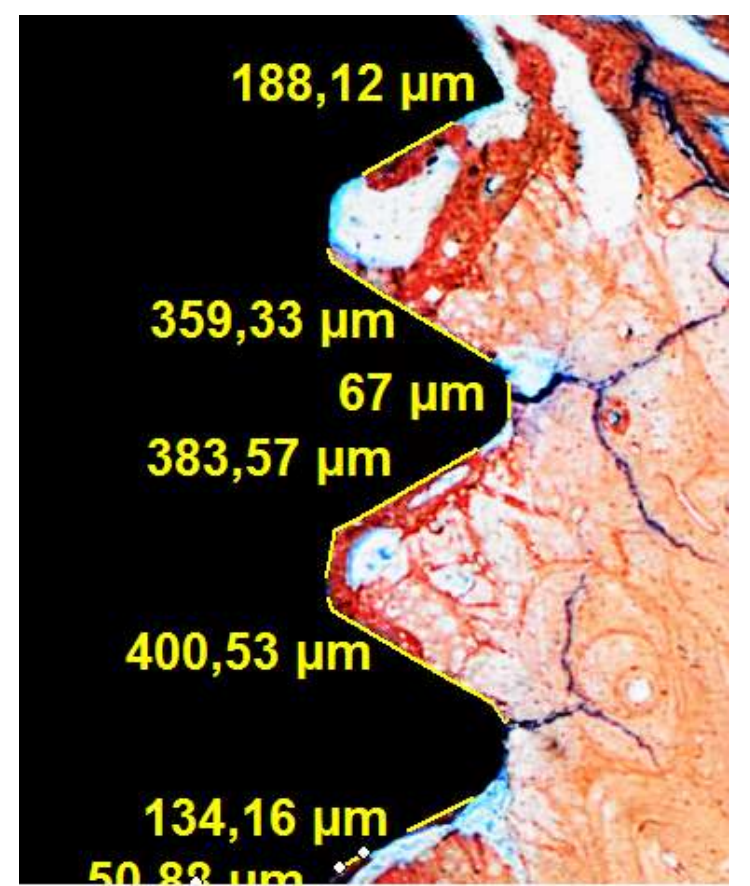

Abb. 15: Analyse der Implantat-Knochen-Kontaktrate

Hier: Ermittlung der Knochenstrecken, die der Implantatoberfläche dicht anlagen

\section{Analyse der Knochendichte in den Gewindegängen}

Da die einzelnen Schliffe durch den verschiedenseitigen Anschliff jeweils unterschiedlich viele Gewindegänge aufwiesen, jedoch auf der rechten und linken Seite des Implantats jeweils mind. 9 Gewindegänge zu finden waren, wurden bei allen Implantaten jeweils die ersten 9 Gewindegänge auf beiden Seiten des Implantats analysiert. Insgesamt wurden damit 18 Gewindegänge je Schliff vermessen. Gewindegänge mit einer Fläche von $\leq$ $25.000 \mu \mathrm{m}^{2}$ blieben unberücksichtigt. In einem ersten Schritt wurde mit dem Werkzeug „Kontur“ (AxioVision) die Fläche $\left(\mu \mathrm{m}^{2}\right)$ jedes einzelnen Gewindegangs vermessen. Hierzu wurde über jedem Gewindegang eine Tangente angelegt, die zusammen mit der Implantatoberfläche jedes Gewindeganges jeweils eine Fläche einschloss. Alle so ermittelten 18 Gewindeflächen wurden im Anschluss addiert. Danach wurden innerhalb dieser Gewindeflächen mit demselben Werkzeug die vorhandenen Knochenflächen vermessen $\left(\mu \mathrm{m}^{2}\right)$ und auch diese addiert (Abb. 16). Flächen von Hohlräumen innerhalb des Knochengewebes, so beispielsweise Havers-Kanäle, wurden ebenso vermessen und von den Knochenflächen subtrahiert, um die Fläche reinen Knochengewebes zu erhalten. Keine Berücksichtigung fanden dabei Fixierungsartefakte wie beispielsweise Risse. Auf diese Weise konnte schließlich die Summe der reinen Knochenflächen von der Gesamtfläche der Gewindegän- 
ge subtrahiert und damit der prozentuale Anteil reinen Knochens in den ersten 9 Gewindegängen beidseitig des Implantats errechnet werden.

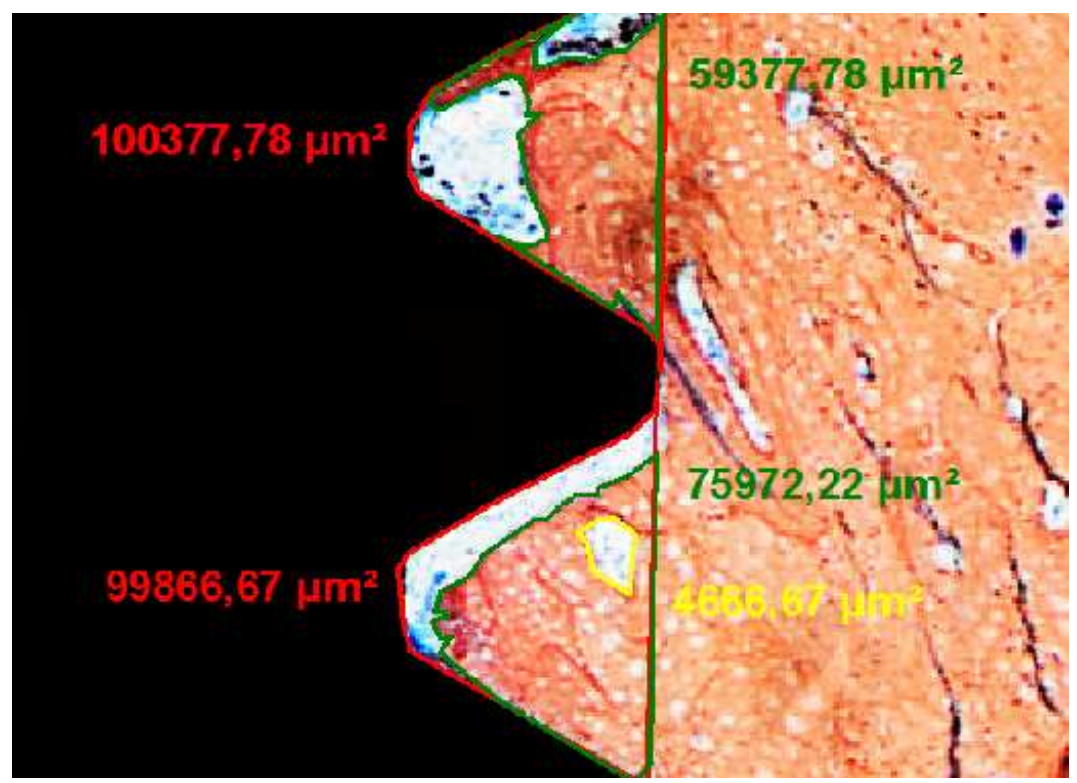

Abb. 16: Analyse der Knochendichte in den Gewindegängen

(Rot: Markierung der Flächen der Gewindegänge; Grün: Markierung der Knochenflächen in den Gewindegängen; Gelb: Markierung von Hohlräumen innerhalb der Knochenflächen).

\section{Analyse der periimplantären Knochendichte}

Um die Knochendichte bis zu einem Abstand von $1 \mathrm{~mm}$ neben dem Implantat zu ermitteln, wurden über die Funktion „Rechteck“ (AxioVision) zwei Rechtecke mit einer Breite von 1 $\mathrm{mm}$ erstellt $\left(\mu \mathrm{m}^{2}\right)$. Diese wurden so ausgerichtet, dass sie jeweils auf der rechten und linken Seite des Implantats, parallel zur Oberfläche der Gewindegänge, zu liegen kamen und in ihrer Länge von der Mitte des 1. bis zur Mitte des 9. Gewindeganges reichten. Die Flächen der so ausgerichteten Rechtecke wurden addiert. In einem nächsten Schritt wurden innerhalb dieser Rechtecke mit der Funktion „Kontur“ die Knochenflächen vermessen und addiert (Abb. 17). Auch hier wurden vorhandene Hohlräume innerhalb der Knochenflächen, mit Ausnahme von Fixierungsartefakten, vermessen und deren Gesamtfläche von der Knochenfläche subtrahiert, um die reine Knochenfläche zu erhalten. Schließlich wurde die Gesamtfläche des ermittelten reinen Knochens von der Gesamtfläche der Rechtecke subtrahiert und der prozentuale Anteil an Knochen bis zu einer Entfernung von $1 \mathrm{~mm}$ neben der Implantatoberfläche errechnet. 

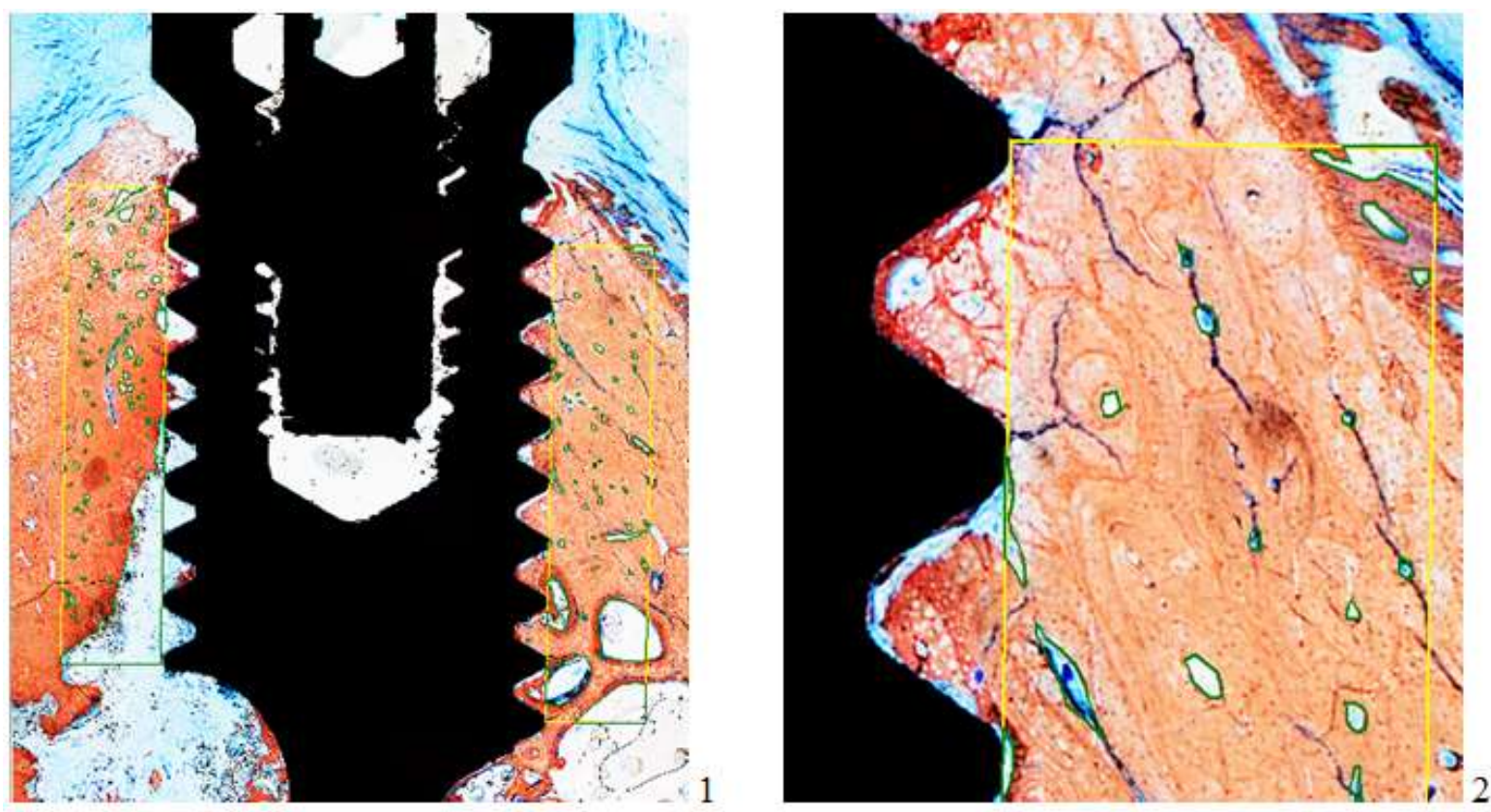

Abb. 17: Analyse der Knochendichte bis 1 mm neben der Implantatoberfläche (Bildfolge 1-2)

(Gelb: Gesamtfläche Rechtecke; Grün: Markierung von Hohlräumen innerhalb der Knochenflächen)

Für die statistische Auswertung wurden jeweils beide Schliffe eines jeden Implantates auf die beschriebene Art und Weise analysiert und aus diesen beiden Ergebnissen für jedes Implantat ein Mittelwert gebildet. Diese Mittelwerte beider Unterkiefer- sowie beider Oberkiefer-Implantate wurden wiederum erneut gemittelt und zu einem finalen Prozentwert je Kiefer zusammengefasst. So gingen in die statistische Analyse für jedes Tier schließlich ein zweifach gemittelter Prozentwert für beide Oberkiefer-Implantate und einer für beide Unterkiefer-Implantate jeden untersuchten Parameters mit ein. 


\subsection{Teil 4: Histologische Analyse}

\subsubsection{Material für die histologische Analyse}

Gerät

Hersteller

Bezeichnung

$\begin{array}{ll}\text { Epifluoreszenzmikroskop } & \begin{array}{l}\text { Carl Zeiss Microscopy GmbH, Axiophot } \\ \text { Göttingen } \\ \text { Tamaco, Taiwan }\end{array}\end{array}$

Geodreieck

Non-permanenter Fettstift

\subsubsection{Methode der histologischen Analyse}

Die histologische Analyse der Schliffpräparate beinhaltete eine absolute Auszählung der Osteoklasten(lakunen) und Osteoblasten in den Gewindegängen sowie bis zu einem Abstand von $1 \mathrm{~mm}$ zirkulär um die Implantatoberfläche. Hierzu wurde je eines der beiden Schliffpräparate pro Implantat herangezogen, wobei die Auswahl des Präparates randomisiert erfolgte. Um die Region der Auswertung zu begrenzen, wurde zunächst bei 20-facher Vergrößerung auf jedem der ausgewählten Objektträger unter dem Mikroskop mit einem non-permanenten Fettstift mittels Lineal eine parallele Linie gezogen, die der Oberfläche der Implantate anlag. Start- und Endpunkt dieser Linie waren analog zur histomorphometrischen Auswertung jeweils der krestal liegende erste Gewindegang auf beiden Seiten des Implantats. Senkrecht zu dieser Linie wurde ein Abstand von $1 \mathrm{~mm}$ markiert. Von hier ausgehend wurde, zirkulär um das Implantat verlaufend, eine weitere Linie gezogen, die parallel zur ersten verlief. Die Auszählung der Osteoklasten(lakunen) und Osteoblasten fand nun streng innerhalb dieses markierten, $1 \mathrm{~mm}$ breiten Bereiches statt. Zusätzlich wurden alle Gewindegänge in die Auszählung mit einbezogen (Abb. 18). 


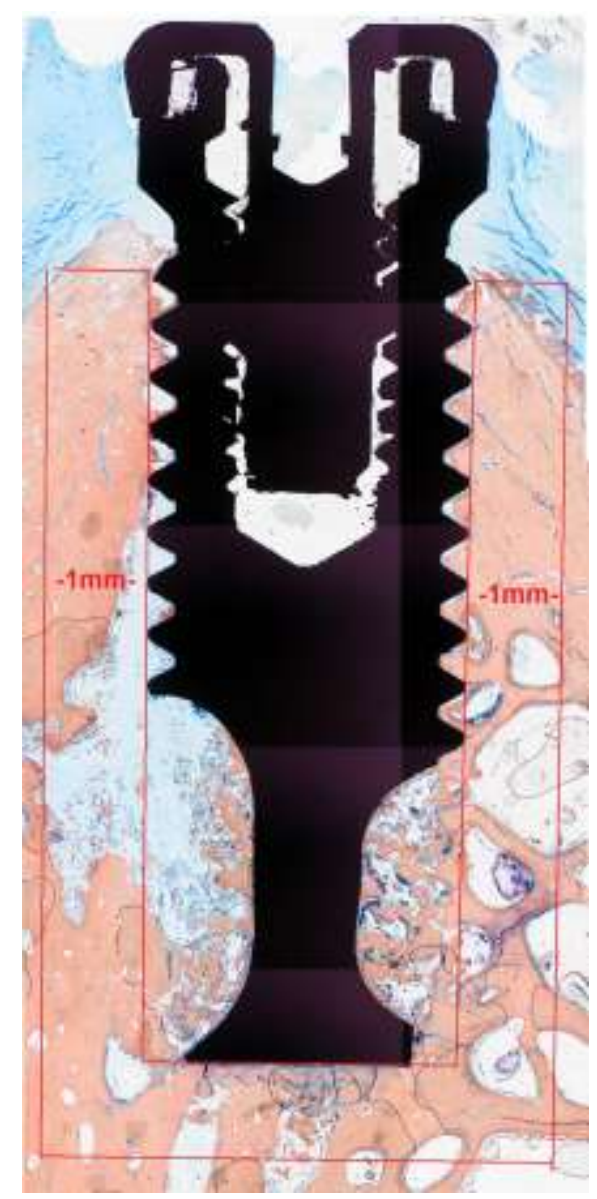

Abb. 18: Markierter Messbereich bis 1 mm zirkulär um ein Implantat

Die Auszählung der Zellen wurde bei einer 100-fachen Vergrößerung unter dem Axiophot Epifluoreszenzmikroskop durchgeführt, wobei eine Zähluhr zu Hilfe genommen wurde. Da, bedingt durch den Schleifprozess bei ihrer Herstellung, in nur wenigen Abschnitten der histologischen Präparate tatsächlich Osteoklasten aufzufinden waren, beschränkte sich deren Zählung auf die Summation der Osteoklastenlakunen, welche bei der genannten Vergrößerung gut zu erkennen waren (Abb. 19). 


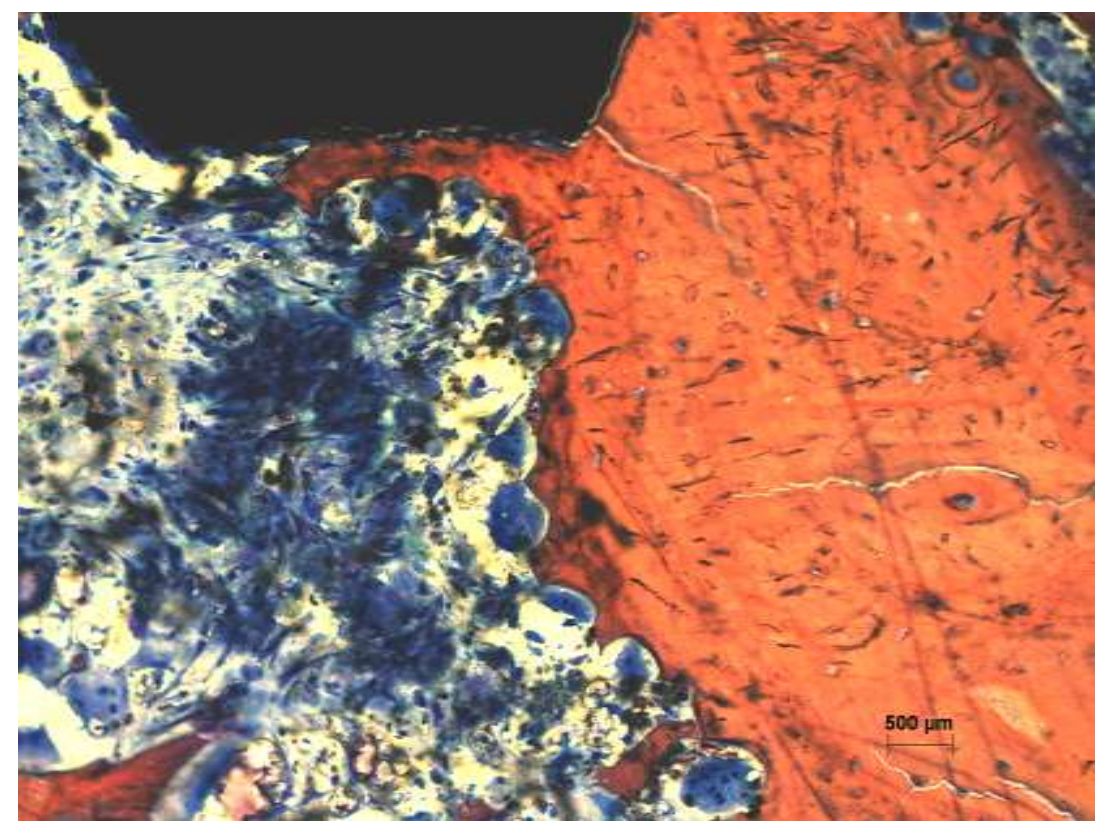

Abb. 19: Histologischer Detailausschnitt eines Schliffpräparats

(Osteoklasten in ihren Resorptionslakunen)

Die sehr viel kleineren Osteoblasten hingegen wurden beim Schleifprozess nicht herausgelöst. Anhand der hellblauen Färbung des durch die Zellen abgesonderten Osteoids und der dunkelblau angefärbten Zellleiber waren sie in den Präparaten gut zu erkennen. Sie stellten sich als eine Aneinanderreihung von Zellkernen auf einer durch den Farbstoff Methylenblau sichtbar gemachten unmineralisierten Knochenmatrix (Osteoid) dar (Abb. 20).

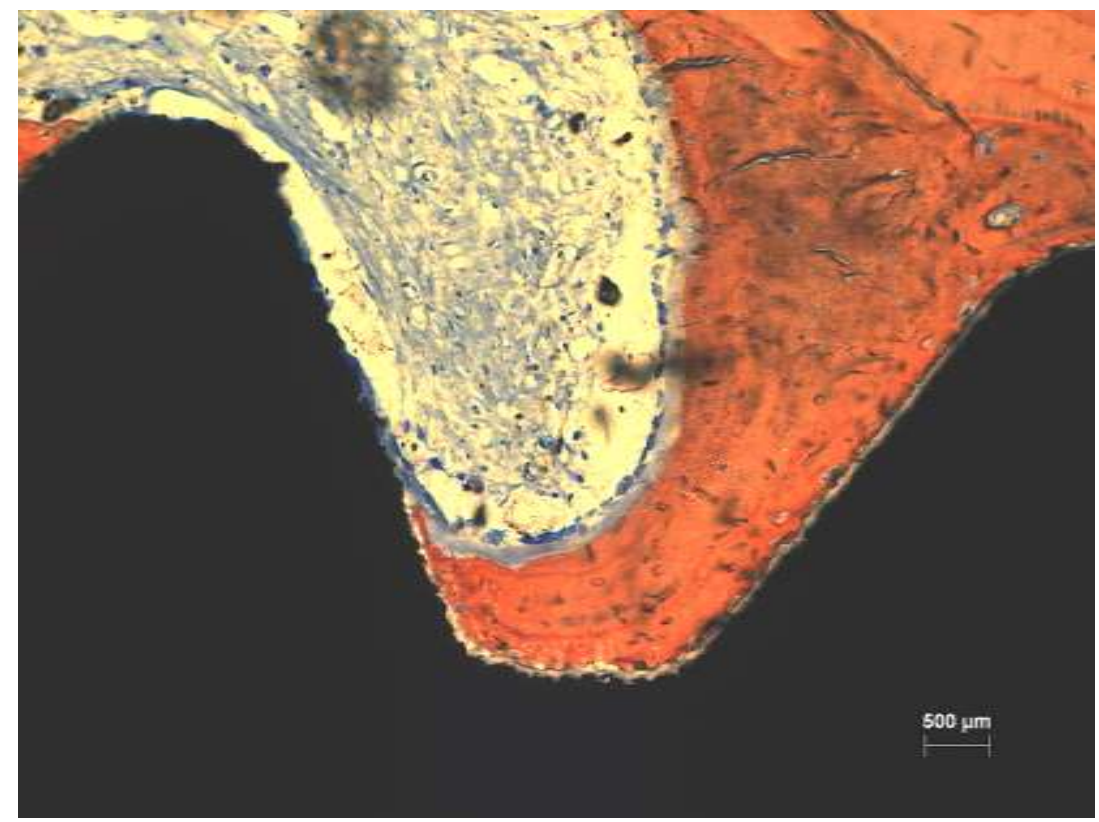

Abb. 20: Histologischer Detailausschnitt eines Schliffpräparats

(Perlschnurartig aufgereihte Osteoblasten auf einem feinen Osteoidsaum) 


\section{ERGEBNISSE}

\subsection{Statistische Auswertung}

Die statistische Auswertung der vorliegenden Arbeit wurde gemeinsam mit dem Institut für Medizinische Statistik (Humboldtallee 32, 37073 Göttingen) durchgeführt.

Alle deskriptiven Statistiken wurden mit dem Statistikprogramm Statistica (Firma StatSoft, Version: 10, 64-bit), die Interferenzstatistik (Signifikanzen) wurde mit SAS (Firma SAS Institute, Version: 9.2) durchgeführt. Hierzu wurde statistisch jeweils ein gemischtes Modell verwendet, um den Effekt der verschiedenen Variablen (möglichen Einflussfaktoren) auf die zu untersuchende Zielgröße zu analysieren. Ein gemischtes Modell ähnelt einer (zwei-/mehrfaktoriellen) ANOVA (Varianzanalyse), jedoch für Messwiederholungen. Das Signifikanzniveau wurde bei allen statistischen Tests auf $\mathrm{p} \leq 0,05$ gesetzt.

\subsection{Ergebnisse der klinischen Analyse}

Für die klinische Analyse der periimplantären Defektgrößen wurde von jedem Tier jeweils ein Foto der Implantationsregion im Unterkiefer und eines im Oberkiefer statistisch ausgewertet. Eines der insgesamt 15 Versuchstiere (zugehörig zur Versuchsgruppe VG2) starb nach der ersten Operation an einem Abszess der Bauchhaut und konnte für die Auswertung nicht berücksichtigt werden. Daraus ergab sich eine Fallzahl von $n=18$ Fotos für die 9 Versuchsgruppentiere und $n=10$ Fotos für die 5 Kontrollgruppentiere. 


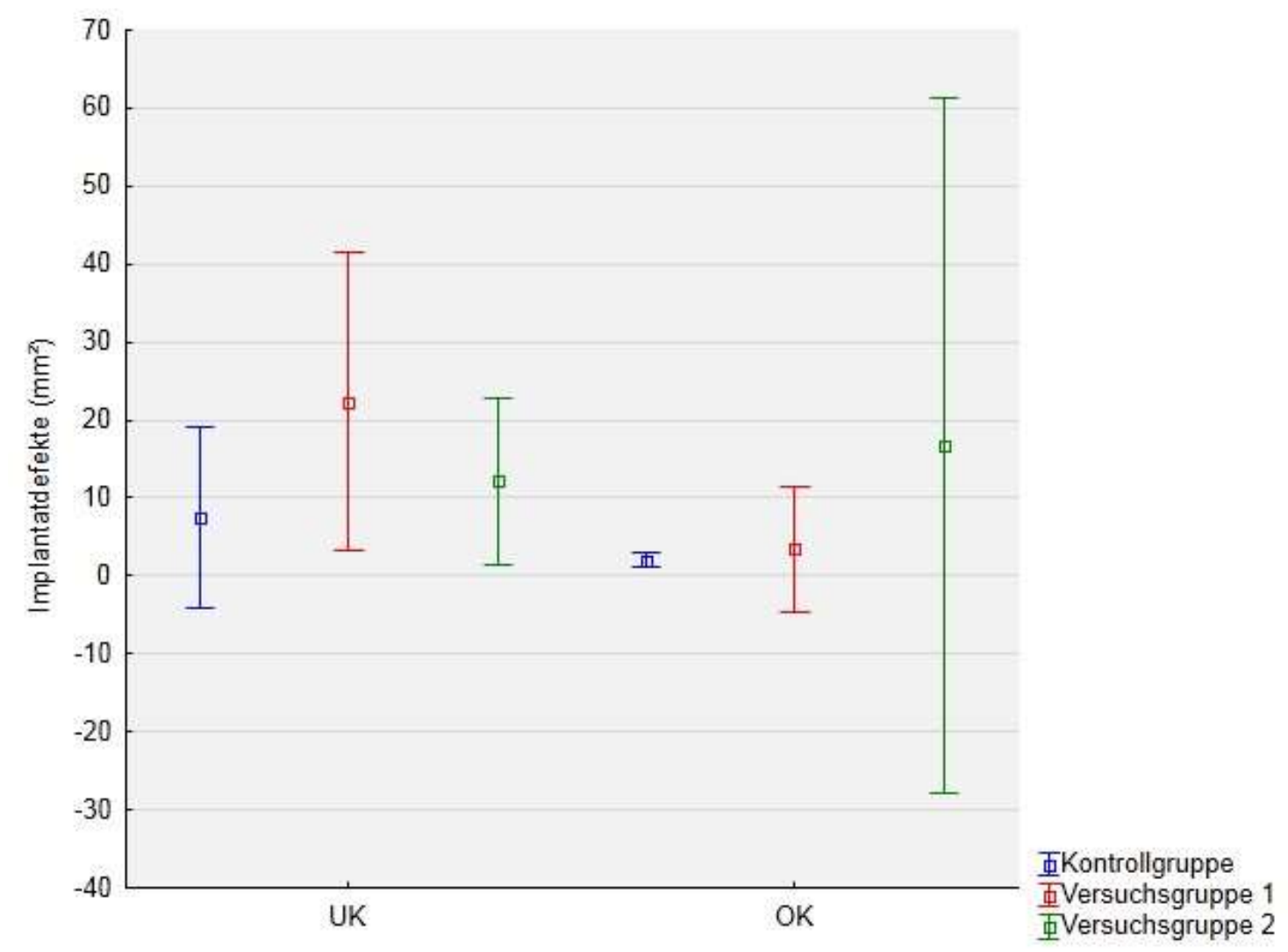

Abb. 21: Periimplantäre Defektgrößen im Unterkiefer und Oberkiefer

Tab. 11: Deskriptive Analyse der periimplantären Schleimhaut

(Wert 0 = unauffällige Schleimhaut, Wert 1 = entzündliche Rötung der Schleimhaut)

\begin{tabular}{|llrrrrr|}
\hline Lokalisation & Gruppe & Mittelwert & N & Std. Abw. & Min. & Max. \\
\hline Unterkiefer & Kontrollgruppe & 7,53 & 5 & 9,28 & 1,61 & 23,23 \\
Oberkiefer & & 2,02 & 5 & 0,74 & 1,00 & 3,10 \\
\hline Unterkiefer & Versuchsgruppe 1 & 22,37 & 5 & 15,41 & 1,00 & 35,45 \\
Oberkiefer & & 3,41 & 5 & 6,52 & 0,00 & 15,03 \\
\hline Unterkiefer & Versuchsgruppe 2 & 12,14 & 4 & 6,71 & 4,75 & 21,03 \\
Oberkiefer & & 16,76 & 4 & 28,07 & 0,00 & 58,67 \\
\hline
\end{tabular}

Tab. 12: Gemischtes Modell der periimplantären Defektgrößen

\begin{tabular}{|l|r|}
\hline Effekt & p-Wert \\
\hline Gruppe (KG/VG1/VG2) & 0,1423 \\
Lokalisation (OK/UK) & 0,2617 \\
Gruppe*Lokalisation & 0,2388 \\
\hline
\end{tabular}


Für die periimplantären Defektgrößen konnten weder zwischen den Gruppen KG, VG1 und VG2 noch bezüglich der Lokalisation der Implantate in Ober- oder Unterkiefer signifikante Unterschiede festgestellt werden (Tab. 12). Innerhalb der Versuchsgruppen VG1 und VG2 wiesen von $\mathrm{n}=18$ ausgewerteten Arealen insgesamt 11 Areale in OK oder UK messbare Gewebedefekte (Wert 2) auf (61,11 \%), 4 Regionen zeigten eine entzündliche Rötung (Wert 1) $(22,22 \%)$ und in weiteren 3 Regionen $(16,66 \%)$ war eine unauffällige Schleimhaut (Wert 0) zu erkennen. In der Kontrollgruppe präsentierten sich bei $40 \%$ (4 Fotos) der insgesamt 10 ausgewerteten Fotos intraorale Defekte in OK und UK, bei 50 \% (5 Fotos) ein Erythem und bei $10 \%$ (1 Foto) wurde die Schleimhaut als unauffällig befundet. Die Tiere der Kontrollgruppe wiesen periimplantär folglich insgesamt weniger messbare Schleimhautdefekte auf als die Versuchsgruppentiere. Wurden VG1 und VG2 separat voneinander betrachtet, so konnten in der VG1 $(n=10$ Fotos) bei $50 \%$ (5 Fotos) messbare Defekte in OK und UK festgestellt werden. 3 Fotos zeigten Erytheme und bei 2 Fotos konnte eine unauffällige Schleimhaut beobachtet werden. In VG2 ( $\mathrm{n}=8$ Fotos) präsentierten hingegen $75 \%$ (6 Fotos) Defekte der Schleimhaut und jeweils 12,5 \% (1 Foto) eine entzündliche Rötung oder eine unversehrte Mukosa.

Wurden UK und OK miteinander verglichen, so lagen von insgesamt 11 gemessenen Schleimhautdehiszenzen in den Versuchsgruppen (VG1+VG2) 72,72 \% (= 8 Defekte) im Unterkiefer im Vergleich zu 27,27 \% (= 3 Defekte) im Oberkiefer. In der Kontrollgruppe waren von den insgesamt 4 gemessenen Defekten $75 \%$ (3 Defekte) im Unterkiefer und 25 $\%$ (1 Defekt) im Oberkiefer zu finden.

Der Vergleich der Mittelwerte (Tab. 11) zeigte insgesamt für die Kontrollgruppe die kleinsten Werte in Ober- und Unterkiefer (UK: 7,53; OK: 2,02) im Vergleich zu VG1 (UK: 22,37; OK: 3,41) und VG2 (UK: 12,14; OK: 16,76). VG1 wiederum zeigt kleinere Werte im Oberkiefer als VG2, im Unterkiefer sind die ermittelten Werte von VG1 größer als von VG2. 


\subsection{Ergebnisse der molekularbiologischen Analyse}

\subsubsection{Ergebnisse der OPG-Expression in Beckenkamm und Unterkiefer}

Für die Expressionsanalyse von OPG in Beckenknochen und Unterkiefer wurden insgesamt 40 Knochenbiopsate vom Beckenkamm und 42 Knochenbiopsate von der Unterkiefer-Submentalregion ausgewertet (Tab. 13). Da ein Tier aus der Versuchsgruppe nach der ersten Operation verstarb, konnte in der 2. und 3. Operation innerhalb der Versuchsgruppe nur noch von $\mathrm{n}=9$ Tieren Knochenprobenmaterial von Beckenkamm und Unterkiefer gewonnen werden. Mit weiteren 4 Knochenproben konnten in der qRT-PCR keine verwertbaren Ergebnisse erzielt werden.

Operation 1 wurde zum Zeitpunkt 0 durchgeführt (Baseline), Operation 2 beschreibt die Implantationen 7 Monate nach Beginn des Experiments unter bereits erfolgter ZoledronatTherapie und Operation 3 ist der Abschluss des Experiments mit finaler Euthanasie der Tiere (8-9 Monate nach Beginn des Experiments).

Tab. 13: Anzahl der ausgewerteten Biopsate von BK und UK

(Versuchsgruppen VG1 und VG2 wurden zu einer Versuchsgruppe (VG) zusammengelegt)

\begin{tabular}{|l|lrr|}
\hline \multirow{2}{*}{ Lokalisation } & Gruppe & \multicolumn{2}{c|}{$\begin{array}{c}\text { Proben- } \\
\text { anzahl }\end{array}$} \\
\hline Beckenkamm & Kontrollgruppe & 1 & 4 \\
& & 2 & 4 \\
& & 3 & 5 \\
\cline { 2 - 4 } & & 1 & 9 \\
& Versuchsgruppe & 9 \\
& & 2 & 9 \\
\hline Total & & 3 & 40 \\
\hline
\end{tabular}

\begin{tabular}{|l|lrr|}
\hline \multirow{2}{*}{ Lokalisation } & Gruppe & \multicolumn{2}{c|}{$\begin{array}{c}\text { Proben- } \\
\text { anzahl }\end{array}$} \\
\hline Unterkiefer & Kontrollgruppe & 1 & 5 \\
& & 2 & 5 \\
& & 3 & 5 \\
\cline { 2 - 4 } & & 1 & 9 \\
& & 2 & 9 \\
& & 3 & 9 \\
\hline Total & & & 42 \\
\hline
\end{tabular}




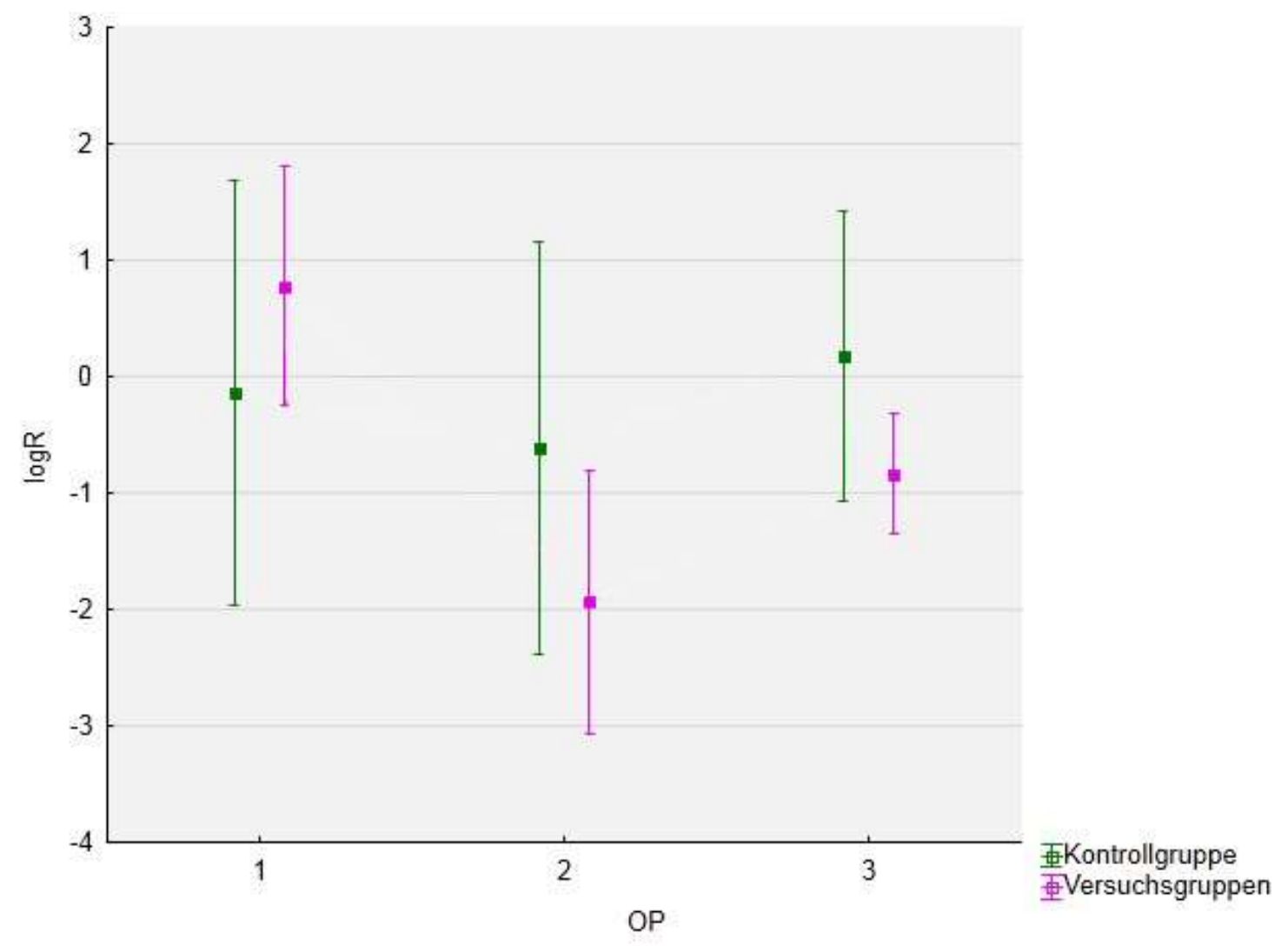

Abb. 22: Expression von OPG in Beckenkamm und Unterkiefer

Die deskriptive Analyse von Beckenkamm und Unterkiefer (Abb. 22) zeigt, dass es sowohl in der KG als auch in der VG vom Ausgangsniveau (OP 1) bis zur 2. Operation (Implantation) zu einem Absinken der OPG-Expression kam und die Expression zum Abschluss des Experiments (OP 3) in beiden Gruppen wieder anstieg. Auffallend ist jedoch, dass die Expression von OPG innerhalb der Kontrollgruppe zum Abschluss des Experiments (OP 3) leicht über dem Ausgangsniveau (OP 1) liegt. Innerhalb der Versuchsgruppen wird das Ausgangsniveau jedoch nach einem zunächst drastischeren Absinken der OPG-Expression bis zum Abschluss des Experiments nicht mehr erreicht.

Die Unterschiede in der deskriptiven Analyse der Expression von OPG im Beckenkamm und in der Unterkiefer-Submentalregion ergaben über ein gemischtes Modell sowohl eine Signifikanz der Lokalisation BK versus UK $(\mathrm{p}=0,0228)$ als auch einen signifikanten Zeiteffekt $(\mathrm{OP})(\mathrm{p}=0,008)$. Ein signifikanter Gruppeneffekt $(\mathrm{KG}$ versus $\mathrm{VG}=\mathrm{ns})$ lag nicht vor (Tab. 14). 
Tab. 14: Gemischtes Modell der Expression von OPG in BK und UK

\begin{tabular}{|l|r|}
\hline Effekt & p-Wert \\
\hline Gruppe $(\mathrm{KG} / \mathrm{VG})$ & 0,4959 \\
OP $(1,2,3)$ & $\mathbf{0 , 0 0 8 0 *}$ \\
OP*Gruppe & 0,0826 \\
Lokalisation (BK/UK) & $\mathbf{0 , 0 2 2 8 *}$ \\
Gruppe*Lokalisation & 0,2776 \\
OP*Lokalisation & $\mathbf{0 , 0 0 1 1 *}$ \\
OP*Gruppe*Lokalisation & 0,8336 \\
\hline
\end{tabular}

Durch signifikante Unterschiede sowohl im zeitlichen Verlauf (OP) als auch in der Lokalisation (BK/UK) stellt sich auch die Interaktion zwischen den Operationszeitpunkten (OP) und der Lokalisation als signifikant dar $(\mathrm{p}=0,0011)$. Im Folgenden wird überprüft, wie sich dieser Unterschied im Einzelnen (BK/UK) äußert.

\subsubsection{Ergebnisse der OPG-Expression im Beckenkamm}

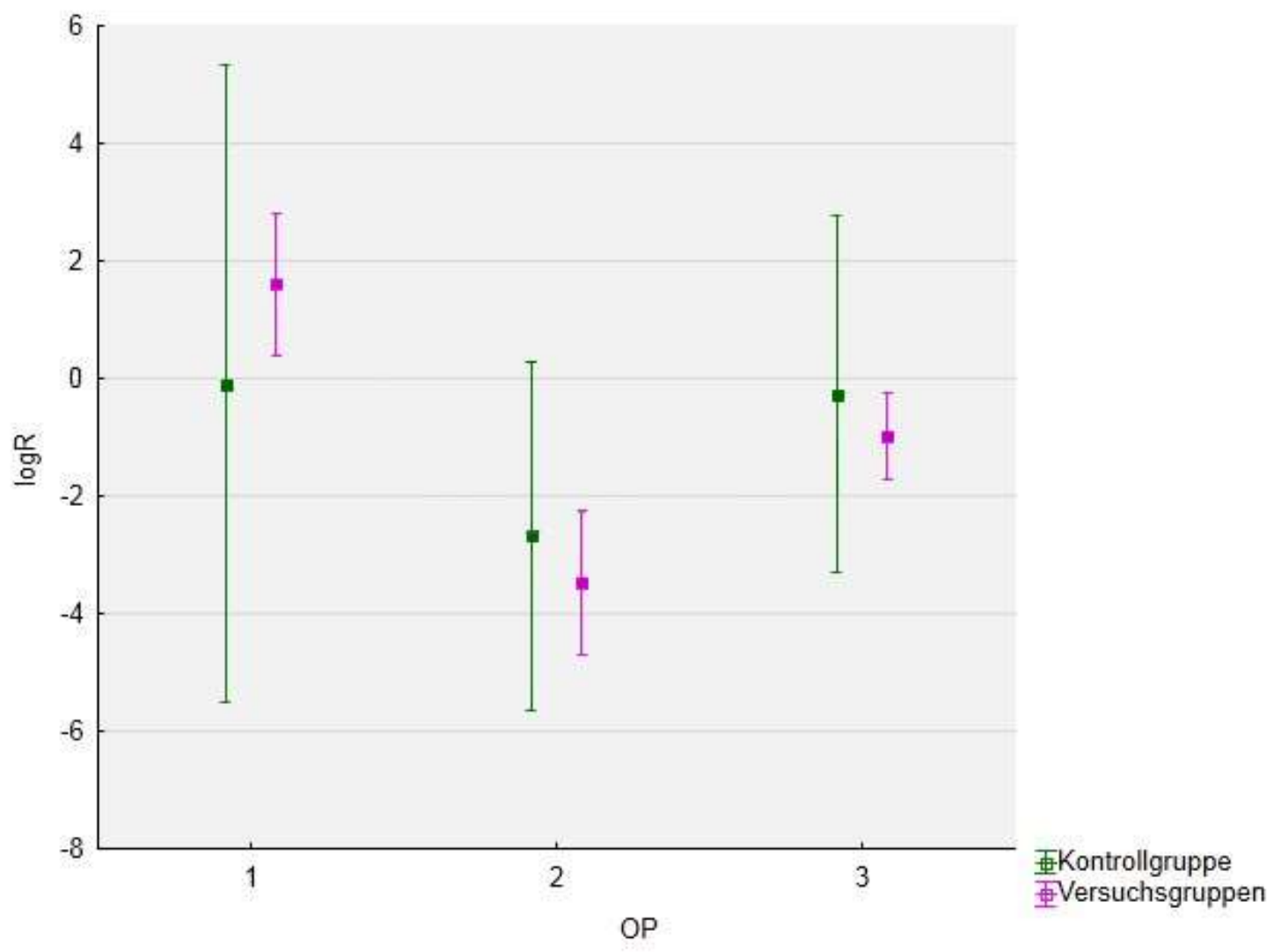

Abb. 23: Expression von OPG im Beckenkamm 
Tab. 15: Deskriptive Analyse der Expression von OPG im Beckenkamm

\begin{tabular}{|l|llrrrrr|}
\hline \multicolumn{1}{|l}{ Lokalisation } & Gruppe & OP & Mittelwert & N & Std.Abw. & Min. & Max. \\
\hline \multirow{3}{*}{ Beckenkamm } & Kontrollgruppe & 1 & $-0,09$ & 4 & 3,41 & $-4,05$ & 4,20 \\
& & 2 & $-2,67$ & 4 & 1,86 & $-5,13$ & $-0,72$ \\
& & 3 & $-0,26$ & 5 & 2,44 & $-2,55$ & 3,80 \\
\cline { 2 - 8 } & \multirow{2}{*}{ Versuchsgruppe } & 1 & 1,60 & 9 & 1,57 & $-0,83$ & 4,03 \\
& & 2 & $-3,47$ & 9 & 1,61 & $-5,34$ & $-0,69$ \\
& & 3 & $-0,98$ & 9 & 0,97 & $-2,66$ & 0,51 \\
\hline
\end{tabular}

Tab. 16: Gemischtes Modell der Expression von OPG im Beckenknochen

\begin{tabular}{|l|r|}
\hline Effekt & p-Wert \\
\hline Gruppe $(\mathrm{KG} / \mathrm{VG})$ & 0,9425 \\
OP $(1,2,3)$ & $\mathbf{0 , 0 0 3 1}$ \\
OP*Gruppe & 0,3649 \\
\hline
\end{tabular}

Die deskriptive Analyse der Expression von OPG im Beckenkamm zeigt in beiden Gruppen einen ähnlichen zeitlichen Verlauf. Nach der ersten Operation kommt es in Kontrollund Versuchsgruppen bis zum Zeitpunkt der zweiten Operation zu einem Absinken der Expression, welche in der VG stärker ausgeprägt ist (Tab. 15). Von OP 2 kommt es bis zum Auswertungszeitpunkt (OP 3) zu einem fast parallelen Anstieg in beiden Gruppen (Abb. 23). Die OPG-Expression innerhalb der Kontrolltiere erreicht zum Ende des Experiments ein Niveau ähnlich dem des Anfangsniveaus. In der Versuchsgruppe liegt das Level der OPG-Expression am Ende des Experiments deutlich unterhalb des Ausgangslevels, womit es hier insgesamt in der VG zu einem Absinken der OPG-Expression kommt. In dem gemischten Modell ergibt sich kein signifikanter Gruppeneffekt $(\mathrm{KG}$ versus VG $=n s)$, jedoch liegt ein signifikanter Zeiteffekt vor $(\mathrm{OP})(\mathrm{p}=0,0031)$ (Tab. 16). Auffällig ist, dass schon zu Beginn des Experiments der Mittelwert der OPG-Expression bei den Versuchstieren höher liegt als bei den Kontrolltieren (Abb. 22/Abb. 23). 


\subsubsection{Ergebnisse der OPG-Expression im Unterkiefer}

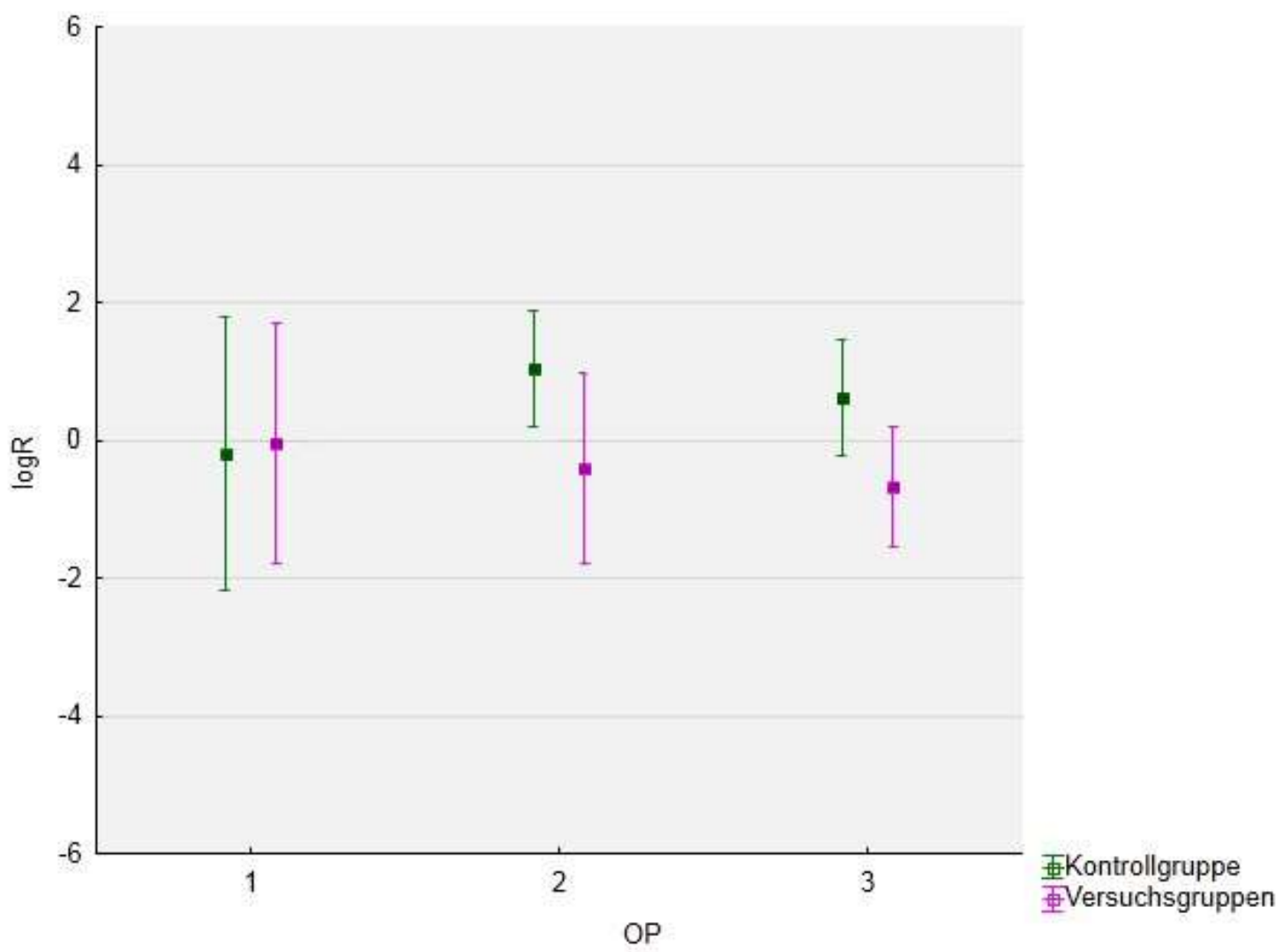

Abb. 24: Expression von OPG im Unterkiefer (Submentalregion)

Tab. 17: Deskriptive Analyse der Expression von OPG in der Unterkiefer-Submentalregion

\begin{tabular}{|l|llrrrrr|}
\hline Lokalisation & Gruppe & OP & Mittelwert & N & Std.Abw. & Min. & Max. \\
\hline Unterkiefer & Kontrollgruppe & 1 & $-0,18$ & 5 & 1,60 & $-2,29$ & 1,56 \\
& & 2 & 1,03 & 5 & 0,68 & $-0,15$ & 1,59 \\
& & 3 & 0,62 & 5 & 0,67 & $-0,10$ & 1,65 \\
\cline { 2 - 8 } & Versuchsgruppe & 1 & $-0,04$ & 9 & 2,27 & $-4,37$ & 2,35 \\
& & 2 & $-0,40$ & 9 & 1,81 & $-2,94$ & 1,76 \\
& & 3 & $-0,68$ & 9 & 1,14 & $-1,80$ & 1,71 \\
\hline
\end{tabular}

Tab. 18: Gemischtes Modell der Expression von OPG im Unterkiefer (Submentalregion)

\begin{tabular}{|l|r|}
\hline Effekt & p-Wert \\
\hline Gruppe (KG/VG) & 0,0742 \\
OP $(1,2,3)$ & 0,7147 \\
OP*Gruppe & 0,2926 \\
\hline
\end{tabular}


Für die Unterkiefer-Submentalregion zeigt sich der zeitliche Verlauf in der deskriptiven Analyse unterschiedlich für Kontrollgruppe und Versuchsgruppe. Zwischen erster und zweiter Operation steigt die OPG-Expression bei den Kontrolltieren leicht an und sinkt bis zum Abschluss des Experiments wieder leicht ab (Abb. 24). Insgesamt ist sie im Vergleich zum Ausgangslevel etwas erhöht. In der Versuchsgruppe sinkt die Expression bis zum Versuchsabschluss ab, womit das Expressionslevel am Ende etwas geringer ist als am Anfang (Tab. 17). Über ein gemischtes Modell zeigt sich weder ein signifikanter Gruppeneffekt noch ein signifikanter Zeiteffekt (Tab. 18). Die Veränderungen der Expression von OPG im Unterkiefer zeigen sich im Vergleich zum Beckenkamm weniger drastisch in beiden Gruppen.

\subsubsection{Ergebnisse der OPG-Expression im Alveolarkamm des OK/UK}

Es wurden insgesamt 29 Knochenproben aus dem Alveolarkamm des Oberkiefers und 29 Knochenproben des Unterkiefer-Alveolarkamms statistisch ausgewertet (Tab. 19). Zum Zeitpunkt der zweiten Operation war es durch den Tod eines Tieres innerhalb der Versuchsgruppen nur noch möglich, die Knochenproben von $n=9$ Tieren zu analysieren. Ansonsten konnten alle Knochenproben jeden Tieres für die Auswertung verwendet werden.

Tab. 19: Anzahl der ausgewerteten Biopsien von AOK und AUK

(Versuchsgruppen VG1 und VG2 wurden zu einer Versuchsgruppe (VG) zusammengelegt)

\begin{tabular}{|l|lcr|}
\hline \multirow{2}{*}{ Lokalisation } & Gruppe & \multicolumn{2}{c|}{$\begin{array}{c}\text { Proben- } \\
\text { anzahl }\end{array}$} \\
\hline Alveolarkamm & Kontrollgruppe & 1 & 5 \\
Oberkiefer & & 2 & 5 \\
\cline { 2 - 4 } & Versuchsgruppe & 1 & 10 \\
& & 2 & 9 \\
\hline Total & & & $\mathbf{2 9}$ \\
\hline
\end{tabular}

\begin{tabular}{|l|lcr|}
\hline \multirow{2}{*}{ Lokalisation } & Gruppe & \multicolumn{2}{c|}{$\begin{array}{c}\text { Proben- } \\
\text { anzahl }\end{array}$} \\
\hline Alveolarkamm & Kontrollgruppe & 1 & 5 \\
Unterkiefer & & 2 & 5 \\
\cline { 2 - 4 } & Versuchsgruppe & 1 & 10 \\
& & 2 & 9 \\
\hline Total & & & $\mathbf{2 9}$ \\
\hline
\end{tabular}




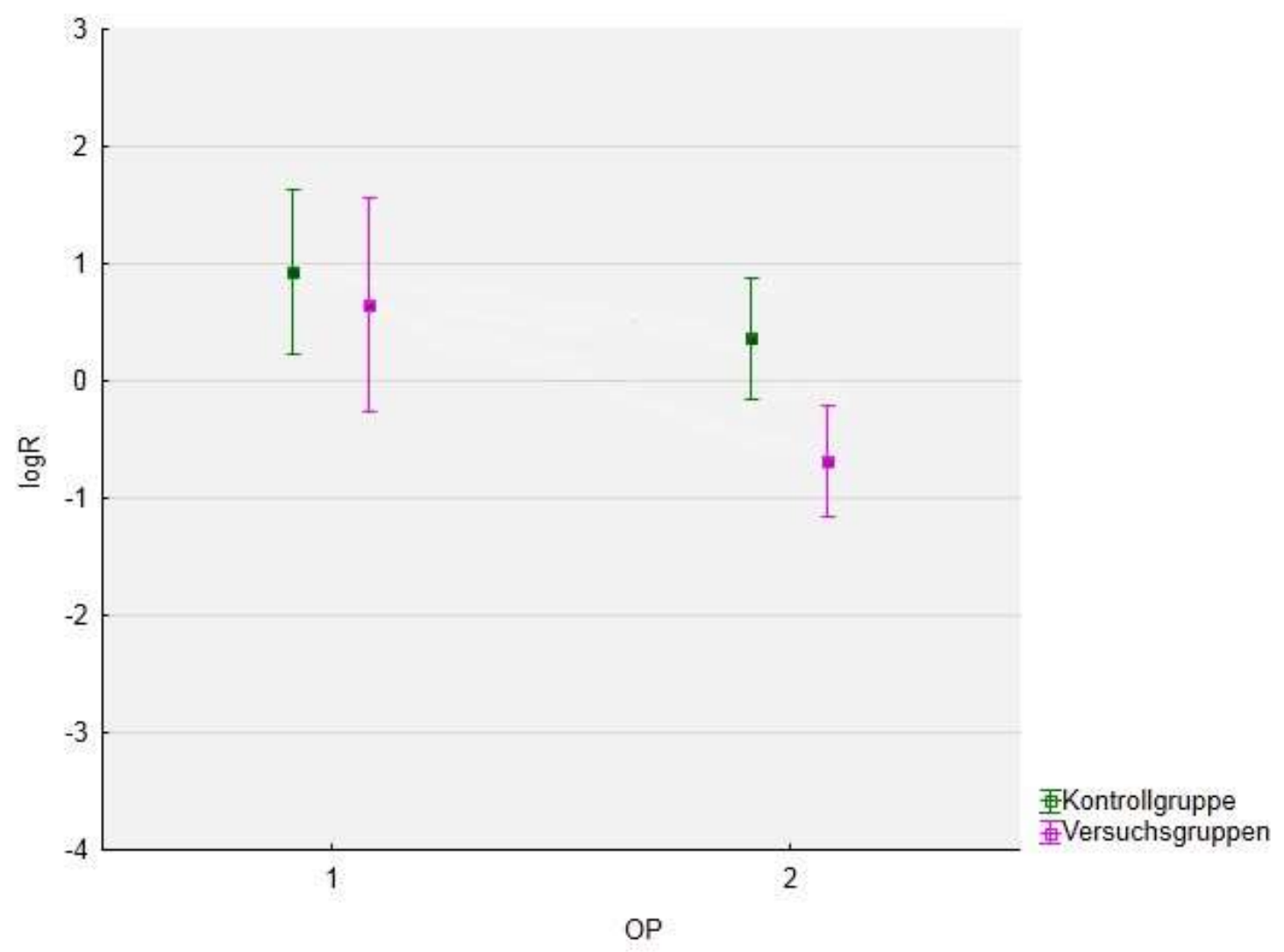

Abb. 25: Expression von OPG im Alveolarkamm des OK/UK

Die Analyse der OPG-Expression ergab im Alveolarkamm des Ober- und Unterkiefers in Kontroll- und Versuchsgruppen einen sehr ähnlichen zeitlichen Verlauf. Die Expression sinkt von der ersten bis zur zweiten Operation, welche bei dieser Analyse den Zeitpunkt der Auswertung darstellt, in beiden Gruppen ab (Abb. 25). Es zeigt sich eine Signifikanz im zeitlichen Verlauf ( $\mathrm{p}=0,0063)$. Zwischen den Lokalisationen AOK und AUK besteht kein signifikanter Effekt ( $\mathrm{p}=0,0521)$. Ebenso liegt kein signifikanter Gruppeneffekt (KG versus $\mathrm{VG}=\mathrm{ns})$ vor $($ Tab. 20).

Tab. 20: Gemischtes Modell der Expression von OPG des Alveolarkamms OK/UK

\begin{tabular}{|l|r|}
\hline Effekt & p-Wert \\
\hline Gruppe $(\mathrm{KG} / \mathrm{VG})$ & 0,1187 \\
OP $(1,2)$ & $\mathbf{0 , 0 0 6 3 *}$ \\
OP*Gruppe & 0,2138 \\
Lokalisation (AOK/AUK) & $\mathbf{0 , 0 5 2 1}$ \\
Gruppe*Lokalisation & 0,9033 \\
OP*Lokalisation & 0,5589 \\
OP*Gruppe*Lokalisation & 0,8918 \\
\hline
\end{tabular}


Um zu analysieren, ob die Signifikanz des Zeiteffekts im Alveolarkamm des Ober- oder des Unterkiefers zu finden ist, wurden im Folgenden AOK und AUK noch einmal separat betrachtet.

\subsubsection{Ergebnisse der OPG-Expression im Alveolarkamm des Oberkiefers}

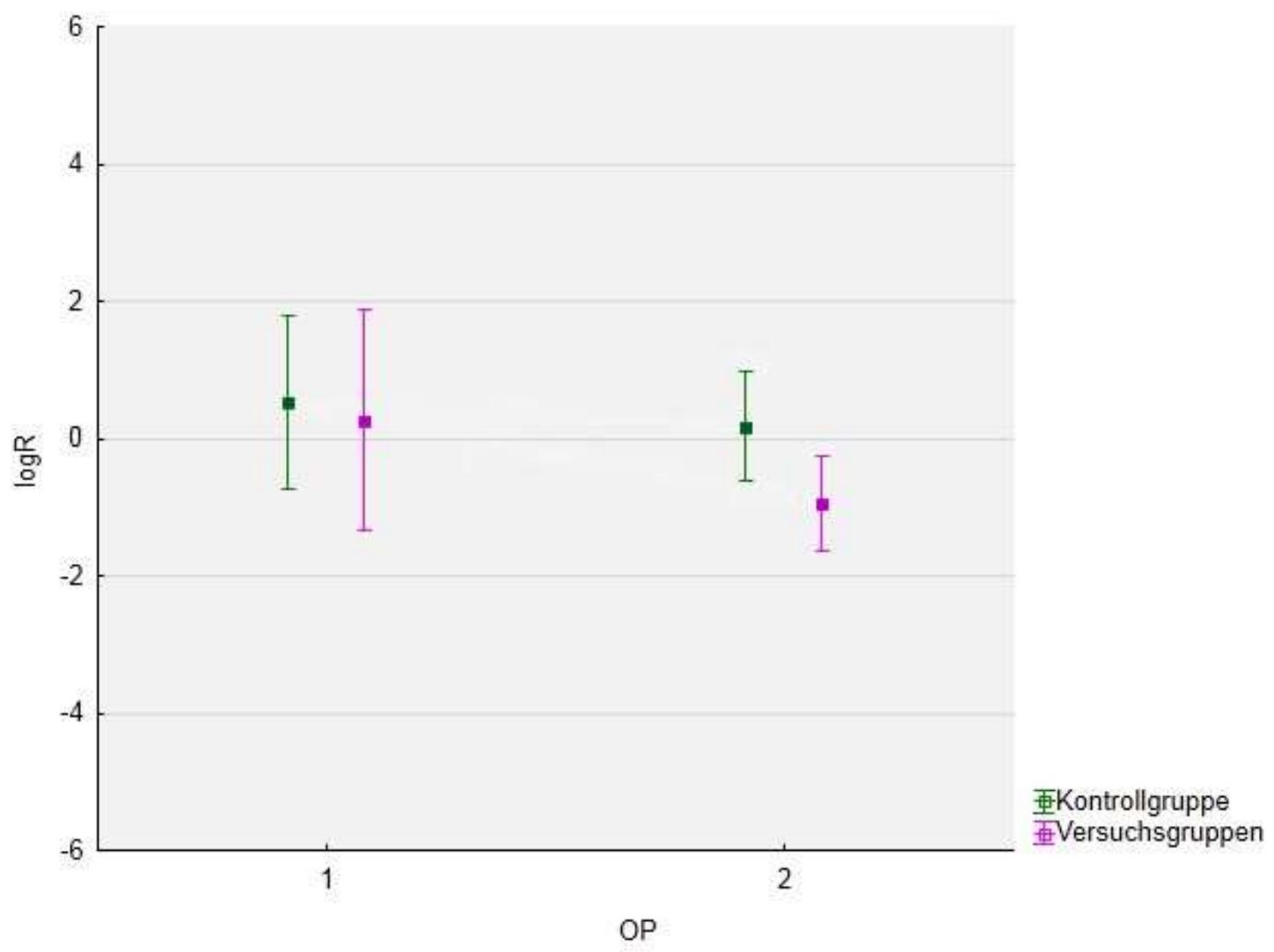

Abb. 26: Expression von OPG des Oberkiefer-Alveolarkamms

Tab. 21: Deskriptive Analyse der Expression von OPG des Oberkiefer-Alveolarkamms

\begin{tabular}{|c|c|c|c|c|c|c|c|}
\hline Lokalisation & Gruppe & OP & Mittelwert & $\mathbf{N}$ & Std.Abw. & Min. & Max. \\
\hline \multirow{4}{*}{$\begin{array}{l}\text { Alveolarkamm } \\
\text { Oberkiefer }\end{array}$} & \multirow[t]{2}{*}{ Kontrollgruppe } & 1 & 0,54 & 5 & 1,02 & $-0,37$ & 2,14 \\
\hline & & 2 & 0,18 & 5 & 0,64 & $-0,37$ & 1,14 \\
\hline & \multirow[t]{2}{*}{ Versuchsgruppe } & 1 & 0,26 & 10 & 2,25 & $-5,15$ & 3,27 \\
\hline & & 2 & $-0,94$ & 9 & 0,90 & $-2,44$ & 0,73 \\
\hline
\end{tabular}

Tab. 22: Gemischtes Modell der Expression von OPG des Oberkiefer-Alveolarkamms

\begin{tabular}{|l|r|}
\hline Effekt & p-Wert \\
\hline Gruppe $(\mathrm{KG} / \mathrm{VG})$ & 0,1733 \\
OP $(1,2)$ & 0,1338 \\
OP*Gruppe & 0,4041 \\
\hline
\end{tabular}


Die Analyse der Expression von OPG im Oberkiefer-Alveolarkamm zeigt in beiden Gruppen einen ähnlichen zeitlichen Verlauf: Nach der ersten Operation kommt es in Kontrollund Versuchsgruppen bis zum Zeitpunkt der Auswertung (OP 2) zu einem Absinken der Expression in beiden Gruppen (Abb. 26). Zwar sinkt die OPG-Expression in den Versuchsgruppen stärker ab als in der Kontrollgruppe, jedoch liegt hierbei keine Signifikanz vor $(\mathrm{KG}$ versus $\mathrm{VG}=\mathrm{ns})$. Ebenso zeigt sich kein signifikanter Zeiteffekt (Tab. 21/Tab. 22).

\subsubsection{Ergebnisse der OPG-Expression im Alveolarkamm des Unterkiefers}

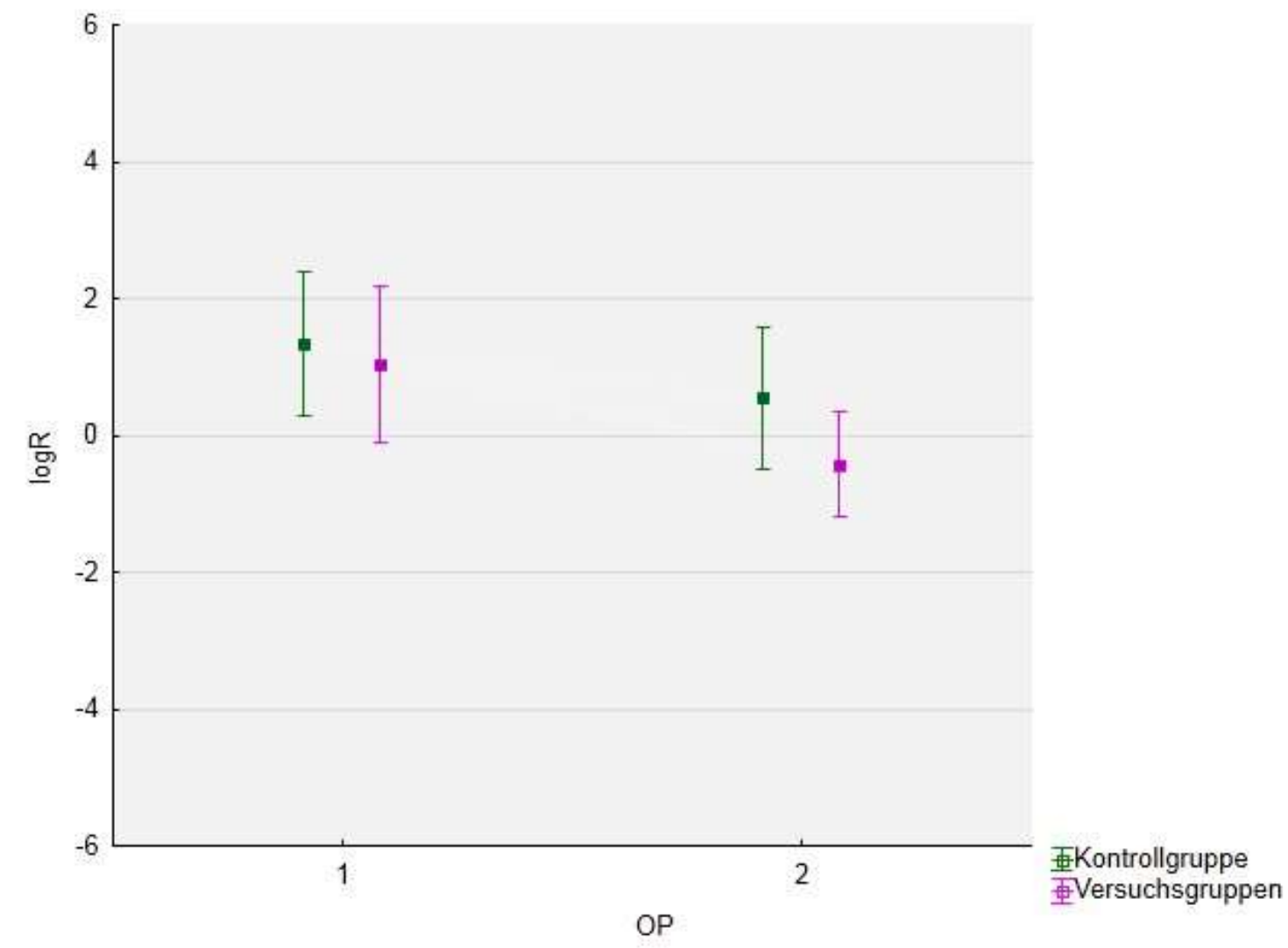

Abb. 27: Expression von OPG des Unterkiefer-Alveolarkamms

Tab. 23: Deskriptive Analyse der Expression von OPG des Unterkiefer-Alveolarkamms

\begin{tabular}{|l|llrrrrr|}
\hline Lokalisation & Gruppe & OP & Mittelwert & N & Std.Abw. & Min. & Max. \\
\hline Alveolarkamm & Kontrollgruppe & 1 & 1,33 & 5 & 0,85 & 0,55 & 2,23 \\
Unterkiefer & & 2 & 0,54 & 5 & 0,85 & $-0,45$ & 1,87 \\
\cline { 2 - 8 } & Versuchsgruppe & 1 & 1,04 & 10 & 1,61 & $-1,48$ & 3,78 \\
& & 2 & $-0,42$ & 9 & 1,00 & $-1,30$ & 1,97 \\
\hline
\end{tabular}


Tab. 24: Gemischtes Modell der Expression von OPG des Unterkiefer-Alveolarkamms

\begin{tabular}{|l|r|}
\hline Effekt & p-Wert \\
\hline Gruppe $(\mathrm{KG} / \mathrm{VG})$ & 0,1509 \\
OP $(1,2)$ & $\mathbf{0 , 0 1 8 2 *}$ \\
OP*Gruppe & 0,4248 \\
\hline
\end{tabular}

Auch im Unterkiefer-Alveolarkamm zeigen Kontrollgruppe und Versuchsgruppe in der deskriptiven Analyse einen ähnlichen zeitlichen Verlauf. Wie im AOK kommt es nach der ersten Operation auch hier in beiden Gruppen zu einem Absinken der OPG-Expression bis zur Auswertung (OP 2) (Abb. 27). Dieses ist in der Versuchsgruppe zwar stärker ausgeprägt als in der Kontrollgruppe, es liegt jedoch auch hier keine Signifikanz vor (KG versus $\mathrm{VG}=\mathrm{ns})$. Es stellt sich ein signifikanter Zeiteffekt dar ( $\mathrm{p}=0,0182)$ (Tab. 24).

Die Differenz der Mittelwerte jeder Gruppe zeigt, dass die OPG-Expression im Unterkiefer stärker absinkt als im Oberkiefer (Tab. 21/Tab. 23).

\subsection{Ergebnisse der histomorphometrischen Analyse}

Bei jedem der 15 Tiere wurden in der zweiten Operation jeweils 2 dentale Implantate in den Ober- und Unterkiefer inseriert, sodass 4 Implantate pro Schwein gesetzt wurden. Insgesamt ergibt sich daraus, und unter der Berücksichtigung des Todes eines Schweins aus der Versuchsgruppe 2, eine Gesamtzahl von 56 inserierten Implantaten (14 Tiere x 4 Implantate). Um eine möglichst objektive und quantitative Analyse der Osseointegration der inserierten Implantate vorzunehmen, wurden die virtuellen Schliffpräparate histomorphometrisch untersucht. Hierbei wurden zwar alle Implantate einzeln untersucht, jedoch wurden jeweils beide Unter- und beide Oberkiefer-Implantate mittelwertig zu einem Implantat zusammengefasst, wodurch sich in dieser Auswertung eine Gesamtzahl von n = 28 Implantaten ergibt. Untersucht wurden bei jedem Tier die Implantat-Knochen-Kontaktrate, die Knochendichte in den Gewindegängen und die periimplantäre Knochendichte in einem Abstand von $1 \mathrm{~mm}$ neben dem Implantat. 


\subsubsection{Implantat-Knochen-Kontaktrate}

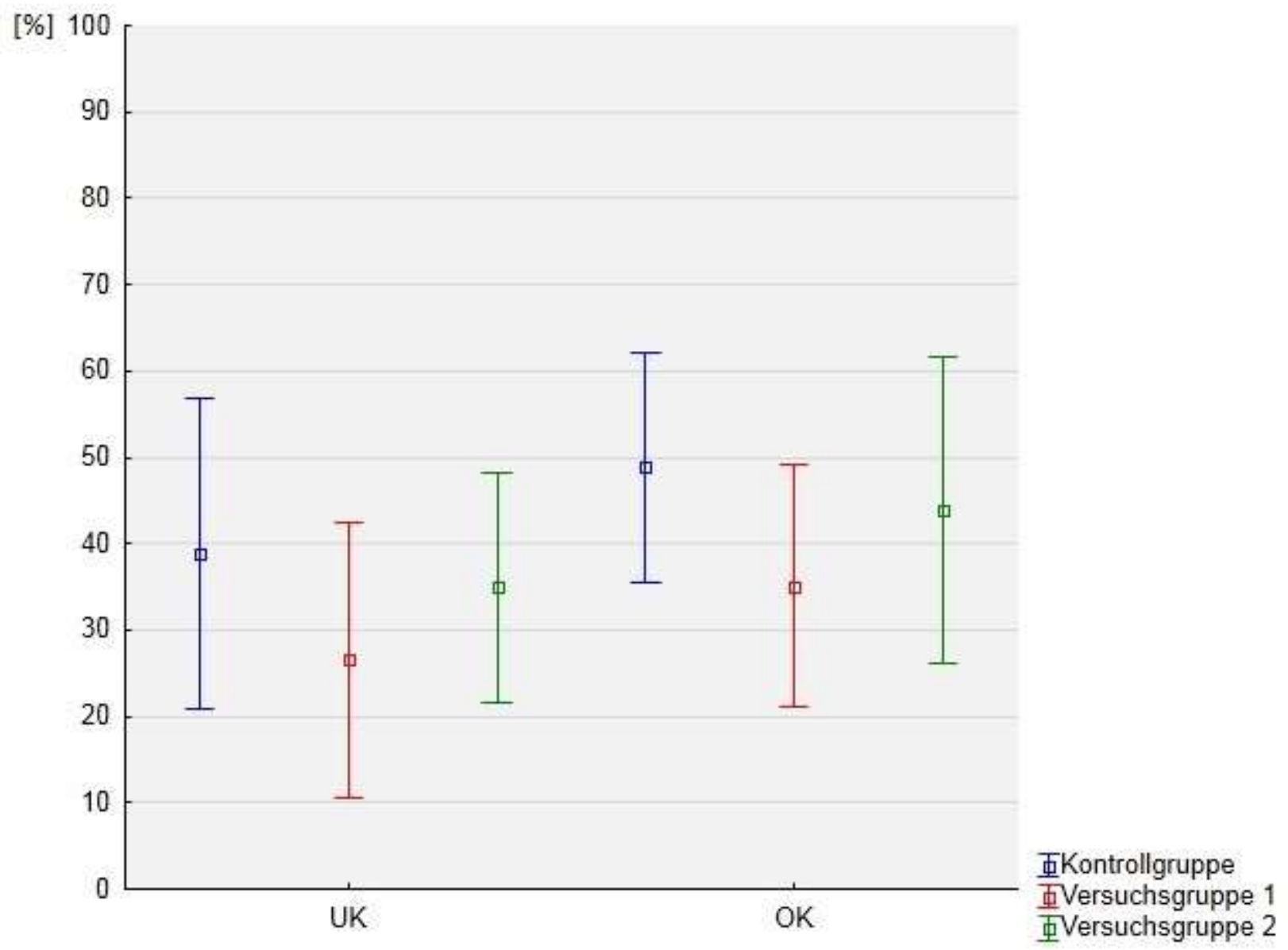

Abb. 28: Implantat-Knochen-Kontaktrate (\%)

Tab. 25: Deskriptive Analyse der Implantat-Knochen-Kontaktrate (\%)

\begin{tabular}{|llrrrrr|}
\hline Lokalisation & Gruppe & Mittelwert & N & Std.Abw. & Min. & Max. \\
\hline Unterkiefer & Kontrollgruppe & 38,94 & 5 & 20,53 & 5,58 & 56,68 \\
Oberkiefer & & 48,88 & 5 & 15,18 & 29,15 & 67,78 \\
\hline Unterkiefer & Versuchsgruppe 1 & 26,56 & 5 & 18,16 & 6,60 & 48,43 \\
Oberkiefer & & 35,08 & 5 & 15,99 & 9,11 & 49,44 \\
\hline Unterkiefer & Versuchsgruppe 2 & 34,98 & 4 & 13,57 & 24,01 & 54,38 \\
Oberkiefer & & 43,88 & 4 & 18,12 & 17,79 & 57,94 \\
\hline Summe & & $\mathbf{2 8}$ & & \\
\hline
\end{tabular}

Tab. 26: Gemischtes Modell der Implantat-Knochen-Kontaktrate

\begin{tabular}{|l|r|}
\hline Effekt & p-Wert \\
\hline Gruppe (KG/VG1/VG2) & 0,2938 \\
Lokalisation (OK/UK) & 0,2359 \\
Gruppe*Lokalisation & 0,9959 \\
\hline
\end{tabular}


Die Mittelwerte der Implantat-Knochen-Kontaktrate liegen in der Kontrollgruppe sowohl für den Unterkiefer $(38,94 \%)$ als auch für den Oberkiefer $(48,88 \%)$ über den Mittelwerten der VG1 (UK: 26,56 \%; OK: 35,08 \%) und der VG2 (UK: 34,98 \%; OK: 43,88 \%). VG2 hat prozentual mehr Kontakt mit der Implantatoberfläche in Unter- und Oberkiefer als VG1. Im Oberkiefer liegen generell mehr Knochen-Kontakte mit der Implantatoberfläche vor als im Unterkiefer (Tab. 25) (Abb. 28). Die Auswertung der Implantat-KnochenKontaktrate über ein gemischtes Modell ergab jedoch weder zwischen den Gruppen KG, VG1 und VG2 ( $\mathrm{p}=0,2938)$ noch bezüglich der Lokalisation der Implantate in Ober- oder Unterkiefer $(\mathrm{p}=0,2359)$ ein signifikantes Ergebnis (Tab. 26).

\subsubsection{Knochendichte in den Gewindegängen}

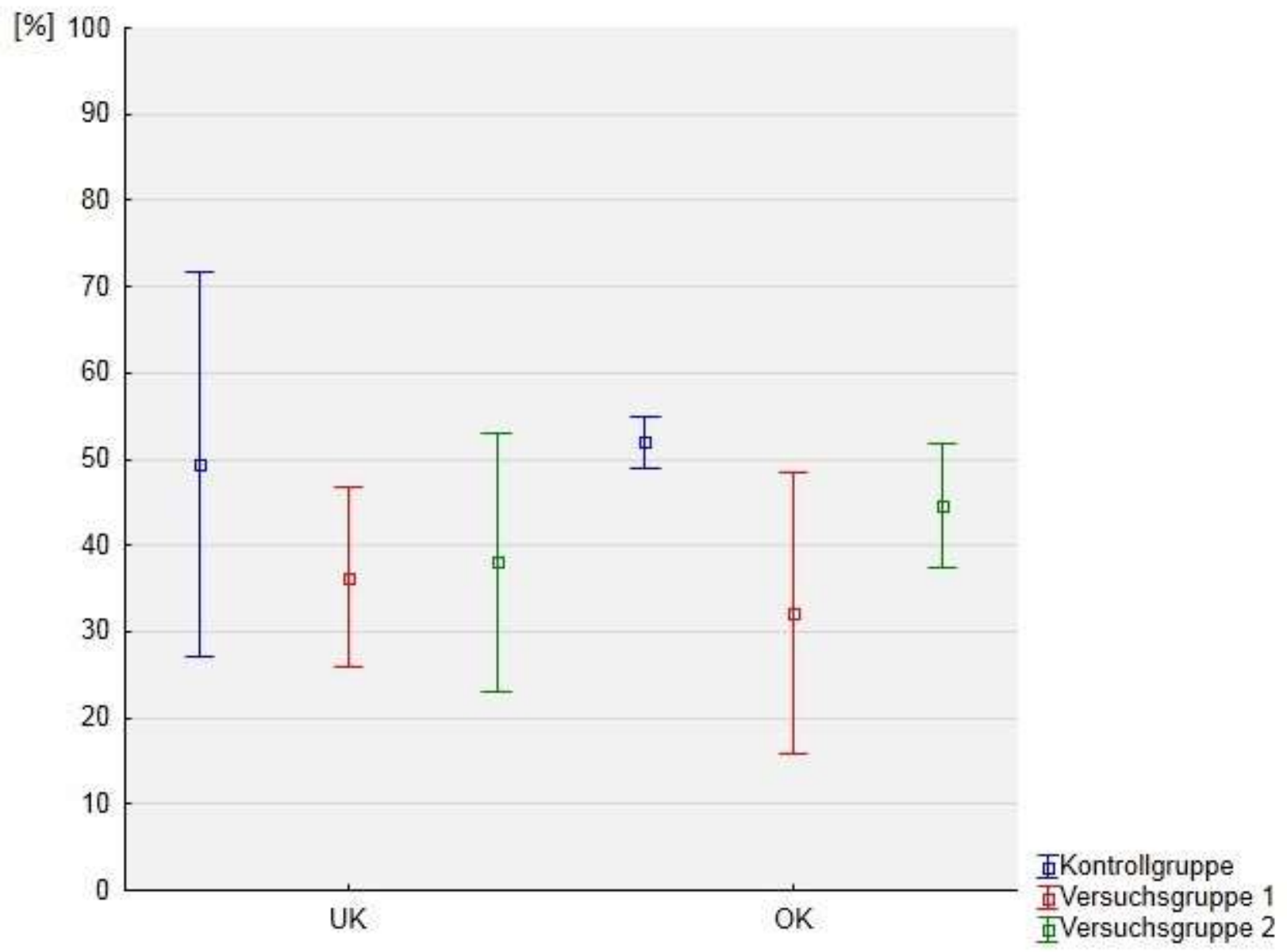

Abb. 29: Knochendichte in den Gewindegängen (\%) 
Tab. 27: Deskriptive Analyse der Knochendichte in den Gewindegängen (\%)

\begin{tabular}{|llrrrrr|}
\hline Lokalisation & Gruppe & Mittelwert & N & Std.Abw. & Min. & Max. \\
\hline Unterkiefer & Kontrollgruppe & 49,37 & 5 & 25,36 & 11,38 & 75,05 \\
Oberkiefer & & 51,99 & 5 & 3,46 & 48,84 & 57,92 \\
\hline Unterkiefer & Versuchsgruppe 1 & 36,31 & 5 & 11,84 & 24,73 & 53,57 \\
Oberkiefer & & 32,18 & 5 & 18,51 & 6,49 & 50,86 \\
\cline { 1 - 2 } Unterkiefer & Versuchsgruppe 2 & 38,06 & 4 & 15,25 & 16,11 & 51,20 \\
Oberkiefer & & 44,61 & 4 & 7,24 & 36,59 & 52,52 \\
\hline Summe & & $\mathbf{2 8}$ & & \\
\hline
\end{tabular}

Tab. 28: Gemischtes Modell der Knochendichte in den Gewindegängen

\begin{tabular}{|l|r|}
\hline Effekt & p-Wert \\
\hline Gruppe (KG/VG1/VG2) & 0,1913 \\
Lokalisation (OK/UK) & 0,7371 \\
Gruppe*Lokalisation & 0,5570 \\
\hline
\end{tabular}

Ein ähnliches Ergebnis wie bei dem gemischten Modell der Implantat-KnochenKontaktrate zeigt sich auch bei der statistischen Auswertung der Knochendichte in den Gewindegängen. Es liegt weder ein signifikanter Gruppeneffekt (KG versus VG1 versus VG2 = ns), noch eine Signifikanz in der Lokalisation $(\mathrm{OK}$ versus UK = ns) vor (Tab. 28). Die Mittelwerte liegen in der Kontrollgruppe für den Unterkiefer $(49,37 \%)$ und für den Oberkiefer (51,99 \%) höher als die Mittelwerte von VG1 (UK: 36,31 \%; OK: 32,18 \%) und VG2 (UK: 38,06 \%; OK: 44,61 \%). VG2 hat prozentual eine höhere Knochendichte in den Gewindegängen als VG1, was hier insbesondere auf den Oberkiefer zutrifft (Abb. 29). Die Ergebnisse für die Lokalisation sind ambivalent (Tab. 27). 


\subsubsection{Periimplantäre Knochendichte}

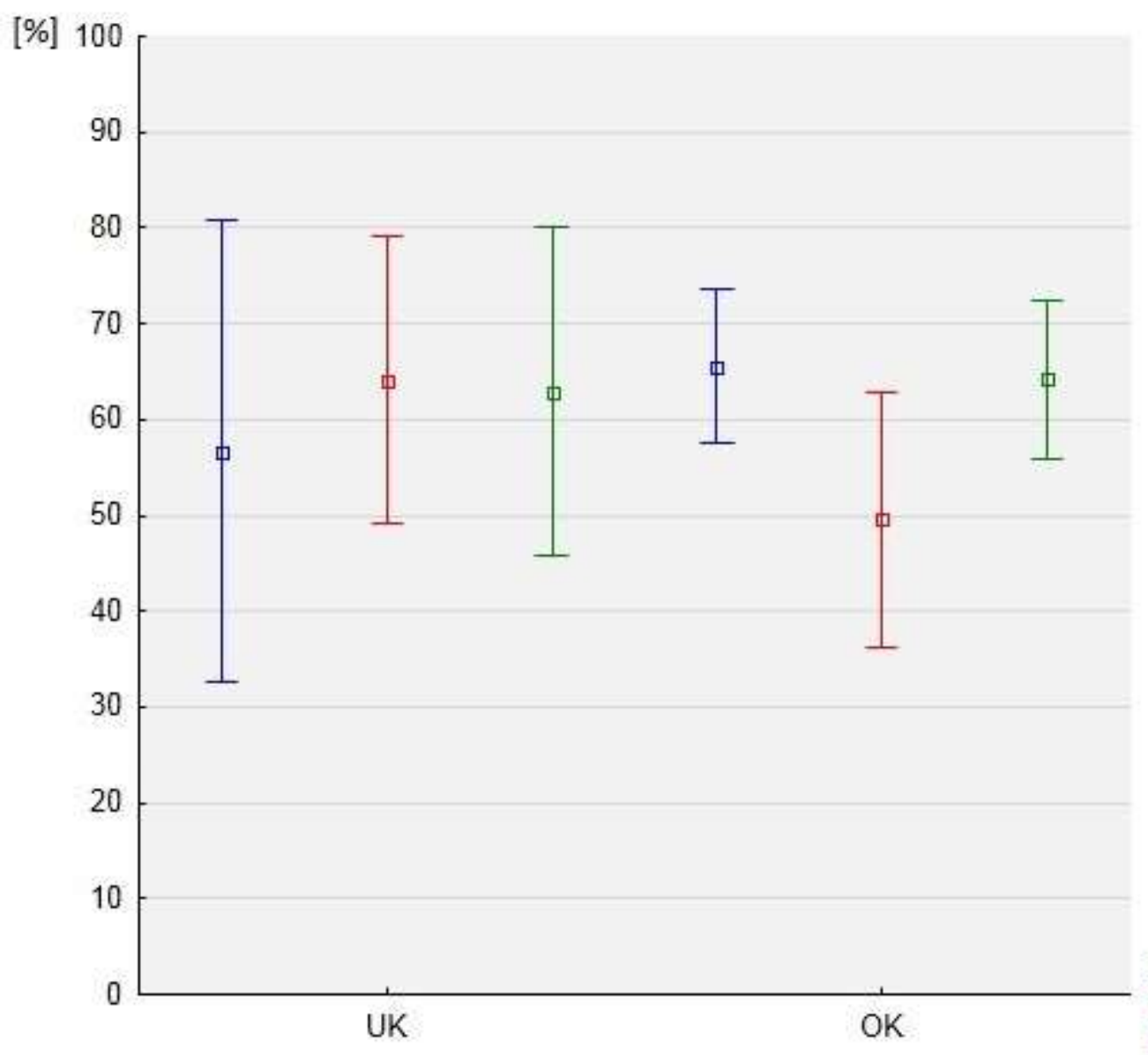

Abb. 30: Periimplantäre Knochendichte (\%)

Tab. 29: Deskriptive Analyse der periimplantären Knochendichte (\%)

\begin{tabular}{|llrrrrr|}
\hline Lokalisation & Gruppe & Mittelwert & N & Std.Abw. & Min. & Max. \\
\cline { 1 - 2 } Unterkiefer & Kontrollgruppe & 56,62 & 5 & 27,49 & 21,45 & 85,06 \\
Oberkiefer & & 65,58 & 5 & 9,26 & 53,61 & 77,10 \\
\cline { 1 - 4 } Unterkiefer & \multirow{2}{*}{ Versuchsgruppe 1 } & 64,10 & 5 & 17,12 & 42,18 & 81,49 \\
Oberkiefer & & 49,55 & 5 & 15,28 & 25,34 & 67,63 \\
\hline Unterkiefer & \multirow{2}{*}{ Versuchsgruppe 2 } & 62,94 & 4 & 17,47 & 41,22 & 83,80 \\
Oberkiefer & & 64,18 & 4 & 8,36 & 55,06 & 72,44 \\
\hline Summe & & $\mathbf{2 8}$ & \\
\hline
\end{tabular}

Tab. 30: Gemischtes Modell der periimplantären Knochendichte

\begin{tabular}{|l|r|}
\hline Effekt & p-Wert \\
\hline Gruppe (KG/VG1/VG2) & 0,7091 \\
Lokalisation (OK/UK) & 0,8035 \\
Gruppe*Lokalisation & 0,2426 \\
\hline
\end{tabular}


Die prozentualen Mittelwerte der periimplantären Knochendichte sind in der Kontrollgruppe für den Unterkiefer niedriger $(56,62 \%)$ als die Mittelwerte der VG1 $(64,10 \%)$ und VG2 $(62,94 \%)$ für den gleichen Kiefer. Für den Oberkiefer sind die Mittelwerte in der Kontrollgruppe $(65,58 \%)$ insbesondere höher als die Oberkiefer-Mittelwerte der VG1 $(49,55 \%)$ und nur leicht höher als die der VG2 (64,18 \%). Ein Vergleich zwischen den Versuchsgruppen zeigt für VG1 im Unterkiefer eine nur leicht höhere Knochendichte als für VG2, im Oberkiefer hat VG1 hingegen eine deutlich geringere Knochendichte in einem Abstand von $1 \mathrm{~mm}$ vom Implantat als VG2 (Tab. 29/Abb. 30).

Das gemischte Modell ergab für die periimplantäre Knochendichte weder zwischen den Gruppen KG, VG1 und VG2 (= ns) noch bezüglich der Lokalisation der Implantate in Ober- oder Unterkiefer (=ns) ein signifikantes Ergebnis (Tab. 30).

Insgesamt zeigen sich in der histomorphometrischen Analyse weder für die ImplantatKnochen-Kontaktrate noch für die Knochendichte in den Gewindegängen oder die periimplantäre Knochendichte signifikante Unterschiede. Dies gilt sowohl für den Gruppenvergleich als auch für den Lokalisationsvergleich. Die Analyse der Implantat-KnochenKontaktrate und der Knochendichte in den Gewindegängen zeigt für den Unter- und Oberkiefer in der Kontrollgruppe mehr Knochenneubildung als in den Versuchsgruppen. Für die periimplantäre Knochendichte trifft dies nur für den Oberkiefer zu. Der Unterkiefer zeigt in der Kontrollgruppe hierbei niedrigere Werte als beide Versuchsgruppen.

\subsection{Ergebnisse der histologischen Analyse}

Nach erfolgter histologischer Analyse wurden die Ergebnisse der beiden Ober- und die der beiden Unterkiefer-Implantate im Folgenden jeweils gemittelt und damit zu einem Implantat je Kiefer zusammengefasst. Hieraus ergibt sich für die histologische Auswertung eine Gesamtzahl von 28 Implantaten (14 Tiere x 2 Implantate). Durch den Tod eines Schweins aus der Versuchsgruppe 2 zu Beginn des Experiments reduziert sich die Gesamtzahl der Versuchstiere auf $n=14$. Die Versuchsgruppen VG1 und VG2 konnten auch in dieser Untersuchung aufgrund der ausreichenden Fallzahl separat betrachtet werden. 


\subsubsection{Anzahl der Osteoklastenlakunen}

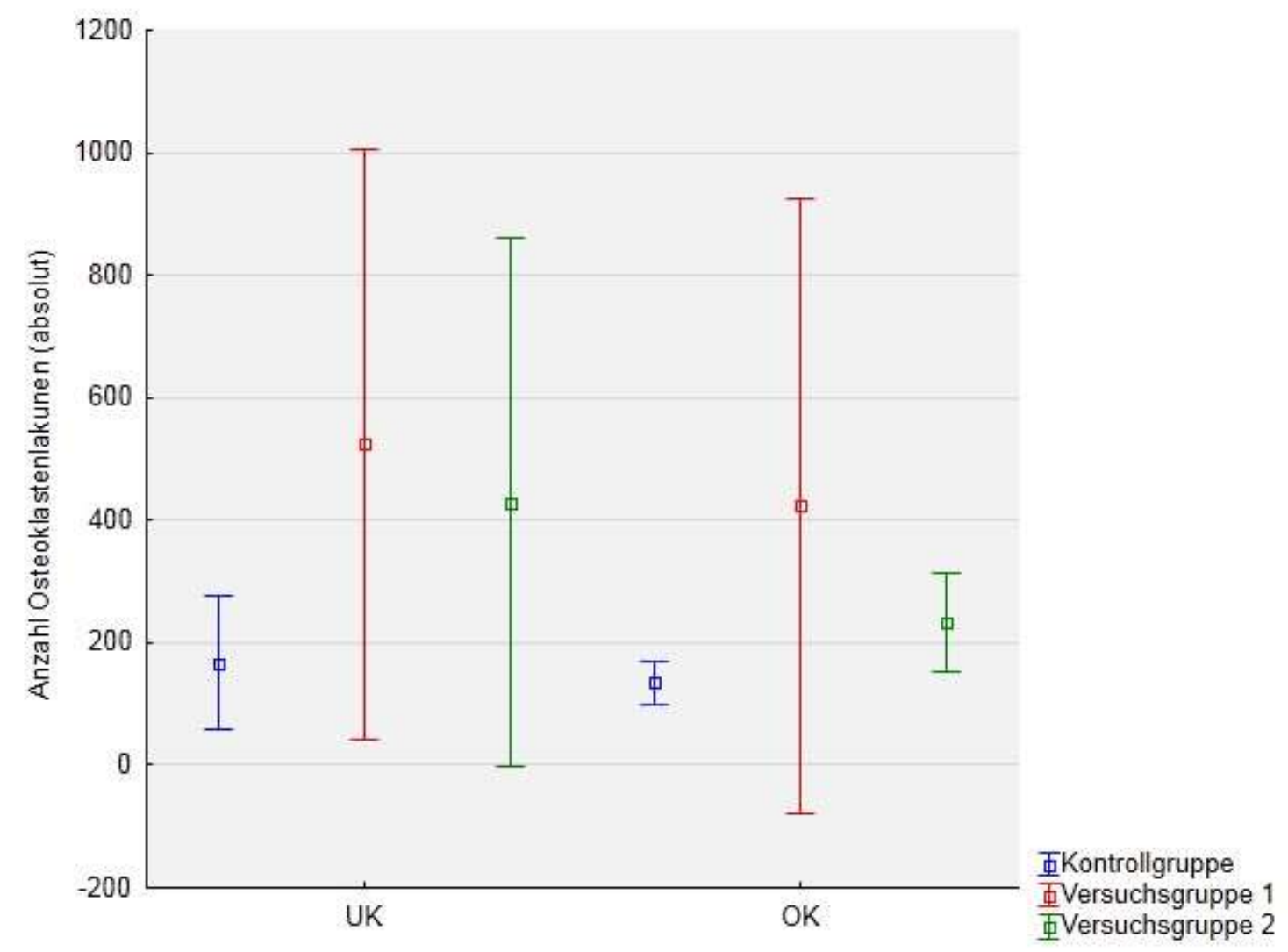

Abb. 31: Anzahl der Osteoklastenlakunen (absolut)

Tab. 31: Deskriptive Analyse der Anzahl der Osteoklastenlakunen (absolut)

\begin{tabular}{|llrrrrr|}
\hline Lokalisation & Gruppe & Mittelwert & N & Std.Abw. & Min. & Max. \\
\hline Unterkiefer & Kontrollgruppe & 167,30 & 5 & 87,63 & 96,50 & 313,00 \\
& Versuchsgruppe 1 & 524,40 & 5 & 387,42 & 96,00 & 918,50 \\
& Versuchsgruppe 2 & 429,00 & 4 & 271,63 & 113,00 & 743,50 \\
\hline Oberkiefer & Kontrollgruppe & 135,60 & 5 & 28,25 & 91,50 & 166,00 \\
& Versuchsgruppe 1 & 423,00 & 5 & 405,36 & 85,00 & 890,50 \\
& Versuchsgruppe 2 & 233,13 & 4 & 50,51 & 180,00 & 299,50 \\
\hline Summe & & $\mathbf{2 8}$ & & \\
\hline
\end{tabular}

Tab. 32: Gemischtes Modell der Anzahl der Osteoklastenlakunen

\begin{tabular}{|l|r|}
\hline Effekt & p-Wert \\
\hline Gruppe (KG/VG1/VG2) & $\mathbf{0 , 0 1 7 0 *}$ \\
Lokalisation (OK/UK) & 0,2796 \\
Gruppe*Lokalisation & 0,5299 \\
\hline
\end{tabular}


Die Mittelwertanalyse repräsentiert in der Kontrollgruppe für beide Kiefer deutlich weniger Osteoklastenlakunen (UK: 167,30; OK: 135,60) als in VG1 (UK: 524,40; OK: 423,00) und VG2 (UK: 429,00; OK: 233,13) (Tab. 31/Abb. 31). Die absolute Anzahl der Osteoklastenlakunen zeigt im gemischten Modell einen statistisch signifikanten Gruppeneffekt zwischen der Kontrollgruppe und den Versuchsgruppen VG1 und VG2 (p = 0,0170) (Tab. 32).

Im Unterkiefer sind in allen Gruppen mehr Osteoklastenlakunen gezählt worden als im Oberkiefer (Tab. 31). Ein statistisch signifikanter Effekt bezüglich der Lokalisation liegt jedoch nicht vor (UK versus $\mathrm{OK}=\mathrm{ns})($ Tab. 32).

Um zu analysieren, zwischen welchen Gruppen der signifikante Unterschied im Einzelnen vorliegt, wurde im Folgenden einmalig ein Gruppenvergleich (KG, VG1, VG2) über eine einfaktorielle ANOVA und ein Kontrasttest durchgeführt. Die Lokalisation (UK/OK) bleiben dabei unberïcksichtigt (Abb. 32/Tab. 33/Tab. 34).

\section{Einfaktorielle Varianzanalyse der Gruppen}

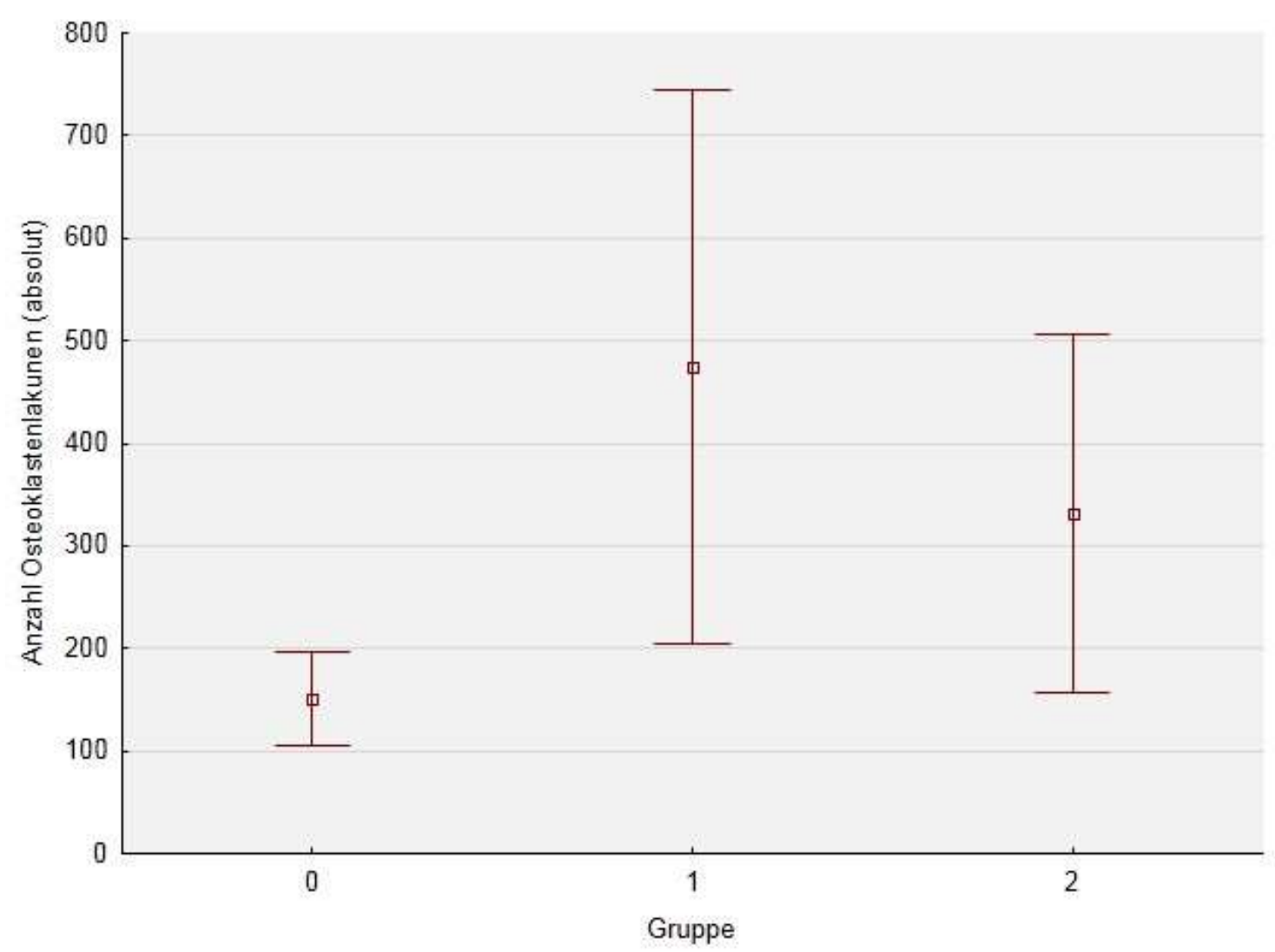

Abb. 32: Anzahl der Osteoklastenlakunen (absolut), Gruppenvergleich 
Tab. 33: Deskriptive Analyse der Anzahl der Osteoklastenlakunen (Gruppenvergleich)

\begin{tabular}{|lrrrrr|}
\hline Gruppe & Mittelwert & N & Std.Abw. & Min. & Max. \\
\hline Kontrollgruppe & 151,45 & 10 & 63,62 & 91,50 & 313,00 \\
Versuchsgruppe 1 & 473,70 & 10 & 377,62 & 85,00 & 918,50 \\
Versuchsgruppe 2 & 331,06 & 8 & 208,99 & 113,00 & 743,50 \\
\hline Summe & $\mathbf{2 8}$ & & & \\
\hline
\end{tabular}

Tab. 34: Gruppenvergleich der Anzahl der Osteoklastenlakunen mittels Kontrasttest

\begin{tabular}{|l|r|}
\hline Effekt & p-Wert \\
\hline KG versus VG1 & $\mathbf{0 , 0 2 7 7 *}$ \\
KG versus VG2 & $\mathbf{0 , 0 2 9 9 *}$ \\
VG1 versus VG2 & 0,3405 \\
\hline
\end{tabular}

Abb. 32 zeigt die deskriptive, einfaktorielle Varianzanalyse der einzelnen Gruppen (KG, VG1, VG2). Der Gruppenvergleich wurde durchgeführt mit einem Kontrasttest (Tab. 34). Die notwendigen Parameter wurden über ein lineares gemischtes Modell geschätzt und die Messwiederholung somit berücksichtigt. Es zeigt sich ein signifikanter Effekt zwischen KG und VG1 ( $p=0,0277)$ und zwischen KG und VG2 ( $p=0,0299)$. Zwischen VG1 und VG2 liegt keine statistische Signifikanz vor (VG1 versus VG2 = ns), jedoch zeigt die deskriptive Analyse mehr Osteoklasten für VG1 als für VG2 (Tab. 33). 


\subsubsection{Anzahl der Osteoblasten}

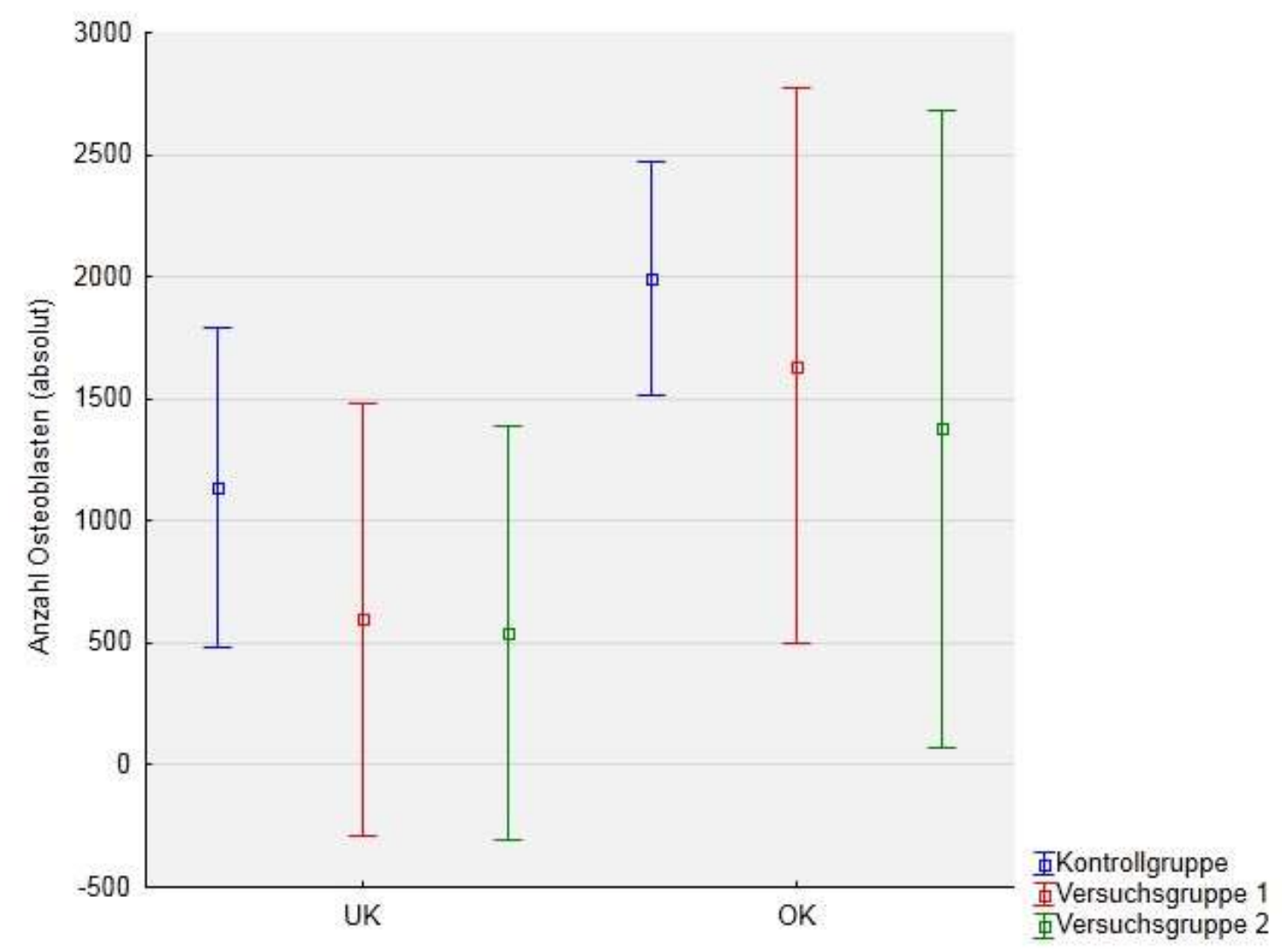

Abb. 33: Anzahl der Osteoblasten (absolut)

Tab. 35: Deskriptive Analyse der Anzahl der Osteoblasten (absolut)

\begin{tabular}{|llrrrrr|}
\hline Lokalisation & Gruppe & Mittelwert & N & Std.Abw. & Min. & Max. \\
\hline Unterkiefer & Kontrollgruppe & 1138,00 & 5 & 529,65 & 585,00 & 1850,00 \\
& Versuchsgruppe 1 & 597,00 & 5 & 711,55 & 0,00 & 1445,00 \\
& Versuchsgruppe 2 & 540,00 & 4 & 534,56 & 50,00 & 1010,00 \\
\hline Oberkiefer & Kontrollgruppe & 1992,00 & 5 & 386,99 & 1620,00 & 2630,00 \\
& Versuchsgruppe 1 & 1634,00 & 5 & 917,06 & 630,00 & 2635,00 \\
& Versuchsgruppe 2 & 1376,25 & 4 & 821,28 & 775,00 & 2575,00 \\
\hline Summe & & $\mathbf{2 8}$ & \\
\hline
\end{tabular}

Tab. 36: Gemischtes Modell der Anzahl der Osteoblasten

\begin{tabular}{|l|r|}
\hline Effekt & p-Wert \\
\hline Gruppe (KG/VG1/VG2) & 0,1067 \\
Lokalisation (OK/UK) & $\mathbf{0 , 0 0 4 7 *}$ \\
Gruppe*Lokalisation & 0,9482 \\
\hline
\end{tabular}


Der Vergleich der Mittelwerte der einzelnen Gruppen zeigt für die Kontrollgruppe sowohl im Unter- als auch im Oberkiefer eine höhere Anzahl an Osteoblasten (UK: 1138,00; OK: 1992,00) als für die Versuchsgruppen VG1 (UK: 597,00; OK: 1634,00) und VG2 (UK: 540,00; OK: 1376,25) (Tab. 35/Abb. 33). Das gemischte Modell der absoluten Anzahl der Osteoblasten ergibt jedoch keinen signifikanten Gruppeneffekt (KG versus VG1 versus VG2 = ns) (Tab. 36). Bezüglich der Lokalisation hingegen ergibt sich eine Signifikanz für den Unter- und Oberkiefer $(\mathrm{p}=0,0047)$. Diese wird auch deutlich bei einem Vergleich der Mittelwerte der Osteoblastenanzahl der einzelnen Gruppen, die insbesondere in den beiden Versuchsgruppen für den Oberkiefer bedeutend höher liegen als für den Unterkiefer (Tab. $35)$.

\section{Einfaktorielle Varianzanalyse der Lokalisation}

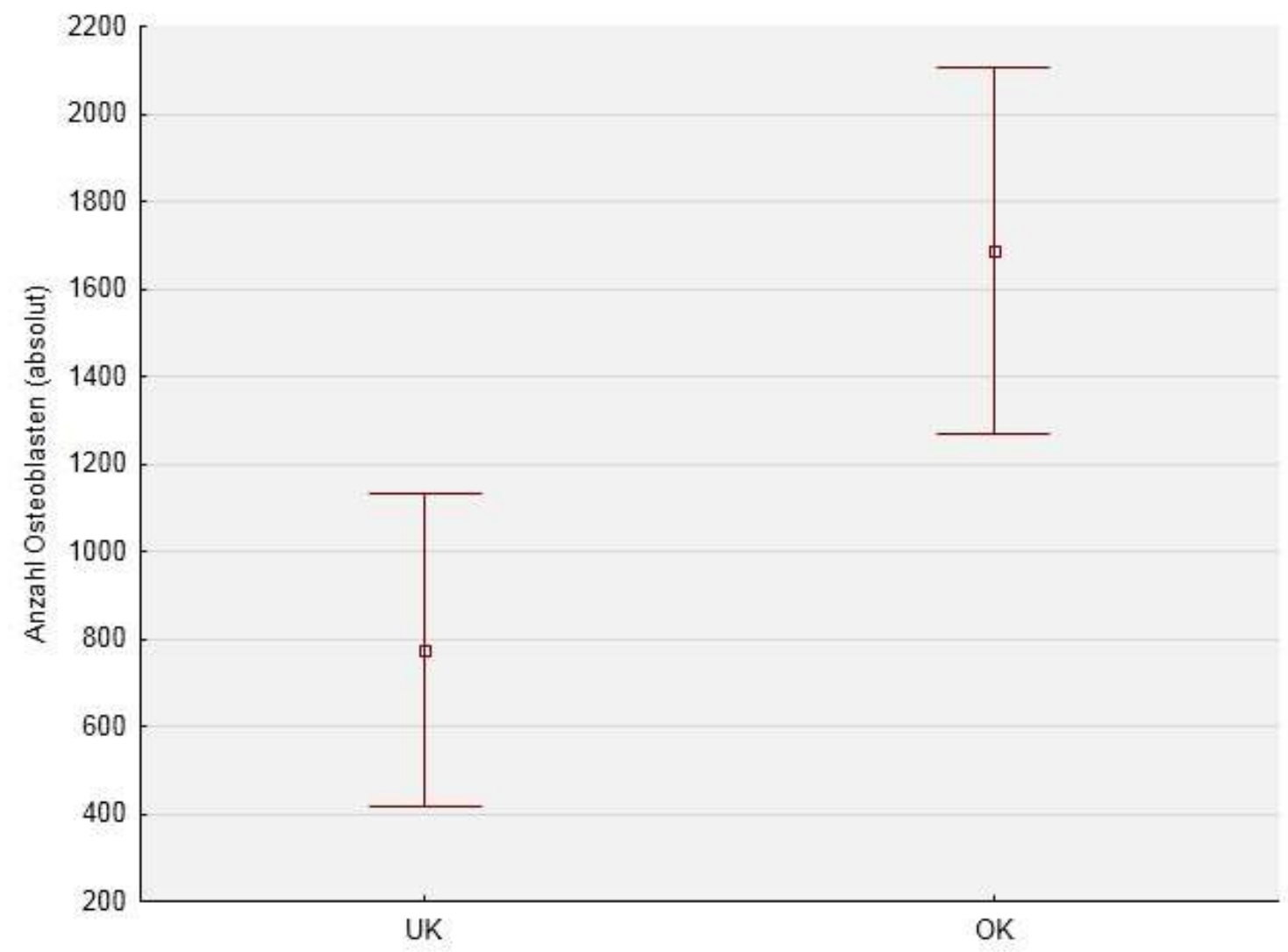

Abb. 34: Anzahl der Osteoklastenlakunen (absolut), Lokalisationsvergleich 
Tab. 37: Deskriptive Analyse der Anzahl der Osteoblasten (absolut), Lokalisationsvergleich

\begin{tabular}{|lrrrrr|}
\hline Lokalisation & Mittelwert & N & Std.Abw. & Min. & Max. \\
\hline Unterkiefer & 773,93 & 14 & 622,82 & 0,00 & 1850,00 \\
Oberkiefer & 1688,21 & 14 & 726,00 & 630,00 & 2635,00 \\
\hline Summe & & $\mathbf{2 8}$ & & & \\
\hline
\end{tabular}

Zur graphischen Verdeutlichung der unter 4.5.2 ermittelten Signifikanz (Tab. 36) wurde an dieser Stelle zusätzlich ein Lokalisationsvergleich über eine einfaktorielle ANOVA durchgeführt. Die einzelnen Gruppen (KG, VG1, VG2) bleiben hierbei unberücksichtigt (Abb. 34). Für den Oberkiefer liegt der Mittelwert der Osteoblastenanzahl signifikant höher $(1688,21)$ als im Unterkiefer $(773,93)$ (Tab. 37). 


\section{DISKUSSION}

Nekrosen der Kiefer (ONJ) sind eine seltene, aber schwerwiegende Nebenwirkung antiresorptiv wirkender Medikamente. Unterschiedlich potente und dosierte Bisphosphonate werden heutzutage bei benignen (z. B. Osteoporose) und malignen (z. B. multiples Myelom; skelettal metastasierende Tumoren) metabolischen Knochenerkrankungen standardmäßig eingesetzt, um die krankheitsbedingt gesteigerte Knochenresorption zu inhibieren und die Knochendichte dadurch zu steigern bzw. aufrechtzuerhalten (Elad et al. 2010). Die Verabreichung von hochpotenten und hochdosierten Bisphosphonaten aufgrund onkologischer Grunderkrankungen geht mit einem deutlich erhöhten Risiko der Entwicklung einer ONJ einher. Es existieren zahlreiche Theorien zur Ätiopathogenese der ONJ und auch über mögliche Risikofaktoren für deren Entwicklung, doch die genaue Ätiologie ist nach wie vor noch nicht vollständig geklärt. Die Therapie einer manifesten ONJ ist schwierig und rezidivanfällig und die Lebensqualität der betroffenen Patienten stark beeinträchtigt (Walter et al. 2016; Pautke et al. 2012).

Dentale Implantationen stellen eine etablierte Methode dar, tegumental abgestützten Zahnersatz zu vermeiden oder zu verbessern, um dadurch die Lebensqualität der Patienten günstig zu beeinflussen (DeBaz et al. 2015). Durch Implantate zur Abstützung des Zahnersatzes findet eine Prävention von Prothesendruckstellen statt und das Risiko der Entwicklung von ONJ kann somit reduziert werden. Gleichzeitig jedoch stellen dentale Implantationen durch den chirurgischen Eingriff, aber auch durch ihre alleinige Existenz als potentieller Triggerfaktor (Jacobsen et al. 2013), ein Risiko für die Entstehung einer ONJ dar.

Es existieren bislang nur wenige Studien, die den Erfolg dentaler Implantationen unter antiresorptiver Therapie in onkologischer Dosierung klinisch untersucht haben. Mehrheitlich wird allerdings dabei von der Entwicklung einer ONJ post implantationem berichtet mit wenigen einzelnen Erfolgen (Giovannacci et al. 2016; Tam et al. 2014; Jacobsen et al. 2013). Explantationen und Sequesterotomien waren oft beobachtete Komplikationen. Implantationen unter antiresorptiver Medikation aufgrund einer benignen Grunderkrankung wie Osteoporose hingegen waren ganz überwiegend erfolgreich (Al-Sabbagh et al. 2015; Mozzati et al. 2015; Famili et al. 2011).

Präklinische Studien können dazu beitragen, den Pathomechanismus der medikamentös induzierten Kiefernekrose zu verstehen und daraus effektive Behandlungsmethoden abzuleiten. In Anlehnung an die Beobachtungen beim Menschen konnte in einer Reihe präklini- 
scher Studien eine erfolgreiche Osseointegration dentaler Implantate unter systemischer niedrigpotenter Bisphosphonat-Medikation (Alendronat) ohne ein Auftreten von ONJähnlichen Läsionen festgestellt werden (Oh et al. 2017; Oh et al. 2015; Abtahi et al. 2013; Kim et al. 2011; Viera-Negrón et al. 2008). Die Auswirkungen systemisch verabreichter hochpotenter und hochdosierter Bisphosphonate auf die Einheilung dentaler Implantate wurden bislang in zwei Studien am Tiermodell untersucht (Kim et al. 2013; Huja et al. 2011).

In der vorliegenden Arbeit wurde zu diesem Zweck das Minipig als Großtiermodell verwendet. Durch seinen dem Menschen ähnlichen Grundumsatz bietet es den Vorteil, ähnliche pharmakologische Dosierungen zu wählen, wie sie auch für die klinische Therapie zum Einsatz kommen, wodurch sich Rückschlüsse auf die Auswirkungen des Medikamentes beim Menschen ziehen lassen (Allen 2015). So erhielten die Minipigs aus den Versuchsgruppen in dieser Arbeit eine Dosierung von $4 \mathrm{mg} / \mathrm{kg} / \mathrm{KG}$ Zoledronat i. v. alle 4 Wochen, was der Bisphosphonat-Medikation bei Patienten mit maligner Grunderkrankung zur Frakturprophylaxe nachempfunden wurde.

Durch die ähnliche Größe und Morphologie ihrer Kiefer ist es beim Großtier (Voss et al. 2016) wie dem Minischwein ebenso möglich, dentale Implantate klinisch relevanter GröBen unter denselben Bedingungen in die Alveolarkämme zu inserieren wie im klinischen Setting. So wurden in dieser Arbeit bei jedem Minipig je Kieferkamm 2 Implantate (Fa. Nobel Biocare, Typ: Brånemark) mit den Maßen 3,75 mm x 11,5 mm in ossifizierte Extraktionsalveolen im Bereich der Prämolaren inseriert und für eine subgingivale Einheilung mit einem Mukoperiostlappen verschlossen.

Zur Analyse der Auswirkungen von antiresorptiven Medikamenten wie Bisphosphonaten in Kombination mit dentochirurgischen Eingriffen wie Zahnextraktionen kamen in letzter Zeit nur selten Großtiere wie Schafe (Voss et al. 2016) und Minipigs (Otto et al. 2017; Pautke et al. 2012) zum Einsatz. Die in Publikationen in diesem Zusammenhang am häufigsten verwendeten Tiermodelle sind Nagetiere, die jedoch aufgrund von starken Unterschieden in ihrer Dentition, in ihrer Knochenmorphologie, der Abwesenheit eines intrakortikalen Knochenremodellings und auch einer nicht übertragbaren pharmakologischen Dosierung der Medikation nur eine recht limitierte Übertragbarkeit auf den Menschen haben (Otto et al. 2017; Voss et al. 2016; Allen et al. 2013). Insbesondere das Minipig erwies sich in diesem Zusammenhang aufgrund der besonderen biologischen Ähnlichkeit seines Knochens zum humanen Knochen, ähnlichen Knochen-Regenerations- und Remodellingpro- 
zessen (Thorwarth et al. 2005; Mosekilde et al. 1987), vergleichbarer Knochenumsatzrate (Glowacki et al. 2004) sowie seiner dem Menschen ähnlichen oralen Mikroflora (Allen 2015) als ein gut geeignetes Tiermodell.

Das Durchschnittsalter der Tiere lag zu Beginn des Experiments bei ca. 5,4 Jahren. Turner gibt an, dass Schweine den Maximalwert ihrer Mineralisationsdichte (peak bone mass/PBM) in einem Alter von 2,5-3 Jahren erreicht haben (Turner 2001). Anhand des Alters der verwendeten Versuchstiere ist folglich davon auszugehen, dass alle Tiere zu Versuchsbeginn ausgewachsen waren und ihr Knochenwachstum abgeschlossen war. So können Wechselwirkungen durch Wachstumsprozesse mit erhöhtem Knochenumsatz ausgeschlossen werden.

\section{Diskussion der Ergebnisse}

Bei der klinischen Analyse der Insertionsorte in dieser Arbeit zeigten sich periimplantäre Gewebedefekte mit der inspektorischen Exposition von Kieferknochen entgegen der Erwartung nicht nur bei Tieren der Versuchsgruppen mit Zoledronat-Medikation, sondern auch bei einigen Tieren der Kontrollgruppe. Mit einer Prävalenz von 40 \% (4 von 10 Tieren der KG) waren diese messbaren Schleimhautdehiszenzen in der Kontrollgruppe in beiden Kiefern seltener vorhanden als bei den Tieren der Versuchsgruppen mit 61,11\% (11 von 18 Tieren beider VG). Entgegen der Ergebnisse von Otto et al. und Pautke et al. haben in der vorliegenden Untersuchung nicht alle mit Zoledronat behandelten Minipigs eine ONJ-ähnliche Läsion im Gebiet der chirurgischen Intervention entwickelt (Otto et al. 2017; Pautke et al. 2012).

Basierend auf der Definition der aktuellen Stellungnahme der AAOMS zu ONJ (Ruggiero et al. 2014) kann die Diagnose einer Bisphosphonat-assoziierten Kiefernekrose bei den vorliegenden Schleimhautdefekten in dieser Arbeit nicht bestätigt werden. Zwar treffen die aktuelle Behandlung mit einem Bisphosphonat und eine fehlende Radiatio im Kieferbereich zu, jedoch kann, bedingt durch den experimentellen Aufbau, keine mehr als 8wöchige Persistenz der klinisch exponierten Kieferknochenareale garantiert werden. Folglich werden die Defekte als „ONJ-ähnliche Defekte“ charakterisiert.

Die Analyse der periimplantären Defekte orientiert sich an der klinischen Stadieneinteilung der ONJ (AAOMS; Ruggiero et al. 2014; Fassio et al. 2017). Der Wert 0 der vorliegenden Auswertung entspricht mit einer intakten Schleimhaut ohne eine Exposition von Knochen und ohne jegliche Anzeichen von Entzündung wie Rötung oder Schwellung dem Stage 0. 
Schmerz als weiteres klassisches Entzündungszeichen und typisch für Stage 0 wurde in dieser Studie nicht ermittelt und blieb aus diesem Grund unberücksichtigt. Bei Zeichen einer Inflammation wie einer erythematösen oder ödematösen Schleimhaut wurde der Wert 1 vergeben. Inspektorisch lag hier bei den Tieren jedoch im Gegensatz zu Stage 2 der AAOMS noch kein Knochen frei. Alle übrigen klinischen Befunde zeichneten sich aus durch einen inspektorisch freiliegenden Knochen (mit oder ohne Entzündungszeichen). Die ermittelten Flächen $\left(\mathrm{mm}^{2}\right)$ dieser Schleimhautdehiszenzen stehen hier als Maß für die Stärke der Ausprägung der Osteonekrose. Extraorale Fistelungen lagen bei keinem der Tiere vor, und ebenso bestanden keine Hinweise auf eine Fraktur oder Ausbreitung der Osteolyse in den Sinus maxillaris oder die UK-Basis (Stage 3).

Diese Häufung höherer Werte bei der Schleimhautbefundung in den Zoledronatgruppen im Vergleich zur unbehandelten Kontrollgruppe lässt eine negative Beeinflussung der Wundheilung post implantationem durch die Bisphosphonat-Medikation vermuten. Gängige Therapieempfehlungen legen bei allen dentoalveolär-chirurgischen Eingriffen unter antiresorptiver Medikation ein atraumatisches operatives Vorgehen und einen primären, dichten Wundverschluss durch Naht nahe. Auch die perioperative Durchführung einer systemischen Antibiotikaprophylaxe ist indiziert.

In Anlehnung an die aktuellen Handlungsempfehlungen fanden auch die Operationen der Minipigs in dieser Arbeit unter systemischer Antibiotikaprophylaxe statt, und auch die Implantationen erfolgten atraumatisch und steril. Post implantationem wurden die Wunden speicheldicht mit einem Mukoperiostlappen vernäht. In den Studien von Kim und Huja wird bei den Implantationen kein plastischer Verschluss erwähnt (Kim et al. 2013; Huja et al. 2011), sodass davon ausgegangen werden muss, dass die Implantate postoperativ möglicherweise offen einheilten und der physiologischen oder pathogen veränderten oralen Mikroflora als Infektionsquelle leichter zugängig waren. Diese könnten am durch das Bisphosphonat in seinem Umsatz reduzierten Alveolarknochen zu subklinischen Entzündungen und Gewebsnekrosen als Trigger einer ONJ beitragen. Auch im klinischen Umfeld treten die meisten ONJ bei Patienten mit Parodontitis oder nach Zahnextraktionen ohne primären dichten Wundverschluss auf (Hoff et al. 2011). Ebenso gibt keine der beiden genannten präklinischen Studien Hinweise auf eine perioperative systemische Verabreichung eines Antibiotikums.

Huja et al. konnten an Hunden unter hochpotenter Bisphosphonat-Gabe nach einer Beobachtungszeit von 8 Wochen keinerlei Anzeichen von Nekrosen feststellen. Die MiniImplantate sind auch in der Zoledronatgruppe gut eingeheilt (Huja et al. 2011). Im Gegen- 
satz zu den Tieren der Kontrollgruppe ohne Medikation entwickelten bei Kim et al. hingegen alle mit Zoledronat behandelten Kaninchen Kiefernekrosen in den OP-Gebieten bei der Auswertung 4-8 Wochen post implantationem (Kim et al. 2013). Auch in dieser Arbeit kam es trotz atraumatischer Operationstechnik, eines speicheldichten Wundverschlusses und einer perioperativen systemischen Antibiotikaprophylaxe bei 61,11\% der Versuchstiere zu der Ausbildung eines ONJ-ähnlichen Defektes im OP-Gebiet mit der Exposition von Kieferknochen. Jedoch war dieser nicht bei allen mit Zoledronat behandelten Tieren vorhanden. In den Untersuchungen am Minipig von Otto (Otto et al. 2017) und Pautke (Pautke et al. 2012) sowie in den Studien an Schafen von Voss (Voss et al. 2016) dagegen haben $100 \%$ der Tiere, die Zoledronat-Infusionen erhielten, post-extractionem eine ONJ entwickelt. In allen drei genannten Studien wurde keine plastische Deckung der Wunden durchgeführt, keine atraumatische Operationstechnik bei den Zahnextraktionen (nur die Verwendung eines Hebels) und keine Verabreichung eines Antibiotikums, wie es in den aktuellen Leitlinien empfohlen wird, um das Risiko, eine ONJ zu entwickeln, zu senken. Nur Allen et al. präsentierten hier andere Ergebnisse (Allen et al. 2013). Post extractionem konnte seine Studiengruppe bei Hunden, die Zoledronat-Infusionen unterzogen wurden, klinisch und histologisch bei den meisten ihrer Tiere (> $80 \%$ ) keinerlei Hinweise auf eine ONJ finden. Allen et al. berichten hierbei von einer präoperativen systemischen Antibiose, einer atraumatischen Operationstechnik sowie einer plastischen Deckung bei ihren Tieren. Auch Huja et al. berichten von einer atraumatischen Extraktionstechnik und der Bildung eines Mukoperiostlappens mit anschließender Naht.

Die Ergebnisse spiegeln die aktuellen Handlungsempfehlungen der Leitlinien zu dentoalveolär-chirurgischen Eingriffen unter antiresorptiver Therapie wider: Das Risiko der Entwicklung einer ONJ kann durch ihre Beachtung nicht ausgeschlossen, aber gesenkt werden. Dies konnte auch in dieser Arbeit gezeigt werden. Zur Applikationsdauer der von der Leitlinie zu Zahnimplantaten empfohlenen systemischen Antibiotika-Prophylaxe bei dentalen Implantationen werden keine Empfehlungen ausgesprochen (Grötz et al. 2016). Ein Hinweis auf die frühere Leitlinie zu Kiefernekrosen (Grötz et al. 2012), welche eine einen Tag prä-OP beginnende und bis zum Abklingen klinischer Zeichen einer Keimbelastung prolongierte Dosierung eines systemischen Antibiotikums empfiehlt, wird jedoch gegeben. Dieser Aspekt sollte in zukünftigen präklinischen Studien zu Implantatinsertionen unter hochpotenter und hochdosierter Antiresorptiva-Verabreichung am Großtiermodell weiter untersucht werden. 
Otto et al. und Voss et al. berichten von multiplen oralen Läsionen bei den mit Zoledronat behandelten Tieren mit der Exposition von nekrotischem Knochen auch in interdentalen Bereichen, in denen keine chirurgische Intervention stattfand. Alle Tiere der Kontrollgruppe ohne Zoledronat-Behandlung zeigten hierbei keine Auffälligkeiten der Mundschleimhaut (Otto et al. 2017; Voss et al. 2016; Voss et al. 2015). Es ist naheliegend, dass die dentoalveolär-chirurgischen Eingriffe der Implantationen in der vorliegenden Arbeit kausal für die Defektentstehung waren, da keines der Tiere vor den Implantationen orale Gewebedefekte aufwies und diese sich nur periimplantär ausbildeten. Dennoch gelten auch lokale orale Infektionen wie Parodontitis als hoher Risikofaktor für die Etablierung einer ONJ, unabhängig von chirurgischen Eingriffen in der Mundhöhle (Walter et al. 2016).

So sollte nach den aktuellen Empfehlungen der Leitlinien (Grötz et al. 2012; Grötz et al. 2016) bei Patienten vor dem Beginn einer antiresorptiven Therapie eine zahnärztliche Gebisssanierung durchgeführt und der Patient in einer optimalen häuslichen und professionell unterstützen Mundhygiene instruiert und motiviert werden. In präklinischen Studien ist dies allerdings nicht umsetzbar und stellt somit neben oralchirurgischen Eingriffen einen zusätzlichen Risikofaktor dar.

In dieser Arbeit traten als Limitation der beobachteten Ergebnisse nicht nur in den Behandlungsgruppen unter Zoledronat-Medikation, sondern in einer geringen Ausprägung auch zum Teil in der Kontrollgruppe ohne Bisphosphonat-Medikation post implantationem Wundheilungsstörungen im OP-Gebiet auf. Ein Zusammenhang von Kiefernekrosen in Folge einer Zoledronatbehandlung kann daher in dieser Untersuchung nicht abschließend gefolgert werden.

Warum es in der vorliegenden Arbeit auch innerhalb der Kontrollgruppe bei einigen Tieren zu einer kompromittierten Wundheilung kam, ist nur schwer erklärbar. Ruehe et al. geben an, dass speziell Minipigs eine exzessive Belastung ihrer Schleimhaut, ihrer Kiefer, Zähne und damit auch intraoralen Wunden durch heftige Kaumuster und das Nagen an ihrem Gehege ausüben, wodurch die Wundheilung nach einem chirurgischen Eingriff möglicherweise kompromittiert ist (Ruehe et al. 2011). Eine Schonung des OP-Gebietes sowie eine Mund- und Wundhygiene ist generell notwendig, um eine regelrechte Wundheilung zu gewährleisten, in präklinischen Studien jedoch nur schwerlich umsetzbar. So berichten Otto et al. von zerkleinerter Kost für die Minipigs zur Schonung des Operationsgebietes post extractionem (Otto et al. 2017), was in dieser Arbeit nicht umgesetzt wurde. Ein hohes Aufkommen intraoraler, pathogener Bakterien, Nahrungsretention sowie eine futtermittel- 
bedingte tägliche Traumatisierung der Wundregionen kann infolgedessen ebenso Auslöser für Heilungsstörungen und Wunddehiszenzen im OP-Gebiet sein, die mit der Bisphosphonat-Medikation eventuell gar nicht assoziiert werden können.

Dies stellt einen wesentlichen Unterschied zwischen Implantationen in präklinischen Studien und im klinischen Alltag dar. Aktuelle Studien, in denen dentale Implantate in die Maxillae und Mandibulae von Schweinen ohne jede Bisphosphonat-Medikation inseriert wurden, verzeichneten keinerlei Hinweise auf eine reduzierte Wundheilung im Bereich der Implantate und ereignislose Einheilungen (Pérez-Albacete Martínez et al. 2016; Friedmann et al. 2014; Hasturk et al. 2014; Lee et al. 2014; Poort et al. 2014). Auffällig bei fast allen diesen Studien ist jedoch, dass die Tiere postchirurgisch über einen gewissen Zeitraum flüssige-weiche Schondiät erhielten und ebenso versucht wurde, ein gewisses Maß an oraler Hygiene nach den operativen Eingriffen zu gewährleisten. Dies inkludierte beispielsweise CHX-Applikationen zur Plaquekontrolle (Pérez-Albacete Martínez et al. 2016; Hasturk et al. 2014) oder sogar mechanische Reinigungen der Mundhöhle mittels Bürste (Hasturk et al. 2014). Lee et al. verabreichen postoperativ eine i. v.-Antibiose, die zusätzlich einer Wundinfektion entgegenwirkt (Lee et al. 2014). In zukünftigen Untersuchungen sollte folglich versucht werden, durch eine Futtermittelumstellung auf eine atraumatische Schonkost sowie Chlorhexidin-Applikationen/Spülungen einer Defektentstehung auch bei den Kontrollgruppen-Tieren entgegenzuwirken.

Die Ergebnisse der vorliegenden präklinischen Studie bestätigen die von Marx et al. berichtete Annahme, dass Osteonekrosen insbesondere im Bereich des Unterkiefers und seltener des Oberkiefers nach Bisphosphonat-Therapie auftreten (Marx et al. 2005). So liegt auch in dieser Arbeit eine Häufung der in den Versuchsgruppen (VG1+VG2) gemessenen Schleimhautdehiszenzen im Unterkiefer $(72,72 \%)$ im Vergleich zum Oberkiefer $(27,27 \%)$ vor.

In Bezug auf den Implantaterfolg lässt sich feststellen, dass in der VG1 zum Zeitpunkt ihrer Euthanasie 4 Wochen nach der Implantation mit $50 \%$ der 10 untersuchten Regionen beider Kiefer weniger Tiere periimplantäre Schleimhautdefekte aufwiesen als in der VG2 8 Wochen nach ihrer Implantation mit $75 \%$ der 8 untersuchten Regionen. Dies unterstützt die Annahme verschiedener Autoren (Rosella et al. 2016; Migliorati et al. 2006; Bamias et al. 2005), dass mit längerer Gesamtdauer der intravenösen Bisphosphonat-Therapie auch die Inzidenz einer ONJ steigt. 
Der Beobachtungszeitraum von 4-8 Wochen nach Implantation in dieser Untersuchung ist relativ kurz, aber ausreichend, um ONJ-ähnliche Gewebeveränderungen in Folge von dentalen Implantationen am Minipig zu beobachten. In ähnlichen präklinischen Studien variieren die Betrachtungszeiträume zwischen 8 Wochen (Otto et al. 2017), 10 Wochen (Pautke et al. 2012), und 16 Wochen (Voss et al. 2016) post operationem, wobei hier wöchentliche klinische intraorale Kontrollen angegeben werden, um jede Form der Abweichung von normaler Wundheilung zu dokumentieren. Auf diese Weise kann die Diagnose einer manifesten ONJ mit ihrer per definitionem mehr als 8-wöchigen Persistenz auch in präklinischen Studien erreicht werden.

Klinische Analysen unterscheiden sich mit einem längeren Zeitraum vom dentoalveolärchirurgischen Ereignis bis zum Auftreten einer ONJ deutlich von den Ergebnissen präklinischer Studien (Giovannacci et al. 2016; Jacobsen et al. 2013). In klinischen Untersuchungen von Jacobsen et al. betrug das Intervall zwischen der Implantation und dem Auftreten der ONJ bei Patienten, die mit Zoledronat aufgrund einer malignen Grunderkrankung behandelt wurden, durchschnittlich 17 Monate. Im Mittel lag die Gesamtzeit der Bisphosphonat-Therapie dieser Patienten bei 38 Monaten bis zum Auftreten der ONJ. Bei den meisten Patienten treten ONJ ohne jeglichen Zusammenhang mit dem Implantatchirurgischen Trauma auf, sondern allein durch die Existenz des Implantates (Giovannacci et al. 2016).

Neben dem primären Mechanismus der Bisphosphonate, einer Hemmung der Osteoklasten und ihrer Vorläuferzellen über einen direkten zellulären Weg (Bartl et al. 2006), rückten auch Osteoblasten als Zielzellen der Bisphosphonate in den Fokus wissenschaftlicher Untersuchungen. Demnach wird die Osteoklastogenese auch indirekt-regulatorisch über die Reduzierung der Genexpression von RANKL und die Steigerung der Expression von OPG, also durch ein erhöhtes Verhältnis von OPG zu RANKL, durch Bisphosphonate gehemmt (Ribeiro et al. 2014; Mercatali et al. 2013; Çankaya et al. 2013; Li et al. 2011). Eine ausgeglichene Bilanz zwischen der Expression von OPG und RANKL durch Osteoblasten stellt einen wesentlichen Faktor für einen physiologischen Knochenstoffwechsel dar (Walsh und Choi 2014). Bisphosphonate inhibieren auf diese direkte und indirekte Weise die pathologische Knochenresorption und steigern dadurch die Knochendichte bzw. halten diese aufrecht (Elad et al. 2010). Daher wurde in dieser Arbeit die OPG-Expression unter Beeinflussung von Zoledronat für unterschiedliche Skelettabschnitte untersucht.

Die im Beckenknochen und im Unterkiefer zum Teil signifikante Reduzierung der OPG- 
Expression in den Versuchsgruppen unterscheidet sich von aktuellen Literaturangaben, welche für die OPG-Expression unter Bisphosphonatbehandlung eine Zunahme angeben: So untersuchten diverse Autoren den Einfluss von Bisphosphonaten auf Zellkulturen aus humanem und selten auch tierischem Knochengewebe (Ribeiro et al. 2014; Çankaya et al. 2013; Sievers 2012; Koch et al. 2012; Pan et al. 2004; Viereck et al. 2002) oder analysierten das OPG-Level im Serum mit Bisphosphonaten behandelter Patienten (Mercatali et al. 2013; Martini et al. 2007; Perifanis et al. 2007; Martini et al. 2006).

Es sind keine präklinischen Studien bekannt, welche die Genexpression von OPG anhand von Knochenproben aus dem Kiefer im Vergleich mit Knochenproben anderer Körperregionen nach einer Behandlung mit intravenösen Bisphosphonaten untersuchten. Der Fokus der vorliegenden Studien liegt im Allgemeinen auf der Analyse der OPG-Expression humaner oder tierischer Osteoblastenkulturen oder der Analyse des Serumlevels von OPG mit Bisphosphonaten behandelter Patienten. In einer Studie (Çankaya et al. 2013) wird an Ratten die Auswirkung einer chronischen Zoledronat-Anwendung auf die Proteinkonzentration von OPG vergleichend für Knochenbiopsien aus Mandibula und Tibia untersucht. Hier war die Proteinkonzentration von OPG unter Zoledronat in der Mandibula und in der Tibia unterschiedlich stark erhöht. Mit ihrem Ergebnis stellten Çankaya et al. wie die vorliegende Arbeit Unterschiede zwischen dem Kieferknochen und dem Knochen einer anderen Körperregion heraus. So konnte in dem vorliegenden Experiment für den Beckenknochen eine signifikante Reduktion der Expression von OPG infolge der ZoledronatInfusionen bei den Versuchsgruppentieren verzeichnet werden, im Unterkieferknochen war diese Reduktion hingegen nicht signifikant und schwächer ausgeprägt. Diese Tatsache lehnt sich an die bereits beschriebenen Theorien zur unterschiedlichen Wirkungsweise von Bisphosphonaten in den Kiefern im Vergleich zu anderen Knochen des Skeletts wie dem Beckenknochen an.

Entgegen den Erwartungen sind in dieser Arbeit ebenso bei den Tieren der Kontrollgruppe ohne Zoledronat-Verabreichung Schwankungen im Verlauf des Experiments in der OPGExpression aufgetreten. Diverse endogene Faktoren wie IL-1, PTH oder PGE2 können zu einer Hemmung der OPG-Expression und damit zu einer Stimulation der Osteoklastogenese führen (Murakami et al. 1998); Estrogene (Hofbauer et al. 1999), TGF- $\beta 1$ (Murakami et al. 1998) oder BMP-2 (Hofbauer et al. 1998) hingegen zu einer Steigerung der OPGExpression. Infolge der Entnahme von Knochenbiopsaten aus Beckenkamm und Unterkiefer wurde damit ein physiologischer Heilungsprozess des Knochengewebes angestoßen, 
welcher aufgrund der Interaktionen verschiedener proinflammatorischer Zytokine, Wachstumsfaktoren und Hormone schließlich zu Veränderungen der OPG-Expression führen kann. So konnten nur wenige Studien, welche die Frakturheilung von Röhrenknochen analysierten, eine mit RANKL korrelierende Steigerung der OPG-Expression in Knochenbiopsaten der Tibiae von Mäusen (Kon et al. 2001) oder des OPG-Levels in humanem Serum (Köttstorfer et al. 2014) nachweisen.

Die Reduktion der OPG-Expression im Beckenknochen bei den Kontrolltieren zwischen der ersten und der zweiten OP könnte verschiedene Gründe haben. So hemmen beispielsweise auch Glukokortikoide die osteoblastäre Expression von OPG (Graefe et al. 2011). Die experimentell bedingte neue Umgebung der Tiere, die Futterumstellung sowie Operation und regelmäßige Blutentnahmen könnten in den ersten Monaten durchaus eine Stresssituation für die Tiere gewesen sein, wodurch es physiologisch zu einer erhöhten Sekretion von Glukokortikoiden aus der Nebennierenrinde kommt. Die allmähliche Gewöhnung der Tiere könnte dann Auslöser für das Zurückkehren der OPG-Expression auf Ausgangsniveau sein. Hier können Begründungen für die leichten Schwankungen der OPG-Expression auch in der Kontrollgruppe liegen, obgleich diese keiner Medikation mit Bisphosphonaten unterzogen wurde. In Folgearbeiten ist es somit ratsam, auch den Kortisolspiegel der Tiere mitzubestimmen.

Die Expressionsabnahme von OPG betrifft allerdings nur die Knochenbiopsate aus dem Beckenkamm. Im Unterkiefer steigt die OPG-Expression in der Kontrollgruppe über die Zeit moderat an. Auch hier scheint der Kieferknochen anders zu reagieren als der Beckenknochen, was sich an die innerhalb der Versuchsgruppen schon berichteten Unterschiede zwischen den beiden Knochen anlehnt. Die mögliche stressbedingte Beeinflussung durch eine endogene Glukokortikoidausschüttung beträfe natürlich in gleicher Weise auch die Versuchstiere, in Folge dessen es neben einer Beeinflussung durch das Bisphosphonat dann zusätzlich zu einer Reduzierung der OPG-Expression kommen würde. Da die Versuchstiere mehrfachen Operationen und Blutentnahmen unterzogen wurden, kann hier sicher grundsätzlich von einem höheren Level inflammatorischer Faktoren ausgegangen werden.

Ähnlich wie beim Beckenknochen und der Unterkiefer-Submentalregion wurde auch im Alveolarkamm des Ober- und Unterkiefers eine Reduktion der OPG-Expression beobachtet. Die Expression war für den Unterkiefer-Alveolarkamm signifikant geringer im zeitlichen Verlauf vom Beginn (OP 1) bis zum Auswertungszeitpunkt (OP 2). Auch für die Alveolarkämme korreliert das Ergebnis einer Reduktion der OPG-Expression für die mit 
Zoledronat behandelten Versuchsgruppentiere nicht mit den mehrheitlichen Literaturangaben einer Steigerung von OPG durch Bisphosphonate (s. o.). Das gleichzeitige Absinken der OPG-Expression innerhalb der Kontrollgruppentiere könnte auch hier durch endogen auf die Osteoblasten einwirkende Faktoren wie beispielsweise Glukokortikoide erklärt werden. Zwischen den Gruppen (KG versus VG) lag kein signifikanter Unterschied vor. Im Gegensatz zum Vergleich der Expression von OPG des Beckenknochens mit dem Unterkieferknochen lag beim Vergleich der Expression von OPG in beiden Kiefern nur knapp keine statistische Signifikanz vor. Dies spiegelt die Theorie verschiedener Autoren wider, dass die Osteoblastenvorläuferzellen der Kiefer und die des Beckenknochens unterschiedlicher embryologischer Herkunft sind und daher unterschiedlich von Bisphosphonaten beeinflusst werden (Rohen und Lütjen-Drecoll 2016; Akintoye et al. 2006; Noden und Trainor 2005).

Das Ergebnis dieser Arbeit, einer Reduktion der OPG-Expression durch Osteoblasten, hat über die dadurch verminderte Antagonisierung von RANKL zur Folge, dass der Knochen nicht vor einer pathologischen Knochenresorption durch Osteoklasten geschützt ist. Damit steht die Wirkung von Zoledronat im Widerspruch zu den Ergebnissen klinischer Anwendungen von Bisphosphonaten. Zukünftige Studien, welche die Beeinflussung von Bisphosphonaten in onkologischer Dosierung auf zentrale Proteine des Knochenstoffwechsels, wie OPG und RANKL, in vivo am Minischwein erörtern, könnten Aufschluss darüber geben, ob die hier ermittelten Ergebnisse für das Tiermodell eines Minischweins normativ sind.

Die Implantat-Knochen-Kontaktrate und die Knochendichte in den Gewindegängen repräsentieren das Maß für die Knochenneubildung, die periimplantäre Knochendichte das Maß für ortsständigen, nicht neugebildeten Knochen nach den Implantationen.

Insgesamt liegen nur wenige experimentelle Studien vor, welche die Einheilung von Implantaten unter systemischer Bisphosphonat-Therapie erörtern. Ganz überwiegend werden zudem in In-vivo-Studien unter systemischer Zoledronatgabe nicht die Kieferknochen zur Implantation ausgewählt, sondern andere Regionen des Skeletts. Hierbei wird für die Zoledronatgruppen mehrheitlich von einer gesteigerten periimplantären Knochendichte im Vergleich zur unbehandelten Kontrollgruppe berichtet (Dikicier et al. 2014; Y1ld1z et al. 2010).

Huja et al und Kim et al. publizierten die Ergebnisse dentaler Implantationen unter hochpotenter und hochdosierter Bisphosphonat-Verabreichung (Zoledronat) an verschiedenen 
Tiermodellen (Kim et al. 2013; Huja et al. 2011): Huja et al. analysierten die Osseointegration kieferorthopädischer Mini-Implantate $(2 \times 6 \mathrm{~mm})$, die in die Interradikulärregion bestehender Molaren und Prämolaren der Ober- und Unterkiefer von Hunden inseriert wurden. Nach einer Beobachtungszeit von 8 Wochen berichten sie hierbei von keinerlei Nekrosen-Anzeichen in Versuchs- oder Kontrollgruppe. Die Implantate waren auch in der Zoledronatgruppe gut eingeheilt, wenngleich auch mit einem reduzierten Knochenremodelling in den Implantations- und Extraktionsbereichen. Es ist zu bedenken, dass die gewählten Mini-Implantate eine maschinierte Oberfläche besitzen. Dentale Implantate zur Aufnahme prothetischer Konstruktionen, wie sie in dieser Arbeit verwendet wurden, besitzen typischerweise angeraute Oberflächen, um die Osseointegration zu begünstigen. Huja et al. berichten nicht von einer plastischen Deckung im Bereich der Implantation, sodass von einer transgingivalen Einheilung ausgegangen werden muss. In der vorliegenden Arbeit heilten die Implantate subgingival ein.

Kim et al. inserierten gewindelose Mini-Schrauben (Durchmesser: 1,5 mm) als Sofortimplantate in die Extraktionsalveolen von Prämolaren bei Kaninchen. Sie konnten 4-8 Wochen postoperativ im Bereich der Implantate bei allen mit Zoledronat behandelten Tieren Kiefernekrosen feststellen. Die Analyse der Implantat-Knochen-Kontaktrate zeigte hier zwar eine gute initiale Stabilität der Implantate bei allen Tieren nach 4 Wochen mit ähnlichen Werten der Knochenkontaktrate in beiden Gruppen, in der 8. Woche dann aber nur noch eine Steigerung der Implantat-Knochen-Kontaktrate in der Kontrollgruppe im Gegensatz zu einer Verminderung dieser bei den mit Zoledronat behandelten Tieren.

Zwar präsentieren beide Studien unterschiedliche Ergebnisse hinsichtlich der Entstehung von Kiefernekrosen im Bereich der inserierten Implantate, jedoch wird in beiden Studien von einer reduzierten periimplantären Knochenneubildung nach 8 Wochen bei den mit Zoledronat behandelten Tieren im Vergleich zu den Kontrollgruppentieren berichtet, was auf eine verminderte Osseointegration der Implantate in beiden Publikationen schließen lässt. Das Ergebnis der vorliegenden Arbeit mit einer reduzierten Implantat-KnochenKontaktrate und Knochendichte in den Gewindegängen für Unter- und Oberkiefer in beiden Versuchsgruppen unter Zoledronat-Einfluss bestätigt folglich die Studienergebnisse und spiegelt die bisweilen für Zoledronat bekannte, äußerst potente Suppression des Knochenremodellings wider.

Bei Kim et al. waren allerdings nach 4 Wochen noch keine Unterschiede zwischen den Gruppen erkennbar, sondern erst nach 8 Wochen. In der vorliegenden Arbeit konnte hinge- 
gen sowohl für die frühe Osseointegration (VG 1; 4 Wochen postoperativ) als auch für die späte Osseointegration (VG 2; 8 Wochen postoperativ) eine reduzierte Implantat-KnochenKontaktrate und Knochendichte in den Gewindegängen analysiert werden.

Die im vorliegenden Experiment gewählte Zoledronat-Dosierung von $4 \mathrm{mg}$ der Minipigs i. v. alle 4 Wochen basiert auf der Dosierung und Applikationsfrequenz des Medikaments bei Patienten mit maligner Grunderkrankung. Eine weitaus höhere Dosierung als diese verwendeten dagegen Kim et al., die Kaninchen $0.1 \mathrm{mg} / \mathrm{kg} / \mathrm{KG}$ Zoledronat alle 2 Wochen intravenös verabreichten, und auch Huja et al., die Hunden monatlich $0.1 \mathrm{mg} / \mathrm{kg} / \mathrm{KG}$ Zoledronat verabreichten. Auch die verabreichte Gesamtdosis des Bisphosphonats vor den Implantationen unterscheidet sich in den präklinischen Studien voneinander. So wurde in dieser Arbeit wie auch bei Huja et al. mit der Medikation 4 Monate vor Implantation begonnen, sodass die Tiere 4 monatliche Dosen Zoledronat erhielten. Kim et al. verabreichten 4-8 Wochen vor OP alle 2 Wochen Zoledronat, sodass sie auf 2-4 Gesamtdosen vor den Implantationen kamen.

Auch andere Großtierstudien verwenden in Bezug auf dental-chirurgische Eingriffe wie Extraktionen unter Zoledronat-Therapie zumeist sehr viel höhere Dosierungen als allgemein üblich in der Onkologie am Patienten: Otto et al und Pautke et al. verabreichen Minipigs $0.05 \mathrm{mg} / \mathrm{kg}$ wöchentlich Zoledronat (Otto et al. 2017; Pautke et al. 2012), Voss et al. injizieren Schafen alle 3 Wochen $0.075 \mathrm{mg} / \mathrm{kg}$ des Medikaments (Voss et al. 2016). Auch die Gesamtdauer der Bisphosphonatgabe bis zur Extraktion schwankt bei den drei Großtierstudien zwischen 5 und 12 Gesamtdosen.

Für die Risikobewertung dentaler Implantationen unter antiresorptiver Therapie hinsichtlich einer ONJ spielen die Art des Bisphosphonats, die Dosis und Applikationsfrequenz sowie die Gesamtdauer der Verabreichung eine wichtige Rolle (Grötz et al. 2016). Zwar wurde in den aufgeführten Studien zu dentalen Implantationen am Tier mit der Verabreichung von Zoledronat schon ein hochpotentes Bisphosphonat ausgewählt, doch unterscheiden sich die Studiendesigns in Dosierung, Applikationsfrequenz und Gesamtdauer bis zum chirurgischen Eingriff der Implantation oft voneinander. So sind in präklinischen Studien die Dosierungen oft viel höher angesetzt, als bei onkologischer Grunderkrankung klinisch verabreicht. Für eine Übertragbarkeit präklinischer Studienergebnisse auf den Menschen ist es sinnvoll, Tiere mit einem ähnlichen Stoffwechsel und Körpergewicht wie erwachsene Patienten sowie eine klinisch real eingesetzte Dosierung und Applikationsfrequenz des Bisphosphonats für weitere Studien zu wählen, um weitere Klarheit über die 
Auswirkungen hochpotenter Bisphosphonate wie Zoledronat auf Heilungsvorgänge um dentale Implantate zu gewinnen. Dies ist in der vorliegenden Arbeit umgesetzt worden.

Relevant ist sicherlich auch, in welcher zeitlichen Abfolge Extraktion und Implantation zueinander stehen. In dieser Arbeit wurde der Ossifikation der Extraktionsalveolen eine Heilungszeit von 3 Monaten gegeben, bevor mit der Medikation begonnen wurde, und insgesamt knapp 7 Monate, bevor die Implantationen erfolgten. Dieses Vorgehen entsprach der Durchführung von Spätimplantationen bei Menschen. Bei einer Sofortimplantation, wie sie bei Kim et al. erfolgte (Kim et al. 2013), kommt zusätzlich zum Gewebetrauma der Implantation die Zahnextraktion als weiterer Risikofaktor hinzu. Gerade dieses Vorgehen sollte jedoch unter antiresorptiver Therapie vermieden werden (Grötz et al. 2016). So entwickelten beispielsweise alle Kaninchen in der Untersuchung von Kim et al. nach Sofortimplantationen ohne Augmentationen ONJ-ähnliche Defekte im Bereich der Implantate, wobei hier unklar bleibt, ob die Extraktion oder die Implantation ursächlich für die Nekrosen sind. Die Kombination von potentiellen Risikofaktoren der ONJ sollte ausgeschlossen werden (Kim et al. 2013).

Der primäre Mechanismus von (Amino-) Bisphosphonaten, die Knochenresorption zu inhibieren, liegt überwiegend auf zellulärer Ebene in einer direkten Hemmung der Bildung von Osteoklasten aus ihren Vorläuferzellen im Knochenmark und ihrer Adhäsion an die Knochenoberflächen, einer Inaktivierung aktiver Osteoklasten sowie einer Reduzierung ihrer Lebensdauer über den programmierten Zelltod (Bartl et al. 2006), wodurch die Anzahl der Osteoklasten und damit der osteoklastären Knochenresorption insgesamt abnimmt (Badros et al. 2006; Licata 2005). Zusätzlich wird in vielen Publikationen ein erhöhtes Verhältnis von OPG zu RANKL über eine Reduzierung der osteoblastären Genexpression von RANKL und eine Steigerung der Expression von OPG durch Bisphosphonate angegeben, was indirekt-regulatorisch zu einer maßgeblichen Einschränkung der Osteoklastogenese führt (Ribeiro et al. 2014; Çankaya et al. 2013; Mercatali et al. 2013; Li et al. 2011). Dies müsste zu einer Reduktion der Osteoklasten auf der Knochenoberfläche führen (Plotkin et al. 2006).

Mit einer signifikanten Steigerung der Osteoklastenanzahl als Marker für eine gesteigerte periimplantären Knochenresorption in den Versuchsgruppen unter dem Einfluss von Zoledronat kam diese Arbeit zu einem gegenteiligen Ergebnis. Innerhalb der Versuchsgruppentiere konnten viele irregulär geformte Knochenoberflächen in Form von HowshipLakunen um die Implantate gefunden werden, die oft leer waren, aber zum Teil auch Zo- 
nen mit einigen mehrkernigen Osteoklasten als mögliches Indiz für aktive Knochenresorption vorwiesen.

Zu dem gleichen Ergebnis kamen auch Otto et al. in ihrer Studie mit Zoledronat behandelter Minipigs, deren histologische Präparate ähnlich aussahen: Sie beschreiben bei den mit Zoledronat behandelten Tieren eine hohe Anzahl Osteoklasten gleich einer „Überaktivierung" in bestimmten Bereichen, in denen auch eine ONJ vorlag sowie ebenso viele leere Resorptionslakunen (Otto et al. 2017). Nagata et al. beschreiben in ihrer Untersuchung an Ratten eine signifikante Steigerung der Osteoklastenanzahl bei den mit Zoledronat behandelten Tieren post extractionem. Zusätzlich präsentierten sich hierbei morphologische Veränderungen vieler Osteoklasten mit starken Größenzunahmen der Zellen, einer atypischen Zunahme von Zellkernen und oftmals einer fehlenden Haftung auf der Knochenoberfläche (Nagata et al. 2017). Bi et al. verzeichneten in ihrer Untersuchung an Mäusen nach einer hochdosierten Behandlung mit Zoledronat über insgesamt 15 Wochen ebenso einen Anstieg der Osteoklasten in Knochenbiopsien der Oberkiefer, auch zum Teil mit Veränderungen der Zellmorphologie. Dass auch die Dauer der Bisphosphonatgabe Einfluss auf die absoluten Zellzahlen hat, konnten Bi et al. ebenso nachweisen: Nach einer Langzeitgabe von Zoledronat kam es zu einer Steigerung der Osteoklastenanzahl, nach einer kurzen hochdosierten Gabe Zoledronat von 1 Woche post extractionem jedoch kam es zu einer Reduktion der Osteoklasten (und -blasten) im Bereich der Extraktionsalveolen, was auf die Zoledronat-induzierte Suppression der Angiogenese hinweisen könnte (Bi et al. 2010).

Auch unter niedrigpotenterer Alendronat-Therapie konnten Weinstein et al. eine dosisabhängige Steigerung der Osteoklastenanzahl in Beckenkammbiopsien von osteoporotischen Patienten, morphologische Veränderungen und eine reduzierte Funktion der Zellen im Vergleich zu unbehandelten Patienten feststellen (Weinstein et al. 2009). Jobke et al. hingegen berichten von keiner Veränderung der Osteoklastenanzahl in Beckenkammbiopsien von Patienten unter Alendronat-Therapie, weisen jedoch ebenso teilweise auf morphologische Veränderungen der Zellen hin (Jobke et al. 2014).

Da in der vorliegenden Arbeit zeitgleich eine Reduktion der OPG-Expression beobachtet wurde, bleibt die RANK/RANKL-Interaktion ungestört. Folglich tritt ein Anstieg der Osteoklastogenese und eine Aktivierung der Osteoklasten ein. Die scheinbar wider Erwarten erhöhte Osteoklastenanzahl und das Absinken der OPG-Expression in den Versuchsgruppen sind daher plausibel verknüpft. 
Die in vielen Publikationen beobachtete Steigerung der Osteoklastenanzahl unter dem Einfluss verschiedener Bisphosphonate würde mit einer gesteigerten Knochenresorption einhergehen und der genutzten Wirkungsweise der Medikamentengruppe mit einer Stabilisierung des Knochengewebes widersprechen. Viele Publikationen weisen zusätzlich hin auf morphologische Veränderungen der Osteoklasten wie atypische Zellvergrößerungen, atypische Vielzahl an Zellkernen und fehlende Haftung auf der Knochenoberfläche infolge von Bisphosphonaten (Nagata et al. 2017; Jobke et al. 2014; Bi et al. 2010; Weinstein et al. 2009). Da die Reduktion des Knochenremodellings durch Bisphosphonate sowohl über eine Veränderung der Quantität der Osteoklasten als auch durch eine Modifikation des Funktionszustandes der Zellen eintreten kann, sollte in zukünftigen Arbeiten auch die Funktion der Zellen analysiert werden. Hierzu müssten andere histochemische Färbungen (z. B. TRAP-Färbung, über die ein spezifisches Enzym aktiver Osteoklasten nachgewiesen werden kann) und höhere mikroskopische Vergrößerungen eingesetzt werden (vergl. Weinstein et al. 2009).

In der vorliegenden Arbeit kam es periimplantär bei den Versuchsgruppentieren zu einer Reduktion der Osteoblastenanzahl im Vergleich zu den Tieren der Kontrollgruppe. Dies korreliert mit den histomorphometrischen Ergebnissen dieser Arbeit, die eine Reduktion der Implantat-Knochen-Kontaktrate und Knochendichte in den Gewindegängen für Unterund Oberkiefer bei den Versuchsgruppentieren unter Zoledronat-Einfluss im Vergleich zu den Kontrollgruppentieren zeigten. Insgesamt spiegelt sich hier die Beeinträchtigung der Knochenneubildung durch den Einfluss von Bisphosphonaten wider.

Dieses Ergebnis lehnt sich an einige aktuelle präklinische Studien an. So konnten Otto et al. kaum Osteoblasten als Marker für Knochenneubildung in ihren histologischen Präparaten von Minipigs unter dem Einfluss von Zoledronat finden (Otto et al. 2017). Auch Ubellacker et al. und Haider et al. kommen in ihren Experimenten an Mäusen nach einmaliger Zoledronatinjektion zu demselben Ergebnis einer zum Teil signifikanten OsteoblastenReduktion auf den untersuchten Knochenoberflächen von Tibia und Femur im Vergleich zur unbehandelten Kontrollgruppe nach einem kurzen Beobachtungszeitraum von bis zu 5 Tagen. Auch konnten beide eine signifikante Reduktion der Osteoblasten-Aktivität feststellen (Ubellacker et al. 2017; Haider et al. 2014).

Über eine Reduktion der Osteoblastenanzahl und eine Steigerung der Osteoklastenanzahl, wie sie in dieser Arbeit festgestellt werden konnte, kann der klinische Effekt von Bisphosphonaten, die Knochenresorption zu inhibieren und die Knochenmasse dadurch zu stabili- 
sieren und damit das Frakturrisiko zu senken, nicht allein erklärt werden. Die Literaturergebnisse machen vielmehr deutlich, dass in Bezug auf Osteoklasten und Osteoblasten als den Knochenstoffwechsel wesentlich modulierende Zellen nicht nur quantitative, sondern auch qualitative Untersuchungen in Zukunft sinnvoll erscheinen, da beide Parameter starke Auswirkungen auf den Knochenstoffwechsel haben. Durch welche Mechanismen und beteiligten Zellen es zu der klinisch feststellbaren Reduktion der Knochenresorption kommt, sollte durch weitere präklinische (In-vivo-) Studien analysiert werden.

Die Anzahl der betrachteten Organismen in dieser Pilotstudie ist auf 15 Versuchstiere beschränkt, mit n = 5 Tieren je untersuchter Gruppe.

Trotz dieser Limitation bietet diese Untersuchung Hinweise auf methodische Erweiterungen oder zu erhebende Messparameter. In Bezug auf die ONJ-ähnlichen Läsionen sollten in Anlehnung an die Studien von Otto et al und Pautke et al. wöchentliche Kontrollen der Mundschleimhaut der Versuchstiere stattfinden, um Hinweise auf den Zeitpunkt der Erstmanifestation einer ONJ-ähnlichen Läsion zu erhalten (Otto et al. 2017; Pautke et al. 2012). Erst nach einer Persistenz dieser Läsionen von $>8$ Wochen ist gemäß der Stellungnahme der AAOMS (Ruggiero et al. 2014) schließlich die Diagnose einer ONJ zu stellen. Dafür ist auch eine hinreichende Ausdehnung der Studiendauer über den Zeitpunkt des dentoalveolär-chirurgischen Eingriffs hinaus notwendig. Im Gegensatz zu den Studienergebnissen von Patientenuntersuchungen, in denen es mehrheitlich erst nach etlichen Monaten bis Jahren zu dem Auftreten einer ONJ nach Implantationen kam (Giovannacci et al. 2016; Jacobsen et al. 2013), zeigen präklinische Studien hier ein sehr viel früheres Auftreten nach wenigen Wochen (Kim et al. 2013). Auch post-extractionem konnten schon nach wenigen Wochen bei den Großtierstudien von Otto et al., Pautke et al. und Voss et al. ONJähnliche Läsionen festgestellt werden (Otto et al. 2017; Voss et al. 2016; Pautke et al. 2012).

Für ein Staging der Läsionen sind spezifische histopathologische Untersuchungen notwendig. Auch radiologische Untersuchungen, um Anzeichen von Osteosklerosen oder im fortgeschrittenen Stadium auch Frakturen feststellen zu können, sind eine mögliche Ergänzung, um ein klinisch anerkanntes Staging der Läsionen durchführen und damit eine verbesserte Vergleichbarkeit der Ergebnisse herzustellen. In dieser Arbeit wurden Defektgrößen inspektorisch freiliegender Knochenareale vermessen, was im Staging der AAOMS keine Berücksichtigung findet. 
Es konnte ebenso herausgearbeitet werden, dass eine Untersuchung der Funktion der Osteoklasten und Osteoblasten nebst einer quantitativen Analyse eine sinnvolle Ergänzung der Untersuchung ist.

Um externe Beeinflussungen der Versuchsergebnisse möglichst gering zu halten, wurden alle Tiere derselben Behandlung wie Operationstechnik oder Futtermittelzusammensetzung unterzogen. Der einzige Unterschied zwischen der Kontrollgruppe und den Versuchsgruppen lag in der intravenösen Verabreichung des Bisphosphonats bei den Versuchstieren, die bei den Kontrolltieren ausblieb. Die Operationen der Tiere wurden stets vom selben Operateur und Veterinärmediziner durchgeführt, um beeinflussende Faktoren wie z. B. unterschiedliche Operationsabläufe und -techniken auf die Studienergebnisse möglichst zu minimieren. Des Weiteren kamen alle Tiere aus demselben Zuchtbetrieb, sodass schon vor dem Versuch eine einheitliche Aufzucht der Tiere erfolgte.

Die Real-Time PCR stellt eine technisch ausgefeilte Methode zur zuverlässigen und exakten Quantifizierung spezifischer mRNA dar (Pfaffl 2004). In der vorliegenden Arbeit wurde die relative Quantifizierung angewendet, bei der die Transkriptmengen eines Zielgens auf die eines Referenzgens (housekeeping gene) bezogen werden (Pfaffl 2004). In dieser Arbeit handelte es sich dabei um TBP, auf welches die Expressionsergebnisse der zu untersuchenden Proben normalisiert wurden. Dies ist ein zentraler und kritischer Schritt bei der qRT-PCR, um methodische Störfaktoren wie z. B. Variationen in der Ausgangsmenge der eingesetzten RNA, Unterschiede in der RNA-Gewinnung, Fehler bei der reversen Transkription oder Gewebe- und Matrixeffekte, die das Zielgen wie auch das Haushaltsgen gleichermaßen betreffen, zu reduzieren (Pfaffl 2004). Wichtig ist dabei, dass Referenz- und Zielgen der gleichen Probe ausgesetzt werden. Es werden folglich auch keine absoluten Mengen einer mRNA eines bestimmten Proteins bestimmt, sondern die mRNA-Expression verschiedener Proben (hier: unterschiedliche OP-Zeitpunkte, mit und ohne Medikation) hinsichtlich quantitativer Unterschiede miteinander verglichen. Dem Referenzgen kommt also eine besondere Bedeutung bei der qRT-PCR zu, und eine hohe Expressionsstabilität und ein hohes Expressionslevel in dem ausgewählten Tiermodell müssen gewährleistet sein. Nygard et al. beschreiben u. a. TBP als geeignetes Referenzgen für niedrige Transkriptmengen in Expressionsstudien unterschiedlicher Gewebetypen des Schweins (Nygard et al. 2007). Alternativ dazu kann ebenso HPRT1 (zentrale Rolle bei der Elongation während der Transkription) verwendet werden. Die vielfach bei der qRT-PCR als Referenzgen 
Verwendung findende GAPDH (Glycerinaldehyd-3-phosphat-Dehydrogenase) zeigte bei Nygard et al. eine Gewebe-spezifische Regulation (Muskel) beim Schwein und wurde deshalb in dieser Arbeit nicht verwendet.

Zur Isolation der RNA aus den gewonnenen Knochenbiopsaten waren jedoch aufgrund der Menge der Proben unterschiedliche RNeasy® Lipid Tissue Mini Kits (Qiagen, Hilden) erforderlich.

Die qualitative RNA-Analytik mittels Nano- oder Pico-Chip im Agilent 2100 Bioanalyzer erfolgte für jede Probe. Hier zeigten sich unterschiedliche RIN-Werte der Proben zwischen mind. 2,4 und max. 7,0 als Aussage für das Maß an Degradierung und Fragmentierung. Trotz mehrfacher Isolierung der RNA war es nicht möglich, höhere RIN-Werte, also eine qualitativ hochwertigere RNA, aus den Knochenbiopsaten zu isolieren. Um dennoch eine ausreichende Qualität der RNA aller Proben für die weitere Verarbeitung sicherzustellen, wurde eine minimale RIN von $\geq 5$ festgelegt.

Trotz sauberen Arbeitens unter strenger Vermeidung einer Kontamination der Proben und zügiger und standardisierter Arbeitsweise konnten keine höheren Werte der Integrität erreicht werden, was vermuten lässt, dass die Qualität der Knochenbiopsate geringer war als erwartet. Insbesondere bei der Unterkiefer-Submentalregion gestaltete sich die operative Gewinnung von Proben spongiösen Knochens wegen einer massiven Kortikalis relativ kompliziert. Zu bemerken ist allerdings, dass bei 4 Proben, die in der qRT-PCR ergebnislos blieben, der Primer des Referenzgens TBP verwendet wurde, der Primer für das Protein OPG hingegen für die selbe Probe erfolgreich eingesetzt werden konnte. Da jedoch die Normalisierung auf TBP dadurch nicht mehr durchgeführt werden konnte, wurden die genannten Proben für die statistische Auswertung nicht herangezogen. Die Optimierung der Gewinnung von Knochenmaterial aus dem Unterkiefer von höherwertiger Qualität für Zellanalysen, d.h. mit einem höheren Anteil an Spongiosa, welches zudem nicht aus dem Bereich der Alveolarkämme stammt, die ja zu Implantationszwecken und für weitere Probenentnahmen dienen, gestaltet sich schwierig. Als weitere Entnahmeregion könnte z. B. der aufsteigende Ast herangezogen werden (Abb. 35). 


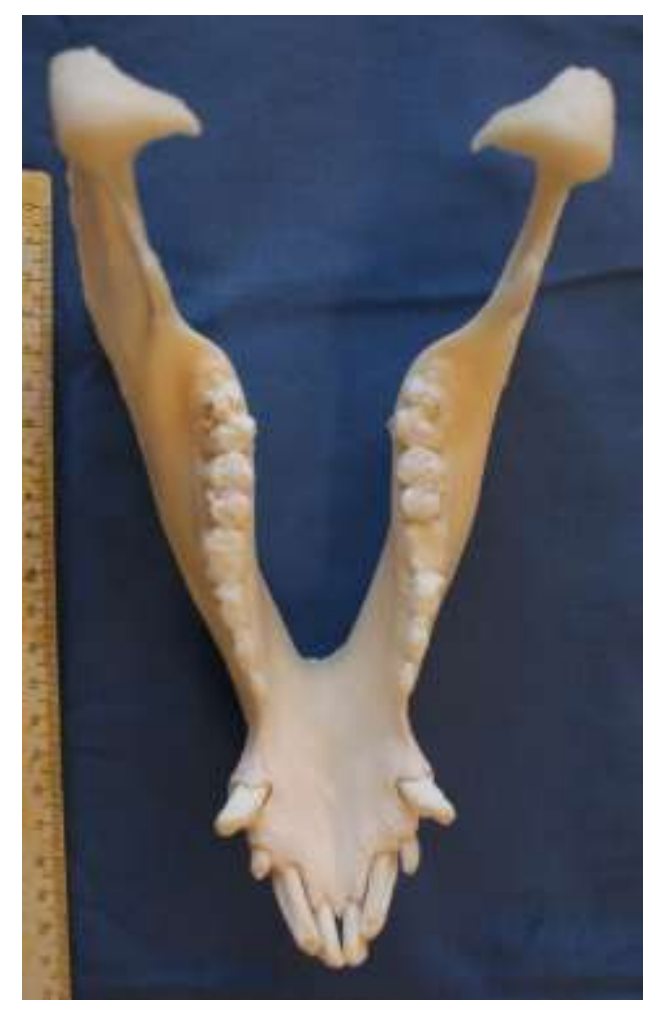

Abb. 35: Unterkieferknochen eines Minipigs

Die Analyse der Dünnschliffpräparate erfolgte histomorphometrisch. Hierzu wurden die Schliffpräparate unter 20-facher Vergrößerung digitalisiert und mit der Software AxioVision (Firma Carl Zeiss Microscopy GmbH) vermessen. Die Histomorphometrie stellt eine gut etablierte Methode für die Analyse von Aspekten der Knochenqualität dar, die es ermöglicht, sowohl statische als auch dynamische Knochenparameter sowie Parameter, welche die Mikrostruktur und Festigkeit des Knochens wiedergeben, zu bestimmen (Favus 2003; Klaushofer et al. 1999) In Tiermodellstudien, die sich z. B. mit Knochenneubildung befassen, ist die Histomorphometrie Standard (Hartman et al. 2002). Dennoch weist die histologische Untersuchung auch Einschränkungen auf, da die histomorphometrische Evaluierung eine zweidimensionale Analyse darstellt. Ein dreidimensionales Konstrukt wie z. B. die in dieser Arbeit gewonnenen Knochenblöcke, die die zu untersuchenden Implantate beinhalteten, wird dabei auf zweidimensionale, histologische Schliffpräparate übertragen. Dies kann dazu führen, dass der ausgewählte Schnitt das Knochenaufkommen am und um das Implantat nicht mehr repräsentativ darstellt. Die verwendbaren Schnitte wurden histomorphometrisch vermessen und für die statistische Auswertung gemittelt. Dadurch konnte zwar die Repräsentativität des periimplantären Knochenaufkommens erhöht werden, dennoch wird mit der Analyse der Schliffpräparate nur ein Bruchteil des umliegenden Gewebes untersucht. Die Digitalisierung der Schliffpräparate und die 
Anwendung einer Mikroskop-Software wie AxioVision ermöglicht jedoch durch die Anwendung verschiedener Messwerkzeuge und der Zoom-Funktion eine äußerst präzise Vermessung der zu untersuchenden Gewebe. Das Knochengewebe konnte gut von anderen Geweben seiner Umgebung abgegrenzt werden, da es sich durch die Färbung nach Smith und Karagianes (1974) orange einfärbte und durch eine digitale Bildbearbeitung Farben und Kontraste noch intensiviert wurden.

Bei den Zellzählungen der Osteoklasten war lediglich eine Beschränkung auf das Zählen der osteoklastären Resorptionslakunen möglich, da herstellungsbedingt beim Schleifen der histologischen Präparate ein Großteil der Osteoklasten herausgelöst wurde. Die Definition einer Resorptionslakune wurde dabei nicht festgelegt, wodurch es im Entscheidungsbereich des Betrachters lag, ob es sich um eine Unebenheit der Knochenoberfläche oder um eine tatsächliche Lakune handelte, was einen Kritikpunkt dieser Auswertungsmethode darstellt. Spezifischere histochemische Färbungen (z. B. TRAP-Färbung) können typische Osteoklastenmarker sichtbar machen und sollten in Folgearbeiten zum Einsatz kommen, um Osteoklasten sicherer zu identifizieren. Die viel kleineren Osteoblasten hingegen konnten durch die dunkelblaue Färbung der Zellen auf einem blassblau angefärbten Osteoidsaum und ihre typische perlschnurartige Aufreihung auf der Knochenoberfläche gut identifiziert und gezählt werden. Eine weitere Möglichkeit zur Identifizierung von Osteoblasten wäre ein immunhistochemischer Nachweis des in erster Linie von reifen Osteoblasten während der Matrixmineralisationsphase sezernierten spezifischen Knochenmarkers Osteocalcin (Gundberg 2000; Caillot-Augusseau et al. 1998), der knochenspezifischen ALP (Anh et al. 1998) oder einer histochemischen Färbung des Typ IKollagens. In dieser Arbeit wurde angenommen, dass sich $1 \mathrm{~mm}$ periimplantär ortsständiger Knochen und in den Gewindegängen neu gebildeter Knochen befindet. Eine immunhistochemische Darstellung oben genannter spezifischer Knochenmarker der Osteoblasten hätte zusätzlich den Vorteil, genau zwischen neugebildetem Knochen und ortsständigem Knochen differenzieren zu können. 


\section{ZUSAMMENFASSUNG}

Gegenstand dieser Arbeit ist eine Analyse der Einheilung dentaler Implantate unter dem Einfluss des Bisphosphonats Zoledronat in onkologischer Dosierung am Tiermodell des Göttinger Minipigs. Der Fokus lag dabei auf der Fragestellung, ob durch Implantationen am Zoledronat-behandelten Minipig Osteonekrosen im Bereich der Kiefer (ONJ) induziert werden können und welche Auswirkungen die Medikation auf die Expression von Osteoprotegerin, einem osteoblastären Syntheseprodukt, in den unterschiedlichen Skelettabschnitten Beckenkamm, Unterkiefer und Alveolarkamm des Ober- und Unterkiefers hat. Des Weiteren sollten die Auswirkungen auf die Osseointegration von Implantaten hinsichtlich der Implantat-Knochen-Kontaktrate, der Knochendichte in den Gewindegängen und der periimplantären Knochendichte analysiert werden.

Die klinische Analyse der periimplantären Regionen ergab für über die Hälfte der Versuchsgruppentiere periimplantäre Gewebedefekte, die als ONJ-ähnliche Defekte charakterisiert werden können. Auch bei einigen Tieren der Kontrollgruppe traten ähnliche Schleimhautdehiszenzen auf, die jedoch sämtlich geringer ausfielen als die der Versuchsgruppentiere. Die Defekte waren häufiger im Unter- als im Oberkiefer zu finden. Die Expression von OPG war in allen untersuchten Skelettabschnitten bei den Versuchsgruppentieren vermindert. Es konnten dabei keine signifikanten Unterschiede zwischen den verschiedenen experimentellen Gruppen festgestellt werden, da auch innerhalb der Kontrollgruppe Schwankungen in der OPG-Expression in den untersuchten Skelettabschnitten auftraten.

Die Implantat-Knochen-Kontaktrate und die Knochendichte in den Gewindegängen war unter Zoledronateinfluss tendenziell reduziert im Vergleich zur Kontrollgruppe. Die Anzahl der Osteoklastenlakunen war bei den Tieren der Versuchsgruppen signifikant erhöht, die der Osteoblasten tendenziell reduziert.

Das Ergebnis dieser Arbeit weist auf eine negative Auswirkung des Medikaments Zoledronat auf die Einheilung dentaler Implantate hin, was durch die histomorphometrischen Ergebnisse belegbar ist. Die signifikant erhöhte Anzahl an Osteoklastenlakunen deutet dabei auf eine gesteigerte periimplantäre Knochenresorption in den Versuchsgruppen hin, die vergleichsweise geringe Anzahl an Osteoblasten gleichzeitig auf eine reduzierte Knochenneubildung. Der klinische Effekt der funktionellen Stabilisierung des Knochengewebes durch Bisphosphonate konnte in dieser Arbeit somit für periimplantäre Einhei- 
lungsprozesse nicht bestätigt werden. Dass nach Implantationen gehäuft Kiefernekrosen entstehen, kann jedoch nicht gefolgert werden, da nicht nur Versuchsgruppentiere, sondern ebenso Tiere der Kontrollgruppe ONJ-ähnliche Defekte periimplantär präsentierten. Auch das geringere Ausmaß der periimplantären Hart- und Weichgewebsdefekte innerhalb der Kontrollgruppe spricht für eine negative Beeinflussung der Osseointegration durch Zoledronat. Die Unterschiede der OPG-Expression zwischen dem Beckenknochen und den verschiedenen Kieferregionen unterstützen aktuelle Theorien zur Ätiopathogenese der ONJ, wonach die Kieferknochen aufgrund ihrer Entwicklung, Physiologie und Funktion anders auf Bisphosphonate reagieren als andere Skelettabschnitte. Dabei können die beobachteten Verringerungen von OPG den klinischen Effekt einer Stabilisierung des Knochenstoffwechsels durch Bisphosphonate nicht erklären.

Die klinischen, histomorphometrischen und auch histologischen Ergebnisse dieser Arbeit geben Hinweise auf ein erhöhtes Verlustrisiko für Implantate unter hochdosierter Zoledronat-Medikation. Da jedoch auch Implantatverluste innerhalb der Kontrollgruppe auftraten, ist eine Verifizierung der Ergebnisse in zukünftigen Studien notwendig. 


\section{ANHANG}

\subsection{Abbildungsverzeichnis}

Abb. 1: RANK-L/RANK/OPG-System (modifiziert nach Consolaro 2015) ........................ 4

Abb. 2: Aufbau und zeitlicher Horizont des Experiments.................................................. 29

Abb. 3: Abfolge der Arbeitsschritte bezüglich der Knochenbiopsate ................................. 30

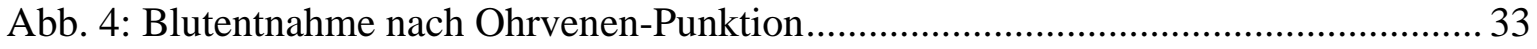

Abb. 5: Gewinnung Knochenbiopsat BK (Bildfolge 1-4) ................................................ 34

Abb. 6: Gewinnung Knochenbiopsat UK (Bildfolge 1-2)................................................ 35

Abb. 7: Gewinnung Knochenbiopsat Alveolarkamm (Bildfolge 1-2)................................. 36

Abb. 8: Insertion zweier Implantate im UK (Bildfolge 1-2) ............................................ 37

Abb. 9: Beispiele für die digitale Darstellung und Analyse intraoraler Defekte (Bildfolge 1-

2)

Abb. 10: Elektropherogramme einiger beispielhafter Proben und ihre RIN-Werte 46

Abb. 11: Berechnungsmodell der Effizienz-korrigierten relativen Quantifizierung (nach: Pfaffl 2004)

Abb. 12: Beispiel für die Auftrennung der PCR-Produkte durch eine Gelelektrophorese.. 54

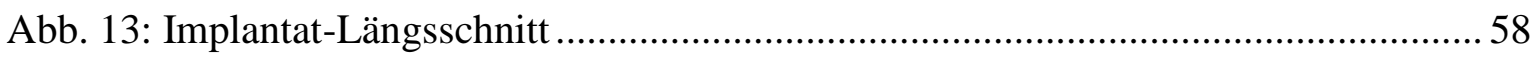

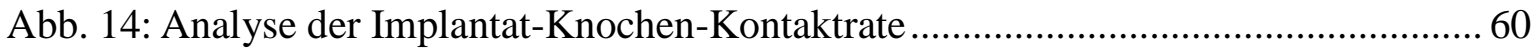

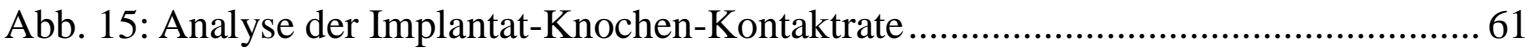

Abb. 16: Analyse der Knochendichte in den Gewindegängen ........................................... 62

Abb. 17: Analyse der Knochendichte bis $1 \mathrm{~mm}$ neben der Implantatoberfläche (Bildfolge $1-2)$ .63

Abb. 18: Markierter Messbereich bis $1 \mathrm{~mm}$ zirkulär um ein Implantat ...............................65

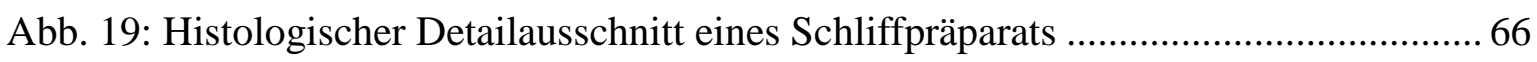

Abb. 20: Histologischer Detailausschnitt eines Schliffpräparats ......................................... 66

Abb. 21: Periimplantäre Defektgrößen im Unterkiefer und Oberkiefer............................... 68

Abb. 22: Expression von OPG in Beckenkamm und Unterkiefer ...................................... 71

Abb. 23: Expression von OPG im Beckenkamm ............................................................... 72

Abb. 24: Expression von OPG im Unterkiefer (Submentalregion) .................................... 74

Abb. 25: Expression von OPG im Alveolarkamm des OK/UK ........................................ 76

Abb. 26: Expression von OPG des Oberkiefer-Alveolarkamms ........................................ 77 
Abb. 27: Expression von OPG des Unterkiefer-Alveolarkamms .78

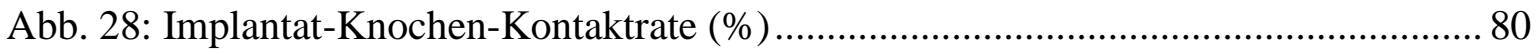

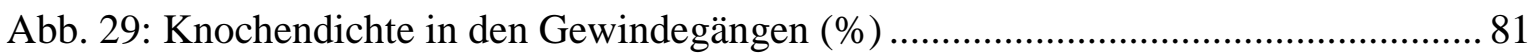

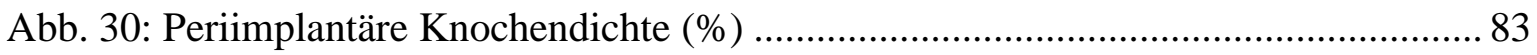

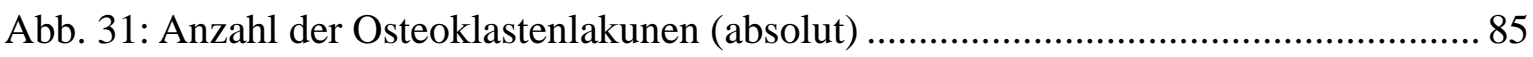

Abb. 32: Anzahl der Osteoklastenlakunen (absolut), Gruppenvergleich ............................ 86

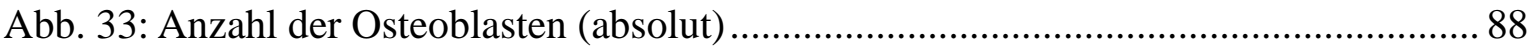

Abb. 34: Anzahl der Osteoklastenlakunen (absolut), Lokalisationsvergleich ...................... 89

Abb. 35: Unterkieferknochen eines Minipigs............................................................... 110

\subsection{Tabellenverzeichnis}

Tab. 1: Verschiedene Bisphosphonate und ihre relative Potenz .......................................... 5

Tab. 2: Typische laborchemisch bestimmbare Knochenumsatzparameter ......................... 10

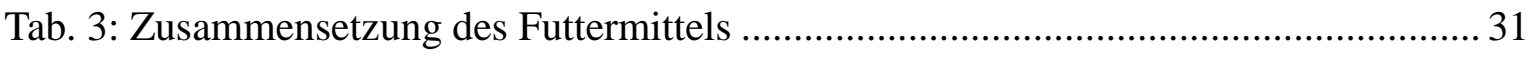

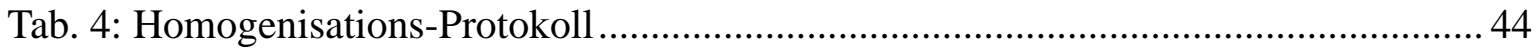

Tab. 5: Art des Chips in Abhängigkeit der RNA-Konzentration ........................................ 45

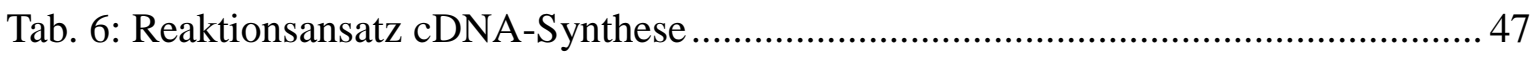

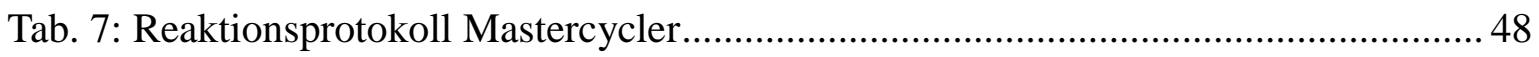

Tab. 8: Ansatz für ein Gefäß einer 96-well-Platte ............................................................. 50

Tab. 9: Plattendesign für qRT-PCR der einzelnen Versuche ............................................. 51

Tab. 10: PCR-Programm für sämtliche Versuche .............................................................. 52

Tab. 11: Deskriptive Analyse der periimplantären Schleimhaut ….................................... 68

Tab. 12: Gemischtes Modell der periimplantären Defektgrößen …..................................... 68

Tab. 13: Anzahl der ausgewerteten Biopsate von BK und UK ....................................... 70

Tab. 14: Gemischtes Modell der Expression von OPG in BK und UK.............................. 72

Tab. 15: Deskriptive Analyse der Expression von OPG im Beckenkamm ........................ 73

Tab. 16: Gemischtes Modell der Expression von OPG im Beckenknochen ....................... 73

Tab. 17: Deskriptive Analyse der Expression von OPG in der Unterkiefer-Submentalregion

Tab. 18: Gemischtes Modell der Expression von OPG im Unterkiefer (Submentalregion) 74

Tab. 19: Anzahl der ausgewerteten Biopsien von AOK und AUK .................................... 75

Tab. 20: Gemischtes Modell der Expression von OPG des Alveolarkamms OK/UK......... 76

Tab. 21: Deskriptive Analyse der Expression von OPG des Oberkiefer-Alveolarkamms .. 77 
Tab. 22: Gemischtes Modell der Expression von OPG des Oberkiefer-Alveolarkamms.... 77

Tab. 23: Deskriptive Analyse der Expression von OPG des Unterkiefer-Alveolarkamms . 78

Tab. 24: Gemischtes Modell der Expression von OPG des Unterkiefer-Alveolarkamms .. 79

Tab. 25: Deskriptive Analyse der Implantat-Knochen-Kontaktrate (\%) .............................. 80

Tab. 26: Gemischtes Modell der Implantat-Knochen-Kontaktrate ..................................... 80

Tab. 27: Deskriptive Analyse der Knochendichte in den Gewindegängen (\%) ................... 82

Tab. 28: Gemischtes Modell der Knochendichte in den Gewindegängen............................ 82

Tab. 29: Deskriptive Analyse der periimplantären Knochendichte (\%) .............................. 83

Tab. 30: Gemischtes Modell der periimplantären Knochendichte ..................................... 83

Tab. 31: Deskriptive Analyse der Anzahl der Osteoklastenlakunen (absolut) ..................... 85

Tab. 32: Gemischtes Modell der Anzahl der Osteoklastenlakunen ...................................... 85

Tab. 33: Deskriptive Analyse der Anzahl der Osteoklastenlakunen (Gruppenvergleich) ... 87

Tab. 34: Gruppenvergleich der Anzahl der Osteoklastenlakunen mittels Kontrasttest ....... 87

Tab. 35: Deskriptive Analyse der Anzahl der Osteoblasten (absolut) .................................. 88

Tab. 36: Gemischtes Modell der Anzahl der Osteoblasten................................................ 88

Tab. 37: Deskriptive Analyse der Anzahl der Osteoblasten (absolut), Lokalisationsvergleich

\subsection{Abkürzungsverzeichnis}

$\begin{array}{ll}\text { ALP } & \text { alkalische Phosphatase } \\ \text { AOK } & \text { Alveolarkamm Oberkiefer } \\ \text { AUK } & \text { Alveolarkamm Unterkiefer } \\ \text { BAP } & \begin{array}{l}\text { bone-specific alkaline phosphatase/knochenspezifische alkalische } \\ \text { Phosphatase }\end{array} \\ \text { BK } & \text { Beckenkamm } \\ \text { bp } & \text { Basenpaare } \\ \text { BP } & \text { Bisphosphonate } \\ \text { BRONJ } & \begin{array}{l}\text { bisphosphonate related osteonecrosis of the jaw/Bisphosphonat-induzierte } \\ \text { Kiefernekrose }\end{array} \\ \text { BSG } & \text { Blutsenkungsgeschwindigkeit } \\ \text { cDNA } & \text { copy/complementary (komplementäre) DNA } \\ \text { CRP } & \text { C-reaktives Protein } \\ \text { DNA } & \text { Desribonukleinsäure } \\ \text { dNTPs } & \text { Desoxynukleosid-Triphosphate } \\ \text { dsDNA } & \text { doppelstrangige DNA } \\ \text { DXM } & \text { Dexamethason } \\ \text { fwd } & \text { forward/ vorwärts } \\ \text { GT } & \text { Gamma-Glutamyl-Transferase }\end{array}$




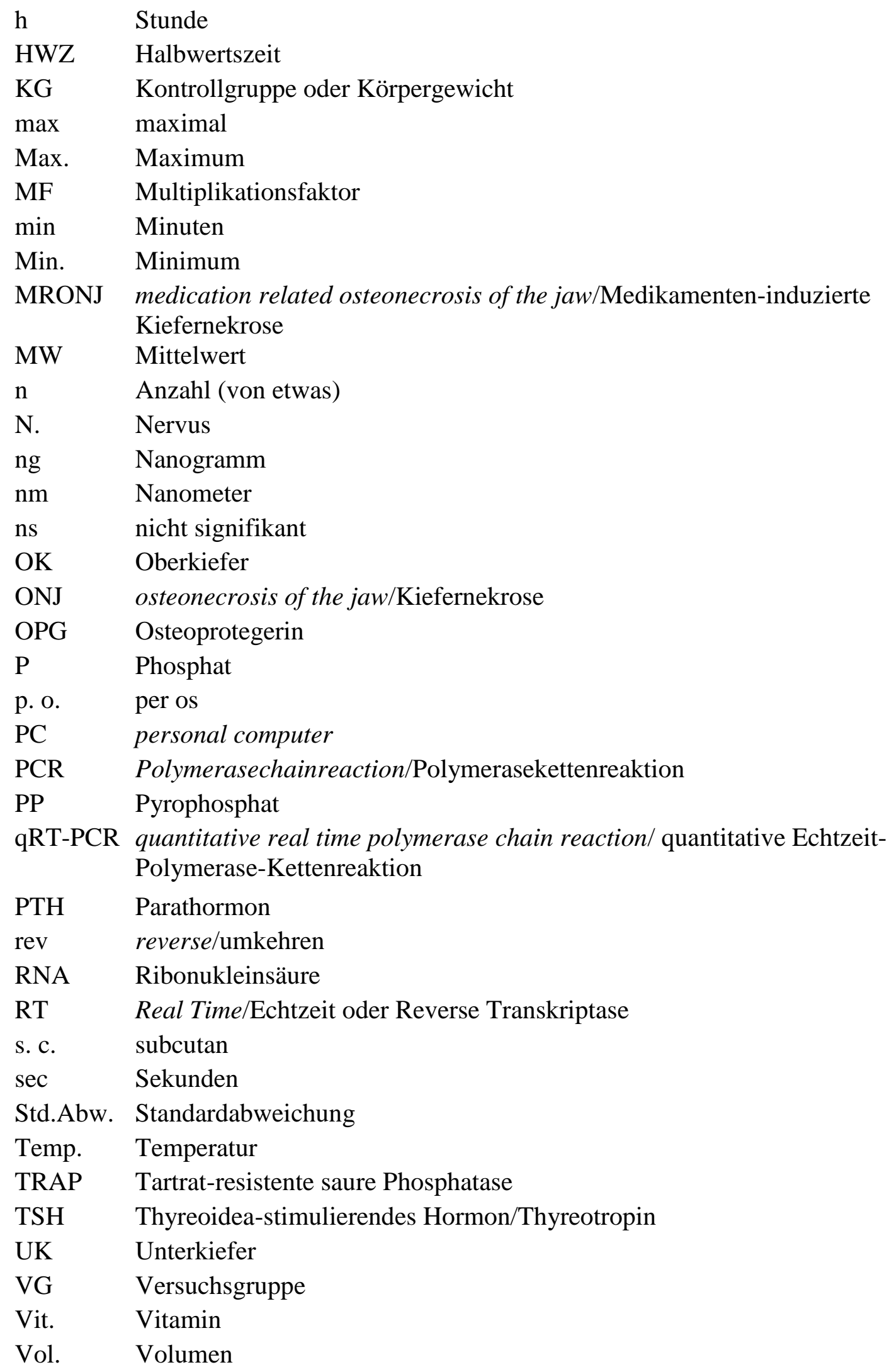




\section{LITERATURVERZEICHNIS}

Abtahi J, Agholme F, Sandberg O, Aspenberg P (2013): Effect of Local vs. Systemic Bisphosphonate Delivery on Dental Implant Fixation in a Model of Osteonecrosis of the Jaw. J Dent Res $\underline{92}$, 279-283

Akintoye SO, Lam T, Shi S, Brahim J, Collins MT, Robey PG (2006): Skeletal site-specific characterization of orofacial and iliac crest human bone marrow stromal cells in same individuals. Bone $\underline{38}, 758-768$

Allen MR: Animal Models of Medication-Related Osteonecrosis of the Jaw; in: Otto S (Hrsg.): Medication-Related Osteonecrosis of the Jaws. Bisphosphonates, Denosumab, and New Agents.; Springer, Berlin Heidelberg 2015, 155-167

Allen MR, Chu T-MG, Ruggiero SL (2013): Absence of Exposed Bone Following Dental Extraction in Beagle Dogs Treated With 9 Months of High-Dose Zoledronic Acid Combined With Dexamethasone. J Oral Maxillofac Surg 1ㅜ, 1017-1026

Al-Sabbagh M, Robinson FG, Romanos G, Thomas MV (2015): Osteoporosis and Bisphosphonate-Related Osteonecrosis in a Dental School Implant Patient Population: Implant Dent 24, 328-332

Anh DJ, Dimai HP, Hall SL, Farley JR (1998): Skeletal alkaline phosphatase activity is primarily released from human osteoblasts in an insoluble form, and the net release is inhibited by calcium and skeletal growth factors. Calcif Tissue Int $\underline{62}, 332-340$

Anić B, Mayer M (2014): Glucocorticoid induced osteoporosis. Reumatizam $\underline{61}$, 105-112

Badros A, Weikel D, Salama A, Goloubeva O, Schneider A, Rapoport A, Fenton R, Gahres N, Sausville E, Ord R, Meiller T (2006): Osteonecrosis of the Jaw in Multiple Myeloma Patients: Clinical Features and Risk Factors. J Clin Oncol 24, 945-952

Bamias A, Kastritis E, Bamia C, Moulopoulos LA, Melakopoulos I, Bozas G, Koutsoukou V, Gika D, Anagnostopoulos A, Papadimitriou C, et al. (2005): Osteonecrosis of the Jaw in Cancer After Treatment With Bisphosphonates: Incidence and Risk Factors. J Clin Oncol 23, 8580-8587

Bartl R, Tresckow E von, Bartl C: Bisphosphonat-Manual: Wirkungen - Indikationen Strategien. Springer-Verlag, Berlin Heidelberg 2006

Becker N: Epidemiology of Multiple Myeloma; in: Moehler T, Goldschmidt H (Hrsg.): Multiple Myeloma. Recent Results in Cancer Research, Band 183; Springer, Berlin Heidelberg 2011, 25-35

Beglinger R, Becker M, Eggenberger E, Lombard C (1975): Das Göttinger Miniaturschwein als Versuchstier. Res Exp Med (Berl) 165, 251-263

Bellido T, Plotkin LI (2011): Novel actions of bisphosphonates in bone: Preservation of osteoblast and osteocyte viability. Bone $\underline{49}, 50-55$ 
Bi Y, Gao Y, Ehirchiou D, Cao C, Kikuiri T, Le A, Shi S, Zhang L (2010): Bisphosphonates Cause Osteonecrosis of the Jaw-Like Disease in Mice. Am J Pathol 177, 280-290

Bischoff H-P, Heisel J, Locher H-A: Praxis der konservativen Orthopädie. Thieme, Stuttgart 2009

Black DM, Schwartz AV, Ensrud KE, Cauley JA, Levis S, Quandt SA, Satterfield S, Wallace RB, Bauer DC, Palermo L, et al. (2006): Effects of Continuing or Stopping Alendronate After 5 Years of Treatment: The Fracture Intervention Trial Long-term Extension (FLEX): A Randomized Trial. JAMA 296, 2927-2938

Black DM, Delmas PD, Eastell R, Reid IR, Boonen S, Cauley JA, Cosman F, Lakatos P, Leung PC, Man Z, et al. (2007): Once-Yearly Zoledronic Acid for Treatment of Postmenopausal Osteoporosis. N Engl J Med 356, 1809-1822

Boyce BF, Xing L (2007): Biology of RANK, RANKL, and osteoprotegerin. Arthritis Res Ther $\underline{9}, \mathrm{~S} 1$

Caillot-Augusseau A, Lafage-Proust MH, Soler C, Pernod J, Dubois F, Alexandre C (1998): Bone formation and resorption biological markers in cosmonauts during and after a 180-day space flight (Euromir 95). Clin Chem 44, $578-585$

Çankaya M, Çizmeci Şenel F, Kadioglu Duman M, Muci E, Dayisoylu EH, Balaban F (2013): The effects of chronic zoledronate usage on the jaw and long bones evaluated using RANKL and osteoprotegerin levels in an animal model. Int J Oral Maxillofac Surg $\underline{42}, 1134-1139$

Clemons M, Gelmon KA, Pritchard KI, Paterson AHG (2012): Bone-targeted agents and skeletal-related events in breast cancer patients with bone metastases: the state of the art. Curr Oncol 19, 259-268

Coleman RE (2006): Clinical Features of Metastatic Bone Disease and Risk of Skeletal Morbidity. Clin Cancer Res 12, 6243s-6249s

Consolaro A (2015): Miniplates and mini-implants: bone remodeling as their biological foundation. Dent Press J Orthod 20, 16-31

Corrado A, Neve A, Maruotti N, Gaudio A, Marucci A, Cantatore FP (2010): Dosedependent metabolic effect of zoledronate on primary human osteoblastic cell cultures. Clin Exp Rheumatol-Incl Suppl 28, 873-879

Cremers SC, Pillai G, Papapoulos SE (2005): Pharmacokinetics/pharmacodynamics of bisphosphonates: use for optimisation of intermittent therapy for osteoporosis. Clin Pharmacokinet $\underline{44}, 551-570$

Daroszewska A, Ralston SH (2005): Genetics of Paget's disease of bone. Clin Sci 109, 257-263

DeBaz C, Hahn J, Lang L, Palomo L (2015): Dental Implant Supported Restorations Improve Quality of Life in Osteoporotic Women. Int J Dent 2015, 1-6 
Diel IJ (2007): Effectiveness of bisphosphonates on bone pain and quality of life in breast cancer patients with metastatic bone disease: a review. Support Care Cancer $\underline{15}$, $1243-1249$

Dikicier E, Karaçaylı Ü, Dikicier S, Günaydın Y (2014): Effect of systemic administered zoledronic acid on osseointegration of a titanium implant in ovariectomized rats. $\mathbf{J}$ Cranio-Maxillofac Surg 2, 1106-1111

Donath K: Der Präparator: Die Trenn-Dünnschliff-Technik zur Herstellung histologischer Präparate von nicht schneidbaren Geweben und Materialien; Apparate- und Methodenbeschreibung. Exakt-Kulzer-Druckschrift, Norderstedt 1988

Elad S, Gomori MJ, Ben-Ami N, Friedlander-Barenboim S, Regev E, Lazarovici TS, Yarom N (2010): Bisphosphonate-related osteonecrosis of the jaw: clinical correlations with computerized tomography presentation. Clin Oral Investig $\underline{14}, 43-50$

Elsaid S, Frame H, Ho M, Mackinnon E, Brown J, Cheung A (2016): Bone strength and management of postmenopausal fracture risk with antiresorptive therapies: considerations for women`s health practice. Int J Womens Health $\underline{8}, 537-547$

Famili P, Quigley S, Mosher T (2011): Survival of dental implants among post-menopausal female dental school patients taking oral bisphosphonates: a retrospective study. Compend Contin Educ Dent $\underline{32}$, E106-109

Fassio A, Bertoldo F, Idolazzi L, Viapiana O, Rossini M, Gatti D (2017): Drug-induced osteonecrosis of the jaw: the state of the art. Reumatismo $\underline{69}, 9-15$

Favus MJ: Primer on the Metabolic Bone Diseases and Disorders of Mineral Metabolism. 5. Auflage; Amer Society for Bone \& Mineral, Washington, DC 2003

Fleisch H: Bisphosphonates in Bone Disease, From the Laboratory to the Patient. Academic Press, San Diego, CA 2000

Fournier P, Boissier S, Filleur S, Guglielmi J, Cabon F, Colombel M, Clézardin P (2002): Bisphosphonates inhibit angiogenesis in vitro and testosterone-stimulated vascular regrowth in the ventral prostate in castrated rats. Cancer Res $\underline{62}, 6538-6544$

Friedmann A, Friedmann A, Grize L, Obrecht M, Dard M (2014): Convergent methods assessing bone growth in an experimental model at dental implants in the minipig. Ann Anat 196, 100-107

Gebrauchsinformation Zometa (2017): Gebrauchsinformation: Information für Anwender; ZOMETA® 4mg/100ml Infusionslösung (Zoledronsäure).

Giovannacci I, Meleti M, Manfredi M, Mortellaro C, Greco Lucchina A, Bonanini M, Vescovi P (2016): Medication-Related Osteonecrosis of the Jaw Around Dental Implants: Implant Surgery-Triggered or Implant Presence-Triggered Osteonecrosis? J Craniofac Surg 27, 697-701

Glowacki J, Shusterman EM, Troulis M, Holmes R, Perrott D, Kaban LB (2004): Distraction Osteogenesis of the Porcine Mandible: Histomorphometric Evaluation of Bone. Plast Reconstr Surg 113, 566-573 
Gnant M (2011): Zoledronic acid in breast cancer: latest findings and interpretations. Ther Adv Med Oncol $\underline{3}, 293-301$

Graefe KH, Lutz W, Bönisch H: Duale Reihe Pharmakologie und Toxikologie. Thieme, Stuttgart 2011

Grbic JT, Landesberg R, Lin S-Q, Mesenbrink P, Reid IR, Leung P-C, Casas N, Recknor CP, Hua Y, Delmas PD, Eriksen EF (2008): Incidence of Osteonecrosis of the Jaw in Women With Postmenopausal Osteoporosis in the Health Outcomes and Reduced Incidence With Zoledronic Acid Once Yearly Pivotal Fracture Trial. J Am Dent Assoc 139, 32-40

Grötz KA, Piesold JU, Al-Nawas B (2012): S3-Leitlinie ONJ: Bisphosphonat-assoziierte Kiefernekrose (BP-ONJ) und andere Medikamenten-assoziierte Kiefernekrosen. AWMF-Register Nr. 007/091.

Grötz KA, Walter C, Al-Nawas B, Haßfeld S, Sader R, Ullner M (2016): S3-Leitlinie: Zahnimplantate bei medikamentöser Behandlung mit Knochenantiresorptiva (inkl. Bisphosphonate). Langversion 1.0. AWMF-Registernummer: 083-026.

Gundberg CM (2000): Biochemical markers of bone formation. Clin Lab Med 20, 489-501

Haider M-T, Holen I, Dear TN, Hunter K, Brown HK (2014): Modifying the osteoblastic niche with zoledronic acid in vivo-Potential implications for breast cancer bone metastasis. Bone $\underline{66}, 240-250$

Hartman EH, Pikkemaat JA, Vehof JW, Heerschap A, Jansen JA, Spauwen PH (2002): In vivo magnetic resonance imaging explorative study of ectopic bone formation in the rat. Tissue Eng $\underline{8}, 1029-1036$

Hasturk H, Kantarci A, Ghattas M, Dangaria SJ, Abdallah R, Morgan EF, Diekwisch TGH, Ashman A, Van Dyke T (2014): The Use of Light/Chemically Hardened Polymethylmethacrylate, Polyhydroxylethylmethacrylate, and Calcium Hydroxide Graft Material in Combination With Polyanhydride Around Implants and Extraction Sockets in Minipigs: Part II: Histologic and Micro-CT Evaluations. J Periodontol $\underline{85}, 1230-1239$

Häussler B, Gothe H, Göl D, Glaeske G, Pientka L, Felsenberg D (2007): Epidemiology, treatment and costs of osteoporosis in Germany - the BoneEVA Study. Osteoporos Int $\underline{18}, 77-84$

Hill PJ, Stewart GSAB (1992): The Polymerase Chain Reaction in Molecular and Microbiology. Biotechnol Genet Eng Rev 10, 343-378

Himelstein AL, Foster JC, Khatcheressian JL, Roberts JD, Seisler DK, Novotny PJ, Qin R, Go RS, Grubbs SS, O'Connor T, et al. (2017): Effect of Longer-Interval vs Standard Dosing of Zoledronic Acid on Skeletal Events in Patients With Bone Metastases: A Randomized Clinical Trial. JAMA $\underline{317}$, 48-58

Hines SL, Mincey B, Dentchev T, Sloan JA, Perez EA, Johnson DB, Schaefer PL, Alberts S, Liu H, Kahanic S, et al. (2009): Immediate versus delayed zoledronic acid for prevention of bone loss in postmenopausal women with breast cancer starting letro- 
zole after tamoxifen-N03CC. Breast Cancer Res Treat 117, 603-609

Hofbauer LC, Dunstan CR, Spelsberg TC, Riggs BL, Khosla S (1998): Osteoprotegerin production by human osteoblast lineage cells is stimulated by vitamin $\mathrm{D}$, bone morphogenetic protein-2, and cytokines. Biochem Biophys Res Commun 250, 776781

Hofbauer LC, Khosla S, Dunstan CR, Lacey DL, Spelsberg TC, Riggs BL (1999): Estrogen Stimulates Gene Expression and Protein Production of Osteoprotegerin in $\mathrm{Hu}$ man Osteoblastic Cells. Endocrinology 140, 4367-4370

Hoff AO, Toth B, Hu M, Hortobagyi GN, Gagel RF (2011): Epidemiology and risk factors for osteonecrosis of the jaw in cancer patients. Ann N Y Acad Sci 1218, 47-54

Huja SS, Mason A, Fenell CE, Mo X, Hueni S, D’Atri AM, Fernandez SA (2011): Effects of Short-Term Zoledronic Acid Treatment on Bone Remodeling and Healing at Surgical Sites in the Maxilla and Mandible of Aged Dogs. J Oral Maxillofac Surg $\underline{69}, 418-427$

Idris AI, Rojas J, Greig IR, van't Hof RJ, Ralston SH (2008): Aminobisphosphonates Cause Osteoblast Apoptosis and Inhibit Bone Nodule Formation In Vitro. Calcif Tissue Int $\underline{82}, 191-201$

Ikeda T, Kasai M, Utsuyama M, Hirokawa K (2001): Determination of Three Isoforms of the Receptor Activator of Nuclear Factor- $\kappa \mathrm{B}$ Ligand and Their Differential Expression in Bone and Thymus. Endocrinology 142, 1419-1426

Jacobsen C, Metzler P, Rössle M, Obwegeser J, Zemann W, Grätz K-W (2013): Osteopathology induced by bisphosphonates and dental implants: clinical observations. Clin Oral Investig 17, 167-175

Jobke B, Milovanovic P, Amling M, Busse B (2014): Bisphosphonate-osteoclasts: Changes in osteoclast morphology and function induced by antiresorptive nitrogencontaining bisphosphonate treatment in osteoporosis patients. Bone $\underline{59}, 37-43$

Kainz P (2000): The PCR plateau phase - towards an understanding of its limitations. Biochim Biophys Acta 1494, 23-27

Kalra S, Jain V (2013): Dental complications and management of patients on bisphosphonate therapy: A review article. J Oral Biol Craniofacial Res $\underline{3}, 25-30$

Khan AA, Rios LP, Sandor GKB, Khan N, Peters E, Rahman MO, Clokie CML, Dore E, Dubois S (2011): Bisphosphonate-associated Osteonecrosis of the Jaw in Ontario: A Survey of Oral and Maxillofacial Surgeons. J Rheumatol 38, 1396-1402

Khan AA, Morrison A, Hanley DA, Felsenberg D, McCauley LK, O'Ryan F, Reid IR, Ruggiero SL, Taguchi A, Tetradis S, et al. (2015): Diagnosis and Management of Osteonecrosis of the Jaw: A Systematic Review and International Consensus: osteonecrosis of the jaw: report from the international ONJ task force. J Bone Miner Res $\underline{30}, 3-23$ 
Khan SA, Kanis JA, Vasikaran S, Kline WF, Matuszewski BK, McCloskey EV, Beneton MNC, Gertz BJ, Sciberras DG, Holland SD, et al. (1997): Elimination and Biochemical Responses to Intravenous Alendronate in Postmenopausal Osteoporosis. J Bone Miner Res $\underline{12}$, 1700-1707

Kim I, Ki H, Lee W, Kim H, Park J-B (2013): The Effect of Systemically Administered Bisphosphonates on Bony Healing After Tooth Extraction and Osseointegration of Dental Implants in the Rabbit Maxilla. Int J Oral Maxillofac Implants 28, 11941200

Kim JH, Park YB, Li Z, Shim JS, Moon HS, Jung HS, Chung MK (2011): Effect of alendronate on healing of extraction sockets and healing around implants: Effect of alendronate on healing around implants. Oral Dis $\underline{17}, 705-711$

Klaushofer K, Roschger P, Nader A, Glantschnig H, Varga F (1999): [Osteoporosis and metabolic bone diseases; clinical relationship]. Wien Med Wochenschr $1946 \underline{149}$, 463-471

Koch FP, Merkel C, Ziebart T, Smeets R, Walter C, Al-Nawas B (2012): Influence of bisphosphonates on the osteoblast RANKL and OPG gene expression in vitro. Clin Oral Investig 16, 79-86

Kon T, Cho T-J, Aizawa T, Yamazaki M, Nooh N, Graves D, Gerstenfeld LC, Einhorn TA (2001): Expression of Osteoprotegerin, Receptor Activator of NF- $\kappa B$ Ligand (Osteoprotegerin Ligand) and Related Proinflammatory Cytokines During Fracture Healing. J Bone Miner Res $\underline{16}, 1004-1014$

Köttstorfer J, Thomas A, Gregori M, Kecht M, Kaiser G, Eipeldauer S, Sarahrudi K (2014): Are OPG and RANKL involved in human fracture healing? J Orthop Res $\underline{32}$, 15571561

Labor Schottdorf GmbH (2014): Knochenstoffwechsel II; Laborinformation Nr. 56.

Lambrinoudaki I, Vlachou S, Galapi F, Papadimitriou D, Papadias K (2008): Once-yearly zoledronic acid in the prevention of osteoporotic bone fractures in postmenopausal women. Clin Interv Aging $\underline{3}$, 445-451

Lee JH, Ryu MY, Baek H-R, Lee H-K, Seo J-H, Lee KM, Lee A-Y, Zheng GB, Chang B-S, Lee C-K (2014): The Effects of Recombinant Human Bone Morphogenetic Protein2-Loaded Tricalcium Phosphate Microsphere-Hydrogel Composite on the Osseointegration of Dental Implants in Minipigs: rhBMP-2-Loaded TCP-Hydrogel Composite. Artif Organs $\underline{38}, 149-158$

Leitlinie Mammakarzinom (2017): Interdisziplinäre S3-Leitlinie für die Früherkennung, Diagnostik, Therapie und Nachsorge des Mammakarzinoms. Kurzversion 4.0. AWMF-Registernummer: 032-045OL.

Leitlinie Osteoporose (2014): DVO-Leitlinie Osteoporose: Prophylaxe, Diagnostik und Therapie der Osteoporose bei Männern ab dem 60. Lebensjahr und bei postmenopausalen Frauen. Leitlinie des Dachverbands der Deutschsprachigen Wissenschaftlichen Osteologischen Gesellschaften e.V. Kurzfassung und Langfassung. Version 1a. 
Li B, Ling Chau JF, Wang X, Leong WF (2011): Bisphosphonates, specific inhibitors of osteoclast function and a class of drugs for osteoporosis therapy. J Cell Biochem $\underline{112}, 1229-1242$

Licata AA (2005): Discovery, Clinical Development, and Therapeutic Uses of Bisphosphonates. Ann Pharmacother 39, 668-677

Lo JC, O'Ryan FS, Gordon NP, Yang J, Hui RL, Martin D, Hutchinson M, Lathon PV, Sanchez G, Silver P, et al. (2010): Prevalence of Osteonecrosis of the Jaw in Patients With Oral Bisphosphonate Exposure. J Oral Maxillofac Surg 68, 243-253

Lyles KW, Colón-Emeric CS, Magaziner JS, Adachi JD, Pieper CF, Mautalen C, Hyldstrup L, Recknor C, Nordsletten L, Moore KA, et al. (2007): Zoledronic Acid and Clinical Fractures and Mortality after Hip Fracture. N Engl J Med 357, 1799-1809

Martini G, Gozzetti A, Gennari L, Avanzati A, Nuti R, Lauria F (2006): The effect of zoledronic acid on serum osteoprotegerin in early stage multiple myeloma. Haematologica $\underline{91,1720-1721}$

Martini G, Gennari L, Merlotti D, Salvadori S, Franci MB, Campagna S, Avanzati A, De Paola V, Valleggi F, Nuti R (2007): Serum OPG and RANKL levels before and after intravenous bisphosphonate treatment in Paget's disease of bone. Bone $\underline{40}, 457-463$

Maruotti N, Corrado A, Neve A, Cantatore FP (2012): Bisphosphonates: effects on osteoblast. Eur J Clin Pharmacol 68, 1013-1018

Marx RE (2003): Pamidronate (Aredia) and zoledronate (Zometa) induced avascular necrosis of the jaws: a growing epidemic. J Oral Maxillofac Surg $\underline{61}$, 1115-1117

Marx RE, Sawatari Y, Fortin M, Broumand V (2005): Bisphosphonate-Induced Exposed Bone (Osteonecrosis/Osteopetrosis) of the Jaws: Risk Factors, Recognition, Prevention, and Treatment. J Oral Maxillofac Surg $\underline{63}$, 1567-1575

Meier C, Uebelhart B, Aubry-Rozier B, Birkhäuser M, Bischoff-Ferrari HA, Frey D, Kressig RW, Lamy O, Lippuner K, Stute P, et al. (2017): Osteoporosis drug treatment: duration and management after discontinuation. A position statement from the SVGO/ASCO. Swiss Med Wkly 147 , w14484

Mercatali L, Ricci M, Scarpi E, Serra P, Fabbri F, Ricci R, Liverani C, Zanoni M, Zoli W, Maltoni R, et al. (2013): RANK/RANK-L/OPG in Patients with Bone Metastases Treated with Anticancer Agents and Zoledronic Acid: A Prospective Study. Int J Mol Sci $\underline{14}, 10683-10693$

Migliorati CA, Siegel MA, Elting LS (2006): Bisphosphonate-associated osteonecrosis: a long-term complication of bisphosphonate treatment. Lancet Oncol 7, 508-514

Mosekilde L, Kragstrup J, Richards A (1987): Compressive strength, ash weight, and volume of vertebral trabecular bone in experimental fluorosis in pigs. Calcif Tissue Int $\underline{40}, 318-322$

Mozzati M, Arata V, Giacomello M, Del Fabbro M, Gallesio G, Mortellaro C, Bergamasco L (2015): Failure Risk Estimates After Dental Implants Placement Associated With 
Plasma Rich in Growth Factor-Endoret in Osteoporotic Women Under Bisphosphonate Therapy. J Craniofac Surg $\underline{26}$, 749-755

Mülhardt C: Der Experimentator: Molekularbiologie / Genomics. 5. Auflage; Spektrum Akademischer Verlag, München 2006

Murakami T, Yamamoto M, Yamamoto M, Ono K, Nishikawa M, Nagata N, Motoyoshi K, Akatsu T (1998): Transforming Growth Factor- $\beta 1$ Increases mRNA Levels of Osteoclastogenesis Inhibitory Factor in Osteoblastic/Stromal Cells and Inhibits the Survival of Murine Osteoclast-like Cells. Biochem Biophys Res Commun 252, $747-752$

Nagata MJH, Messora MR, Antoniali C, Fucini SE, de Campos N, Pola NM, Santinoni CS, Furlaneto FAC, Ervolino E (2017): Long-term therapy with intravenous zoledronate increases the number of nonattached osteoclasts. J Cranio-Maxillofac Surg $\underline{45}, 1860-1867$

Nakazawa T, Nakamura M, Matsuda R, Nishimura F, Park YS, Motoyama Y, Hironaka Y, Nakagawa I, Yokota H, Yamada S, et al. (2016): Antitumor effects of minodronate, a third-generation nitrogen-containing bisphosphonate, in synergy with $\gamma \delta \mathrm{T}$ cells in human glioblastoma in vitro and in vivo. J Neurooncol $\underline{129}, 231-241$

Nienhuis HH, Arjaans M, Timmer-Bosscha H, de Vries EGE, Schröder CP (2015): Human stromal cells are required for an anti-breast cancer effect of zoledronic acid. Oncotarget $\underline{6}, 24436-24447$

Noden DM, Trainor PA (2005): Relations and interactions between cranial mesoderm and neural crest populations: Neural crest-mesoderm interactions, D. M. Noden and P. A. Trainor. J Anat 207, 575-601

Nygard A-B, Jørgensen CB, Cirera S, Fredholm M (2007): Selection of reference genes for gene expression studies in pig tissues using SYBR green qPCR. BMC Mol Biol $\underline{8}$, 67

Oh K, Moon H, Lee J, Park Y, Kim J-H (2015): Effects of alendronate on the peri-implant bone in rats. Oral Dis $\underline{21}, 248-256$

Oh KC, Hwang W, Park YB, Lee JH, Moon HS, Kim JH (2017): Effects of Alendronate on Bone Remodeling Around Osseointegrated Implants in Rats. Implant Dent 26, 4653

Orriss IR, Key ML, Colston KW, Arnett TR (2009): Inhibition of osteoblast function in vitro by aminobisphosphonates. J Cell Biochem $\underline{106}, 109-118$

Otto S, Pautke C, Opelz C, Westphal I, Drosse I, Schwager J, Bauss F, Ehrenfeld M, Schieker M (2010): Osteonecrosis of the Jaw: Effect of Bisphosphonate Type, Local Concentration, and Acidic Milieu on the Pathomechanism. J Oral Maxillofac Surg $\underline{68}, 2837-2845$

Otto S, Pautke C, Martin Jurado O, Nehrbass D, Stoddart MJ, Ehrenfeld M, Zeiter S (2017): Further development of the MRONJ minipig large animal model. J CranioMaxillofac Surg 45, 1503-1514 
Pan B, Farrugia AN, To LB, Findlay DM, Green J, Lynch K, Zannettino AC (2004): The Nitrogen-Containing Bisphosphonate, Zoledronic Acid, Influences RANKL Expression in Human Osteoblast-Like Cells by Activating TNF- $\alpha$ Converting Enzyme (TACE). J Bone Miner Res 19, 147-154

Pautke C, Kreutzer K, Weitz J, Knödler M, Münzel D, Wexel G, Otto S, Hapfelmeier A, Stürzenbaum S, Tischer T (2012): Bisphosphonate related osteonecrosis of the jaw: A minipig large animal model. Bone 51, 592-599

Pérez-Albacete Martínez C, Vlahović Z, Šćepanović M, Videnović G, Barone A, CalvoGuirado JL (2016): Submerged flapless technique vs. conventional flap approach for implant placement: experimental domestic pig study with 12-month follow-up. Clin Oral Implants Res 27, 964-968

Perifanis V, Vyzantiadis T, Tziomalos K, Vakalopoulou S, Garipidou V, AthanassiouMetaxa M, Harsoulis F (2007): Effect of zoledronic acid on markers of bone turnover and mineral density in osteoporotic patients with beta-thalassaemia. Ann Hematol $\underline{86}, 23-30$

Pfaffl MW (2004): Real-time RT-PCR: neue Ansätze zur exakten mRNA Quantifizierung. BIOspektrum $\underline{1}, 92-95$

Plotkin LI, Manolagas SC, Bellido T (2006): Dissociation of the pro-apoptotic effects of bisphosphonates on osteoclasts from their anti-apoptotic effects on osteoblasts/osteocytes with novel analogs. Bone $\underline{39}$, 443-452

Poort LJ, Bittermann GKP, Böckmann RA, Hoebers FJ, Houben R, Postma AA, Kessler PAWH (2014): Does a Change in Bone Mineral Density Occur in the Mandible of Göttingen Minipigs After Irradiation in Correlation With Radiation Dose and Implant Surgery? J Oral Maxillofac Surg 2, 2149-2156

Ralston SH (2008): Pathogenesis of Paget's disease of bone. Bone $\underline{43}, 819-825$

Reinholz GG, Getz B, Pederson L, Sanders ES, Subramaniam M, Ingle JN, Spelsberg TC (2000): Bisphosphonates directly regulate cell proliferation, differentiation, and gene expression in human osteoblasts. Cancer Res $\underline{60}$, 6001-6007

Ribeiro V, Garcia M, Oliveira R, Gomes PS, Colaço B, Fernandes MH (2014): Bisphosphonates induce the osteogenic gene expression in co-cultured human endothelial and mesenchymal stem cells. J Cell Mol Med 18, 27-37

Rogers MJ (2004): From Molds and Macrophages to Mevalonate: A Decade of Progress in Understanding the Molecular Mode of Action of Bisphosphonates. Calcif Tissue Int $\underline{75}, 451-461$

Rohen JW, Lütjen-Drecoll E: Funktionelle Embryologie: Die Entwicklung der Funktionssysteme des menschlichen Organismus. 5. Auflage; Schattauer, Stuttgart 2016

Roodman GD, Windle JJ (2005): Paget disease of bone. J Clin Invest 115, 200-208 
Rosella D, Papi P, Giardino R, Cicalini E, Piccoli L, Pompa G (2016): Medication-related osteonecrosis of the jaw: Clinical and practical guidelines. J Int Soc Prev Community Dent $\underline{6}, 97-104$

Ruehe B, Heberer S, Bayreuther K, Nelson K (2011): Effect of Dehiscences to the Bone Response of Implants With an Acid-Etched Surface: An Experimental Study in Miniature Pigs. J Oral Implantol 37, 3-17

Ruggiero SL, Mehrotra B, Rosenberg TJ, Engroff SL (2004): Osteonecrosis of the jaws associated with the use of bisphosphonates: a review of 63 cases. J Oral Maxillofac Surg $\underline{62}, 527-534$

Ruggiero SL, Dodson TB, Fantasia J, Goodday R, Aghaloo T, Mehrotra B, O'Ryan F (2014): American Association of Oral and Maxillofacial Surgeons Position Paper on Medication-Related Osteonecrosis of the Jaw-2014 Update. J Oral Maxillofac Surg $\underline{72}, 1938-1956$

Russell RGG, Croucher PI, Rogers MJ (1999): Bisphosphonates: Pharmacology, Mechanisms of Action and Clinical Uses: Osteoporos Int $\underline{9}$, S66-S80

Schindler C, Kirch W (2008): Tumor und Osteoporose: So soll der Zahnarzt bei Bisphosphonatgabe verfahren. $\mathrm{zm} \underline{24}, 44-46$

Schröder J, Fietz T, Köhler A, Petersen V, Tesch H, Spring L, Fleitz A, Jänicke M, Marschner N (2017): Treatment and pattern of bone metastases in 1094 patients with advanced breast cancer - Results from the prospective German Tumour Registry Breast Cancer cohort study. Eur J Cancer 79, 139-148

Schroeder A, Mueller O, Stocker S, Salowsky R, Leiber M, Gassmann M, Lightfoot S, Menzel W, Granzow M, Ragg T (2006): The RIN: an RNA integrity number for assigning integrity values to RNA measurements. BMC Mol Biol 7, 3

Sedghizadeh PP, Stanley K, Caligiuri M, Hofkes S, Lowry B, Shuler CF (2009): Oral bisphosphonate use and the prevalence of osteonecrosis of the jaw. J Am Dent Assoc 140, 61-66

Sievers N: Auswirkung von Bisphosphonaten auf die Expression von Osteoprotegerin (OPG) und Rezeptor activator of nuclear $\kappa \mathrm{B}$ ligand (RANKL) in Osteoblastenkulturen aus Unterkiefer und Becken-Eine Pilotstudie am Hausschwein. Med. Diss. Göttingen 2012

Smith LG, Karagianes MT (1974): Histological preparation of bone to study ingrowth into implanted materials. Calcif Tissue Res $\underline{14}$, 333-337

So A, Chin J, Fleshner N, Saad F (2012): Management of skeletal-related events in patients with advanced prostate cancer and bone metastases: Incorporating new agents into clinical practice. Can Urol Assoc J $\underline{6}, 465-470$

Stefanik D, Sarin J, Lam T, Levin L, Leboy P, Akintoye S (2008): Disparate osteogenic response of mandible and iliac crest bone marrow stromal cells to pamidronate. Oral Dis $\underline{14}, 465-471$ 
Talreja D (2012): Importance of antiresorptive therapies for patients with bone metastases from solid tumors. Cancer Manag Res 4, 287-297

Tam Y, Kar K, Nowzari H, Cha H-S, Ahn K-M (2014): Osteonecrosis of the Jaw after Implant Surgery in Patients Treated with Bisphosphonates - A Presentation of Six Consecutive Cases: Bisphosphonate-Related Osteonecrosis of the Jaw. Clin Implant Dent Relat Res $\underline{16}$, 751-761

Thorwarth M, Schultze-Mosgau S, Kessler P, Wiltfang J, Schlegel KA (2005): Bone Regeneration in Osseous Defects Using a Resorbable Nanoparticular Hydroxyapatite. J Oral Maxillofac Surg $\underline{63}$, 1626-1633

Turner A (2001): Animal models of osteoporosis - necessity and limitations. Eur Cell Mater $\underline{1}, 66-81$

Ubellacker JM, Haider M-T, DeCristo MJ, Allocca G, Brown NJ, Silver DP, Holen I, McAllister SS (2017): Zoledronic acid alters hematopoiesis and generates breast tumor-suppressive bone marrow cells. Breast Cancer Res $\underline{19}, 23$

Van Poznak CH, Temin S, Yee GC, Janjan NA, Barlow WE, Biermann JS, Bosserman LD, Geoghegan C, Hillner BE, Theriault RL, et al. (2011): American Society of Clinical Oncology Executive Summary of the Clinical Practice Guideline Update on the Role of Bone-Modifying Agents in Metastatic Breast Cancer. J Clin Oncol 29, 1221-1227

Viera-Negrón YE, Ruan W, Winger JN, Hou X, Sharawy MM, Borke JL (2008): Effect of Ovariectomy and Alendronate on Implant Osseointegration in Rat Maxillary Bone. J Oral Implantol 34, 76-82

Viereck V, Emons G, Lauck V, Frosch K-H, Blaschke S, Gründker C, Hofbauer LC (2002): Bisphosphonates Pamidronate and Zoledronic Acid Stimulate Osteoprotegerin Production by Primary Human Osteoblasts. Biochem Biophys Res Commun 291, 680686

Voss PJ, Stoddart M, Ziebart T, Zeiter S, Nelson K, Bittermann G, Schmelzeisen R, Poxleitner P (2015): Zoledronate induces osteonecrosis of the jaw in sheep. J CranioMaxillofac Surg 43, 1133-1138

Voss PJ, Stoddart MJ, Bernstein A, Schmelzeisen R, Nelson K, Stadelmann V, Ziebart T, Poxleitner PJ (2016): Zoledronate induces bisphosphonate-related osteonecrosis of the jaw in osteopenic sheep. Clin Oral Investig 20, 31-38

Wada T, Nakashima T, Hiroshi N, Penninger JM (2006): RANKL-RANK signaling in osteoclastogenesis and bone disease. Trends Mol Med 12, 17-25

Walsh MC, Choi Y (2014): Biology of the RANKL-RANK-OPG System in Immunity, Bone, and Beyond. Front Immunol $\underline{5}, 511$

Walter C, Al-Nawas B, Frickhofen N, Gamm H, Beck J, Reinsch L, Blum C, Grötz KA, Wagner W (2010): Prevalence of bisphosphonate associated osteonecrosis of the jaws in multiple myeloma patients. Head Face Med $\underline{6}, 11$ 
Walter C, Al-Nawas B, Wolff T, Schiegnitz E, Grötz KA (2016): Dental implants in patients treated with antiresorptive medication - a systematic literature review. Int $\mathbf{J}$ Implant Dent $\underline{2}, 9$

Weinstein RS, Roberson PK, Manolagas SC (2009): Giant Osteoclast Formation and LongTerm Oral Bisphosphonate Therapy. N Engl J Med 투, 53-62

Weiss HM, Pfaar U, Schweitzer A, Wiegand H, Skerjanec A, Schran H (2008): Biodistribution and Plasma Protein Binding of Zoledronic Acid. Drug Metab Dispos 36, 20432049

Wellington K, Goa KL (2003): Zoledronic acid: a review of its use in the management of bone metastases and hypercalcaemia of malignancy. Drugs $\underline{63}, 417-437$

Welsch U: Sobotta Lehrbuch Histologie. 2. Auflage; Urban \& Fischer Verlag/Elsevier GmbH, München 2005

Whyte MP (2006): Paget's Disease of Bone. N Engl J Med 355, 593-600

Wiedemann C, Schulz HL, Weber BHF (2004): Quantitative Real-time PCR - eine Frage der Normalisierung. Biospektrum $\underline{1}, 99-102$

Xiong Y, Yang HJ, Feng J, Shi ZL, Wu LD (2009): Effects of alendronate on the proliferation and osteogenic differentiation of MG-63 cells. J Int Med Res $\underline{37}$, 407-416

Yıldız A, Esen E, Kürkçü M, Damlar İ, Dağlığlu K, Akova T (2010): Effect of Zoledronic Acid on Osseointegration of Titanium Implants: An Experimental Study in an Ovariectomized Rabbit Model. J Oral Maxillofac Surg 68, 515-523 